\title{
AVALIAÇÃO EPIDEMIOLÓGICA DA CONDIÇÃO PERIODONTAL DOS PACIENTES PORTADORES DE FISSURAS LABIOPALATINAS DO HOSPITAL DE REABILITAÇÃO DE ANOMALIAS CRANIOFACIAIS
}

\section{Ana Lúcia Pompéia Fraga de Almeida}

Tese apresentada à Faculdade de Odontologia de Bauru, da Universidade de São Paulo, como parte dos requisitos para obtenção do título de Doutor em Odontologia, área de Reabilitação Oral. 


\section{AVALIAÇÃO EPIDEMIOLÓGICA DA CONDIÇÃO PERIODONTAL DOS PACIENTES PORTADORES DE FISSURAS LABIOPALATINAS DO HOSPITAL DE REABILITAÇÃO DE ANOMALIAS CRANIOFACIAIS}

Ana Lúcia Pompéia Fraga de Almeida

Tese apresentada à Faculdade de Odontologia de Bauru, da Universidade de São Paulo, como parte dos requisitos para obtenção do título de Doutor em Odontologia, área de Reabilitação Oral.

Orientador: Prof. Dr. Sebastião Luiz Aguiar Greghi 
Almeida, Ana Lúcia Pompéia Fraga de

AL64a Avaliação epidemiológica da condição periodontal dos pacientes portadores de fissuras labiopalatinas do Hospital de Reabilitação de Anomalias Craniofaciais / Ana Lúcia Pompéia Fraga de Almeida. Bauru, 2007.

153 p.:il.;30 cm.

Tese (Doutorado) - - Faculdade de Odontologia de Bauru, USP.

Orientador: Prof. Dr. Sebastião Luiz Aguiar Greghi

Autorizo, exclusivamente para fins acadêmicos e científicos, areprodução total ou parcial desta tese, por processos fotocopiadores e outros meios eletrônicos.

Assinatura:

Data: 01 de junho de 2007.

Data de aprovação pelo Comitê de Ética do HRAC/USP

Número de protocolo: 099/2004:

Data: 31de maio de-2004. 


\section{Ana Lúcia Pompéia Fraga de Almeida}

\begin{tabular}{|c|c|}
\hline $\begin{array}{l}23 \text { de julho de } 1966 \\
\text { Bauru - SP }\end{array}$ & Nascimento \\
\hline Filiação & $\begin{array}{l}\text { Renato Pompéia Fraga } \\
\text { Maria Lúcia de Castro Pompéia Fraga }\end{array}$ \\
\hline $1986-1989$ & $\begin{array}{l}\text { Curso de Graduação em Odontologia pela } \\
\text { Universidade de São Paulo - SP }\end{array}$ \\
\hline $1996-2000$ & $\begin{array}{l}\text { Curso de Pós-Graduação - Mestrado em } \\
\text { Periodontia, pela Faculdade de Odontologia de } \\
\text { Bauru - USP - SP }\end{array}$ \\
\hline 2001-atual & $\begin{array}{l}\text { Periodontista do Hospital de Reabilitação de } \\
\text { Anomalias Craniofaciais da Universidade de } \\
\text { São Paulo - SP }\end{array}$ \\
\hline $2003-2007$ & $\begin{array}{l}\text { Curso de Pós-Graduação - Doutorado em } \\
\text { Reabilitação Oral, pela Faculdade de } \\
\text { Odontologia de Bauru - USP - SP }\end{array}$ \\
\hline Associações & $\begin{array}{l}\text { Conselho Regional de Odontologia - Seção de } \\
\text { São Paulo }\end{array}$ \\
\hline
\end{tabular}


"O tempo é o melhor autor:

sempre encontra o final perfeito"

Charles Chaplin 


\section{Agradecimentos}

Agradeço primeiramente a Deus, pela minha vida.

Aos meus pais Renato e Maria Lúcia, agradeço pela formação pessoal que recebi de vocês, sempre baseada em amor, compreensão, moral e ética. Amo vocês.

Aos meus filhos, Carolina e Henrique, por quem tenho um amor incomensurável. Vocês são a razão do meu trabalho, da minha dedicação, do meu viver. Obrigada por compreenderem minha ausência em muitos momentos. Amo muito vocês.

Aos meus irmãos José Renato e Ana Cecília pelo carinho, amizade, solidariedade, amor.

Aos que já não se encontram mais aqui, José Luiz e Carlos Henrique, pelo amor compartilhado nos anos de convivência.

Aos meus tios Maurício e Rita, Luiz Augusto e Edna pelo apoio.

"As palavras de conforto podem ser breves e fácies, mas os seus ecos são verdadeiramente infinitos."

Madre Teresa

Aos meus sempre amigos: Silvia Damasceno, Glauco Bazzo, Renata Fernandes, Luciana Traldi, Osny Ferreira Júnior, José Mauro Granjeiro, Daniel Resende, Valéria Gelani.

"O valor das coisas não está no tempo em que elas duram, mas na intensidade com que acontecem. Por isso existem momentos inexplicáveis e pessoas incomparáveis"

Fernando Pessoa 
À Faculdade de Odontologia de Bauru, representada pelo seu diretor professor Dr. Luiz Fernando Pegoraro.

À Comissão de Pós-graduação da Faculdade de Odontologia de Bauru, representada pela Profa Dra Maria Aparecida de A. M. Machado.

À todos os professores da Faculdade de Odontologia de Bauru pela minha formação profissional.

Aos docentes da Periodontia: Prof. Dr. Euloir Passanezzi, Profa. Dra. Adriana Campos Passanezi Sant’Ana, Dra. Maria Lúcia Rubo Rezende e Prof. Dr. Sebastião Luiz Aguiar Greghi .

Aos professores doutores do Departamento de Prótese: Accácio Lins do Valle, Carlos dos Reis Pereira de Araújo, Gérson Bonfante, José Henrique Rubo, Lucimar Falavinha Viera, Luiz Fernando Pegoraro, Milton Carlos G. Salvador, Paulo César Rodrigues Conti, Paulo Martins Ferreira, Pedro César Garcia de Oliveira, Renato de Freitas, Ricardo Marins de Carvalho, Vinícius Carvalho Porto, Wellington Cardoso Bonachela, por permitirem a presença de periodontistas em seu curso de pós-graduação, pela agradável convivência, pelos ensinamentos transmitidos.

“ Os grandes feitos não são realizados por impulso, mas por uma série de pequenos feitos unidos Vincent Van Gogh".

Ao professor Dr. José Roberto Pereira Lauris pela penosa estatística deste trabalho, sempre prestativo.

Aos meus colegas de doutorado: Antônio Ricardo Duarte, Eduardo Ayube, Jefferson Pereira, Leylha Maria Oliveira, Luis Gustavo Bastos, Marinele de Campos, Osvaldo Kaizer, Paulo Rossetti, Paulo Yamaguti, Rafael dos Santos Silva, Renato Ferreira da Silva, Tatiany de Mendonça Neto e Marly Kimie Sonohara Gonzales, minha irmã de coração.

Aos funcionários de todos os Departamentos da Faculdade de Odontologia de Bauru, especialmente aos da Prótese (Déborah Andréa Riêra Blasca, Edna Zaupa Nebo) e Periodontia (Marcos Antonio de Godoy, Edilaine Lúcio Rodrigues Torrecilha) pela acolhida, amizade, consideração. Agradeço em especial a Ivânia Komatsu da Costa Arruda, pela prezerosa convivência. 
Ao meu orientador Prof. Dr. Sebastião Luiz Aguiar Greghi, que mais uma vez aceitou meu convite para me orientar; sua simplicidade, amizade, dedicação, disponibilidade, honestidade estarão sempre em minha memória.

"A simplicidade é a coisa mais difícil de alcançar neste mundo: ela é a última fronteira da experiência e a última relização do gênio". George Sand

Ao Superintendente do Hospital de Reabilitação de Anomalias Craniofaciais, Dr. José Alberto de Souza Freitas, pelo exemplo de amor e dedicação a uma Instituição, pelo reconhecimento do meu trabalho e carinho dispendido a mim.

Aos meus colegas do Setor Odontológico: Celso Kenji, Roberta Martinelli, Roberto Macoto, Reinaldo Mazzotini, José Carlos Bastos Jr, Carlos Alberto Aiello, Rita Lauris, Andréia Machado, Tiago Ribeiro, Arlete Cavassan, Terumi Ozawa, Araci Almeida, Laerte Fiori, Aparício Deko, Nádia Svizero, Cleide Carrara, Márcia Gomide, Beatriz Costa, Lucimara Neves, Sueli Devides, Roberta Pires, Caio Figueiredo, Flávio Amado, Rosa Ribeiro e Homero Aferri.

Em especial aos meus colegas e amigos: Fernando Lopes, Mônica Lopes, Rosângela Cerigatto, João Henrique Nogueira, Gisele Dalben, Renata Hussne, Lílian Matsunaga e Renato Faco pela companheirismo, reconhecimento e incentivo. Sem o apoio de vocês teria sido difícil acreditar que na vida eu poderia alçar grandes vôos. Muito obrigada.

“. a gente não far amigos, reconhece-os.”

Vinícius de Moraes

À todos os funcionários do Hospital de Reabilitação de Anomalias Craniofaciais, em especial aos do Setor Odontológico, Kátia Teixeira, Carlos Alberto do Prado, Alexandre Rodrigo Merques Santos, Lucília Aparecida dos Santos e Mariuza Gonçalves Vieira Marques.

A todos os meus ex-alunos da FUNDAP e aperfeiçoamento em Periodontia. 
A primeira turma de Especialização da Periodontia: Eliane, Érick, Samuel, Rosane, Michyele, Ingrid, Luis e Paula; sem vocês muitas das realizações conquistadas não seriam possíveis. Obrigada pela amizade.

Aos atuais alunos de especialização: Vanessa, Cibele, Stephania, Matheus, Tiago, Gabriel, Willian e Rafael, obrigada pelo carinho e paciência.

Aos pacientes do Hospital de Reabilitação de Anomalias Craniofaciais, por terem consentido participar deste e de outros estudos realizados por mim na Periodontia.

A todos aqueles que de certa forma me ajudaram, apoiaram, orientaram, aconselharam, torceram para que eu conseguisse ultrapassar tantos obstáculos para chegar a ser a profissional que sou hoje em dia.

"Um pássaro nunca terá voado alto demais se for com as próprias asas". Willian Blake 


\section{SUMÁRIO}

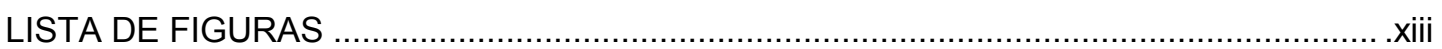

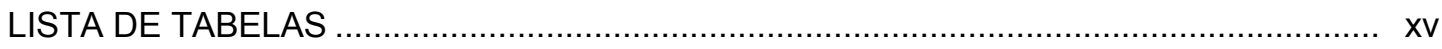

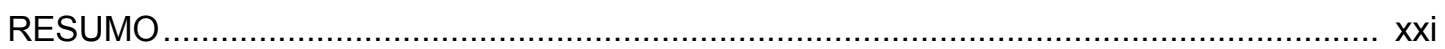

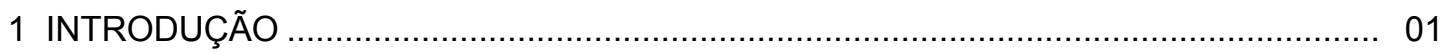

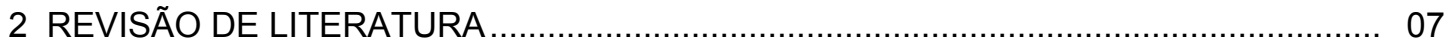

2.1 Prevalência da fissura labiopalatina no Brasil................................................ 09

2.2 Epidemiologia da Doença Periodontal ........................................................... 10

2.3 Epidemiologia da Doença Periodontal em indivíduos portadores de fissuras labiopalatinas .

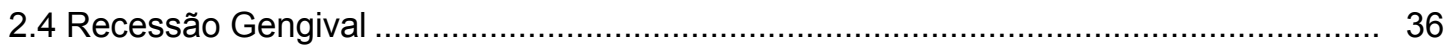

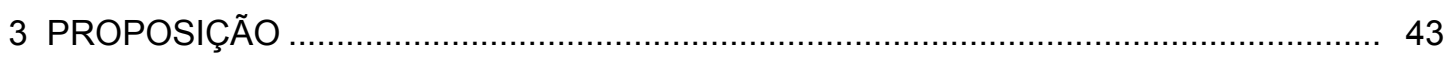

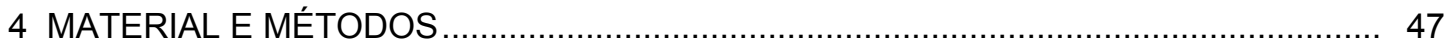

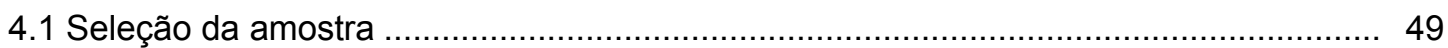

4.2 Considerações éticas do estudo ....................................................................... 49

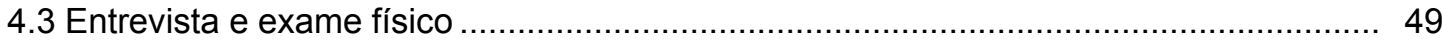

4.3.1 Classificação das fissuras labopalatinas........................................................... 50

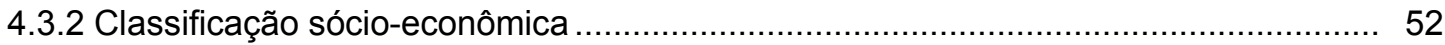

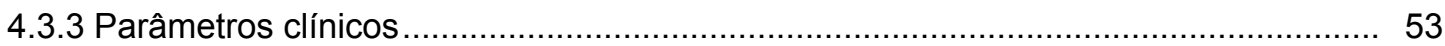

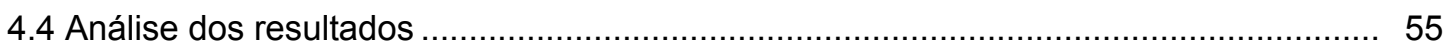

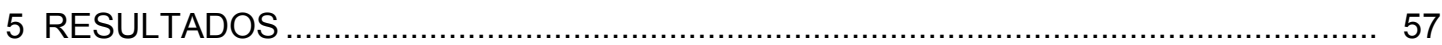

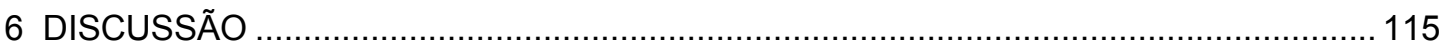

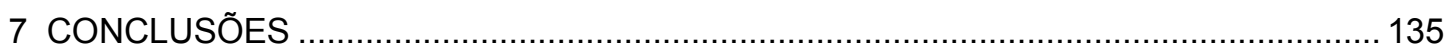

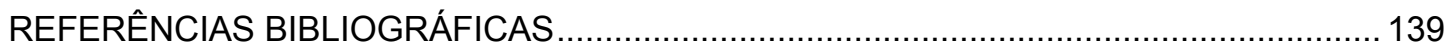

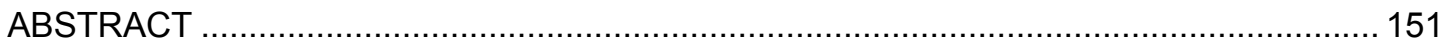




\section{LISTA DE FIGURAS}

FIGURA 1- Fissura de lábio e rebordo alveolar esquerda (LAE).

FIGURA 2- $\quad$ Fissura de lábio e rebordo alveolar bilateral (LAB).

FIGURA 3- $\quad$ Fissura de lábio, rebordo alveolar e palato esquerda (LAPE).

FIGURA 4- Fissura de lábio, rebordo alveolar e palato bilateral (LAPB).

FIGURA 5- Distribuição do número de indivíduos por faixa etária.

FIGURA 6- Distribuição do número de indivíduos por gênero em cada faixa etária.

FIGURA 7- Distribuição da freqüência dos indivíduos por faixa etária e classificação sócio-economica.

FIGURA 8- Distribuição dos indivíduos segundo raça e faixa etária.

60

FIGURA 9- Distribuição da freqüência dos indivíduos por tipo de fissura e faixa etária.

FIGURA 10- Distribuição da freqüência dos indivíduos por tipo de fissura e gênero.

FIGURA 11- Distribuição das médias da profundidade de sondagem por sextante.

FIGURA 12- Distribuição das médias da profundidade de sondagem da amostra.

FIGURA 13- Distribuição das medidas do nível de inserção clínico por sextante.

FIGURA 14- Distribuição da medida do nível de inserção clínico da amostra.

FIGURA 15- Distribuição da extensão da recessão gengival por sextante.

FIGURA 16- Distribuição da recessão gengival em cada dente superior.

FIGURA 17- Distribuição da recessão gengival em cada dente inferior.

FIGURA 18- Distribuição da recessão gengival por tipo de fissura.

FIGURA 19- Distribuição de freqüência (\%) dos dentes com recessão gengival de acordo com a classificação de Miller (1985). 


\section{LISTA DE TABELAS}

TABELA 1- Médias, medianas e desvios padrão dos parâmetros periodontais: profundidade de sondagem (PS) (mm), nível de inserção clínica $(\mathrm{NI})(\mathrm{mm})$, recessão gengival na face vestibular $(\mathrm{RV})(\mathrm{mm})$, índice de placa (IP) (escores) e índice gengival (IG) (escores).

TABELA 2- $\quad$ Médias e desvios padrão da profundidade de sondagem (mm) por faixas etárias, gêneros, tipos de fissuras dos sextantes superiores.

TABELA 3- $\quad$ Médias e desvios padrão da profundidade de sondagem ( $\mathrm{mm}$ ) por faixas etárias, gêneros, tipos de fissuras dos sextantes inferiores.

TABELA 4- $\quad$ Comparações das médias de profundidade de sondagem $(\mathrm{mm})$ entre as faixas etárias (1), gêneros (2), tipos de fissuras (4) ANOVA (quatro critérios).

TABELA 5- $\quad$ Médias e desvios padrão da profundidade de sondagem ( $\mathrm{mm}$ ) por faixas etárias, tipos de fissuras dos sextantes superiores.

TABELA 6- Médias e desvios padrão da profundidade de sondagem ( $\mathrm{mm}$ ) por faixas etárias, tipos de fissuras dos sextantes inferiores.

TABELA 7- $\quad$ Comparação das médias da profundidade de sondagem (mm) entre faixas etárias (1), tipos de fissuras (2) e sextantes (3) ANOVA (três critérios).

TABELA 8- $\quad$ Teste de Tukey - Comparação das médias de profundidade de sondagem $(\mathrm{mm})$ entre faixas etárias (1- 15 a 25 anos, 2- 26 a 35 anos, 3- 36 a 49 anos) e tipos de fissuras por sextante.

TABELA 9- $\quad$ Teste de Tukey - Comparação das médias de profundidade de sondagem $(\mathrm{mm})$ entre os sextantes e tipos de fissuras dos indivíduos de 15 a 25 anos.

TABELA 10- Teste de Tukey - Comparação das médias de profundidade de sondagem $(\mathrm{mm})$ entre os sextantes e tipos de fissuras dos indivíduos de 26 a 35 anos.

TABELA 11- $\quad$ Teste de Tukey - Comparação das médias de profundidade de sondagem $(\mathrm{mm})$ entre os sextantes e tipos de fissuras dos indivíduos de 36 a 49 anos.

TABELA 12- Correlação de Pearson - Comparação da profundidade de sondagem $(\mathrm{mm})$ entre os sextantes.

TABELA 13- Médias e desvios padrão do nível de inserção clínico (mm) por faixas etárias, gêneros, tipos de fissuras dos sextantes superiores.

TABELA 14- Médias e desvios padrão do nível de inserção clínico (mm) por faixas etárias, gêneros, tipos de fissuras dos sextantes inferiores.

TABELA 15- Comparação do nível de inserção clínico $(\mathrm{mm})$ entre faixas etárias (1), gêneros (2), tipos de fissuras (3) e sextantes (4) - ANOVA (quatro critérios).

TABELA 16- Médias e desvios padrão do nível de inserção clínico (mm) por faixas etárias e tipos de fissuras dos sextantes superiores. 
TABELA 17- Médias e desvios padrão do nível de inserção clínica $(\mathrm{mm})$ por faixas etárias e tipos de fissuras dos sextantes inferiores.

TABELA 18- Comparação das médias do nível de inserção clínico $(\mathrm{mm})$ entre faixas etárias (1), tipos de fissuras (2) e sextantes (3) - ANOVA (três critérios).

TABELA 19- Teste de Tukey - Comparação das médias do nível de inserção clínico $(\mathrm{mm})$ entre faixas etárias (1- 15 a 25 anos, 2- 26 a 35 anos, 3- 36 a 49 anos) e tipos de fissuras por sextante

TABELA 20- Teste de Tukey - Comparação das médias do nível de inserção clínico $(\mathrm{mm})$ entre os sextantes dos indivíduos de 15 a 25 anos de idade e tipos de fissuras.

TABELA 21- Teste de Tukey - Comparação das médias do nível de inserção clínico $(\mathrm{mm})$ entre os sextantes dos indivíduos de 26 a 35 anos de idade e tipos de fissuras.

TABELA 22- $\quad$ Teste de Tukey - Comparação das médias do nível de inserção clínico $(\mathrm{mm})$ entre os sextantes dos indivíduos de 36 a 49 anos de idade e tipos de fissuras.

TABELA 23- Correlação de Pearson - Comparação do nível de inserção clínico $(\mathrm{mm})$ entre os sextantes.

TABELA 24- Médias e desvios padrão do índice gengival por faixas etárias, gêneros e tipos de fissura dos sextantes superiores.

TABELA 25- Médias e desvios padrão do índice gengival por faixas etárias, gêneros e tipos de fissura dos sextantes inferiores.

TABELA 26- Distribuição da freqüência dos escores do índice gengival dos dentes inferiores.

TABELA 27- Distribuição da freqüência dos escores do índice gengival dos dentes superiores.

TABELA 28- Médias e desvios padrão do índice gengival por sextante.

TABELA 29- Distribuição da freqüência (\%) dos escores do índice gengival em cada sextante

TABELA 30- Médias e desvios padrão do índice gengival por tipos de fissura nos sextantes superiores.

TABELA 31- Médias e desvios padrão do índice gengival dos sextantes por tipos de fissuras nos sextantes inferiores.

TABELA 32- Médias e desvios padrão do índice gengival dos sextantes por tipos de fissura.

TABELA 33- Médias e desvios padrão do índice gengival por gêneros dos sextantes superiores.

TABELA 34- Médias e desvios padrão do índice gengival por gêneros dos sextantes inferiores. 
TABELA 35- Médias e desvios padrão do índice gengival por faixas etárias dos sextantes superiores.

TABELA 36- Médias e desvios padrão do índice gengival por faixas etárias dos sextantes inferiores.

TABELA 37- Teste de Friedman - Comparação entre índice gengival e os sextantes.

TABELA 38- $\quad$ Teste de Kruskal-Wallis - Comparação entre índice gengival e faixas etárias para sextante 2 .

TABELA 39- Teste de Kruskal-Wallis - Comparação entre índice gengival e faixas etárias para sextante 3 .

TABELA 40- Teste de Kruskal-Wallis - Comparação entre índice gengival e os tipos de fissuras do sextante 1.

TABELA 41- Teste de Kruskal-Wallis - Comparação entre índice gengival e os tipos de fissuras do sextante 2 .

TABELA 42- Teste de Kruskal-Wallis - Comparação entre índice gengival e tipos de fissuras do sextante 3 .

TABELA 43- Teste de Kruskal-Wallis - Comparação entre índice gengival e tipos de fissuras do sextante 4 .

TABELA 44- Teste de Kruskal-Wallis - Comparação entre índice gengival e tipos de fissuras do sextante 5 .

TABELA 45- Teste de Kruskal-Wallis - Comparação entre índice gengival e tipos de fissuras do sextante 6 .

TABELA 46- Teste Mann-Whitney - Comparação entre índice gengival, sextantes e gêneros.

TABELA 47- Médias e desvios padrão do índice de placa por faixas etárias, gêneros e tipos de fissuras dos sextantes superiores.

TABELA 48- Médias e desvios padrão do índice de placa por faixas etárias, gêneros e tipos de fissuras dos sextantes inferiores.

TABELA 49- Distribuição da freqüência (N) dos escores do índice de placa dos dentes inferiores.

TABELA 50- Distribuição da freqüência $(\mathrm{N})$ dos escores do índice de placa dos dentes superiores.

TABELA 51- Médias e desvios padrão do índice de placa por sextantes.

TABELA 52- Distribuição da freqüência (\%) dos escores do índice de placa em cada sextante.

TABELA 53- Médias e desvios padrão do índice de placa por tipos de fissuras nos sextantes superiores.

TABELA 54- Médias e desvios padrão do índice de placa por tipos de fissuras nos sextantes inferiores. 
TABELA 55- Médias e desvios padrão do índice de placa por gêneros dos sextantes superiores.

TABELA 56- Médias e desvios padrão do índice de placa por gêneros dos sextantes inferiores.

TABELA 57- Médias e desvios padrão do índice de placa por faixas etárias dos sextantes superiores.

TABELA 58- Médias e desvios padrão do índice de placa por faixas etárias dos sextantes inferiores.

TABELA 59- $\quad$ Teste de Friedman - Comparação entre o índice de placa e os sextantes.

TABELA 60- Teste de Student-Newman-Keuls - Comparação múltipla entre índice de placa e sextantes.

TABELA 61- Teste de Kruskal-Wallis - Comparação entre índice de placa e faixas etárias para sextante 4 .

TABELA 62- $\quad$ Teste de Kruskal-Wallis - Comparação entre índice de placa e faixas etárias para sextante 5 .

TABELA 63- $\quad$ Teste de Kruskal-Wallis - Comparação entre índice de placa e tipos de fissuras no sextante 1.

TABELA 64- Teste de Kruskal-Wallis - Comparação entre índice de placa e tipos de fissuras no sextante 2 .

TABELA 65- Teste de Kruskal-Wallis - Comparação entre índice de placa e tipos de fissuras no sextante 3 .

TABELA 66- Teste de Kruskal-Wallis - Comparação entre índice de placa e tipos de fissuras no sextante 4.

TABELA 67- Teste de Kruskal-Wallis - Comparação entre índice de placa e tipos de fissuras no sextante 5 .

TABELA 68- $\quad$ Teste de Kruskal-Wallis - Comparação entre índice de placa e tipos de fissuras no sextante 6.

TABELA 69- Teste de Kruskal-Wallis - Comparação entre índice de placa e tipos de fissuras nos sextantes.

TABELA 70- Teste de Mann-Whitney - Comparação entre os gêneros, por sextante, quanto ao índice de placa.

TABELA 71- Correlação entre a classifiação sócio-econômica e os parâmetros periodontais (Correlação de Spearman).

TABELA 72 Médias e desvios padrão da recessão gengival por faixas etárias, gêneros, tipos de fissuras dos sextantes superiores.

TABELA 73- Médias e desvios padrão da recessão gengival por faixas etárias, gêneros, tipos de fissuras dos sextantes inferiores.

TABELA 74- Médias e desvios padrão da recessão gengival por sextantes. 
TABELA 75- Médias e desvios padrão da recessão gengival por tipos de fissuras 106 nos sextantes superiores.

TABELA 76- Médias e desvios padrão da recessão gengival por tipos de fissuras nos sextantes inferiores.

TABELA 77- Médias e desvios padrão da recessão gengival por gêneros nos sextantes superiores.

TABELA 78- Médias e desvios padrão da recessão gengival por gêneros dos sextantes inferiores.

TABELA 79- Médias e desvios padrão da recessão gengival por faixas etárias dos sextantes superiores.

TABELA 80- Médias e desvios padrão da recessão gengival por faixas etárias dos sextantes inferiores.

TABELA 81- Teste de Friedman - Comparação entre a recessão gengival e os sextantes.

TABELA 82- Teste de Kruskal-Wallis - Comparação entre recessão gengival e faixas etárias para o sextante 1.

TABELA 83- Teste de Kruskal-Wallis - Comparação entre recessão gengival e faixas etárias para o sextante 2 .

TABELA 84- Teste de Kruskal-Wallis - Comparação entre recessão gengival e faixas etárias para o sextante 3 .

TABELA 85- Teste de Kruskal-Wallis - Comparação entre recessão gengival e faixas etárias no sextante 4 .

TABELA 86- Teste de Kruskal-Wallis - Comparação entre recessão gengival e faixas etárias no sextante 5 .

TABELA 87- Teste de Kruskal-Wallis - Comparação entre recessão gengival e faixas etárias no sextante 6 .

TABELA 88- $\quad$ Teste de Kruskal-Wallis - Comparação entre tipos de fissura e recessão gengival no sextante 1 .

TABELA 89- Teste de Kruskal-Wallis - Comparação entre tipos de fissura e recessão gengival no sextante 4 .

TABELA 90- Teste de Kruskal-Wallis - Comparação entre tipos de fissura e recessão gengival no sextante 6 .

TABELA 91- Teste de Mann-Whitney- Comparação entre recessão gengival, sextantes e gêneros.

TABELA 92- Descrição das amostras dos estudos de periodontia em indivíduos portadores de fissura labiopalatina 


\section{RESUMO}

Em odontologia as pesquisas na área da Periodontia em indivíduos portadores de fissura labiopalatina são escassas, com poucos estudos de prevalência, incidência, extensão e severidade das alterações periodontais, assim como tratamento dessas alterações em adultos. O objetivo deste trabalho foi analisar a prevalência e severidade da doença periodontal em 400 indivíduos portadores de fissura de lábio, rebordo alveolar e palatino, uni e bilateral, com idade entre 15 e 50 anos, do Hospital de Reabilitação de Anomalias Craniofaciais da Universidade de São Paulo sem tratamento periodontal prévio. No exame clínico foram realizadas as medidas de profundidade de sondagem, nível de inserção clínico, índice gengival, índice de placa e recessão gengival. 86,75\% apresentaram profundidade de sondagem $\leq 3 \mathrm{~mm}$. Não houve nenhum sextante com profundidade de sondagem $\geq 6 \mathrm{~mm}$. Houve diferença estatisticamente significante entre profundidade de sondagem e idade, tipos de fissura e sextantes $(p<0,001) .95,87 \%$ dos dentes examinados apresentaram medida do nível de inserção menor ou igual a $3 \mathrm{~mm}$. O sextante da fissura não apresentou as maiores médias de profundidade de sondagem, nível de inserção clínico, índice de placa e índice gengival. Não houve diferença estatisticamente significante entre gênero e as demais variáveis. Houve sangramento gengival na maior parte da amostra, tanto para dentes superiores quanto para inferiores. A freqüência e severidade das recessões gengivais aumentaram com a idade, os dentes mais acometidos foram os prés e molares. Os incisivos e caninos apresentaram freqüência de recessão dez vezes maior que a população em geral. O tipo de fissura não foi um fator importante para a prevalência da doença periodontal. O gênero não influenciou nenhum dos parâmetros clínicos nesta amostra. A idade parece ser um fator importante na prevalência e severidade da doença periodontal, para todos os parâmetros estudados. A doença periodontal em indivíduos portadores de fissura, neste estudo, demonstrou ocorrer de maneira semelhante a outras populações. A presença da fissura parece não ser um fator agravante para a prevalência da doença.

Palavras chaves: doença periodontal, epidemiologia, fissura de lábio/palato 
INTRODUÇÃO 


\section{INTRODUÇÃO}

O desenvolvimento facial embrionário humano é muito complexo. A face humana é formada pelo crescimento e união de dois processos bilaterais separados: os processos maxilares e mandibulares, e um processo ímpar, o frontonasal, que dará origem aos processos nasais mediais e laterais. As fissuras são resultados da falta de coalescência desses processos. Podem acometer lábio, alvéolo e/ou palato, ser unilaterais ou bilaterais ${ }^{42}$.

As malformações da face ocupam o $3^{\circ}$ lugar depois das deformidades do aparelho locomotor; particularmente as fissuras de lábio e palato, isoladas ou conjuntas, estão entre os defeitos congênitos mais freqüentes nos dias atuais ${ }^{45}$, sendo que em Bauru a prevalência média encontrada foi de 1:650 indivíduos ${ }^{101}$.

A partir da década de 60, a reabilitação integral dos indivíduos portadores de fissura labiopalatinas tornou-se uma das prioridades médico-sociais dentro dos programas de saúde comunitária nos países desenvolvidos. As implicações psicológicas, estéticas e funcionais das fissuras do lábio e palato são diversas, implicando no desenvolvimento de pesquisas e terapias para tratamento desses indivíduos ${ }^{41}$.

No Hospital de Reabilitação de Anomalias Craniofaciais da Universidade de São Paulo (HRAC/USP), assim como em outros centros $115,130,135$ os pacientes recebem atendimento interdisciplinar com o intuito de reabilitá-los física e emocionalmente, possibilitando uma vida saudável.

O Setor Odontológico do HRAC/USP é composto por todas as especialidades da área odontológica, dentre elas a periodontia que tem por objetivo prevenir e tratar as alterações nos tecidos periodontais. Poucos trabalhos têm sido desenvolvidos com o objetivo de verificar as necessidades periodontais desses indivíduos, alguns descrevem apenas tratamentos curativos, principalmente de problemas mucogengivais causados por cirurgias plásticas e de enxerto ósseo na área da fissura ${ }^{8,9,10,11,108}$. Alguns estudos salientam a importância da prevenção periodontal e principalmente da cárie dentária que parece ser um dos maiores causadores da perda dentária ${ }^{25,33,113 .}$

Nos indivíduos portadores de fissura, o mecanismo de formação da doença periodontal em nada se diferencia do indivíduo não portador desta anomalia. Assim, a instalação da placa bacteriana, formação de cálculo e o início do comprometimento das estruturas periodontais acontecem pelo mesmo mecanismo já acontecido ${ }^{123}$, porém ainda não é clara a epidemiologia desta doença nesta população.

Com o intuito de investigar a prevalência (número de casos de uma doença existente em um determinado período de tempo), a incidência (número de casos de uma doença por unidade de população dentro de um intervalo de tempo definido), a severidade (intensidade) 
de uma doença, os fatores de risco relacionados a ela, a efetividade das intervenções, devese realizar estudos epidemiológicos. A maioria destes estudos é de observação, dentre os quais figura os estudos transversais, que são úteis para determinar a ausência ou presença de uma doença em um determinado período de tempo ${ }^{47}$.

A partir de estudos epidemiológicos pode-se avaliar o comportamento e as condições clínicas de uma população, de maneira a estabelecer diretrizes à elaboração de programas preventivos adequados, com o intuito de se impedir o início e/ou progressão de doenças.

As diferenças entre severidade da doença periodontal podem ser encontradas entre regiões demográficas diferentes, gênero e raça, população rural e urbana, diferentes níveis de educação, etc ${ }^{2,19}$, portanto torna-se necessária a avaliação em populações distintas.

Estudos realizados na Década de 80 mudaram o conceito da universalidade da doença periodontal, assim como o fato da doença se manifestar igualmente em todos os dentes de um mesmo indivíduo ${ }^{77,88,89}$. Sabe-se que alguns indivíduos pertencem ao grupo de maior risco para desenvolver alguma das formas desta doença ${ }^{71}{ }^{89}$, e mesmo em um indivíduo há sítios que desenvolvem a doença enquanto que em outros não ${ }^{84}$. Nos indivíduos portadores de fissura labiopalatinas a doença periodontal não deve se comportar de maneira diferente, porém não existem estudos que analisem a prevalência e severidade desta doença nessa população.

As condições dos tecidos periodontais têm sido pouco exploradas pela pesquisa científica. Poucos trabalhos, como o de BRÄGGER et al. ${ }^{31}$ (1985), ANDRADE ${ }^{14}$ (1990) e BOTTA $^{29}$ (1991) avaliaram a condição periodontal do indivíduo fissurado e classificaram-na como mais severa quando comparada à de indivíduo sem esse tipo de malformação. Outros trabalhos analisaram a presença de gengivite em crianças ${ }^{48}$ ou adolescentes com fissura labiopalatina ${ }^{51}$, e em outros a análise é realizada somente nos dentes próximos ou na área

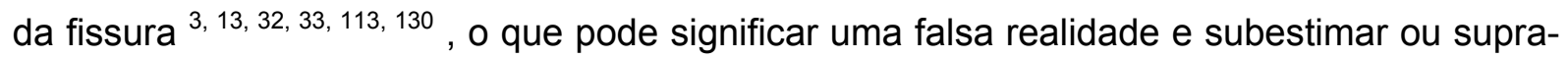
estimar a condição periodontal nestes indivíduos. O exame da condição periodontal de um dado indivíduo inclui a avaliação clínica da inflamação dos tecidos periodontais, o registro da profundidade de sondagem, dos níveis de inserção clínico e as avaliações radiográficas do osso alveolar.

A recessão gengival é outra medida clínica muito utilizada nos estudos epidemiológicos em periodontia, a qual é caracterizada pela mudança da margem gengival, de sua posição normal na superfície radicular para níveis além da junção amelocementária; pode ser localizada ou generalizada e associada com uma ou mais faces dentárias ${ }^{66,128}$, podendo gerar vários problemas de importância funcional e clínica ${ }^{61,66}$ e na sua etiologia encontram-se fatores considerados predisponentes ${ }^{30,75,131,134}$ e precipitantes ${ }^{53,93,104}$.

Nos estudos epidemiológicos contemporâneos, procura-se avaliar a perda dos tecidos periodontais de sustentação através de mensurações da profundidade de sondagem 
e do nível de inserção clínico. A profundidade de sondagem (bolsa) é definida como a distância entre a margem gengival até a posição em que a ponta de uma sonda periodontal inserida no sulco encontra resistência. Da mesma forma, a medida do nível de inserção ou nível de inserção clínico, é definida como a distância entre a junção amelo-cementária até a posição em que a ponta da sonda que foi inserida até encontrar resistência.

O protocolo usado atualmente para medir perda de inserção clínica e profundidade de sondagem com sonda manual foi primeiramente descrito há mais de 45 anos ${ }^{112}$ e não mudou muito desde então.

Muitos índices foram usados desde o passado, mas eles eram índices compostos por escores para gengivite e periodontite na mesma escala. Estes índices hoje são considerados inválidos e têm sido descartados. Estudos têm mensurado a perda de inserção clínica e profundidade de sondagem em todos os dentes, ou todos os dentes em dois quadrantes, ou o pior dente de cada sextante, ou um dente índice. Medidas têm sido feitas em seis, quatro, dois e um sítio por dente. Como exemplo deste problema sobre esta falta de uniformidade de metodologia, numa pesquisa realizada nos EUA (Pesquisa Nacional de Saúde Oral) houve uma subestimação da presença da periodontite porque somente dois sítios por dente em um quadrante superior e um inferior foram avaliados ${ }^{38}$.

A prevalência e severidade da doença periodontal em indivíduos portadores de fissura labiopalatina ainda é obscura, existe a grande lacuna na literatura sobre a condição periodontal nesses indivíduos, principalmente estudos que avaliem todos os dentes e sítios na tentativa de estabelecer a prevalência e severidade da doença periodontal. Esse conhecimento se faz necessário para estabelecer programas preventivos e de tratamento conforme a necessidade dessa população ou mesmo para averiguar se a área da fissura é mais um fator de risco para o estabelecimento da doença periodontal.

Dessa forma, este estudo procurou avaliar a prevalência e severidade da doença periodontal em indivíduos portadores de fissura labiopalatina através de parâmetros clínicos periodontais, examinando todos os sítios de todos os dentes, além de comparar a área da fissura com as demais. 
REVISÃO DE LITERATURA 


\section{REVISÃO DE LITERATURA}

\subsection{Prevalência da fissura labiopalatina no Brasil}

Em 1968, NAGEM FILHO; MORAIS; ROCHA ${ }^{101}$ realizaram um levantamento epidemiológico na cidade de Bauru com o objetivo de avaliar a prevalência da fissuras labiopalatinas em crianças com idade escolar. Neste estudo, foram examinadas 13.249 crianças da região de Bauru (SP). Foram encontradas crianças com fissuras em uma prevalência de um para cada $650(0,15 \%)$. Os autores afirmam que proporcionalmente houve uma predominância da raça amarela entre as crianças portadoras de fissura, seguidas pela raça branca e negra. Também foi observada predominância do gênero masculino, em uma proporção de 2,3: 1, com maior prevalência de fissuras unilaterais sobre as bilaterais e do lado esquerdo em relação ao lado direito.

Neste mesmo ano ARCE ${ }^{17}$, estudou a prevalência da fissura examinando 58.761 crianças no estado de Minas Gerais e 9.822 no estado do Paraná. Encontrou 56 indivíduos portadores de fissura (0,08\%). 92\% das fissuras eram de lábio com ou sem fissura de palato e $8 \%$ envolveram apenas o palato. Neste estudo não foi encontrado diferença significante na prevalência da fissura entre pacientes brancos e não brancos $(0,087$ e 0,075\%, respectivamente). $\mathrm{O}$ autor sugere que não houve influência da condição sócio-econômica sobre a ocorrência da fissura.

FONSECA; REZENDE ${ }^{58}$ em 1971 examinaram 67.321 crianças nascidas em uma maternidade na cidade de Tatuapé, estado de São Paulo. Encontraram uma prevalência de um entre cada 673 nascimentos $(0,14 \%)$. Seus resultados revelaram uma predominância de fissuras completas de lábio e palato, do lado esquerdo e para o gênero masculino.

Em 1987, SOUZA; BUCHALA; LAURENTI ${ }^{124}$ realizaram um estudo epidemiológico em maternidades nos estados de São Paulo, Rio de Janeiro e Santa Catarina, no período de 1981 e 1982, no qual foram incluídas 12.782 crianças nascidas vivas. Foi encontrada uma prevalência total de $2,24 \%$ de anomalias congênitas, sendo que as fissuras labiopalatinas constituíam 3,3\% do total de anomalias. No geral não foi observada correlação positiva de anomalias congênitas e gênero.

COLLARES et al. ${ }^{43}$, no ano de 1995 avaliaram, através de exame físico de rotina, os defeitos congênitos de todos os bebês nascidos vivos e natimortos, entre 1983 e 1993, no Hospital de Clínicas de Porto Alegre. Das 31.058 crianças incluídas no estudo, foram encontradas 41 crianças com fissuras labiopalatinas $(0,13 \%)$, o que corresponde a uma criança fissurada em cada 757 avaliadas. Quatorze casos apresentaram fissura de lábio e palato $(34,14 \%), 11$ fissura de palato $(26,8 \%)$ e 16 fissura de lábio e palato (39\%). Ao avaliar 
as características da amostra de crianças com fissura, os autores afirmaram que a fissura de lábio é influenciada pela etnia, mas a de palato não. Entre as fissuras de lábio, foi encontrada predominância para o gênero masculino e do lado esquerdo, enquanto as fissuras de palato ocorreram principalmente no gênero feminino.

Em 2002, DALBEN ${ }^{50}$ realizou um estudo com objetivo de levantar a epidemiologia dos vários tipos de fissuras labiopalatinas não operadas que chegaram ao Hospital de Reabilitação de Anomalias Craniofaciais da Universidade de São Paulo no ano de 2000. Foram examinados 803 indivíduos casos novos. Os resultados demonstraram que $61,7 \%$ eram provenientes da região Sudeste e $55,04 \%$ da amostra eram do gênero masculino. Quanto á classe sócio-econômica $30, \%$ eram baixa inferior e $40 \%$ baixa superior. A autora concluiu que as fissuras completas de lábio e palato exibiram maior prevalência que os outros tipos de fissura labiopalatinas, totalizando $37,1 \%$ dos indivíduos; $24,9 \%$ apresentaram fissuras unilaterais e $12,2 \%$ bilaterais. No gera, as fissuras labiopalatinas apresentam uma predileção pelo gênero masculino ( $55 \%$ dos indivíduos).

FREITAS et al. ${ }^{58}$ (2005) investigaram a distribuição dos vários tipos de fissura nos pacientes que receberam tratamento no Hospital de Reabilitação de Anomalias Craniofaciais da Universidade de São Paulo. Foram examinados 803 indivíduos com idade entre seis dias e 49 anos. Os parâmetros avaliados foram: tipo de fissura, etnia, gênero, idade e área de residência. De todos os indivíduos avaliados 55\% eram homens, $80 \%$ caucasianos ou brancos não caucasianos e 70\% com nível sócio-econômico baixo. Quanto às fissuras, $37,1 \%$ eram de lábio e palato, uni ou bilaterais; $20 \%$ do total eram fissuras de lábio, $15,2 \%$ de lábio e palato acometeram o lado esquerdo. Ao autores concluíram que a fissura de lábio e palato foi mais freqüente que os demais tipos de fissura, $37,1 \%$ do total da amostra, na qual $24,9 \%$ eram unilaterais e $12,2 \%$ bilaterais. Em geral, as fissuras foram mais comuns entre os homens.

\subsection{Epidemiologia da doença periodontal}

O primeiro estudo de epidemiologia da periodontite foi realizado por BLACK ${ }^{28}$ (1918), em 600 adultos na cidade de Chicago, que revelou a prevalência da infecção periodontal em $13 \%$ de indivíduos de 20 a 24 anos, aumentando para $88 \%$ em indivíduos com 50 anos ou mais.

Em 1955, MARSHALL-DAY; STEPHENS; QUIGLEY ${ }^{87}$ avaliaram 1279 indivíduos, de 13 a 65 anos quanto aos aspectos clínicos da gengiva (tamanho, cor, tipo, consistência e posição), profundidade de sondagem, mobilidade, supuração e presença de cálculo. Os homens demonstraram maior prevalência que as mulheres, com uma média total de $88 \% \mathrm{e}$ $80 \%$ para homens e mulheres, respectivamente. Alteração gengival (gengivite) foi mais 
prevalente entre os homens. A região posterior superior foi a mais afetada (74\%) que a anterior superior (62\%) em todos os grupos. Na mandíbula não houve grandes diferenças entre a região posterior anterior, $64 \%$ e $66 \%$ respectivamente. A incidência da gengivite foi extremamente alta nos grupos mais jovens, variando de $80 \%$ no grupo de 13 a 15 aos a 95\% no grupo 60 anos, particularmente em mulheres. A doença periodontal moderada avançada estava mais presente nos indivíduos de 35 a 60 anos ou mais (67-89\%).

LÖE et al. ${ }^{80}$ em 1965, realizaram um estudo experimental para observar o papel da placa bacteriana no desenvolvimento da gengivite. Estabeleceram a função da placa bacteriana como principal fator etiológico no início e desenvolvimento da gengivite.

No ano de 1976, PAGE; SCHROEDER ${ }^{105}$ descreveram que a progressão da gengivite para a periodontite não se apresenta de forma linear, e em alguns casos as lesões se mantêm confinadas aos tecidos gengivais, sem perda de inserção conjuntiva ou de osso alveolar e em outros casos progridem rapidamente para a periodontite destrutiva com perdas de tecido periodontal de suporte.

JENSEN ${ }^{70}$ (1974) realizou um estudo sociológico em 2047 indivíduos dinamarqueses de 16 a 45 anos de idade, aos quais aplicou um questionário para determinar o local de residência, idade, sexo, nível sócio-econômico, freqüência atual de visitas ao dentista, número de dentes presentes, hábitos de higiene oral e freqüência ao dentista durante a infância. Para determinar os grupos sócio-econômicos foram utilizados critérios como a educação escolar, ocupação do indivíduo e renda familiar anual. Na faixa etária de 35 a 45 anos, $84 \%$ do grupo social alto, $55 \%$ do grupo social médio e $37 \%$ da classe baixa faziam visitas regulares ao dentista. As mulheres visitavam mais regularmente o dentista do que os homens, assim como as idades mais precoces freqüentavam mais o dentista do que a população adulta. Os indivíduos de classe social mais alta tiveram maiores cuidados com seus dentes em relação aos demais grupos. A freqüência de visitas regulares foi menor na área rural que na área urbana e em relação ao número de dentes perdidos, pôde-se concluir que os indivíduos de classes sociais mais baixas perdiam mais precocemente seus dentes.

Em 1978, OLSSON ${ }^{103}$ avaliou a doença periodontal e higiene oral na província de Arussi (Etiópia). A amostra foi constituída por 1700 indivíduos, de 6 a 54 anos. A doença periodontal destrutiva foi encontrada em $7 \%$ dos indivíduos e gengivite em $76 \%$. A gengivite aumentou com a idade. A formação de bolsa periodontal ocorreu em $52 \%$ no grupo de 45-54 anos e em $12 \%$ no grupo de 30 a 34 anos. Nos grupos com faixa etária menor (até 20 anos) somente $1-2 \%$ exibiram doença periodontal destrutiva. Com avanço da idade, ocorreu maior número de dentes afetados pela doença periodontal e aumentou também o número de dentes com escores mais altos. Os incisivos inferiores foram os dentes mais comumente 
afetados e mais severamente afetados pela doença periodontal. A placa estava presente em $100 \%$ dos indivíduos e a quantidade de depósitos aumentou com a idade.

Dentre os estudos clássicos sobre a história natural da Doença Periodontal em humanos estão os levantamentos de LÖE et al. ${ }^{81,82}$ (1978a,b). Na primeira parte de uma seqüência de publicações, foram estabelecidos dois grupos distintos de homens com idade entre 15 a 30 anos. O grupo da Noruega foi composto por 565 estudantes com acesso a cuidados odontológicos e outro no Sri Lanka composto por 480 coletores de chá, sem cuidados odontológicos. O objetivo desta parte da pesquisa foi caracterizar a situação periodontal, em relação à freqüência, padrão e taxa de perda de suporte periodontal ${ }^{81}$. Avaliou-se índice gengival, índice de placa e cálculo e a perda de inserção das faces mesial e vestibular de todos os dentes. O grupo norueguês apresentou excelente higiene bucal, gengivite moderada, pouca presença tanto de cálculo supra quanto subgengival, pequena perda de inserção aparente em primeiros molares e primeiros pré-molares na maxila e mandíbula nos indivíduos mais jovens, aumentando com a idade (aproximadamente 0,05 $\mathrm{mm} / \mathrm{ano}$ ). A média de perda de inserção no grupo de mais de 30 anos foi menor que $1 \mathrm{~mm}$ e nenhum dente exibiu mais de $5 \mathrm{~mm}$ de perda de inserção. O grupo de Sri Lanka mostrou pobre higiene bucal, cálculo abundante e gengivite generalizada de moderada a severa. Observou-se pequena perda de inserção em primeiros molares e incisivos nos indivíduos de 15 anos, aumentando com a idade em aproximadamente $0,20 \mathrm{~mm}$ por ano. $\mathrm{O}$ grupo de mais de 30 anos mostrou uma média de perda de inserção maior que $3 \mathrm{~mm}$ e um número substancial de dentes exibiram perda de inserção de mais de $10 \mathrm{~mm}$.

Numa segunda publicação, LÖE et al. ${ }^{82}$ (1978b) tiveram o propósito de descrever o desenvolvimento natural e o progresso da Doença Periodontal em humanos, utilizando as amostras da Noruega e do Sri Lanka como parte de uma investigação longitudinal. Após os 20 anos de idade, todos os estudantes noruegueses exibiram uma ou mais superfícies com perda de inserção periodontal em áreas localizadas, como face vestibular da maxila e primeiros pré-molares e molares na mandíbula. Aos 30 anos, a média de perda de inserção ainda era menor que $1 \mathrm{~mm}$, com maior perda nas superfícies vestibulares de pré-molares e molares do que nas mesiais, sendo este padrão menos notável em dentes anteriores. Aos 40 anos, $50 \%$ das superfícies radiculares apresentaram perda entre 2 a $4 \mathrm{~mm}$, sendo a média de perda de inserção ligeiramente acima de $1,5 \mathrm{~mm}$. A média da taxa de perda de inserção foi de aproximadamente $0,08 \mathrm{~mm} / \mathrm{ano}$ na superfície mesial e 0,1 mm/ano na superfície vestibular. No Sri Lanka, a taxa de perda de inserção aos 20 anos foi de aproximadamente $0,25 \mathrm{~mm} / \mathrm{ano}$, aumentando para $0,30 \mathrm{~mm} / \mathrm{ano}$ aos 30 anos. A amostra mostrou maior perda nas superfícies vestibular e mesial de incisivos inferiores e primeiros molares superiores e inferiores. Antes dos 40 anos, a média de perda de suporte periodontal 
foi de 4,5 mm. Considerando-se que está perda continuasse, um grande número de dentes seriam perdidos antes dos 50 anos. A média da taxa de perda de inserção foi de aproximadamente $0,30 \mathrm{~mm} /$ ano na superfície mesial e $0,20 \mathrm{~mm} /$ ano na superfície vestibular. Os autores concluíram que sem interferência, a lesão periodontal progride com velocidade relativamente lenta e contínua.

ANERUD et al. ${ }^{15}$ (1979), avaliaram a prevalência e severidade da placa bacteriana e gengivite e suas variações da adolescência aos 40 anos, nas superfícies mesial e vestibular de todos os dentes, dando continuidade aos estudos realizados na Noruega e Sri Lanka por LÖE et al. ${ }^{81,82}\left(1978^{a}\right.$,b). Os resultados desses exames em relação ao Índice de Placa e ao Índice Gengival mostraram que apesar de todos os pacientes da Noruega examinados apresentaram pelo menos uma ou mais áreas com gengivite, mostraram estado gengival de bom a excelente, não havendo aumento na prevalência e severidade da gengivite com o avanço da idade. Houve diferença no padrão de distribuição do grau de gengivite em relação à superfície e ao tipo de dente, com maior prevalência e severidade em áreas interproximais de dentes posteriores, com mais saúde em superfícies vestibulares. Em dentes anteriores a diferença foi menor. Aproximadamente $60-70 \%$ de todas as superfícies dentárias não apresentaram placa visível e a higiene bucal continuou melhorando até os 40 anos. Os jovens de 17 anos de Sri Lanka mostraram pobre saúde gengival com aumento nos níveis do Índice Gengival até os 40 anos. Todos os participantes nos quatro exames tiveram um ou mais sítios gengivais com sangramento. Nos jovens, encontraram-se baixos escores nos dentes anteriores superiores, enquanto nos adultos todos os dentes e suas faces exibiram gengivite evidente. Encontrou-se acúmulo de placa clinicamente visível em quase todas as superfícies dentárias de jovens e não ocorreu mudança deste achado até os 40 anos.

A avaliação transversal de CUTRESS; POWELL; BALL ${ }^{49}$ (1982) em 398 indivíduos de 15-59 anos das populações de Tonga e Samoa procuraram estabelecer o perfil da progressão da Doença Periodontal em indivíduos sem acesso ao tratamento odontológico. Nas duas populações, os grupos mais jovens apresentaram maior acúmulo de placa, cálculo e gengivite. Porém, houve um aumento na porcentagem de indivíduos com Doença Periodontal com o avanço da idade. O sangramento à sondagem apresentou alta prevalência em todas as idades das populações, sendo que a maxila e mandíbula apresentaram o mesmo padrão, com maior porcentagem de sítios com sangramento em dentes posteriores e principalmente na face lingual. Em Tonga, a média da perda de inserção periodontal foi maior e, nas duas populações houve um aumento da perda de inserção com o avanço da idade, com maior perda na maxila comparada a mandíbula. Considerando-se o tipo de dente, os molares superiores tiveram maior perda de inserção 
nas duas populações, sendo que em Tonga, molares e incisivos inferiores apresentaram perda substancial. A Doença Periodontal em Tonga foi mais evidente e com maior número de dentes ausentes. Todos os critérios avaliados mostraram menor valor para o sexo feminino quando comparado ao sexo masculino nas populações, sendo similares para os dois sexos as mudanças ocorridas com o avanço da idade e os tipos de dentes acometidos. Embora o acúmulo de placa tenha sido abundante e a gengivite extensamente presente, apenas uma pequena parcela de indivíduos apresentou perda óssea alveolar, ressaltando a provável existência de patógenos específicos associados a certas formas da Doença Periodontal.

Buscando avaliar a necessidade de tratamento periodontal numa amostra de 4752 adultos finlandeses com mais de 30 anos, MARKKANEN; RAJALA; PAUNIO ${ }^{86}$ (1983) demonstraram que $51 \%$ dos indivíduos, em todos os grupos etários, apresentaram bolsas periodontais de 4-6 mm. As bolsas maiores que $6 \mathrm{~mm}$ foram mais comuns nos grupos acima de 50 anos. Uma pequena porcentagem de indivíduos (em média 3,4\%) apresentou-se com estado periodontal saudável. Houve uma diminuição na porcentagem de indivíduos com presença de inflamação até os 50 anos, seguido por aumento dessa porcentagem até os 70 anos. Verificou-se que $96,6 \%$ dos indivíduos apresentaram retenção de placa, havendo relação positiva entre a retenção de placa, presença de gengivite e bolsas periodontais. Ao se considerar o gênero, encontrou-se uma maior porcentagem de homens com bolsas periodontais moderadas e profundas. Em vista dos resultados obtidos os autores concluíram que pequena porcentagem da população é completamente saudável, grande parte apresenta bolsas moderadas e as perdas severas aumentam com o avanço da idade.

Trezentos e sessenta e um vietnamitas foram avaliados por SCHEUTZ; HEIDMANN; POULSEN ${ }^{118}$ (1983) quanto ao sangramento gengival e perda de inserção periodontal, além da presença de cáries e cálculo. O sangramento gengival teve freqüência quase constante nos diferentes grupos. A perda de inserção periodontal $\geq 4 \mathrm{~mm}$ ocorreu em quase $10 \%$ das superfícies examinadas nos grupos acima de 20 anos e a perda de inserção $\geq 6 \mathrm{~mm}$ foi encontrada em menos de $5 \%$ em todos os grupos, exceto os de mais de 45 anos (cerca de $15 \%)$. Os molares mostraram perda de inserção mais freqüente do que os pré-molares e incisivos e as faces proximais mais do que faces vestibular e lingual. A perda de inserção ocorreu com maior freqüência nas faixas etárias mais avançadas.

No mesmo ano, DOUGLASS et al. ${ }^{55}$ avaliaram o comportamento da Doença Periodontal em duas populações com idade entre 55 e 79 anos, utilizando dois levantamentos do National Center for Health Statistics (NCHS) conduzidos respectivamente entre 1960-1962 e 1971-1974. Foi utilizado o IP de RUSSEL, sendo possível observar na comparação das duas populações, uma diminuição da gengivite, significante melhora no 
estado de higiene bucal e aumento do número de pessoas com bolsa periodontal após os 35 anos. Um importante relato feito pelos autores visou explicar os resultados obtidos. Eles afirmaram que com um maior número de dentes presentes na cavidade bucal, há maior exposição destes ao risco da Doença Periodontal com o avanço da idade, este fato talvez explique o aumento do número de pessoas com bolsa periodontal.

ANERUD et al. ${ }^{16}$ (1983) avaliaram e compararam a prevalência e severidade da doença periodontal além de relatar fatores etiológicos em 665 homens jovens, de 19 a 30 anos de idade, dos Estados Unidos, Noruega e Sri Lanka. Foram avaliados: índice de placa, índice gengival, índice de retenção, cáries, perda de inserção. A face mesial foi a mais acometida pela placa. Em todas s populações, os altos escores de placa foram encontradas em molares na superfície mesial e bucal e os mais baixos foram nas mesiais dos dentes anteriores. Em todas as superfícies, 11,95 (Noruegueses), 25,4\% (Americanos) e 32,9\% (Sri Lanka) receberam escore 2. O escore 3 foi raro nas três populações, e o escore 0 ocorreu em 17,1\% (Estados Unidos), 16,9\% (Noruega), e 10,6\% (Sri Lanka) dos sítios examinados. Em todas as populações, as faces mesiais tiveram altos índices, assim como a perda de inserção nesta face foi essencialmente a mesma nos três grupos na idade de 19-20 anos, quando aproximadamente $95 \%$ das superfícies examinadas mediram 0-1 mm. A face vestibular teve mais perda de inserção do que a mesial. A média de perda de inserção na vestibular foi $0,47 \pm 0,62 \mathrm{~mm}$ (Americanos), 0,43 $\pm 0,73 \mathrm{~mm}$ (Noruega) e 0,34 \pm 0,5 $\mathrm{mm}$ (Sri Lanka). Nesta faixa etária, menos que $1 \%$ de toda as faces tiveram menos que $3 \mathrm{~mm}$ de perda de inserção. Entretanto 3-8\% de todas foram 2 ou $3 \mathrm{~mm}$. Um pequeno aumento geral na perda de inserção foi encontrado com avanço da idade, na faixa de 27-29 anos. Essa perda de inserção foi $0,88 \pm 0,9 \mathrm{~mm}$ (Americanos, $0,65 \pm 0,77 \mathrm{~mm}$ (Noruega) e 0,71 $\pm 0,69$ $\mathrm{mm}$ (Sri Lanka) para superfície mesial e 1,30 \pm 0,99 $\mathrm{mm}$ (Estados Unidos), 0,98 \pm 1,06 mm (Noruega) e 1,08 \pm 0,96 mm (Sri Lanka) para superfície vestibular. No grupo mais velho, a perda de inserção maior que $3 \mathrm{~mm}$ foi encontrado em menos de $2 \%$ das áreas examinadas e ocorreu primariamente nas faces vestibulares. Em todas as populações, as vestibulares tiveram maior perda de inserção nos primeiros molares superiores e primeiro pré-molar inferior. Na face mesial, no grupo de 19 a 20 anos, os dentes mais acometidos foram os primeiros molares superiores.

Em 1984, BECK et al. ${ }^{24}$ examinaram uma amostra de 1200 indivíduos moradores do estado de lowa. Aproximadamente $40 \%$ da população tiveram sangramento à sondagem, houve aumento da porcentagem de sítios sangrantes com o avanço da idade, porém com a maior porcentagem no grupo de $25-34$ anos. $25 \%$ dos indivíduos no grupo de 25 a 44 anos apresentaram bolsas periodontais de $3-6 \mathrm{~mm}$, aumentando para $30 \%$ nos grupos de 45 anos ou mais. Uma pequena parcela da amostra (2\%) teve bolsas periodontais de profundidade $\geq 6 \mathrm{~mm}$ e no grupo de $45-54$ anos este valor foi de $6,8 \%$, sendo considerado o 
grupo de maior risco. Os grupos acima desta idade apresentaram menor porcentagem, provavelmente por terem seus dentes já extraídos. Apesar dos homens apresentarem mais sangramento, cálculo e bolsas periodontais do que as mulheres, a diferença não foi significante. Segundo os autores, o sexo não é um fator de risco, mas a idade é um possível fator de risco para Doença Periodontal. Como em outros relatos anteriores, os achados sustentam a hipótese de que mais de um processo está envolvido na etiologia da Doença Periodontal, sendo que uma pequena parte da população apresenta alto risco à doença levando à perda dentária.

Com o objetivo de analisar a confiabilidade do exame parcial na avaliação da severidade média e na prevalência da doença periodontal, AINAMO; AINAMO ${ }^{3}$ (1985) examinaram 126 indivíduos com idade entre 13 e 30 anos e 160 com idade entre 31 e 68 anos quanto à presença ou ausência de sangramento gengival, cálculo supra e subgengival e profundidade de bolsa de 4,5 a $6 \mathrm{~mm}$ ou mais, em 6 sítios de cada dente remanescente. A partir deste conjunto de dados três grupos de valores para severidade e prevalência média foram tomados. Um deles foi baseado no exame total da boca, um segundo realizou observação a partir de 10 dentes para registro do CPITN e o último, em seis dentes para o registro do Índice de Doença Periodontal de Ramfjord. Quando as avaliações foram baseadas no CPITN, os resultados médios da severidade ultrapassaram aqueles baseados nos exames de boca toda para todos os indicadores registrados e os valores para prevalência foram mais altos do que aqueles baseados nos seis dentes de Ramfjord. Houve uma subestimação da proporção de indivíduos afetados, variando de $16 \%$ para as bolsas de 4-5 $\mathrm{mm}$ a $21 \%$ para as bolsas de $6 \mathrm{~mm}$ ou mais de profundidade no grupo de idade mais avançada. Os autores concluíram que o estudo forneceu informação valiosa a respeito da escolha dos métodos de exame parcial para diferentes fins, confirmando a opinião de que o exame parcial não é suficientemente aceitável para a determinação das necessidades de tratamento periodontal de pacientes individuais.

Um dos estudos mais importantes sobre a história natural da Doença Periodontal foi o de LÖE et al. ${ }^{83}$ (1986), no qual os autores puderam observar claramente à existência de grupos susceptíveis a destruição periodontal em 480 trabalhadores de plantações de chá no Sri Lanka. Esta população era desprovida de cuidados odontológicos e apresentou extenso acúmulo de placa, cálculo e inflamação gengival. No exame inicial, a presença de sangramento foi identificada em 60, 90 e 100\% das faces interproximais nos grupos de 20 , 30 e 40 anos respectivamente. A média de perda de inserção interproximal foi de $3,5 \mathrm{~mm}$ (30 anos), $5 \mathrm{~mm}$ (40 anos) e $6 \mathrm{~mm}$ (45 anos). O número médio de dentes presentes nas faixas etárias de 20, 30, 40 e 45 anos foi de 27,5, 26,4, 22,4 e 21,8 dentes, respectivamente. Devido à completa ausência de cáries nessa população, a perda dentária ocorreu em 
decorrência da Doença Periodontal. Após as sucessivas reavaliações, foi demonstrado extenso acúmulo de placa, cálculo e inflamação gengival em todos os indivíduos. No entanto, foram identificadas três subpopulações, baseado na perda de inserção interproximal e taxa de perda dentária: (1) grupo com Doença Periodontal de progressão rápida (8\%); (2) progressão moderada (81\%); (3) sem progressão (11\%). Frente aos resultados, os autores ressaltaram a hipótese de variações na taxa de progressão da Doença Periodontal entre grupos de indivíduos, dentro da dentição de um mesmo indivíduo e em diferentes idades. Afirmaram que na ausência de intervenção odontológica e independente de variações na velocidade e padrão de progressão da doença, a lesão periodontal progride constantemente durante o tempo até comprometer todo o periodonto com perda de alguns ou todos os dentes. Eles não excluíram a existência de episódios de exacerbação local como possível mecanismo de progressão da doença.

O estudo transversal desenvolvido por BAELUM; FEJERSKOV; KARRING ${ }^{20}$ (1986) teve como objetivo caracterizar as condições periodontais em 170 indivíduos adultos de 30 a 69 anos, avaliando placa, cálculo, gengivite, perda de inserção e bolsas periodontais. Os grupos de maior idade apresentaram mais placa e cálculo e o sangramento gengival afetou $30-40 \%$ das superfícies em todos os grupos etários. Menos de $35 \%$ de todas as superfícies exibiram perda de inserção $\geq 4 \mathrm{~mm}$ e menos de $10 \%$ tiveram perda de inserção excedendo 6 $\mathrm{mm}$. A média de perda de inserção no grupo de 35-39 anos foi de 1,73 mm e no grupo de 40-49 anos foi de 1,77 mm. A perda de inserção foi acompanhada por recessão da margem gengival. A razão pela grande ocorrência de recessões gengivais não é clara e parece não estar relacionada à excelente higiene bucal. Segundo os autores, poucos indivíduos foram responsáveis pela maior perda de inserção e bolsas periodontais e sugeriram dar ênfase à identificação desta sub-população susceptível nos futuros estudos epidemiológicos.

Os efeitos da idade e da higiene bucal na progressão da Doença Periodontal foram analisados em 14690 americanos de 15 a 74 anos de idade, participantes de uma pesquisa nacional americana (National Health and Nutrition Examination Survey - NHANES I). ABDELLATIF; BURT ${ }^{1}$ (1987) constataram que apesar da incidência e prevalência da periodontite acentuar-se com a idade, esse aumento foi mais pronunciado em grupos com pobre higiene bucal comparado aos indivíduos com saúde bucal. O efeito da idade pode ser negligenciado quando uma boa higiene bucal é mantida. A idade pode estar correlacionada à prevalência e severidade da Doença Periodontal, mas não seria considerado um fator de risco. Nesta avaliação, houve discordância em relação ao padrão de progressão lenta e linear da Doença Periodontal com o avanço da idade. Alguns sítios em certos indivíduos foram afetados pela doença quando a higiene bucal era pobre. Contudo, nem todos os indivíduos com pobre higiene bucal apresentaram necessariamente Doença Periodontal 
severa. Portanto, além de estar relacionada ao estado de saúde bucal, a Doença Periodontal depende também da resposta do hospedeiro.

Ainda em 1987, CARLOS; BRUNELLE; WOLFE ${ }^{46}$ buscaram as diferenças entre as medidas mais extensamente utilizadas em levantamentos epidemiológicos: profundidade de sondagem e perda de inserção. As duas medidas foram obtidas de 14 sítios mechais sondados em 15132 indivíduos com idade entre 18 a 60 anos. Para calcular a prevalência de indivíduos consideraram as perdas periodontais mais severas de cada indivíduo, sendo que os indivíduos foram separados em dois grupos de acordo com a severidade da perda (4-6 mm e $>6 \mathrm{~mm}$ ). As porcentagens de indivíduos com bolsas moderadas e severas mostraram-se estáveis depois dos 34 anos de idade, sendo que a correlação entre profundidade de sondagem e a idade foi fraca. Em contraste, houve um acentuado aumento da proporção de indivíduos com perda de inserção moderada e severa com o avanço da idade, assim como uma maior prevalência de indivíduos com maior destruição periodontal. Os autores concluíram que o uso de índices como o IP de RUSSEL e o CPITN, os quais utilizam apenas a profundidade de sondagem, podem subestimar a ocorrência de Doença Periodontal na população.

Neste mesmo ano, BAELUM ${ }^{22}$ realizou um estudo transversal na Tanzânia. A amostra foi constituída por 170 indivíduos, com idade entre 30 e 69 anos, foram avaliadas as superfícies mesial, vestibular, distal e lingual de todos os dentes com exceção dos $3^{\circ}$ molares. Os parâmetros avaliados foram: nível de inserção clínico, profundidade de bolsa, recessão gengival, placa e gengivite. Os dentes mais afetados pela perda de inserção foram os primeiros molares superiores, incisivo inferior e primeiro pré-molar em todas as faixas etárias. Em todas as faixas etárias a maioria da população teve perdas menores que $1 \mathrm{~mm}$. Os dentes mais afetados pela recessão em todos os grupos etários foram os primeiros molares e primeiros prés superiores e nos inferiores os incisivos e primeiros pres. Independente da faixa etária e tipo de dentário, menos que $20 \%$ das superfícies exibiram bolsa periodontal $\geq 4 \mathrm{~mm}$. O sangramento a sondagem foi menor nos dentes anteriores superiores do que nos posteriores. Um importante achado deste estudo é que a distribuição da placa não ter sido paralela a perda de inserção e recessão gengival.

Em 1988, SCHÜRCH Jr. et al. ${ }^{118}$ coletaram dados de perda de inserção, profundidade de sondagem, índice de placa e gengival das quatro faces de todos os dentes, para avaliar a condição periodontal de uma amostra de 206 suíços de 20-70 anos. Observou-se um aumento na média do índice de placa e do índice gengival com uma diminuição no número médio de dentes presentes com o avanço da idade. A maxila apresentou maior número de dentes perdidos em relação à mandíbula. A mandíbula apresentou maior perda de inserção (face lingual) do que a maxila, porém em relação à 
profundidade de sondagem não houve diferença entre as duas. Na mandíbula (face lingual) o índice de placa e índice gengival foram maiores. Comparando-se molares, pré-molares e dentes anteriores, notou-se que os molares tiveram maior índice de placa, índice gengival e porcentagem de dentes perdidos. As faces proximais (mesial e distal) tiveram maior profundidade de sondagem que as faces livres (vestibular e lingual). Não houve diferença estatisticamente significante dos dados avaliados entre os dois sexos. Em relação às medidas de profundidade de sondagem e perda de inserção periodontal obtiveram-se as seguintes porcentagens respectivamente: $72 \%$ e $76 \%$ de todas as medidas foram $\leq 3 \mathrm{~mm}$, $26 \%$ e $21 \%$ foram entre $4-6 \mathrm{~mm}$ e apenas $2 \%$ e $3 \%$ maior que $6 \mathrm{~mm}$. Contudo, é importante ressaltar como esses sítios estão distribuídos na população, sendo que $28 \%$ dos indivíduos possuem sítios com profundidade de sondagem $>6 \mathrm{~mm}$ e $42 \%$ têm pelo menos um sítio com profundidade de 5 ou $6 \mathrm{~mm}$. Sendo assim, uma parcela significativa dessa amostra necessita, em pelo menos algum sítio, de um tratamento periodontal especializado.

As mudanças conceituais sobre a epidemiologia da Doença Periodontal ocorreram devido à substituição dos índices periodontais pelos parâmetros clínicos como perda de inserção e profundidade de sondagem, registrados de sítios, dentes, quadrantes, tipo de dente, arco, exames de boca toda e médias da população ${ }^{60}$. Isto permitiu a identificação real do problema da Doença Periodontal na população, reforçando que uma pequena porcentagem dos pacientes são afetados pela Doença Periodontal severa. Concomitante à modificação no registro de dados, iniciou-se uma busca de diferentes métodos de análise desses dados colhidos, abortando a utilização única de valores médios para a caracterização da Doença Periodontal. Com esse intuito, OKAMOTO et al. ${ }^{102}$ (1988) realizaram um exame clínico em 319 pacientes japoneses de 20 a 79 anos de idade, incluindo avaliação de placa, gengivite, profundidade de sondagem, nível de inserção à sondagem e número de dentes ausentes. Os dados obtidos foram avaliados de três maneiras: (1) valores médios de cada parâmetro clínico para cada indivíduo e por faixa etária; (2) a freqüência de sujeitos com um ou mais sítios com perda de inserção segundo medidas estabelecidas ( $>2,>3,>4,>5,>6,>7$ e $>8 \mathrm{~mm}$ ) e porcentagem desses indivíduos com $>0,>3,>9$ e $>19$ sítios apresentando as perdas estabelecidas (3) porcentagem de sítios com diferentes níveis de inserção determinados para cada faixa etária. Os resultados mostraram higiene bucal deficiente desses pacientes (65-75\%) e alta freqüência de gengivite (35-65\%). A média de dentes ausentes foi de 7, 2, com maior valor médio no grupo de 60-79 anos (15 dentes perdidos). Os valores médios mostraram um perfil geral da Doença Periodontal com a idade, assim como a severidade desta nos diferentes tipos de dentes e superfícies dentárias. Houve um aumento na perda de inserção periodontal, principalmente em molares e incisivos, sendo que todas as médias dos parâmetros 
avaliados aumentaram com o avanço da idade. A média anual de perda de inserção foi menor que $0,1 \mathrm{~mm}$. A média de profundidade de sondagem variou pouco entre as faixas etárias, apresentando maiores valores nas superfícies proximais, enquanto a superfície lingual obteve maiores médias que a superfície vestibular. A freqüência de indivíduos com sítios com determinados valores de perda de inserção, revelou a proporção de indivíduos afetados e a análise percentual proveu informações sobre a severidade da doença entre os indivíduos da amostra. A maioria dos indivíduos entre 20-59 anos apresentaram pequena evidência de Doença Periodontal severa, esta se encontrou restrita a um pequeno grupo de pessoas. Após os 60 anos, a Doença Periodontal teve distribuição mais generalizada.

Corroborando com a filosofia emergente, BAELUM; FEJERSKOV; MANJI ${ }^{22}$ (1988) estudaram uma amostra de 1131 indivíduos com acesso limitado a cuidados odontológicos e com idade de 15-65 anos no Quênia. A porcentagem de superfícies com placa variou de $75-95 \%$, com maior índice nos grupos mais idosos. O sangramento à sondagem foi observado em $40 \%$ das superfícies do grupo de $15-24$ anos e aumentou para $60-70 \%$ nos grupos de maior idade. Os primeiros molares e incisivos inferiores foram os dentes mais afetados pela perda de inserção, sendo os caninos superiores e pré-molares inferiores os menos acometidos. As superfícies linguais foram as que mostraram maior perda de inserção do que as vestibulares. Contudo, bolsas periodontais profundas foram freqüentes em sítios interproximais. Os homens tiveram maior proporção de superfícies com perda de inserção e mais placa visível, porém o sangramento à sondagem não diferiu entre os gêneros. Os autores constataram que a proporção de sítios com perda de inserção $\geq 4 \mathrm{~mm}$ ou $\geq 7 \mathrm{~mm}$ mostrou uma distribuição irregular entre os pacientes, indicando que em cada faixa etária uma fração dos indivíduos é responsável por um maior comprometimento periodontal. 0 número de indivíduos dentro dessas frações se torna maior com o aumento da idade. Até mesmo um dente individualmente, considerando tipos e sítios específicos, mostrou variação marcante na severidade da Doença Periodontal. Foi contestado o padrão contínuo de progressão da Doença Periodontal e ressaltou-se a importância da identificação da subpopulação de maior risco, objetivando estratégias racionais para prevenção e tratamento adequados da Doença Periodontal destrutiva.

Com o mesmo objetivo das pesquisas anteriores, LEMBARITI; FRENCKEN; PILOT ${ }^{76}$ (1988) buscaram obter informações sobre a situação periodontal de 809 adultos residentes na Tanzânia. A prevalência de placa bacteriana $(99,6 \%)$ e gengivite $(93,8 \%)$ foram altas em todos os grupos etários (20-45 anos). As bolsas periodontais de 3,5-5,5 mm e $>5,5 \mathrm{~mm}$ foram encontradas respectivamente em $69,3 \%$ e $5,2 \%$ das pessoas examinadas. O número de dentes comprometidos periodontalmente e o número de dentes ausentes aumentaram com o avanço da idade, mesmo assim, metade da dentição permaneceu intacta. Estes 
valores indicam que apesar da alta prevalência de placa e gengivite, apenas alguns casos evoluem para Doença Periodontal avançada e perda dentária.

No mesmo ano, uma amostra de 319 indivíduos, entre 20 e 79 anos de idade foi estudada por YONEYAMA et al. ${ }^{137}$ (1988) analisando a perda de inserção clínica, profundidade de sondagem, presença e ausência de sangramento e placa e recessão gengival. Praticamente toda amostra estudada apresentou um ou mais sítios da dentição afetada por Doença Periodontal destrutiva. Houve também um aumento na severidade da doença com a idade, expresso pelo aumento na média de profundidade de sondagem e perda de inserção. Em cada faixa etária, encontrou-se maior perda de inserção e profundidade de sondagem em molares do que em incisivos, caninos e pré-molares. Apesar da maioria dos pacientes terem apresentado pobre higiene bucal e sangramento gengival, a perda de inserção severa afetou apenas alguns dentes de alguns indivíduos. Nos grupos etários entre 20-59 anos encontrou-se Doença Periodontal avançada em um pequeno subgrupo dos indivíduos da amostra, enquanto que após os 60 anos, o comprometimento periodontal generalizado foi um achado comum. A doença na fase avançada esteve mais prevalente e difundida entre os indivíduos mais velhos, sendo que a perda de inserção foi geralmente acompanhada por recessão da margem gengival. As bolsas periodontais profundas foram relativamente infreqüentes. Avaliou-se a progressão da Doença Periodontal com o avanço da idade comparando-se a freqüência de distribuição de sítios com perda de inserção $\geq 3 \mathrm{~mm}$ nos indivíduos dos diferentes grupos etários. Os dados sugerem que nos grupos incluindo indivíduos mais novos, a progressão da doença é confinada a alguns pacientes, enquanto que nos grupos de idosos, maior número de indivíduos e sítios estão envolvidos.

Com a maior individualização das análises, vários conceitos foram sendo gradativamente alterados. A partir do levantamento epidemiológico de BROWN; OLIVER; LÖE ${ }^{35}$ (1989) várias observações puderam ser feitas acerca da prevalência, severidade, extensão e papel da Doença Periodontal na perda dentária. Apenas 15\% da população adulta americana não apresentavam qualquer sinal de Doença Periodontal, sendo que a gengivite foi encontrada em $50 \%$ da população. As bolsas periodontais de 4-6 mm estavam presentes em $33 \%$ da amostra e a periodontite severa (pelo menos uma face com perda maior que $6 \mathrm{~mm}$ ) encontrou-se presente em $8 \%$ da população e usualmente afetando apenas um ou dois dentes. Obteve-se pequena porcentagem da população adulta com periodontite severa, porém a periodontite moderada foi um achado comum. A prevalência da Doença Periodontal (presença de bolsas) aumentou com a idade; na faixa etária acima dos 65 anos, a porcentagem de idosos com bolsas periodontais foi similar ao grupo de 45-64 anos porem o número de dentes presentes nesses indivíduos era menor. Nas faixas etárias 
de 19-44 anos, 45-64 anos e de 65 anos ou mais, os molares foram os dentes mais frequentemente afetados pela Doença Periodontal e os incisivos foram os menos afetados, principalmente os centrais superiores. Foi feita uma análise da simetria da distribuição das doenças entre os quadrantes, comparando-se lados direito e esquerdo de quadrantes superiores e inferiores. A simetria bilateral foi mais substancial nos grupos jovens, os idosos apresentaram menor simetria provavelmente pelo maior porcentagem de dentes ausentes. Apenas $4 \%$ da amostra tiveram indicação para extração de dentes com destruição periodontal severa e menos de $20 \%$ de todos os dentes ausentes foram extraídos por comprometimento periodontal. Frente aos resultados, a periodontite não foi considerada a maior causa de perda de dentes nos Estados Unidos.

MILLER et al. ${ }^{95}$, em 1990, realizaram uma análise em 1005 indivíduos adultos na França, utilizando o índice CPITN. Compararam os resultados de exames bucais parciais e totais. Observaram que os exames parciais superestimaram o número de indivíduos apresentando cálculo sem bolsa periodontal (549 no exame parcial e 484 no exame total) e por outro lado o sangramento não é tão bem detectado através do exame de dentes selecionados: apenas 53 dos 62 casos foram corretamente evidenciados. As diferenças entre os exames parciais e totais consistiram de $23,5 \%$ para bolsas profundas, $17,6 \%$ para bolsas rasas, $13,4 \%$ para cálculo, 3,2\% para sangramento e $53 \%$ para regiões saudáveis. Assim os autores concluíram que ao se realizar o exame parcial, as aproximações do número de indivíduos necessitando orientações de higiene oral e raspagem são aceitáveis, mas a avaliação do número de indivíduos necessitando terapia periodontal complexa subestima a realidade. Assim, os exames bucais totais são mais adequados.

O objetivo do trabalho de BHAT ${ }^{26}$ (1991) foi descrever a prevalência da condição periodontal, incluindo o status gengival, presença de cálculo, recessão gengival, e perda de inserção em 11.111 adolecentes americanos de 14 a 17 anos. Os resultados obtidos demonstraram que mais de $56 \%$ dos adolecentes apresentaram pelo menos um sitio com sangramento, $8 \%$ com 10 ou mais sítios sangrantes. $O$ sangramento mais freqüente foi em molares superiores e incisivos inferiores. A média de perda de inserção foi de $0.33 \mathrm{~mm}$. A média de perda de inserção foi consistentemente maior $(0.13-0.18 \mathrm{~mm})$ nos sítios mesiais em ambos os gêneros em todas as idades. Os sítios mais comuns com perda de inserção $\geq$ $2 \mathrm{~mm}$ foram os molares e pres superiores, seguidos pelos molares e caninos inferiores. A perda de inserção $\geq 4 \mathrm{~mm}$ e $\geq 6 \mathrm{~mm}$ foi observado em $0.72 \%$ e $0.04 \%$ dos indivíduos, respectivamente. A recessão gengival $\geq 1 \mathrm{~mm}$ e $\geq 4 \mathrm{~mm}$ foi observada em $3.29 \%$ e $4 \%$ respectivamente.

Um levantamento epidemiológico, utilizando CPITN em 5425 indivíduos foi realizado na cidade de Bauru-SP por CAMPOS, Jr. et al. ${ }^{39}$ (1992), revelando uma predominância dos 
índices 1 e 2, sendo os índices 3 e 4, que correspondem a profundidades de sondagem maiores que $4 \mathrm{~mm}$, encontrados respectivamente em $3,7 \%$ e $1,3 \%$ da população. O CPITN médio foi maior no sextante inferior anterior $(22,8 \%)$; talvez por ser esta região a que apresenta menor índice de edentulismo, há maior tempo real de vida para progressão da doença. O sextante menos afetado foi o superior anterior. Segundo este levantamento, uma pequena parcela da população bauruense avaliada apresenta perdas periodontais.

O estudo de HOHLFELD; BERNIMOULIN ${ }^{68}$ (1993) descreveu o comportamento da Doença Periodontal em 143 trabalhadores alemães de 45-54 anos de idade, utilizando o CPITN e a média da perda de inserção periodontal. Nenhum indivíduo da amostra apresentou completa saúde periodontal. Considerando-se o escore mais severo, a maioria da população apresentou bolsas moderadas $(39,86 \%)$ ou profundas $(53,85 \%)$. Os dentes anteriores mostraram menor perda de inserção quando comparados aos posteriores e as faces vestibulares e linguais menores perdas de inserção do que as proximais (mesial e distal). Essa diferença entre as faces proximais e livres foi maior nos dentes anteriores do que nos posteriores e pode ser explicada pela maior higiene nos anteriores e dificuldade de limpeza interproximal nos posteriores. Os dentes inferiores mostraram menor perda de inserção do que os dentes superiores. De uma maneira geral, os molares superiores foram os dentes mais afetados pela perda de inserção e as superfícies vestibulares e linguais dos dentes anteriores foram as menos afetadas. O grupo apresentou um alto número de dentes remanescentes com média de 23 dentes. Os dados sugeriram devido a esse fato, que houve uma alta prevalência da Doença Periodontal em diferentes graus nos indivíduos em geral, mas apenas alguns indivíduos mostraram destruição periodontal severa generalizada.

MUMGHAMBA; MARKKANEN; HONKALA ${ }^{99}$ (1995) avaliando 1764 indivíduos de 3 a 84 anos na Tanzânia buscaram não apenas dados epidemiológicos dessa população, mas também os fatores de risco associados à Doença Periodontal. As proporções de indivíduos com gengivite, constatada por meio da ausência ou presença de sangramento, foram $75 \%$ (20-34anos), $81 \%$ (35-44anos) e $84 \%$ (acima dos 44 anos). A gengivite foi mais comum entre homens $(85 \%)$ do que entre mulheres $(74 \%)$. Os fatores de risco mais significantes para gengivite foram o sexo masculino e a presença de placa. Considerando-se as contagens dicotômicas adotadas, houve pequena presença de bolsas periodontais $\geq 4 \mathrm{~mm}$ (8\%) e recessão gengival (13\%). As proporções de bolsas periodontais e recessão gengival aumentaram com a idade, sendo mais acentuadas nos grupos de 35 anos ou mais. Em relação à presença de bolsas periodontais, não houve diferença entre os gêneros, porém a idade e a presença de placa foram consideradas fatores de risco. A recessão gengival foi mais prevalente no sexo masculino e em indivíduos com placa visível. 
Dados de uma extensa pesquisa realizada nos Estados Unidos (NHANES III) foram empregados por ALBANDAR; BRUNELLE; KINGMAN ${ }^{6}$ (1999) para determinar a prevalência e extensão da Doença Periodontal em uma amostra de 9689 indivíduos de 30 a 90 anos. Foram colhidos dados de profundidade de sondagem e perda de inserção. Estimou-se que pelo menos $35 \%$ da amostra tinham periodontite, sendo $21,8 \%$ na forma leve e $12,6 \%$ da forma moderada ou severa. A prevalência e extensão da perda de inserção aumentaram consideravelmente com a idade, ou seja, mais pessoas e mais dentes por pessoa apresentaram perda de inserção com o passar dos anos. Contudo, nos idosos acima de 80 anos houve um declínio dos valores, provavelmente devido a maior perda dentária. A profundidade de sondagem não variou tanto quanto a perda de inserção em relação ao avanço da idade. A perda de inserção foi mais freqüente em molares superiores e incisivos inferiores e menos freqüente em incisivos centrais superiores. Maiores profundidades de sondagem foram encontradas em molares e foram menores em incisivos e caninos superiores. A prevalência de perda de inserção e da profundidade de sondagem foram maiores nas superfícies vestibulares e mesiais respectivamente. Os homens mostraram maior prevalência e extensão de perda de inserção e profundidade de sondagem. O número total de dentes perdidos aumentou com a idade de 1,49 (30 anos) para 11,29 dentes (85 anos). O exame foi parcial envolvendo dois sítios de cada dente, sendo apenas dois quadrantes avaliados. Os autores acreditam que devido a esse fator, a verdadeira prevalência e extensão da Doença Periodontal na população americana sejam significantemente maiores.

O objetivo do estudo de BAELUM et al. ${ }^{23}$ (2003) foi descrever as condições periodontais de 359 indivíduos tailandeses com idades entre 30-39 anos e 50-59 anos. No exame clínico foi medida a quantidade de placa e cálculo em seis dentes, sangramento à sondagem, nível de inserção e profundidade de bolsa em seis sítios de todos os dentes presentes, exceto terceiros molares. Os indivíduos foram re-examinados quanto ao nível de inserção seis meses depois. Mais de $95 \%$ dos indivíduos apresentaram sangramento à sondagem e de 65,6\% (30-39 anos) a 81,3\% (50-59 anos) de indivíduos com placa abundante. A prevalência de perda de inserção $\geq 4 \mathrm{~mm}$ foi $92 \%$ entre $30-39$ anos e de $100 \%$ entre $50-59$ anos e a porcentagem média de sítios com perda de inserção foi de $23,9 \%$ e $63,9 \%$ respectivamente. Quanto a profundidade de sondagem, bolsas $\geq 4 \mathrm{~mm}$ estavam presentes em $84 \%$ nos de $30-39$ anos e $93 \%$ no grupo de $50-59$ anos e bolsas maiores ou iguais a $7 \mathrm{~mm}$ estava mais prevalente nos mais idosos ( $28 \%$ vs $10 \%)$.

Neste mesmo ano RAGGHIANTI ${ }^{111}$, com o objetivo de analisar o perfil comportamental da Doença Periodontal, avaliou uma amostra de 380 indivíduos, de ambos os gêneros, com mais de 20 anos de idade, sendo que foram registradas medidas de 
profundidade de sondagem, nível de inserção, índice de sangramento e índice de placa de quatro superfícies dentárias em todos os dentes. Os dados obtidos foram analisados para detectar diferenças relativas à faixa etária, sexo e hábito de fumar, além de avaliar diferenças entre arcos, sextantes e superfícies dentárias. As análises estatísticas demonstraram que a maxila, os sextantes posteriores e superfícies proximais têm maior susceptibilidade para Doença Periodontal. Com o avanço da idade, houve um agravamento das condições periodontais e um maior número de indivíduos com perdas severas e comprometimento das superfícies livres, caracterizado pela recessão gengival. A prevalência e a porcentagem de sítios sangrantes e com placa foram altas, havendo correlações positivas com as perdas periodontais e entre os índices. Concluiu que a maioria dos indivíduos necessita de avaliação ou tratamento periodontal em pelo menos um sítio. $A$ idade, o sexo masculino e o hábito de fumar foram associados ao maior comprometimento periodontal, sendo fatores importantes no diagnóstico da Doença Periodontal. Desta maneira, a estimativa da situação periodontal dessa amostra propiciou possibilidades de análise e planejamento de ações de saúde para maior efetividade de programas de tratamento e prevenção da Doença Periodontal.

SUSIN; ALBANDAR ${ }^{125}$, no ano de 2005, estudaram a prevalência da periodontite agressiva e sua possível associação com variáveis demográficas, fumo, classe sócioeconômica, entre outras, de uma população jovem do sul do Brasil. A amostra foi constituída de 612 indivíduos divididos em dois grupos etários: 14 a 19 anos e 20 a 29 anos que foram classificados com periodontite agressiva se apresentassem quatro ou mais dentes com perda de inserção clínica $\geq 4 \mathrm{~mm}$ ou $\geq 5 \mathrm{~mm}$, respectivamente. Além do nível se inserção foram avaliados o sangramento à sondagem, profundidade de bolsa e recessão gengival. Vinte e oito indivíduos apresentaram periodontite agressiva, 47,6\%, 28,5\% e 13,6\% dos dentes mostraram perda de inserção $\geq 4 \mathrm{~mm}, \geq 5 \mathrm{~mm}$ e $\geq 6 \mathrm{~mm}$ respectivamente. Este estudo demonstrou prevalência relativamente alta de periodontite agressiva nesta população de adolescentes e adultos jovens. Indivíduos com periodontite agressiva tiveram significantemente altos índices de placa, sangramento gengival, e cálculo supragengival. As variáveis: nível sócio-econômico, fumo, cálculo supragengival são indicadores de risco para a periodontite agressiva. Se programas preventivos forem implementados esses indicadores de risco podem prevenir ou reduzir a prevalência da periodontite agressiva nesta população e população similares.

Neste mesmo ano, COLLINS et al. ${ }^{44}$, realizaram um estudo transversal na cidade de Santo Domingo com o objetivo de avaliar a perda de inserção periodontal em 2007 estudantes de 14 a 21 anos de idade. Foram avaliados recessão gengival e profundidade de sondagem em seis sitos por dente com subseqüente cálculo da perda de inserção clínica de cada sítio. Os resultados demonstraram que $49,5 \%$ dos estudantes tiveram pelo menos um 
sítio com perda de inserção clínica $\geq 1 \mathrm{~mm}$, e $15 \%$ e $4 \%$ tiveram perdas $\geq 2 \mathrm{~mm}$ e $\geq 3 \mathrm{~mm}$, respectivamente. A porcentagem de indivíduos com perda de inserção $\geq 3 \mathrm{~mm}$ aumentou com a idade. O modelo de regressão logística foi realizado para analisar as variáveis associadas com a alta probabilidade de perda de inserção clínica: idade, gênero, fumo, medicamentos e nenhuma visita ao dentista durante o período de um ano. Somente a idade teve aumento significante na probabilidade de ter maior perda de inserção clínica. Os autores concluíram que deve ser dada mais ênfase na aplicação de medidas preventivas em crianças, adolescentes e adultos jovens.

Em 2005, BURT et al. ${ }^{37}$ publicaram uma revisão de literatura sobre a epidemiologia da doença periodontal. Fizeram um apanhado dos principais resultados alcançados pelas principais pesquisas realizadas sobre este assunto. A gengivite é encontrada em crianças, é mais prevalente e severa em adolescentes e tende a aumentar em grupos de indivíduos mais velhos. Hoje somente de 5 a $10 \%$ de qualquer população sofre de periodontite severa generalizada, entretanto, a doença moderada afeta a maioria dos adultos. Se a periodontite é definida como a identificação de pelo menos um sítio com perda de inserção clínica $\geq 2$ $\mathrm{mm}$, cerca de $80 \%$ de todos os adultos são afetados e por volta de $90 \%$ com idade entre 55 e 64 anos. Quando a definição é de que pelo menos um sítio com perda de inserção clínica for $\geq 4 \mathrm{~mm}$, a prevalência neste grupo etário cai para $50 \%$. Quando é $\geq 6 \mathrm{~mm}$, a prevalência é menor que $20 \%$. Utilizando a medida de profundidade de sondagem para definição, quando for $\geq 4 \mathrm{~mm}$ em pelo menos três ou quatro dentes, $30 \%$ dos adultos terão a doença. A prevalência e severidade da perda de inserção clínica estão, invariavelmente, diretamente relacionadas à idade nas pesquisas longitudinais. A profundidade de sondagem é também relacionada com a idade, porém em menores proporções. Em pesquisas realizadas nos Estados Unidos foi encontrado que bolsas de 4 a $6 \mathrm{~mm}$ estavam presentes em $13,4 \%$ de todos os adultos e eram mais freqüentes em grupos mais velhos. Bolsas $\geq 7 \mathrm{~mm}$ foram encontradas somente em $0,6 \%$ dos examinados e não foi relacionada com a idade. Estes autores entendem que a maior destruição periodontal nos indivíduos idosos reflete o acúmulo de perda ao longo da vida e não pelo fator idade. Quanto a diferenças entre o gênero masculino e feminino, os diversos trabalhos sugerem que a perda de inserção clínica, em todos os níveis de severidade, é geralmente mais prevalente em homens do que em mulheres, e que também os homens usualmente exibem pior higiene oral. Os autores ainda afirmaram que os indivíduos que tem melhor nível educacional e econômico apresentam melhor saúde gengival. 


\subsection{Epidemiologia da doença periodontal em indivíduos portadores de fissura labiopalatinas}

No ano de 1979 BENINGTON et al. ${ }^{25}$ salientaram a importância dos aspectos preventivos e periodontais em indivíduos portadores de fissura labiopalatina enfatizando a grande importância da colaboração do paciente durante todo tratamento reabilitador. Sugeriram que estabelecer um programa intensivo de controle de placa onde os pacientes deveriam ser instruídos quanto à escovação, uso do fio dental e serem examinados periodicamente quanto á eficácia e domínio das técnicas de higiene oral.

Com o intuito de avaliar a condição periodontal de caninos erupcionados no enxerto ósseo alveolar em fissuras, HINRICHS et al. ${ }^{69}$ (1984) examinaram 18 indivíduos com fissura unilateral, com idade média de 16,2 anos, os dentes contra-laterais da fissura serviram como grupo controle. Mediram o índice de placa e gengival, quantidade de mucosa quaratinizada, profundidade de sondagem e perda de inserção destes dentes. Os resultados demonstraram que o grupo teste teve maior perda de inserção $(0,72 \mathrm{~mm})$ nas faces mésiovestibular, vestibular e mésio-lingual. Não houve diferença estatisticamente significante entre o grupo teste e controle para os índices de placa e gengival e profundidade de sondagem. Uma quantidade de mucosa queratinzada significantemente maior foi encontrada na face vestibular dos caninos controles. Concluíram que caninos erupcionados em áreas fissuradas submetidas ao enxerto ósseo apresentam condições periodontais satisfatórias.

BRÄGGER et al. ${ }^{31,32,33}$ realizaram vários trabalhos com indivíduos portadores de fissura de lábio, alvéolo e palato. Em 1985 avaliaram por um período de 18 anos os hábitos de higiene oral e condições periodontais de um grupo de 80 pacientes jovens de ambos os gêneros com fissura de lábio, rebordo alveolar e palato (uni e bilaterais), fissura de lábio e fissura de palato ${ }^{31}$. Avaliaram as condições periodontais através dos seguintes parâmetros clínicos: índice de placa, índice de cálculo, índice de sangramento a sondagem, profundidade de sondagem, nível de inserção clínico, além de exame radiográfico para determinar a distância da crista alveolar a junção amelo-cementária. A porcentagem de superfícies com placa bacteriana foi alta em todos os grupos, variando de $65 \%$ nas fissuras isoladas de lábio a $77 \%$ nas fissuras isoladas de palato. Consequentemente, o índice gengival foi alto variando entre $65 \%$ na fissura de lábio a $79 \%$ na isolada de palato. A média da profundidade de sondagem variou de 2,6 a 2,9 mm e a média de perda de inserção foi de 1,7 a $1,9 \mathrm{~mm}$. Entre todos os tipos de fissura, não houve diferença estatisticamente significante para todos os parâmetros com exceção da média de profundidade de sondagem vestibular e lingual que foi mais rasa no grupo de fissura de lábio. Essas diferenças foram atribuídas ao tratamento ortodôntico fixo. Quando profundidade de 
sondagem e nível de inserção clínico da área da fissura foram comparados com o lado não afetado, não foram encontradas diferenças estatisticamente significantes. Os resultados indicaram a presença de uma inserção conjuntiva longa sem suporte ósseo na região da fissura. Esses pacientes necessitam de longo tratamento ortodôntico, eles necessitam ser incorporados em programas preventivos intensos tão precoce quanto possível.

PAUL; BRANDT ${ }^{108}$ (1988) avaliaram 114 indivíduos de 3 a 18 anos, de diferentes etnias, portadores de fissura de lábio, alvéolo e/ou palato. Os autores avaliaram higiene oral, placa, cálculo e gengivite. $51,8 \%$ dos indivíduos eram portadores de fissura de lábio e palato, $38,6 \%$ de lábio, $9,6 \%$ eram só de lábio. Dos portadores de fissura de lábio ou de lábio e palato, $64,3 \%$ eram unilaterais e $35,7 \%$ bilaterais. Os indivíduos com fissura bilateral apresentaram média de placa significantemente maior que em indivíduos com fissura unilateral, assim como foi maior nos segmentos anteriores quando comparados com os posteriores e os superiores também apresentaram índices maiores. Cálculo estava presente em $13,6 \%$ em indivíduos com fissura de palato e em $23,75 \%$ em portadores de fissura de lábio e palato. Houve diferença estatisticamente entre os grupos de lábio e palato quando comparados com o grupo de palato quanto à gengivite. O grupo de palato $(93,20 \%)$ teve melhores níveis de higiene oral do que o grupo de lábio e palato $(84,7 \%)$. Não houve diferenças estatisticamente significantes entre o lado da fissura e o lado não fissurado. Os autores concluíram que os indivíduos apresentaram pobre higiene oral e saúde gengival, provavelmente pela dificuldade de higiene oral, principalmente nos dentes anteriores superiores após cirurgias de reparo (plásticas).

RAMSTAD ${ }^{113}$ (1989) analisou as condições periodontais do arco superior de 50 indivíduos adultos jovens, com idade entre 20 e 35 anos, portadores de fissura unilateral completa e tratamento protético reabilitador finalizado, se detendo a influência da fissura e do tratamento protético na saúde periodontal. Analisou a presença de placa visível, sangramento e profundidade de sondagem nos dentes pilares de prótese comparando-os aos não pilares. Nos dentes não pilares foi encontrada pouca placa bacteriana visível, menor sangramento e menor profundidade de sondagem. A condição periodontal destes 50 indivíduos com relação aos dentes pilares e não pilares estão em concordância com os valores da população normal. A higiene diferente dos pacientes, indiretamente, mostra ser a causa de problemas no tratamento protético.

ANDRADE ${ }^{14}$ (1990) comparou a condição periodontal dos dentes posteriores superiores de indivíduos normais e dos dentes superiores posteriores de pacientes portadores de fissura lábio, alvéolo e/ou palato uni e bilateral, operados pela técnica de Van Langenbek citada por LINDSAY ${ }^{78}$ (1971). Foram avaliados 41 pacientes, com idade entre 16 e 31 anos de ambos os sexos. O grupo controle foi composto por 50 indivíduos não fissurados da mesma faixa etária. Foram avaliadas todas as faces palatinas quanto à 
profundidade de sondagem, recessão gengival, índice de placa e índice gengival Os resultados demonstraram não haver muita diferença entre as médias entre profundidade de sondagem (3,43 e 2,00 mm), recessão gengival (1,60 e 0,80 mm), índice de placa $(1,35$ e $1,28)$ e índice gengival $(1,68$ e 1,36) entre o grupo teste e controle, respectivamente.

Em 1990, BOTTA ${ }^{29}$ avaliou a condição periodontal de 50 pacientes com fissura de lábio e/ou palato portadores de placas de acrílico (contenção ortodôntica) e idade mínima de 16 anos e comparou a um grupo controle $(n=50)$ de pacientes fissurados não submetidos a tratamento ortodôntico e não portadores de placas palatinos de acrílico. Os parâmetros periodontais utilizados foram: índice de placa, índice de sangramento gengival, recessão gengival e profundidade de sondagem, todos avaliados somente na face palatina; foram excluídos os terceiros molares. O grupo com aparelho foi subdividido em dois subgrupos: (i) pacientes que usaram a placa de 0 a 12 meses e (ii) pacientes com uso por mais de 12 meses. Comparando os grupos, verificou que a profundidade média de sondagem dos pacientes com placa acrílica foi maior que a dos pacientes do grupo controle. $O$ índice de recessão palatina foi menor no grupo experimental sugerindo uma tendência à hiperplasia gengival e o sangramento gengival, embora em índices elevados, não mostrou diferenças significantes entre os dois grupos. O índice de placa bacteriana foi maior no grupo controle $(51,3 \%)$ que no grupo experimental $(44,3 \%)$. O autor concluiu que a placa de contenção não pode ser considerada responsável pelas alterações observadas no estudo. Foi mostrado que pacientes que fazem ou fizeram uso de placas acrílicas, independente do tempo de utilização, possuem condição periodontal mais severa do que pacientes não portadores desse tipo de aparelho móvel.

Neste mesmo ano com o objetivo de avaliar se o tecido conjuntivo longo no dente adjacente a fissura representaria um local de menor resistência à doença periodontal, BRÄGGER et al. ${ }^{32}$ analisaram as condições periodontais dos dentes adjacentes à fissura de 25 indivíduos com fissura de rebordo alveolar (19 com fissura unilateral e seis com bilateral), sendo o grupo controle os dentes contra-laterais. Foram realizados os seguintes exames no início do estudo e após oito anos: índices de placa e gengival, profundidade de sondagem, nível de inserção clínica e altura da crista óssea (exame radiográfico). Os resultados demonstraram alta prevalência de placa bacteriana e inflamação gengival tanto no exame inicial quanto no final em todos os indivíduos. A média de perda de inserção clínica variou de 1,7 a $1,9 \mathrm{~mm}$ e a de perda de crista óssea de $1,85 \%$ a $1,96 \%$ no grupo teste. Não foram encontradas diferenças, estatisticamente significantes, entre pacientes com diferentes tipos de fissura e entre dente teste e controle. Concluíram que a progressão da doença periodontal segue o mesmo padrão nos dentes adjacentes à fissura e nos contra-laterais, independentemente do tipo de fissura. 
BRÄGGER et al. ${ }^{33}$ em 1992 acompanharam a progressão da doença periodontal em 80 pacientes caucasianos portadores de fissura labiopalatina com idade média entre 18 e 20 anos por um período de oito anos, não submetidos a nenhum programa intensivo de prevenção quanto à higiene oral. Os sítios adjacentes à fissura e sítios não acometidos pela lesão foram avaliados a fim de analisar o risco dessas áreas à doença periodontal. Através de exames clínicos e radiográficos foram observados presença de placa bacteriana, recessão gengival, bolsas periodontais e cálculo dental. Os resultados demonstraram que houve acúmulo de placa bacteriana em todas as áreas analisadas; a média de progressão da doença periodontal durante os oito anos em áreas de tecido conjuntivo longo não foi maior que as áreas controle. Para os autores o programa de reabilitação de um paciente fissurado, independente do tipo de fissura, deveria incluir um programa de manutenção regular de higiene oral.

No ano de 1992 TEJA; PERSON; OMNELL ${ }^{130}$ realizaram um estudo para comparar a condição periodontal de dentes adjacentes à fissura alveolar com dentes contra-laterais de 18 adultos de ambos os sexos, portadores de fissura unilateral de lábio e palato não submetidos a enxerto ósseo na área da fissura. O índice de placa bacteriana, profundidade de sondagem, largura de mucosa queratinizada, presença de recessão e mobilidade dental foram analisados e o exame radiográfico foi realizado para determinação da altura óssea interdental. Comparando-se o lado teste (dente adjacente à fissura) com o controle (dente contra-lateral), os autores observaram que o lado teste mostrou maior perda óssea e maior mobilidade dental, a largura de mucosa queratinizada foi significantemente diferente entre os incisivos teste $(0,8 \pm 0,3 \mathrm{~mm})$ e controle $(1,6 \pm 0,3 \mathrm{~mm})$; não houve diferença quanto à presença de recessão gengival; a profundidade de sondagem e os índices de placa e gengival foram maiores para o grupo teste. Concluíram que os pacientes apresentaram risco para gengivite, mas não para periodontite e sugeriram que é deveras importante a execução de um estudo longitudinal nesta mesma população para determinar se estes indivíduos desenvolvem a doença periodontal da mesma forma (extensão) que uma população sem fissura ou se exibem um maior risco.

DOURADO ${ }^{56}$ em 1993 realizou um estudo com o objetivo de avaliar a necessidade de tratamento periodontal utilizando o índice Periodontal das Necessidades de tratamento (CPITN) em 200 indivíduos portadores de fissura labiopalatina, com idade entre 12 e 66 anos. Não observaram alterações significantes nos escores do CPITN quando relacionou os diferentes tipos de fissura. Não foram encontrados indivíduos com todos os sextantes periodontalmente sadios. Os sextantes relacionados com a fissura não apresentaram diferenças significantes nos escores com relação aos demais. Observou-se uma predominância de indivíduos com bolsas periodontais de $4-5 \mathrm{~mm}$ (37,50\% dos indivíduos) e $29,50 \%$ com bolsas de $6 \mathrm{~mm}$ ou mais. Concluiu que a fissura predominante foi a 
transforame unilateral $(40 \%)$, não houve relação direta entre idade e gênero com os diferentes escores do índice utilizado. Não houve uma relação direta entre as classes sócioeconômicas e as necessidades de tratamento periodontal.

Com o propósito de avaliar comparativamente as causas de perdas dentárias, classificadas como: por cárie, doença periodontal, indicação ortodôntica, indicação endodôntica, protética e cirúrgica, fraturas, iatrogenias e outras, levando em consideração a influência dos fatores sexo e nível sócio-econômico, CAMPOS ${ }^{40}$ em 1995 avaliou aleatoriamente 404 pacientes portadores de fissura labiopalatina, de ambos os sexos, maiores de 10 anos. Os resultados demonstraram que a cárie dentária é a principal causa de perda dentária, a causa periodontal $(7,01 \%)$ foi a segunda colocada. Em relação ao sexo, apenas houve diferença estatisticamente significante em relação à doença periodontal, sendo que o sexo feminino foi mais atingido que o masculino (9,67 e 4,78\% respectivamente). $\mathrm{O}$ autor concluiu que devem ser tomadas medidas preventivas para conscientizar e motivar esse grupo populacional a preservar a saúde periodontal.

Em 1995, ANDLIN-SOBOCKI; ELLASSON; PAULIN ${ }^{13}$ avaliaram as condições periodontais dos dentes adjacentes às fissuras de lábio, alvéolo e palato unilateral e dos caninos que irromperam no local do enxerto ósseo, durante os períodos pré ou pósoperatório em 28 indivíduos. Os índices de placa, gengival, profundidade de sondagem do sulco gengival, largura da mucosa queratinizada e perda óssea, nos quais o lado contra lateral aos dentes examinados serviu como grupo controle. Os resultados mostraram altos índices de placa e gengival tanto no período pré como pós-operatório do enxerto ósseo. Houve um pequeno aumento na largura de mucosa queratinizada nos dentes localizados mesial e distalmente à fissura e não houve diferenças significantes entre caninos associados e não associados à fissura. O número de recessões gengivais foi reduzido no período pósoperatório e os níveis de inserção dos dentes adjacentes à fissura aumentaram com a diminuição das recessões e os níveis ósseos aumentaram significantemente no período pós-operatório. Os caninos que irromperam através do enxerto ósseo mostraram condições periodontais semelhantes aos contra laterais. Os autores concluíram que o enxerto ósseo antes da erupção dos caninos resultou em condições periodontais satisfatórias para os dentes adjacentes à fissura.

TAN et al. ${ }^{134}$, em 1996, realizaram um estudo dos aspectos periodontais de adolescentes portadores de fissura submetidos à reabilitação na Austrália. Para os autores, os problemas periodontais desses indivíduos se restringem a gengiva marginal e muito raramente as estruturas de suporte do dente são afetadas. Relataram que após a cirurgia corretiva do lábio, que pode torná-lo curto e também o vestíbulo tornar-se raso, o acesso para a higiene oral adequada é dificultado. O uso de placas de contenção após tratamento ortodôntico, bem como próteses provisórias, segundo os autores poderia ocasionar 
hiperplasia gengival inflamatória no palato. Os autores concluem afirmando que deve haver um controle rigoroso da placa bacteriana para obter sucesso do tratamento reabilitador.

Em 1998, PEDREIRA ${ }^{109}$ avaliou a necessidade de tratamento periodontal cirúrgico em portadores de fissura congênita labiopalatina com o objetivo de determinar quais os procedimentos periodontais foram mais realizados (cirúrgicos, não cirúrgicos e preventivos) e verificar quais as áreas bucais mais atingidas por estas terapias, e também correlacionar o tratamento ortodôntico com as necessidades periodontais. Foram analisados 219 prontuários do Hospital de Reabilitação de Anomalias Craniofaciais (141 homens e 78 mulheres), idade superior ou igual a 18 anos. O tratamento foi realizado entre 1973 e 1976, totalizando 952 atendimentos. Oitenta pacientes (28\%) receberam tratamento cirúrgico, 158 (55\%) receberam tratamento preventivo e 49 (17\%) não receberam nenhum tipo de tratamento periodontal. A técnica cirúrgica mais realizada foi a gengivectomia interna $(5 \%)$. O sextante posterior foi mais acometido (62\%) que o anterior (38\%); o sextante posterior inferior foi o mais afetado (31\%) que o sextante posterior superior (30\%); o sextante anterior superior foi mais afetado (31\%) que o sextante anterior inferior (8\%). A média de procedimentos periodontais cirúrgicos por paciente foi de 3,4 no período estudado e houve uma média de 1,78 retratamentos por paciente em 27 indivíduos. Dos 80 pacientes que receberam algum tipo de tratamento cirúrgico, 66 (82\%) realizaram tratamento ortodôntico e dos 158 pacientes que receberam algum tratamento periodontal preventivo, 130 (82\%) realizaram tratamento ortodôntico. Esse trabalho possibilitou demonstrar que os pacientes fissurados não são periodontalmente diferente dos demais pacientes e sugeriu que a alta taxa de cirurgia por paciente, assim como a taxa de repetições cirúrgicas são reflexos da falta de um programa rigoroso de higiene oral.

Em 1999, SCHUTLES; GAGGL; KARCHER ${ }^{118}$ compararam as condições periodontais de indivíduos adultos com fissura unilateral de lábio, alvéolo e palato (grupo 1) com indivíduos com fissura de palato (grupo 2). 30 indivíduos de 17 a 24 anos de idade foram avaliados quanto à presença de sangramento gengival à sondagem, presença de placa supra e subgengival, perda de tecido periodontal de suporte, profundidade de sondagem (seis sítios por dente) e mobilidade dental. O índice utilizado foi CPITN. Os resultados demonstraram alto índice de placa em ambos os grupos (grupo 1 - 73\% e grupo $2-65 \%$ ), sangramento à sondagem de $73 \%$ nos dentes posteriores do grupo 1 e de $100 \%$ no grupo 2, $90 \%$ no segmento anterior próximo à fissura (grupo 1) e $25 \%$ no segmento anterior do grupo 2. Ambos os grupos apresentaram alta prevalência de cálculo na região anterior inferior (média de 95\%). A profundidade de sondagem mais freqüente em ambos os grupos foi de 2,5 a $5 \mathrm{~mm}$. No grupo 1 houve uma Prevalência de $80 \%$ de bolsas maiores que $6 \mathrm{~mm}$ nos dentes próximos a área da fissura. Os autores concluíram que os pacientes com fissura unilateral de lábio, palato e alvéolo apresentam extensa lesão periodontal na 
região anterior superior quando comparado com a população em geral. Geralmente apresentam perda óssea prematura de dente na área estética. Os indivíduos com fissura de palato apresentam padrão periodontal semelhante a indivíduos não fissurados e finalmente, que o tratamento ortodôntico longo agrava a perda de inserção clínica.

Neste mesmo ano, GAGGL et al. ${ }^{60}$ avaliaram a doença periodontal em 80 pacientes com idade entre 17 e 24 anos, 30 indivíduos com fissura de lábio, rebordo alveolar e palato unilateral, $30 \mathrm{com}$ fissura de palato e $20 \mathrm{com}$ fissura de lábio, rebordo alveolar e palato bilateral, com o objetivo de elucidar os diferentes graus e localização da doença perioondtal. Os parâmetros clínicos utilizados foram: índice de sangramento gengival, índice de placa interproximal, perda de inserção clínica e perda dentária. Em indivíduos com fissura de lábio, rebordo alveolar e palato unilateral houve uma perda de inserção média de 4,3 mm com um alto grau de dano periodontal na maxila, não houve perda de inserção menor que 2,5 $\mathrm{mm}$ nas regiões de incisivos, prés e molares. Perda de inserção $\geq 6,0 \mathrm{~mm}$ foi encontrada na área próxima a fissura. Neste grupo foi encontrado alta freqüência de placa (73\%) e de sangramento gengival (63\%) com maior prevalência de inflamação na área da fissura (93\%). $\mathrm{Na}$ fissura bilateral a média de perda de inserção foi menor $(3,9 \mathrm{~mm})$ também concentrada na maxila. Nenhum indivíduo apresentou perda menor que 2,5 $\mathrm{mm}$ e médias maiores que 6 $\mathrm{mm}$ foram frequentemente encontradas nas regiões de incisivos superiores e dentes próximos a fissura. Altos graus de inflamação e placa foram encntrados também neste grupo (64 a 95\% e 69\%, respectivamente). Na fissura de palato a média de perda de inserção foi menor que nas demais $(2,9 \mathrm{~mm})$. Sangramento foi encontrado em $43 \%$ e placa em $65 \%$. Uma situação perioodntal crítica foi encontrada nos pacientes com fissura de lábio, rebordo alveolar e palato (uni e bilaterais).Já os indivíduos com fissura de palato a situação periodontal encontrada foi similar a população em geral com um dano adicional ao uso de tratamento ortodôntico.

DEWINTER et al. ${ }^{51}$, no ano de 2003 , realizaram um trabalho para avaliar a freqüência de anormalidades dentárias e a condição periodontal dos dentes próximos e na fissura de um grupo de 75 indivíduos de 8 a 20 anos com fissura unilateral de lábio e palato, antes durante e após um longo período de tratamento ortodôntico e cirúrgico. Os parâmetros periodontais utilizados foram: (i) nível de inserção clínica e profundidade de sondagem em seis sítios, (ii) recessão gengival, e (iii) radiografias pela técnica do paralelismo. Os resultados demonstraram que não houve diferenças importantes entre os grupos, os parâmetros foram aproximadamente constantes ao longo do tempo. Concluíram que não há conseqüências do tratamento ortodôntico prolongado e pelas várias intervenções cirúrgicas no tecido periodontal nos dentes próximos ou na fissura.

Neste mesmo ano, QUIRYNEN et al. ${ }^{110}$ realizaram um estudo de boca dividida para estudar os parâmetros periodontais e microbiológicos de crianças com fissura de lábio, 
rebordo alveolar e palato unilateral. Foram examinados os dentes: vizinhos a fissura, erupcionados na fissura e seus respectivos contra-laterais nos quadrantes não afetados de 75 indivíduos, de ambos os gêneros, de 8 a 20 anos de idade, 34 com aparelho ortodôntico, 30 sem e 11 em manutenção. Os parâmetros periodontais avaliados foram: índice de sangramento e de placa, profundidade a sondagem, nível de inserção clínica e mobilidade dentária. Além disso, foram colhidas de duas a três amostras por dentes para o exame microbiológico. Em geral altos escores foram encontrados, especialmente nos índices de placa $(60 \%)$ antes e durante a terapia ortodôntica. As diferenças entre as áreas de fissura e não fissura foram pequenas, apesar dos dentes ao lado ou na fissura mostraram um índice um pouco maior, talvez devido à dificuldade de escovação. Os dentes próximos ou na fissura mostraram significante aumento na profundidade de sondagem e alta perda de inserção clínica. Não houve nenhuma diferença estatisticamente significante nos exames microbiológicos. Este estudo indicou que o periodontoium nos indivíduos com fissura de lábio, rebrodo alveolar e palato unilaterais pode se comportar bem com uso prolongado de aparelho ortodôntico, mesmo em condições adversas (como ausência de gengiva inserida e pobre higiene oral).

Outro estudo realizado neste ano foi o de SALVI; BRÄGGER; LANG. ${ }^{115}$ fizeram um estudo longitudinal de 14 anos (foram examinados em 1979, 1987 e 1993) em 26 indivíduos portadores de fissura (fissura de lábio, rebordo alveolar e palato, fissura de lábio e fissura de palato) sem manutenção periodontal como objetivo de avaliar a progressão da doença periodontal dos indivíduos com fissura de lábio, rebordo alveolar e palato e compará-los com os indivíduos com fissura de lábio e com de palato. Avaliaram a presença ou ausência de sangramento gengival a sondagem, presença ou ausência de placa supragengival, profundidade de sondagem e nível de inserção clínica em 32 sítios controles e 32 sítios testes (faces mesial, distal, vestibular e lingual). Houve extenso acúmulo de placa e alta freqüência de sangramento gengival nos três exames. Ocorreu um aumento estatisticamente significante nas médias de profundidade de sondagem e nível de inserção clínico em todos os grupos. Não houve diferença estatisticamente significante entre os grupos quanto á média de placa. Entretanto, a média de sangramento à sondagem diminuiu em ambos os grupos. Os sítios próximos à área da fissura apresentaram maior perda de inserção. Os níveis inadequados de higiene oral resultaram em reação inflamatória dos tecidos periodontais neste grupo. Os indivíduos deste estudo tiveram alto grau de perda de inserção clínica comparados a não fissurados. Concluíram que as fissuras são de alto risco para a progressão da doença periodontal se não forem realizados programas de prevenção.

LAGES; BADEIA; PORDEUS ${ }^{74}$ (2004) realizaram um estudo com 75 indivíduos com fissura de lábio e/ou palato, com idade entre 1 a 32 anos. Os parâmetros avaliados foram: aumento do volume gengival, sangramento a sondagem, recessão gengival presença de 
cálculo; também foram utilizados índices de cárie. Os indivíduos foram agrupados por faixa etária: 1 a 5 anos, 6 a 12 anos, 13 a 18 anos, 19 a 32 anos. Nenhum indivíduo de 1 a 5 anos apresentou bolsa periodontal, $8 \%$ dos indivíduos apresentaram profundidade de sondagem menor ou igual a $5 \mathrm{~mm}$ e $100 \%$ de toda a amostra não apresentou profundidade de sondagem maior que $5 \mathrm{~mm}$. A gengivite ocorreu em 62 (86,67\%) dos 75 indivíduos. Esta condição foi observada em $60 \%$ das crianças com 1 a 5 anos de idade, $97 \%$ no grupo de 6 a 12 anos, aproximadamente $85 \%$ nos grupos de 13 a 18 e 19 a 32 anos. Os autores concluíram que a condição dental e gengival de indivíduos com fissura de lábio e/ou palato neste estudo são similares à população em geral na região em que este estudo foi conduzido.

Avaliar e comparar o nível de doença periodontal e cárie de 31 indivíduos com fissura de lábio e palato (uni e bilaterais) e sem fissura com idade entre 10 e 28 anos, foi objetivo do estudo de AL - WAHADNI; ALHAIJA; AL-OMARI ${ }^{7}$ (2005). Os indivíduos foram divididos em dois grupos etários: 10 a 15 anos (40\%) e 16 a 28 anos (60\%). O exame clínico avaliou quantidade de placa, inflamação gengival e profundidade de sondagem e presença de cárie nos dentes índices de RAMFJORD ${ }^{112}$. Diferenças significantes entre a média de índice de placa foram encontradas entre os dois grupos etários de fissurados e controle. Os dados revelaram diferença significante entre a média de índice gengival e profundidade de sondagem nos dois grupos de fissura e seu grupo controle similar. Indivíduos portadores de fissura de lábio e palato têm risco significante para cárie e doença periodontal. Os autores relatam que há certa negligência dos cuidados orais por parte dos pacientes e responsáveis. Isto ocorre devido à grande necessidade de primeiro solucionar os problemas estéticos e funcionais (cirurgias plásticas corretivas) para depois se preocupar com a saúde bucal. Salientam que os profissionais especialistas da área odontológica devem estar atentos para este fato e incluir estes indivíduos em programas preventivos e de manutenção, além de identificar os indivíduos de alto risco para cárie e doença periodontal.

A grande preocupação de todos esses autores foi avaliar os dentes próximos ou que irromperam na área da fissura, mas se esqueceram dos conceitos básicos de risco da doença periodontal, deve-se avaliar todos os dentes e todos os sítios de cada paciente para observar as condições periodontais dos pacientes portadores de fissura labiopalatinas.

Em 2006, SIQUEIRA ${ }^{122}$ avaliou a condição periodontal de 50 indivíduos portadores de fissura de lábio, alvéolo e palato e comparou com 50 indivíduos não portadores, de ambos os gêneros e com idade entre 16 e 50 anos. O exame periodontal consistia na medida da profundidade de sondagem, nível de inserção clínica, índice gengival e de placa, e recessão gengival. Observou que as médias da profundidade de sondagem, nível de inserção e recessão vestibular foram maiores nos indivíduos portadores de fisssura $(2,29$ $\mathrm{mm}, 1,48 \mathrm{~mm}$ e $0,25 \mathrm{~mm})$ quando comparadas a indivíduos não fissurados $(2,18 \mathrm{~mm}, 1,00$ 
$\mathrm{mm}$ e 0,21 mm). Quando comparadas as médias do índice gengival e de placa, observou-se que nos não fissurados eram maiores (1,57 e 1,64 vs 1,29 e 1,60). Houve diferença estatisticamente significante para profundidade de sondagem, nível de inserção, índice de placa e gengival. O autor concluiu que o grupo com fissura apresentou melhor higiene oral apesar de apresentarem maiores médias de profundidade de sondagem e nível de inserção.

STEC et al. ${ }^{127}$ (2007) realizaram um estudo com a finalidade de comparar a higiene oral e a condição periodontal de crianças e adolescente com fissura de lábio e palato, uni e bilateral, tratados em Lodz, Polônia, e Erlangen, Alemanha. A saúde oral foi avaliada pela presença de placa, bolsa periodontal, inflamação gengival, recessão gengival, hiperplasia gengival e mobilidade dental, em cinco áreas: (I) dente na área da fissura, (II) dente vizinho a área da fissura, (III) dente superior contra-lateral a área da fissura, (IV) face mais distal do dente superior vizinho a área da fissura e $(\mathrm{V})$ dente inferior correspondente aos dentes da fissura. A amostra foi constituída por 37 poloneses e 63 alemães. $57 \%$ de todos os indivíduos apresentaram pobre higiene oral. Na Erlangen, $60 \%$ dos indivíduos tinham ótima higiene oral, comparados a $19 \%$ em Lodz. Altos escores de placa foram notados em ambos os grupos na região da fissura. Sangramento gengival foi significantemente mais freqüente nos poloneses. Bolsa maior que $6 \mathrm{~mm}$ ocorreu somente nos alemães. Não houve diferença estatisticamente significante entre a quantidade de dentes com recessão gengival e a origem do indivíduo. Bolsa periodontal maior que $3,5 \mathrm{~mm}$ ocorreu mais frequentemente durante o tratamento ortodôntico. Os autores concluíram que os Poloneses apresentaram pior condição de higiene oral; que o acúmulo de placa parece não ser o fator chave na destruição periodontal da área da fissura. Outros fatores além da higiene oral devem ser considerados em relação ao desenvolvimento da recessão gengival nos dentes na área da fissura.

\subsection{Recessão gengival}

Segundo PARFITT; MJÖR ${ }^{107}$ (1964) a relação entre arco e posicionamento dentário foi considerada o principal fator etiológico da recessão gengival em crianças. O acúmulo de placa e cálculo, e conseqüente gengivite, foram propostos como fatores secundários, e não causais no desenvolvimento destas lesões, visto que uma maior quantidade de placa estava presente nos sítios onde já estava presente a recessão gengival, ao contrario do que ocorreu nos dentes adjacentes.

Em 1966, TROTT; LOVE ${ }^{132}$ analisaram a recessão gengival localizada em 766 estudantes em Winnipeg de 14 a 19 anos. A incidência total de recessão gengival foi de $13.1 \%$, o incisivo central inferior foi mais afetado do que o lateral, independentemente da 
extensão da recessão; para recessões menores que $3 \mathrm{~mm}$, a porcentagem foi de 61.0 para os centrais e 26 para os laterais, e para recessões maiores que $3 \mathrm{~mm}, 9.3 \%$ e $3.7 \%$, respectivamente.

GORMAN ${ }^{62}$ em 1967 se propôs a avaliar a prevalência e etiologia da recessão gengival em 164 indivíduos de 16 a 86 anos. Aproximadamente $78 \%$ de todos os indivíduos apresentaram dentes com exposição radicular $\geq 0.5 \mathrm{~mm}$. A prevalência de uma recessão, assim como dimensão linear de raiz exposta, aumentou com a idade. No grupo mais jovem (16 a 25 anos) 62\% apresentaram recessão, e a amplitude média de exposição radicular foi de $0.97 \mathrm{~mm}$, no centro da face vestibular. Já no grupo com idade mais avançada (46 - 86 anos) todos os indivíduos mostraram-se portadores de recessão, e a exposição média na face vestibular foi de $1.40 \mathrm{~mm}$. Os dentes que apresentaram mais recessão foram os caninos e pré-molares.

A prevalência e etiologia da recessão gengival foram discutidas por WOOFTER ${ }^{136}$ em 1969. Concluiu que a incidência de recessão gengival na população varia extensamente de $8 \%$ em crianças a $100 \%$ em adultos com mais de 50 anos. Em crianças, a recessão é mais comum em área anterior inferior. Na população adulta, entretanto, a superfície vestibular dos incisivos superiores, caninos e pré-molar são os mais freqüentemente envolvidos. A mais importante causa da recessão parece ser a má posição dentária seguida pela falta ou excesso de escovação. A recessão parece ter uma forte correlação com a idade, quanto mais velho os indivíduos avaliados, maior a prevalência de recessão.

AINAMO et al. ${ }^{2}$, em 1986, avaliaram a prevalência e extensão da recessão gengival em 100 estudantes de 7, 12 e 17 anos. 5\% das crianças apresentavam recessão já aos sete anos de idade. Dos indivíduos de 17 anos, 74\% apresentaram recessão. Apenas 10\% de todos os estudantes apresentaram mais de seis dentes acometidos por recessão, sendo esta porcentagem maior, especificamente $23 \%$, quando se considerava a presença de 1 a 3 dentes com recessão. Tanto as recessões leves quanto extensas foram as mais freqüentemente encontradas nos primeiros molares, pré-molares e caninos.

A recessão gengival de universitários, com idade média de 25 anos, foi avaliada por MURTOMAA et al. ${ }^{100}$ em 1987. A amplitude média das recessões gengivais relatadas foi de $1,5 \mathrm{~mm}$, sendo os primeiros molares superiores e primeiros prés inferiores os dentes mais severamente acometidos. No mínimo um sítio com mais de $1 \mathrm{~mm}$ de cemento exposto foi observado em $69 \%$ das mulheres e $49 \%$ dos homens.

Neste mesmo ano, PALOHEIMO et al. ${ }^{106}$ avaliaram qual a extensão da recessão gengival em 360 adolescentes de 15 a 20 anos de idade. Além da presença de recessão foi avaliada a presença de placa, inflamação e profundidade de sondagem. $25 \%$ da amostra apresentaram recessão em um ou mais dentes. A proporção de indivíduos com recessão 
aumentou de $4 \%$ para $60 \%$ com o aumento da idade (15 para 20 anos, respectivamente). A recessão estava mais presente na face vestibular que lingual.

No ano de 1988, YONEYAMA et al. ${ }^{137}$ analisaram além de outros parâmetros a recessão gengival em diferentes segmentos e superfícies dentárias de 319 indivíduos em vários grupos etários (20 a 79 anos de idade). Os resultados obtidos foram que em $23 \%$ das superfícies vestibulares, $13 \%$ das proximais e $21 \%$ das linguais exibiram recessão gengival. As recessões gengivais tornaram-se mais severas e freqüentes com o aumento da idade. Nos grupos mais jovens, somente $10 \%$ dos indivíduos tinham sítios com mais de $2 \mathrm{~mm}$ de recessão gengival. Tanto em dentes unirradiculares como multirradiculares, a recessão era mais freqüente na face vestibular do que nas interproximais e linguais. $E$ as recessões vestibulares parecem ocorrer com mais freqüência e mais severas nos dentes unirradiculares do que nos molares. $25 \%$ dos indivíduos não apresentaram nenhum sitio com recessão $\geq 2 \mathrm{~mm}$

VEHKALAHTI ${ }^{133}$, em 1989, avaliou a ocorrência da recessão gengival em 258 adultos com média de 46 anos de idade. A recessão gengival foi encontrada em, no mínimo, uma superfície dentária de $68 \%$ dos indivíduos com mais de 30 anos de idade. As mulheres tiveram uma maior freqüência de recessões comparada aos homens; embora não estatisticamente significante. Não se observaram diferenças entre o lado direito e esquerdo, uma vez que as recessões ocorreram quase que simetricamente, por outro lado, os dentes inferiores foram mais freqüentemente envolvidos do que os superiores.

No ano de 1990, BROWN; OLIVER; LÖE ${ }^{35}$ observaram o estado periodontal de adultos americanos. Constataram que a superfície vestibular é a mais acometida; $50 \%$ de toda amostra avaliada tinha pelo menos um sítio com recessão gengival. Apenas $20 \%$ dos mais jovens, entre 18 e 24 anos e quase $85 \%$ dos indivíduos de 55 a 64 anos mostraram-se portadores de recessão gengival. Entre os mais jovens, menos de $3 \%$ tiveram recessões avançadas ( $\geq 3 \mathrm{~mm}$ ), comparando a $45 \%$ dos indivíduos do grupo mais velho.

Neste mesmo ano, MATTHESEN et al. ${ }^{91}$ avaliaram a saúde dental de crianças e adultos africanos. A maior prevalência, extensão e severidade da recessão gengival foram verificadas em indivíduos mais velhos e menos de $10 \%$ das crianças de 12 anos apresentaram recessão gengival. No grupo etário de 50 a 59 anos de idade, $50 \%$ tiveram recessão em mais de $20 \%$ dos sítios. Recessão gengival $\geq 4 \mathrm{~mm}$ foi observada em $35 \%$ dos indivíduos entre 30 a 39 anos e em mais de $80 \%$ dos de $50-59$ anos.

MILLER et al. ${ }^{94}$ em 1991, estudaram se a inter-relação entre a recessão gengival e a profundidade de sondagem seria suficiente para indicar a perda de inserção clínica. Foram avaliados todos os dentes de 1005 indivíduos adultos quanto à presença ou não de cálculo e sangramento à sondagem, recessão gengival, e bolsas moderadas (3.5 - $5.5 \mathrm{~mm}$ ) e avançadas ( $\geq 6.0 \mathrm{~mm}$ ). 93,8\% dos dentes não apresentaram recessão gengival maior que 
$1 \mathrm{~mm}, 26,6 \%$ dos indivíduos tinha pelo menos um dente com recessão $\geq 2 \mathrm{~mm} .508$ indivíduos não apresentaram bolsa periodontal, cálculo e sangramento à sondagem, destes $71,3 \%$ não tinham recessão, 23,4\% apresentaram recessão de $2-3 \mathrm{~mm}$, e 5,3\% recessão $\geq 4 \mathrm{~mm}$. A recessão envolveu mais dentes sem bolsa ou com bolsas moderadas do que com bolsas profundas: 3,5 dentes por pessoa com recessão moderada ( $2-3 \mathrm{~mm}$ ), combinadas com bolsa moderada $(3,5-5,5 \mathrm{~mm})$ ocorreu em 2.2 dentes e combinada com bolsas profundas (seis mm ou mais) em 1,7 dentes. A prevalência da recessão aumentou com a idade.

O objetivo do estudo de SERINO et al. ${ }^{116}$ (1994) foi avaliar a prevalência e a distribuição da recessão gengival em indivíduos com alto padrão de higiene oral. Para tanto avaliou 225 indivíduos de 18 a 65 anos. Observou além da presença da recessão, o número de dentes remanescentes, presença de placa, gengivite, profundidade de sondagem, perda de inserção à sondagem. A recessão gengival foi frequentemente encontrada, e sua proporção aumentou com a idade. A prevalência assim como a incidência da recessão. De toda a mostra, $44 \%$ indivíduos com 30 anos tinham pelo menos um sítio com recessão vestibular, e mais de $90 \%$ com 41 anos. Uma pequena proporção de indivíduos foi responsável pela maioria dos sítios com recessão. Os dentes mais afetados foram os pres e molares.

Neste mesmo ano, HOLMGREN; CORBET; LIM ${ }^{68}$ estudaram as condições periodontais de 900 chineses de 35 a 74 anos de idade divididos em dois grupos etários: 35 a 44 e 65 a 74 anos. Entre outras medidas periodontais foi analisada recessão gengival, que se mostrou mais prevalente, severa e afetando maior número de dentes nos indivíduos mais velhos. As recessões gengivais maiores que $4 \mathrm{~mm}$ ocorreram respectivamente em 22 e $69 \%$ dos indivíduos do grupo mais jovem e mais velho, tendo sido recessões maiores de $6 \mathrm{~mm}$ verificadas em apenas $3 \%$ dos jovens, enquanto $26 \%$ dos mais velhos apresentaram esta condição.

Em um estudo epidemiológico transversal realizado entre os anos de 1988 e 1991, na III National Health and Nutrition Examination Survey (III NHANES,) BROWN; BRUNELLE; KINGMAN ${ }^{34}$ (1996) avaliaram 7447 americanos com idade acima de 13 anos quanto à prevalência de recessão gengival. Observaram que 42\% dos indivíduos tiveram pelo menos um dente com recessão $\geq 1 \mathrm{~mm}$. $E$ que tanto a freqüência como a severidade aumentavam com a idade.

A prevalência e severidade de recessões gengivais obtidas a partir dos dados do NHANES III, realizado entre 1988 e 1994 foram descrito por ALBANDAR; KINGMAN ${ }^{6}$ em 1999, A amostra foi constituída por 9689 indivíduos entre 30 e 90 anos de idade, mostrou uma prevalência média de $58 \%$ de indivíduos com recessões gengivais $\geq 1 \mathrm{~mm}$. A prevalência e o número de dentes acometidos por indivíduos aumentaram com a idade: no 
grupo mais jovem (30 a 39 anos) em torno de 37\% apresentavam recessão em 8,6\% dos dentes, enquanto que $90 \%$ dos indivíduos de 80 a 90 anos tiveram registros de recessão em $56 \%$ dos dentes. Os dentes mais freqüentemente afetados foram os primeiros molares superiores e os incisivos centrais inferiores, estando à superfície vestibular principalmente envolvida.

KASSAB; COHEN ${ }^{72}$ no ano de 2003, revisaram estudos epidemiológicos transversais sobre a etiologia e prevalência da recessão gengival, e encontraram que muitos estudos correlacionavam a prevalência da recessão com trauma, gênero, mau posicionamento dentário, inflamação. Os estudos revisados revelaram que $88 \%$ dos indivíduos de 65 anos ou mais e 50\% dos indivíduos de 18 a 64 anos tinham um ou mais sítios com recessão. A presença e extensão da recessão também aumentam com a idade. $A$ prevalência da recessão foi encontrada em indivíduos tanto com ótima quanto com higiene oral ruim.

A recessão gengival é uma manifestação comum da doença periodontal, porém é também associada a outros fatores de risco tais como idade, deiscência alveolar, inserção alta de freio e fumo. Com a finalidade de avaliar a prevalência, extensão e severidade da recessão, assim como a associação dos fatores de risco potenciais na ocorrência desta alteração em uma população urbana Brasileira, SUSIN et al. ${ }^{126}$ (2004) avaliaram todos os dentes, exceto os terceiros molares, de 1460 indivíduos, adolescentes e adultos (maiores de 14 anos). As recessões mais prevalentes foram as rasas até $2 \mathrm{~mm}$. As recessões $\geq 3 \mathrm{~mm}$ e $\geq 5 \mathrm{~mm}$ afetaram uma pequena parcela dos indivíduos com menos de 40 anos. Do grupo com mais de 40 anos, mais de $79 \%$ dos indivíduos e mais de $32 \%$ dos dentes tiveram recessões $\geq 3 \mathrm{~mm}$. Na faixa etária de 14 a 29 anos os incisivos centrais e laterais mostraram alta prevalência de recessão $\geq 1 \mathrm{~mm}$, com $32,8 \%$ e $24,8 \%$ de dentes afetados, respectivamente, seguidos pelos segundos pré-molares inferiores $(17,1 \%)$, primeiros molares superiores $(16,2 \%)$ e primeiros pré-molares superiores. Nos indivíduos de 30 a 49 anos e 50 anos ou mais os dentes mais afetados com recessões maiores ou iguais a $3 \mathrm{~mm}$ foram os primeiros molares superiores $(25,7 \%$ e $58,8 \%)$ seguidos pelos segundos prémolares inferiores $(24,8 \%$ e $62,0 \%$, respectivamente). Não houve diferença estatisticamente significante entre os gêneros para indivíduos com 30 anos ou menos, diferentemente do que ocorreu com os maiores de 30 anos, onde os homens tiveram maior prevalência e extensão.

MARINI et al. ${ }^{85}$, no ano de 2005 , avaliaram a prevalência, extensão e severidade das recessões gengivais de indivíduos adultos atendidos na Faculdade de Odontologia de Bauru. Foram examinados 9379 dentes de 380 adultos, 234 mulheres e 146 homens, com mais de 20 anos de idade. A recessão gengival foi considerada presente quando mais de 1 $\mathrm{mm}$ de raiz estivesse exposta e sua amplitude vertical foi medida em milímetros da junção cemento-esmalte a margem gengival. As recessões foram ainda classificadas segundo os 
parâmetros de classificação proposta por Miller, em 1985. A recessão gengival foi encontrada em pelo menos uma superfície dentária em aproximadamente $89 \%$ dos indivíduos avaliados. A prevalência, extensão e severidade desta condição clínica aumentaram com o avanço da idade. As recessões classe I foram as mais freqüentes, mas houve um aumento gradual das recessões classe III e IV à medida que os indivíduos mais idosos foram avaliados, $12.89 \%$ para $39.51 \%$ e $17,5 \%$ para $10.06 \%$, respectivamente. Os dentes inferiores tiveram mais superfícies envolvidas do que os superiores, e os mais freqüentemente envolvidos foram os incisivos inferiores. Os autores concluíram que diante da elevada prevalência de recessão gengival em adultos, os cirurgiões dentistas devem estar atentos à importância clínica destas alterações a ao diagnóstico de seus fatores causais.

Em 2007, ALMEIDA et al. ${ }^{11}$ analisaram a prevalência, extensão e severidade da recessão gengival e a reação entre a recessão com presença de inflamação, quantidade de mucosa queratinizada, inserção de freio, e posicionamento dentário no arco. Examinaram 200 indivíduos portadores de fissura de lábio, alvéolo e/ou palato, com idades entre 16 e 56 anos. Os resultados demonstraram que a prevalência da recessão aumentou com a idade. $\mathrm{Na}$ maxila o dente com maior prevalência foram os primeiros molares, seguido pelos caninos e pré-molares, já na mandíbula foram os pré-molares. $25(0,54 \%)$ indivíduos tiveram pelo menos um dente com recessão maior que 4 mm, 229 (4,92\%) com recessão medindo entre 3 e $4 \mathrm{~mm}$ e 4398 (94,54\%) menores que $3 \mathrm{~mm}$. 54,60\% das recessões presentes eram classe I de Miller. Através dos testes de Correlação de Pearson e Sperman pode-se observar que houve correlação positiva e significante da recessão com idade, posicionamento dentário e inserção de freio, negativa e significante entre recessão e quantidade de mucosa queratinizada. Não houve correlação entre recessão gengival e inflamação. A regressão linear múltipla revelou um alto coeficiente de determinação para as variáveis: idade, mucosa queratinizada e índice gengival demonstrando que a recessão é diretamente proporcional a idade e inflamação gengival e inversamente proporcional com a quantidade de mucosa queratinizada. Os autores concluíram a prevalência, extensão e severidade da recessão gengival em indivíduos portadores de fissura labiopalatina segue os mesmos moldes de indivíduos não portadores dessa anomalia. A recessão aumenta com a idade, apresentam relação positiva com a quantidade de mucosa ceratinizada e negativa com o índice gengival. Os dentes mais afetados não foram os adjacentes a área da fissura (incisivos centrais e caninos) como poderia se esperar, apesar da prevalência de recessão ser dez vezes mais alta nesses dentes quando comparamos os resultados com os mesmos dentes de indivíduos não portadores, e também as recessões, quando estavam presentes, não eram muito severas o que clinicamente é muito importante pois melhora o prognóstico do tratamento. Os fatores etiológicos das recessões gengivais são muitos e geralmente 
agem em conjunto no desenvolvimento das mesmas, devem sempre ser analisados todos os fatores que interagem na recessão para poder traçar um planejamento e tratamento desta condição clínica objetivando ótimos resultados. Freqüentemente uma associação de fatores é que determina a ocorrência da recessão gengival, podendo um ser o fator principal, mas nem sempre o único responsável pela lesão. 


\section{PROPOSIÇÃO}




\section{PROPOSIÇÃO}

Este estudo tem como objetivos:

1- $\quad$ Analisar a prevalência e severidade da doença periodontal em indivíduos portadores de fissura labiopalatinas

2- Comparar as condições periodontais de indivíduos com fissura de lábio, rebordo alvéolar e/ou palato unilateral e bilateral.

3- Comparar a prevalência e severidade da doença periodontal no sextante da área da fissura com as demais.

4- $\quad$ Analisar a condição periodontal de indivíduos portadores de fissura de lábio, rebordo alveolar e/ou palato em relação a classificação sócioeconômica.

5- $\quad$ Avaliar a prevalência e extensão da recessão gengival em indivíduos portadores de fissura de lábio, rebordo alveolar e/ou palato.

6- $\quad$ Avaliar a prevalência extensão da recessão gengival por sextantes, faixas etárias, tipos de fissuras.

7- $\quad$ Avaliar a distribuição da extensão da recessão gengival por sextantes.

8- $\quad$ Avaliar a distribuição da recessão gengival em cada elemento dentário.

9- Comparar a ocorrência da recessão gengival entre os sextantes, faixas etárias e tipos de fissuras. 


\section{MATERIAL E MÉTODOS}

\subsection{Seleção da amostra}

A amostra foi composta de 400 indivíduos, de 15 a 50 anos, portadores de fissuras de lábio, rebordo alveolar e/ou palato, unilaterais ou bilaterais, de ambos os gêneros, matriculados no Hospital de Reabilitação de Anomalias Craniofaciais da Universidade de São Paulo (HRAC/USP), em Bauru.

Foram excluídos da amostra os indivíduos:

- Portadores de outras anomalias congênitas

- Indivíduos com alterações sistêmicas

- Usuários de prótese total superior ou inferior ou prótese parcial removível provisória e aparelho ortodôntico fixo

- Que tenham realizado tratamento periodontal prévio ao estudo, com exceção de profilaxia dentária.

- Menos de 15 dentes

- Fumantes

- Gestantes

- Etílicos

- Usuários de qualquer tipo de droga

- Que estivessem fazendo uso de antidepressivos, anti-inflamatórios, anticonvulsivantes, bloqueadores de cálcio ou qualquer outro fármaco que pudesse interferir nos resultados deste estudo.

\subsection{Consideracões Éticas do Estudo}

Os indivíduos foram informados a respeito da avaliação a qual seriam submetidos e assinaram o documento de Consentimento Livre e Esclarecido, apresentado nos Anexos, firmando sua anuência em participar do estudo.

Este trabalho foi aprovado pelo Comitê de Ética do HRAC/USP (ofício nº. 099/2004 UEP - CEP).

\subsection{Entrevista e exame físico}

Durante o exame clínico foi realizada a anamnese para a obtenção de informações sobre cada indivíduo: idade, sexo, número do RG do hospital, saúde geral, tipo de fissura, 
classificação do nível sócio-econômico, dentre outros conforme ficha nos anexos. Também foram avaliados vários parâmetros clínicos para diagnosticar a situação periodontal de cada indivíduo.

\subsubsection{Classificação das fissuras lábiopalatinas}

Todo paciente que é matriculado no HRAC/USP tem sua fissura classificada de acordo com a classificação preconizada por SPINA modificada por SILVA FILHO et al. ${ }^{121}$, (1992), que toma o forame incisivo como ponto de referência para sua classificação. $\mathrm{Na}$ verdade, ao incluir o forame incisivo na sua terminologia agrupou as fissuras da seguinte forma:

Grupo I - fissuras pré-forame incisivo (fissuras que se estendem anteriormente ao forame incisivo). Fissura de lábio com ou sem fissura do rebordo alveolar.

a) Unilateral

Direita completa ou incompleta

Esquerda completa ou incompleta

b) Bilateral (completa ou incompleta)

c) Medianas (completa ou incompleta)

Grupo II - Fissuras transforame incisivo

a) Unilateral (direita ou esquerda)

b) Bilateral

Grupo III - Fissura pós-forame incisivo (fissuras que se entendem posteriormente ao forame incisivo)

a) Total

b) Parcial

Grupo IV-Fissuras raras da face

A classificação de Spina não é universal, ou seja, não é usada na literatura internacional, portanto foi substituída pela classificação de FOGH - ANDERSEN ${ }^{57}$ (1942) nos resultados, discussão e conclusão deste trabalho, visando futuras publicações.

Classificação de FOGH - ANDERSEN ${ }^{57}$ (1942):

- Fissura de lábio com ou sem fissura do rebordo alveolar (LAE: lábio e alvéolo esquerda, LAD: lábio e rebordo alveolar direita, LAB: lábio e rebordo alveolar bilateral) 
- Fissura de lábio e palato (LAPE: lábio, rebordo alveolar e palato esquerda, LAPD: lábio, rebordo alveolar e palato direita, LAPB: lábio, rebordo alveolar e palato bilateral)

- Fissura isolada de palato

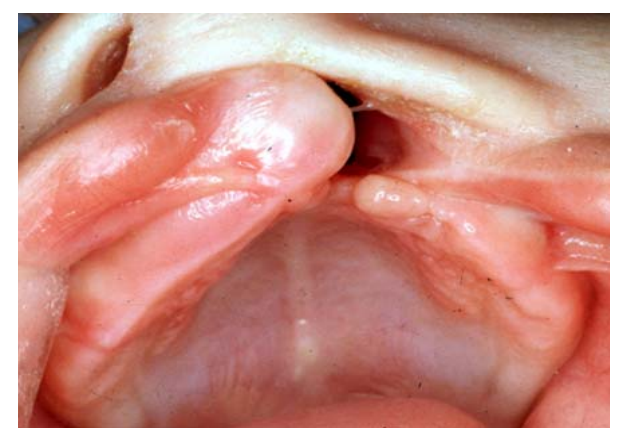

Fig. 1 - Fissura de lábio e rebordo alveolar esquerda (LAE)



Fig. 2 - Fissura de lábio e rebordo alveolar bilateral (LAB)

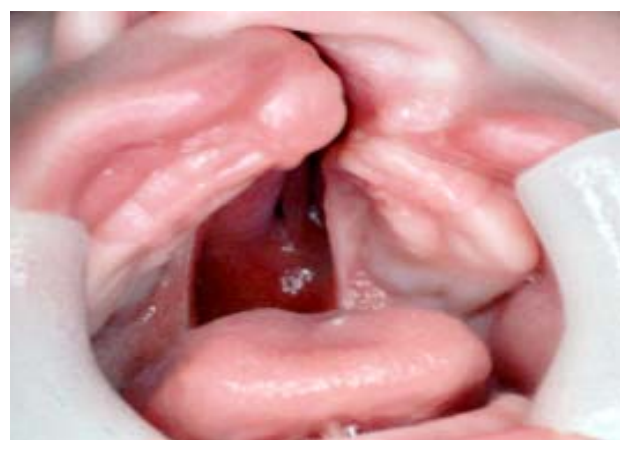

Fig. 3 - Fissura de lábio, rebordo alveolar e palato esquerda (LAPE) 


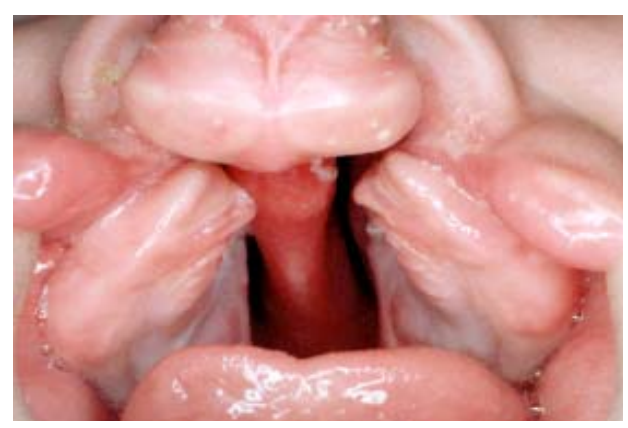

Fig. 4 - Fissura de lábio, rebordo alveolar e palato bilateral (LAPB)

\subsubsection{Classificação sócio-econômica}

Todos os indivíduos matriculados no HRAC/USP apresentam no prontuário uma classificação sócio-econômica que é estabelecida pelo Serviço Social. Esta classificação se baseia na somatória de pontos obtidas na entrevista do indivíduo ao ingressar ao Hospital (GRACIANO ${ }^{64}$, 1976). São avaliados:

- Situação econômica da família - salários mínimos

- Tipo de rendimento - salário, retirada pró-labore, rendimento financeiro, aluguéis, honorários, aposentadoria, pensionista, outros.

- $\quad$ Escolaridade - maior nível educacional do responsável.

- Situação da habitação - precária, insatisfatória, regular, boa, ótima.

- Condição da habitação - própria, financiada, alugada, cedida, outras.

- Tipo de habitação: tijolos, madeira, tijolos e madeira, outras.

- Localização - zona rural, zona urbana, suburbana.

- Infra-estrutura - água encanada ou mina, esgoto ou fossa, luz elétrica ou lamparina.

- Nível ocupacional - ativo, aposentado, pensionista, desempregado.

- Setor - primário (recurso da natureza), secundário (industriais), terciário (comércio e prestação de serviços).

Todos estes itens recebem uma pontuação para que o indivíduo seja classificado como nível sócio-econômico:

- Baixo inferior

- Baixo superior

- Médio inferior

- Médio

- Médio superior 
- $\quad$ Alto

A classificação utilizada neste trabalho foi aquela que Assistente Social registrou no prontuário de cada indivíduo da amostra.

\subsubsection{Parâmetros Clínicos}

a) Medida da profundidade de sondagem do sulco ou bolsa periodontal: medida da margem gengival a base do sulco gengival/bolsa periodontal. Foram analisados seis sítios em todos os dentes (mésio-vestibular, vestibular, disto-vestibular, mésio-lingual, lingual, disto-lingual), com exceção dos terceiros molares.

b) Medida do nível de inserção clínico: medida da junção amelocementária a base do sulco gengival/bolsa periodontal. Assim como na profundidade de sondagem, foram avaliados seis sítios por dente (mésio-vestibular, vestibular, disto-vestibular, mésio-lingual, lingual, disto-lingual), com exceção dos terceiros molares.

Para obtenção destas medidas foi utilizada uma sonda periodontal do modelo COLOR CODED PROBE CP-ISUNC-PCPUNC15 (Hu-friedy, USA), corresponde a uma sonda graduada em $15 \mathrm{~mm}$, com demarcações negras a cada milímetro, sendo o intervalo entre a $4^{a}$ e a $5^{a}$, entre $9^{a}$ e $10^{a}$ e entre $14^{\circ}$ e $15^{\circ}$ a demarcação é totalmente preenchida por cor negra, de maneira similar as marcações de Williams. A ponta deste instrumento apresenta um diâmetro de aproximadamente $0,5 \mathrm{~mm}$ na extremidade e de $0,9 \mathrm{~mm}$ na base.

c) Avaliação do Índice Gengival

O método empregado para avaliação do Índice Gengival (IG) foi o preconizado por LÖE ${ }^{79}$ em 1967. Este índice foi elaborado para avaliar qualitativa e quantitativamente o estado gengival. Avaliaram-se os tecidos gengivais ao redor de cada dente, divididos em seis unidades: disto-vestibular, vestibular, mésio-vestibular, disto-lingual, lingual e mésiolingual. Os critérios para atribuição do índice gengival são:

$0=$ gengiva normal.

$1=$ inflamação incipiente: discreta alteração de cor e edema, ausência de sangramento á sondagem.

2= inflamação moderada: gengiva avermelhada, edemaciada e brilhante, sangramento à sondagem.

3= inflamação severa: tendências a sangramento espontâneo.

De acordo com os índices obtidos, podemos classificar como gengivite incipiente quando o grau for de 0,1 a 1,0; gengivite moderada de 1,1 a 2,0 e gengivite severa, entre 2,1 e 3,0 . 
d) Avaliação do Índice de Placa

O índice de placa (IP) que foi empregado foi preconizado por SILNESS; LÖE ${ }^{120}$ (1964), o qual avalia a presença da placa na área cervical do dente. As áreas dentais avaliadas foram os sítios: disto-vestibular, vestibular, mésio-vestibular e lingual. A avaliação é feita com auxílio do espelho bucal, explorador ou sonda periodontal e jato de ar. Os critérios para avaliação deste índice são:

$0=$ ausência de placa

$1=$ uma película de placa aderida à cervical do dente adjacente à margem gengival. A placa pode ser reconhecida apenas correndo-se uma sonda pela superfície do dente.

2= acúmulo moderado dentro da bolsa ou na margem gengival vista a olho nu.

3= acúmulo abundante de placa dentro da bolsa e próximo á margem gengival.

e) Recessão gengival

Corresponde à medida da distância da junção amelocementária à margem gengival em milímetros. Foi realizada no centro da face vestibular de cada dente com a sonda periodontal já citada e classificada em leves $(<3 \mathrm{~mm})$, moderada $(3-4 \mathrm{~mm})$ e severa $(4 \mathrm{~mm})$.

As recessões gengivais foram classificadas de acordo com Miller ${ }^{96}$ (1985) na qual se baseia no envolvimento da junção mucogengival, pela recessão do tecido marginal, na integridade do osso alveolar interproximal, no posicionamento dentário e na altura das papilas interdentais.

Classe l: a recessão não se estende até a junção mucogengival, estando confinada a faixa de mucosa queratinizada. Não há perda de estrutura periodontal (tecido ósseo ou mole) na região interproximal.

Classe II: a recessão do tecido marginal estende-se até ou ultrapassa a junção amelocementária, não havendo ainda perda do tecido ósseo ou mole na região interproximal.

Classe III: a recessão do tecido marginal estende-se até ou ultrapassa a junção amelocementária. Há perda de tecido ósseo e mole na região interproximal e/ou posicionamento dentário inadequado, com as papilas interdentais encontrando-se coronalmente à margem gengival na área da recessão.

Classe IV: a recessão do tecido marginal estende-se até ou ultrapassa a junção amelocementária. Há uma acentuada perda de tecido ósseo e mole na região interproximal e/ou posicionamento dentário inadequado severo. As papilas interdentais apresentam-se quase na mesma altura ou até mesmo nos casos mais graves, apicalmente à margem gengival na área da recessão. 
Para facilitar a análise estatística e discussão dos resultados, foram feitas médias de todos os parâmetros por sextantes:

- $\quad$ Sextante 1 - posterior superior direito (dentes: 17, 16, 15 e 14)

- $\quad$ Sextante 2 - anterior superior (dentes: 13, 12, 11, 21, 22 e 23)

- $\quad$ Sextante 3 - posterior superior esquerdo (dentes: 24, 25, 26 e 27)

- $\quad$ Sextante 4 - posterior inferior esquerdo (dentes: 37, 36, 35 e 34)

- $\quad$ Sextante 5 - anterior inferior (dentes: 33, 32, 31, 41, 42 e 43)

- $\quad$ Sextante 6 - posterior inferior direito (dentas: 44, 45, 46 e 47)

Os exames clínicos foram realizados por três periodontistas experientes após calibração. O erro inter e intra-examinador foi bem baixo. 30 indivíduos foram examinados duas vezes com intervalo de uma semana. A concordância foi maior que $89 \%$ (Teste Kappa).

\subsection{Análise Estatística}

Testes estatísticos utilizados

- $\quad$ ANOVA

- Friedman

- Kruskal - Wallis

- Dunn

- Tuckey

- Man - Whitney

- Correlação de Pearson

- Correlação de Spearman

O teste ANOVA (Análise de Variância) foi utilizado para variáveis quantitativas (nível de inserção clínica, profundidade de sondagem), quando houve diferença estatisticamente significante, foram utilizados para comparações múltiplas o Teste de Tuckey.

A comparação das variáveis ordinais (índice gengival, índice de placa e recessão) foi feita utilizando-se o teste não paramétrico de Kruskall-Walis e Friedman, quando houve diferença estatisticamente significante, foi utilizado o Teste de Dunn para comparações múltiplas. 
As correlações utilizadas entre os parâmetros foram a de Pearson para as variáveis: profundidade de sondagem e nível de inserção clínica e de Spearman para as correlações de classe sócio-econômica com as demais variáveis. 
RESULTADOS 


\section{RESULTADOS}

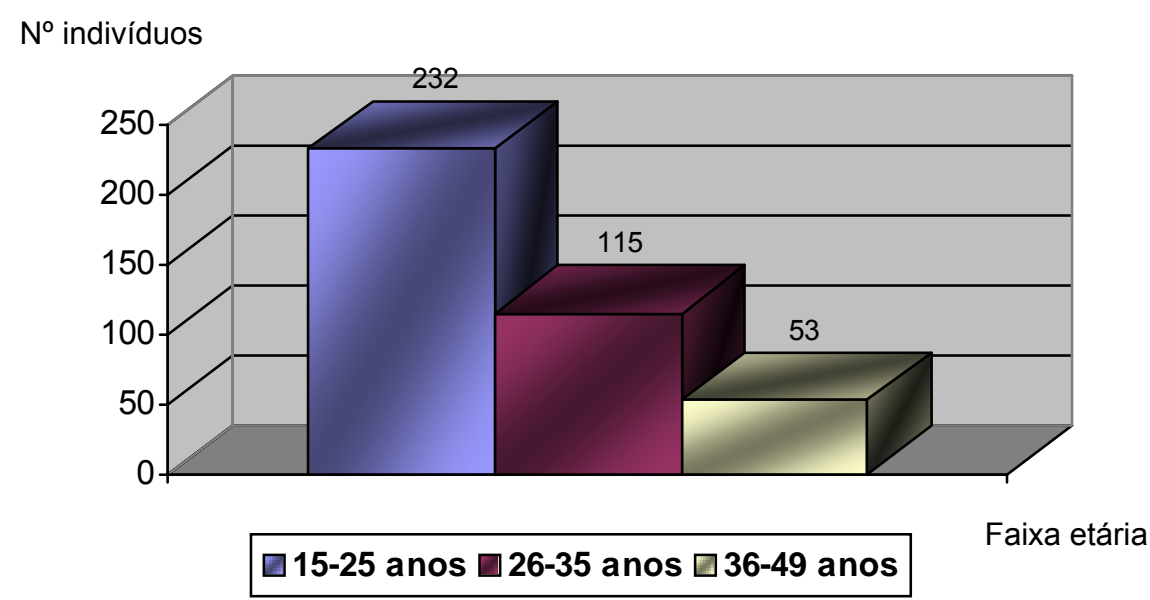

Figura 5. Distribuição do número de indivíduos por faixa etária.

A amostra foi constituída por 400 indivíduos, com idade variando entre 15 e 49 anos. 232 (58\%) indivíduos estavam entre a faixa etária de 15 a 25 anos, 115 (28,75\%) tinham entre 26 e 35 anos e $53(13,25 \%)$ de 36 a 49 anos de idade (figura 5 ).

$\mathrm{N}^{\circ}$ indivíduos

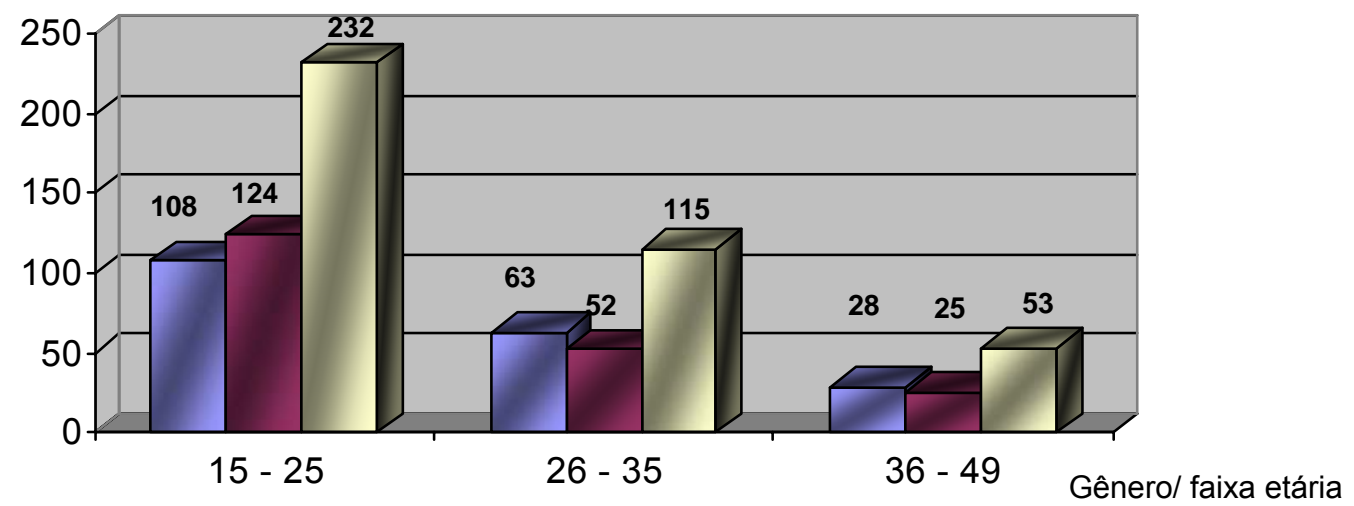

$\square$ Masculino $\square$ Feminino $\square$ Total

Figura 6. Distribuição do número de indivíduos por gênero de acordo com a faixa etária. 
O número total de indivíduos do gênero masculino foi igual ao do gênero feminino. Na faixa etária de 15 a 25 anos houve predominância do gênero feminino, o que já não ocorreu nas demais categorias de faixa etária (figura 6).



$\square$ 15-25 $\square$ 26-35 $\square$ 36-49 Faixa etária/ nível sócio-econômico

Figura 7. Distribuição da freqüência dos indivíduos por faixa etária e classificação sócioeconômica.

Nesta amostra a classe sócio-econômica variou de baixa inferior a média superior, sendo que maioria dos indivíduos pertencia à classe baixa superior (figura 7).

$\mathrm{N}^{\circ}$ indivíduos

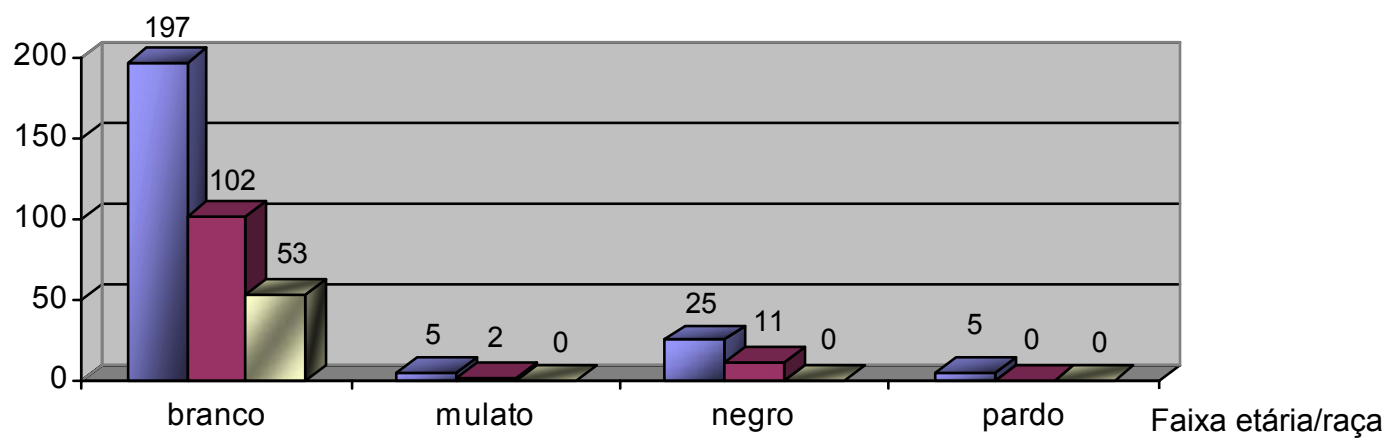

$\square$ 15-16 $\square$ 26-35 $\square 36-49$

Figura 8. Distribuição dos indivíduos segundo raça e faixa etária. 
A grande maioria dos indivíduos da amostra era da raça branca (352), seguida pela raça negra (36), mulato (7) e pardo (5) (figura 8 ).

$\mathrm{N}^{\circ}$ indivíduos

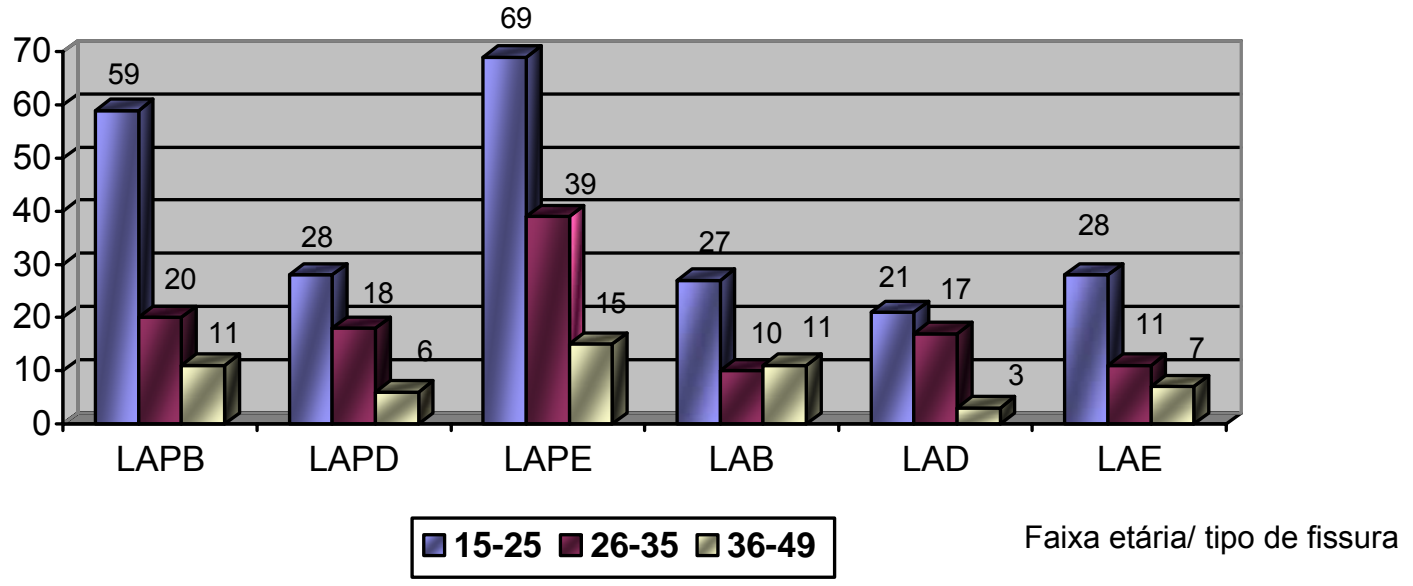

Figura 9. Distribuição da freqüência dos indivíduos por tipo de fissura e faixa etária.

O tipo de fissura mais freqüente na amostra foi a que acometeu lábio, alvéolo e palato do lado esquerdo nos indivíduos mais jovens (123), a menos freqüente foi a de lábio e alvéolo do lado direito (41), particularmente nos indivíduos de 36 a 49 anos (3) (figura 9).

№ indivíduos

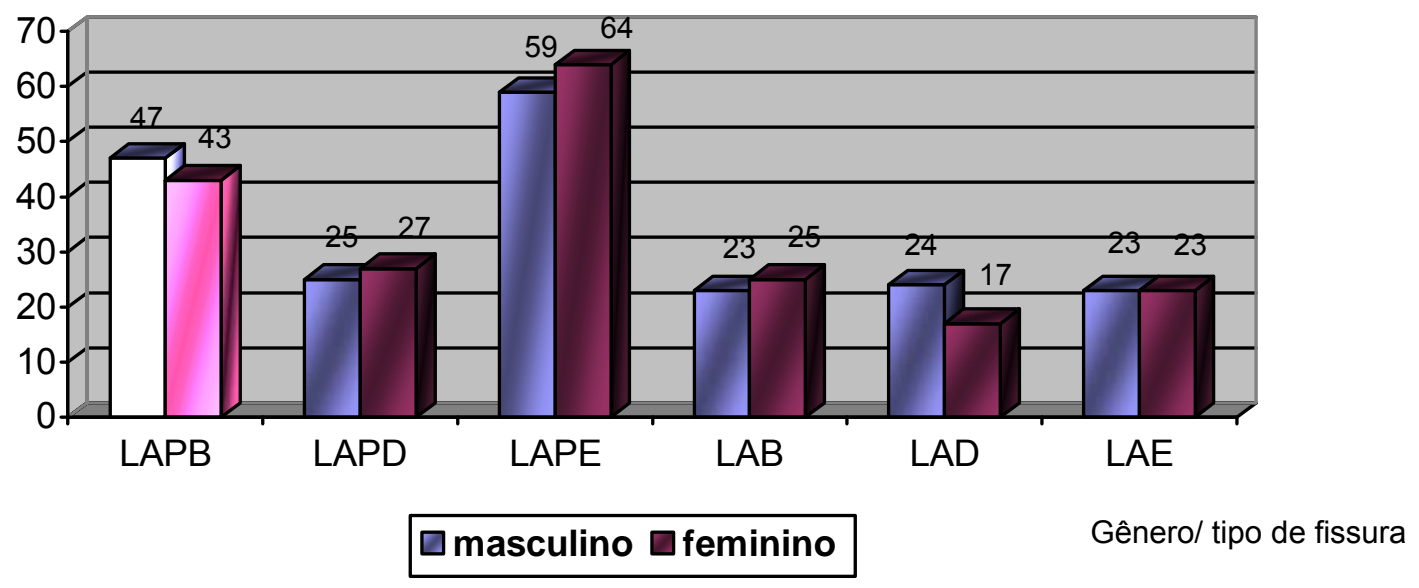

Figura 10. Distribuição de freqüência dos indivíduos por tipos de fissuras e gênero. 
A distribuição da amostra quanto ao tipo de fissura e gênero foi bem homogênea. Nas fissuras LAPB, e LAD houve maior número em homens do que em mulheres (47 e 43, 24 e 17 respectivamente), já nas fissuras LAPD, LAB e LAPE tiveram mais mulheres $(27,25$ e 64, respectivamente). O mesmo número de homens e mulheres foram portadores da fissura LAE.

A fissura mais prevalente foi a LAPE $(n=123)$, seguida pela LAPB $(n=90)$, LAPD $(n=52)$, LAB $(n=48)$, LAE $(n=46)$ e LAD $(n=41)$ (figura 10).

Quanto ao lado da fissura, houve maior prevalência do lado esquerdo ( $n=169)$, seguido pela fissura bilateral $(n=138)$ e lado direito $(n=93)$.

Tabela 1. Médias, medianas e desvios padrão dos parâmetros periodontais: profundidade de sondagem (PS) $(\mathrm{mm})$, nível de inserção clínico $(\mathrm{NI})(\mathrm{mm})$, recessão gengival na face vestibular (RV) (mm), índice de placa (IP) (escores) e índice gengival (IG) (escores).

\begin{tabular}{ccccc}
\hline Variável & Média & Desvio. padrão & Mediana & $N$ \\
\hline PS & 2,3 & 0,737 & 2,2 & 9679 \\
NI & 1,5 & 0,951 & 1,3 & 9679 \\
RV & 0,2 & 0,868 & 0 & 9679 \\
IP & 1,5 & 0,677 & 1 & 9679 \\
IG & 1,7 & 0,446 & 2 & 9679 \\
\hline
\end{tabular}

A média da profundidade de sondagem de todos os 9679 sítios da amostra foi de 2,3 $\mathrm{mm}$, do nível de inserção clínico foi $1,5 \mathrm{~mm}$, recessão gengival por vestibular foi $0,2 \mathrm{~mm}$ e do índice gengival foi 1,7 e de placa 1,5 (tabela 1). 
Tabela 2. Médias e desvios padrão da profundidade de sondagem $(\mathrm{mm})$ por faixas etárias, gêneros, tipos de fissuras dos sextantes superiores.

\begin{tabular}{|c|c|c|c|c|c|c|c|c|}
\hline \multirow{2}{*}{$\begin{array}{l}\text { Faixas } \\
\text { etárias }\end{array}$} & \multirow[t]{2}{*}{ Gêneros } & \multirow{2}{*}{$\begin{array}{l}\text { Tipos de } \\
\text { fissuras }\end{array}$} & \multicolumn{2}{|c|}{ S1 } & \multicolumn{2}{|c|}{ S2 } & \multicolumn{2}{|c|}{ S3 } \\
\hline & & & Média & $d p$ & Média & $d p$ & Média & $d p$ \\
\hline \multirow[t]{12}{*}{$15-25$} & $M$ & LAPE & 2,48 & 0,371 & 2,29 & 0,419 & 2,52 & 0,436 \\
\hline & M & LAB & 2,24 & 0,550 & 2,28 & 0,754 & 2,35 & 0,420 \\
\hline & $\mathrm{M}$ & LAPD & 2,88 & 0,697 & 2,59 & 0,663 & 2,76 & 0,271 \\
\hline & $\mathrm{M}$ & LAPB & 2,43 & 0,416 & 2,65 & 0,798 & 2,42 & 0,610 \\
\hline & $\mathrm{M}$ & LAE & 2,46 & 0,724 & 2,26 & 0,916 & 2,49 & 0,872 \\
\hline & M & LAD & 2,52 & 0,553 & 2,22 & 0,457 & 2,46 & 0,486 \\
\hline & $F$ & LAPE & 2,44 & 0,370 & 2,26 & 0,429 & 2,48 & 0,410 \\
\hline & $F$ & LAB & 2,25 & 0,630 & 2,35 & 0,772 & 2,39 & 0,467 \\
\hline & $\mathrm{F}$ & LAPD & 2,89 & 0,769 & 2,69 & 0,713 & 2,64 & 0,324 \\
\hline & $F$ & LAPB & 2,48 & 0,494 & 2,51 & 0,753 & 2,40 & 0,630 \\
\hline & $F$ & LAE & 2,54 & 0,861 & 2,39 & 0,840 & 2,72 & 1,102 \\
\hline & $F$ & LAD & 2,52 & 0,540 & 2,21 & 0,489 & 2,43 & 0,307 \\
\hline \multirow[t]{12}{*}{$26-35$} & M & LAPE & 2,69 & 0,591 & 2,52 & 0,593 & 2,69 & 0,672 \\
\hline & M & LAB & 2,54 & 0,709 & 2,02 & 0,427 & 2,26 & 0,706 \\
\hline & M & LAPD & 2,47 & 0,469 & 2,41 & 0,502 & 2,71 & 0,461 \\
\hline & $\mathrm{M}$ & LAPB & 2,63 & 0,723 & 3,06 & 0,836 & 2,85 & 0,489 \\
\hline & M & LAE & 2,92 & 0,550 & 2,58 & 0,327 & 2,86 & 0,658 \\
\hline & M & LAD & 3,02 & 0,554 & 2,83 & 0,657 & 2,87 & 0,492 \\
\hline & $F$ & LAPE & 2,71 & 0,632 & 2,63 & 0,715 & 2,67 & 0,670 \\
\hline & $\mathrm{F}$ & LAB & 2,48 & 0,716 & 2,00 & 0,430 & 2,26 & 0,733 \\
\hline & $\mathrm{F}$ & LAPD & 2,35 & 0,363 & 2,33 & 0,477 & 2,74 & 0,515 \\
\hline & $\mathrm{F}$ & LAPB & 2,42 & 0,622 & 3,33 & 1,009 & 2,77 & 0,456 \\
\hline & $\mathrm{F}$ & LAE & 2,78 & 0,585 & 2,47 & 0,403 & 2,80 & 0,607 \\
\hline & $\mathrm{F}$ & LAD & 2,60 & 0,648 & 2,76 & 0,702 & 2,40 & 0,339 \\
\hline \multirow[t]{12}{*}{$36-49$} & $\mathrm{M}$ & LAPE & 2,48 & 0,376 & 2,30 & 0,743 & 2,60 & 0,268 \\
\hline & M & LAB & 2,10 & 0,548 & 2,00 & 0,274 & 2,02 & 0,657 \\
\hline & M & LAPD & 3,10 & 0,000 & 2,80 & 0,000 & 3,20 & 0,000 \\
\hline & $\mathrm{M}$ & LAPB & 3,13 & 0,822 & 2,40 & 0,346 & 2,92 & 1,228 \\
\hline & $\mathrm{M}$ & LAE & 4,38 & 0,991 & 2,67 & 0,395 & 3,45 & 0,700 \\
\hline & $\mathrm{M}$ & LAD & 3,65 & 0,919 & 2,80 & 0,283 & 3,20 & 0,849 \\
\hline & $F$ & LAPE & 2,40 & 0,440 & 2,53 & 0,528 & 2,57 & 0,382 \\
\hline & F & LAB & 1,98 & 0,500 & 1,95 & 0,315 & 1,92 & 0,677 \\
\hline & $\mathrm{F}$ & LAPD & 2,65 & 0,636 & 2,30 & 0,707 & 2,95 & 0,354 \\
\hline & $\mathrm{F}$ & LAPB & 3,40 & 1,697 & 2,40 & 0,424 & 3,10 & 1,414 \\
\hline & $\mathrm{F}$ & LAE & 4,23 & 1,501 & 2,57 & 0,404 & 3,33 & 0,808 \\
\hline & $F$ & LAD & 3,00 & 0,000 & 2,60 & 0,000 & 2,60 & 0,000 \\
\hline
\end{tabular}


Tabela 3. Médias e desvios padrão da profundidade de sondagem $(\mathrm{mm})$ por faixas etárias, gêneros, tipos de fissuras dos sextantes inferiores.

\begin{tabular}{|c|c|c|c|c|c|c|c|c|}
\hline \multirow{2}{*}{$\begin{array}{l}\text { Faixas } \\
\text { etárias }\end{array}$} & \multirow[t]{2}{*}{ Gêneros } & \multirow{2}{*}{$\begin{array}{l}\text { Tipos de } \\
\text { fissuras }\end{array}$} & \multicolumn{2}{|c|}{ S4 } & \multicolumn{2}{|c|}{$S 5$} & \multicolumn{2}{|c|}{ S6 } \\
\hline & & & Média & $d p$ & Média & $d p$ & Média & $d p$ \\
\hline \multirow[t]{12}{*}{$15-25$} & $M$ & LAPE & 2,25 & 0,261 & 1,95 & 0,239 & 2,21 & 0,280 \\
\hline & $M$ & LAB & 2,18 & 0,499 & 1,92 & 0,428 & 2,20 & 0,624 \\
\hline & $M$ & LAPD & 2,28 & 0,490 & 2,04 & 0,476 & 2,54 & 0,602 \\
\hline & $M$ & LAPB & 2,17 & 0,651 & 2,16 & 0,619 & 2,36 & 0,596 \\
\hline & $M$ & LAE & 2,12 & 0,437 & 2,04 & 0,717 & 2,46 & 0,511 \\
\hline & $M$ & LAD & 2,17 & 0,157 & 2,07 & 0,544 & 2,44 & 0,453 \\
\hline & $\mathrm{F}$ & LAPE & 2,24 & 0,293 & 1,97 & 0,215 & 2,25 & 0,325 \\
\hline & $\mathrm{F}$ & LAB & 2,17 & 0,473 & 1,89 & 0,455 & 2,19 & 0,550 \\
\hline & $\mathrm{F}$ & LAPD & 2,18 & 0,511 & 2,03 & 0,503 & 2,51 & 0,685 \\
\hline & $\mathrm{F}$ & LAPB & 2,16 & 0,650 & 2,04 & 0,501 & 2,34 & 0,570 \\
\hline & $\mathrm{F}$ & LAE & 2,12 & 0,312 & 2,16 & 0,770 & 2,55 & 0,673 \\
\hline & $\mathrm{F}$ & LAD & 2,25 & 0,242 & 2,02 & 0,542 & 2,35 & 0,270 \\
\hline \multirow[t]{12}{*}{$26-35$} & $M$ & LAPE & 2,34 & 0,572 & 2,20 & 0,669 & 2,37 & 0,565 \\
\hline & $M$ & LAB & 1,96 & 0,371 & 1,96 & 0,550 & 2,06 & 0,493 \\
\hline & M & LAPD & 2,24 & 0,341 & 1,90 & 0,323 & 2,14 & 0,207 \\
\hline & $M$ & LAPB & 2,74 & 0,721 & 2,60 & 0,797 & 2,57 & 0,484 \\
\hline & M & LAE & 2,78 & 0,460 & 2,32 & 0,550 & 2,56 & 0,288 \\
\hline & M & LAD & 2,71 & 0,470 & 2,82 & 0,717 & 2,87 & 0,537 \\
\hline & $\mathrm{F}$ & LAPE & 2,35 & 0,485 & 2,27 & 0,689 & 2,42 & 0,555 \\
\hline & $\mathrm{F}$ & LAB & 2,00 & 0,300 & 1,96 & 0,550 & 2,08 & 0,476 \\
\hline & $\mathrm{F}$ & LAPD & 2,10 & 0,321 & 1,84 & 0,177 & 2,14 & 0,169 \\
\hline & $\mathrm{F}$ & LAPB & 2,67 & 0,654 & 2,41 & 0,372 & 2,48 & 0,244 \\
\hline & $\mathrm{F}$ & LAE & 2,60 & 0,597 & 2,20 & 0,629 & 2,58 & 0,331 \\
\hline & $\mathrm{F}$ & LAD & 2,62 & 0,638 & 2,44 & 0,590 & 2,74 & 0,602 \\
\hline \multirow[t]{12}{*}{$36-49$} & $M$ & LAPE & 2,22 & 0,445 & 2,02 & 0,436 & 2,03 & 0,423 \\
\hline & $\mathrm{M}$ & LAB & 2,02 & 0,657 & 1,92 & 0,522 & 2,18 & 0,712 \\
\hline & $M$ & LAPD & 2,50 & 0,000 & 3,20 & 0,000 & 3,30 & 0,000 \\
\hline & $\mathrm{M}$ & LAPB & 2,33 & 0,386 & 2,05 & 0,661 & 2,88 & 1,040 \\
\hline & $M$ & LAE & 3,17 & 0,665 & 2,67 & 0,386 & 2,50 & 0,523 \\
\hline & $\mathrm{M}$ & LAD & 2,85 & 0,778 & 2,40 & 0,566 & 2,75 & 0,636 \\
\hline & $\mathrm{F}$ & LAPE & 2,24 & 0,435 & 2,16 & 0,675 & 2,30 & 0,739 \\
\hline & $\mathrm{F}$ & LAB & 2,15 & 0,698 & 1,60 & 0,657 & 2,17 & 0,659 \\
\hline & $\mathrm{F}$ & LAPD & 2,30 & 0,283 & 2,50 & 0,990 & 2,65 & 0,919 \\
\hline & $\mathrm{F}$ & LAPB & 2,90 & 1,131 & 2,30 & 0,990 & 3,10 & 1,414 \\
\hline & $\mathrm{F}$ & LAE & 3,13 & 0,808 & 2,63 & 0,462 & 2,53 & 0,635 \\
\hline & $\mathrm{F}$ & LAD & 2,30 & 0,000 & 2,00 & 0,000 & 2,30 & 0,000 \\
\hline
\end{tabular}

Nas tabelas 2 e 3 estão descritas as médias e desvio padrão da profundidade de sondagem da amostra de cada sextante dividida quanto à faixa etária, gênero e tipo de fissura. Ao compararmos as médias dos sextantes observamos valores muito parecidos. As fissuras com maiores médias foram a de lábio e alvéolo esquerda nos sextantes 1 , 3 e 4 no gênero masculino e faixa etária de 36 a 49 anos $(4,38 \mathrm{~mm}, 3,45 \mathrm{~mm}$ e $3,17 \mathrm{~mm}$ respectivamente). As fissuras de lábio, alvéolo e palato, no lado direito também tiveram 
maiores médias no gênero masculino nos sextantes 5 e 6 nos indivíduos mais velhos $(3,20$ $\mathrm{mm}$ e 3,30 $\mathrm{mm}$ respectivamente. O sextante 2 teve maiores médias no gênero feminino, na fissura de lábio, alvéolo e palato bilateral, na faixa etária de 23 a 35 anos de idade $(3,33$ $\mathrm{mm}$ ). A área da fissura (sextante 2) não apresentou maiores médias quando comparadas com as demais.

$N^{\circ}$ indivíduos

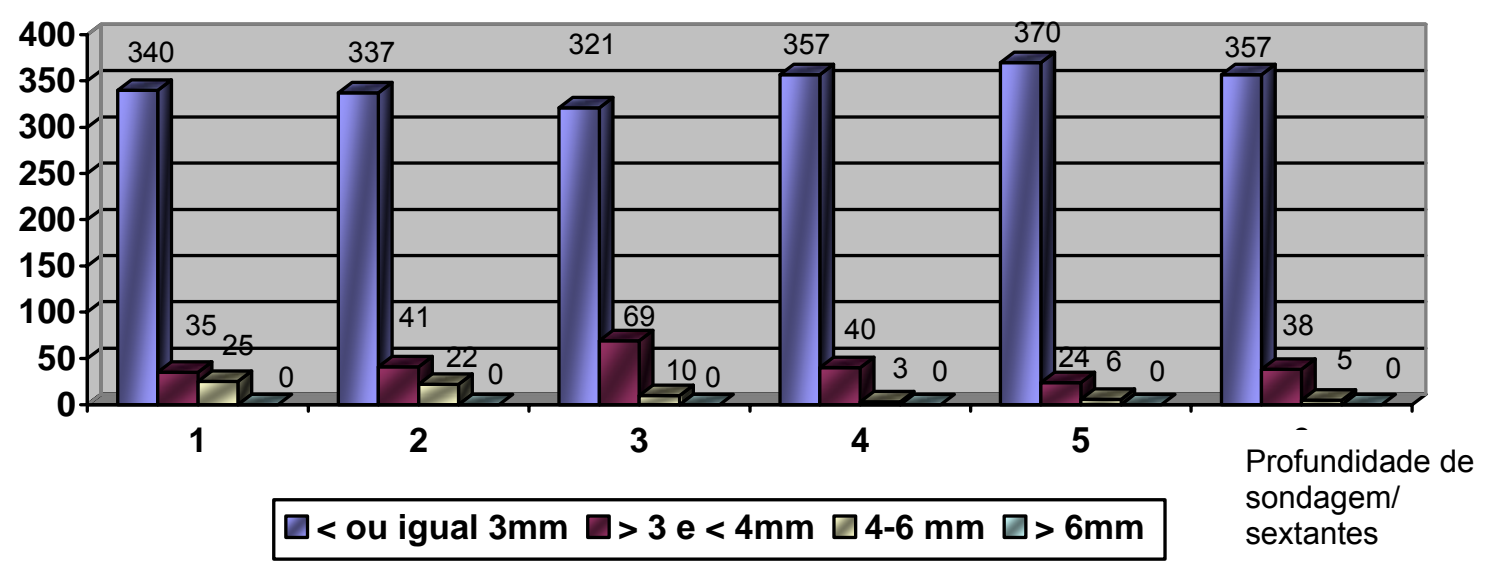

Figura 11. Distribuição das médias da profundidade de sondagem (PS) por sextante.

A profundidade de sondagem menor ou igual a $3 \mathrm{~mm}$ foi a mais prevalente indicando que a maioria dos sextantes, em média, não apresentava bolsa periodontal. Considerandose os valores médios, não houve nenhum sextante com profundidade de sondagem maior que $6 \mathrm{~mm}$ (figura 11).

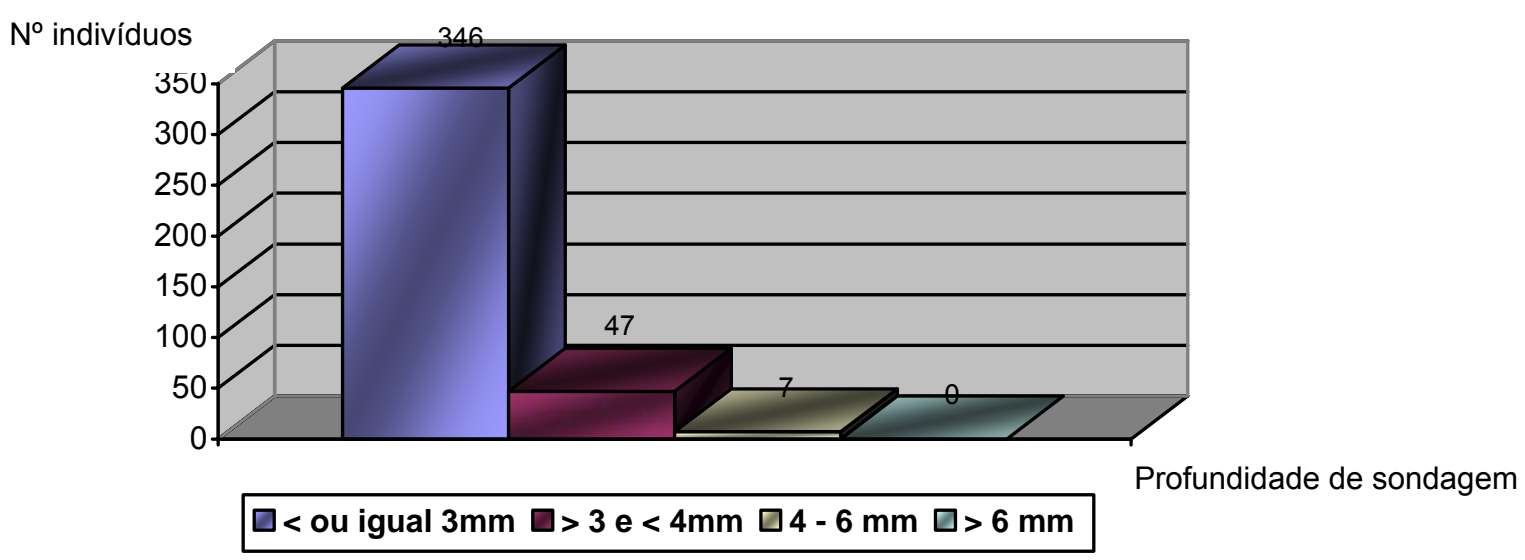

Figura 12. Distribuição das medidas da profundidade de sondagem (PS) de toda a amostra. 
Quando foram observados os dados de profundidade de sondagem para a média da amostra os mesmos resultados foram observados, poucos indivíduos apresentaram bolsas de 4 a $6 \mathrm{~mm}$ (7), nenhum com bolsas maiores que $6 \mathrm{~mm}$. 346 indivíduos apresentaram profundidade de sondagem menor ou igual a $3 \mathrm{~mm}$ (figura 12).

Tabela 4. Comparação das médias de profundidade de sondagem $(\mathrm{mm})$ entre faixas etárias (1), gêneros (2), tipos de fissuras (3), sextante (4) - ANOVA (quatro critérios).

\begin{tabular}{lc}
\hline Critérios & $p$ \\
\hline 1 & $0,001^{*}$ \\
2 & 0,355 \\
3 & $\mathrm{p}<0,001^{*}$ \\
4 & $\mathrm{p}<0,001^{*}$ \\
$1 \times 2$ & 0,681 \\
$1 \times 3$ & $0,002^{*}$ \\
$2 \times 3$ & 0,804 \\
$1 \times 4$ & $\mathrm{p}<0,001^{*}$ \\
$2 \times 4$ & 0,686 \\
$3 \times 4$ & $\mathrm{p}<0,001^{*}$ \\
$1 \times 2 \times 3$ & 0,989 \\
$1 \times 2 \times 4$ & 0,937 \\
$1 \times 3 \times 4$ & $\mathrm{p}<0,001^{*}$ \\
$2 \times 3 \times 4$ & 0,999 \\
$1 \times 2 \times 3 \times 4$ & 1,000 \\
\hline${ }^{*}$ Diferença estatisticamente significante &
\end{tabular}

Ao compararmos a profundidade de sondagem entre faixa etária, gênero, tipo de fissura e sextante constatou-se que não houve diferença estatisticamente significante somente para gênero (2) (tabela 4). 
Tabela 5. Médias e desvios padrão da profundidade de sondagem $(\mathrm{mm})$ por faixas etárias, tipos de fissuras dos sextantes superiores.

\begin{tabular}{cccccccc}
\hline Faixas & Tipos de & \multicolumn{2}{c}{$S 1$} & \multicolumn{2}{c}{$S 2$} & \multicolumn{2}{c}{$S 3$} \\
etárias & fissuras & Média & $d p$ & Média & $d p$ & Média & $d p$ \\
\hline $15-25$ & LAPE & 2,46 & 0,368 & 2,27 & 0,422 & 2,50 & 0,419 \\
& LAB & 2,24 & 0,581 & 2,31 & 0,750 & 2,37 & 0,437 \\
& LAPD & 2,89 & 0,726 & 2,65 & 0,681 & 2,69 & 0,303 \\
& LAPB & 2,46 & 0,454 & $\mathbf{2 , 5 8}$ & 0,772 & 2,41 & 0,615 \\
& LAE & 2,50 & 0,782 & 2,33 & 0,865 & 2,60 & 0,982 \\
& LAD & 2,52 & 0,533 & 2,21 & 0,462 & 2,44 & 0,392 \\
\hline $26-35$ & LAPE & 2,70 & 0,602 & 2,57 & 0,646 & 2,68 & 0,663 \\
& LAB & 2,51 & 0,672 & 2,01 & 0,404 & 2,26 & 0,679 \\
& LAPD & 2,42 & 0,418 & 2,37 & 0,479 & 2,72 & 0,471 \\
& LAPB & 2,54 & 0,670 & $\mathbf{3 , 1 8}$ & 0,903 & 2,81 & 0,463 \\
& LAE & 2,85 & 0,545 & 2,52 & 0,357 & 2,83 & 0,598 \\
& LAD & 2,89 & 0,595 & 2,81 & 0,649 & 2,73 & 0,493 \\
\hline $36-49$ & LAPE & 2,44 & 0,397 & 2,42 & 0,619 & 2,58 & 0,321 \\
& LAB & 2,04 & 0,499 & 1,97 & 0,283 & 1,96 & 0,636 \\
& LAPD & 2,88 & 0,450 & 2,55 & 0,500 & 3,08 & 0,250 \\
& LAPB & 3,22 & 1,001 & 2,40 & 0,329 & 2,98 & 1,146 \\
& LAE & 4,31 & 1,117 & 2,63 & 0,368 & $\mathbf{3}, 40$ & 0,683 \\
& LAD & $\mathbf{3 , 4 3}$ & 0,751 & 2,73 & 0,231 & 3,00 & 0,693 \\
\hline
\end{tabular}

Tabela 6. Médias e desvios padrão da profundidade de sondagem $(\mathrm{mm})$ por faixas etárias, tipos de fissuras dos sextantes inferiores.

\begin{tabular}{cccccccc}
\hline Faixas & Tipos de & \multicolumn{2}{c}{$S 4$} & \multicolumn{2}{c}{$S 5$} & \multicolumn{3}{c}{$S 6$} \\
etárias & fissuras & Média & $d p$ & Média & $d p$ & Média & $d p$ \\
\hline $15-25$ & LAPE & 2,25 & 0,277 & 1,96 & 0,225 & 2,23 & 0,304 \\
& LAB & 2,17 & 0,476 & 1,90 & 0,434 & 2,19 & 0,576 \\
& LAPD & 2,22 & 0,496 & 2,03 & 0,482 & 2,52 & 0,639 \\
& LAPB & 2,16 & 0,645 & 2,10 & 0,561 & 2,35 & 0,578 \\
& LAE & 2,12 & 0,373 & 2,10 & 0,733 & 2,50 & 0,588 \\
& LAD & 2,21 & 0,206 & 2,04 & 0,530 & 2,40 & 0,361 \\
\hline $26-35$ & LAPE & 2,35 & 0,527 & 2,23 & 0,670 & 2,39 & 0,554 \\
& LAB & 1,98 & 0,319 & 1,96 & 0,519 & 2,07 & 0,457 \\
& LAPD & 2,18 & 0,330 & 1,87 & 0,263 & 2,14 & 0,185 \\
& LAPB & 2,70 & 0,675 & 2,52 & 0,634 & 2,53 & 0,388 \\
& LAE & 2,68 & 0,521 & 2,25 & 0,568 & 2,57 & 0,297 \\
& LAD & 2,68 & 0,505 & $\mathbf{2 , 7 1}$ & 0,687 & 2,83 & 0,541 \\
\hline $36-49$ & LAPE & 2,23 & 0,421 & 2,09 & 0,559 & 2,18 & 0,606 \\
& LAB & 2,09 & 0,649 & 1,75 & 0,594 & 2,17 & 0,648 \\
& LAPD & 2,40 & 0,200 & 2,85 & 0,700 & 2,97 & 0,650 \\
& LAPB & 2,52 & 0,659 & 2,13 & 0,689 & 2,95 & 1,031 \\
& LAE & $\mathbf{3 , 1 6}$ & 0,663 & 2,66 & 0,382 & 2,51 & 0,521 \\
& LAD & 2,67 & 0,635 & 2,27 & 0,462 & 2,60 & 0,520 \\
\hline
\end{tabular}


Nas tabelas 5 e 6 estão descritas as médias e desvio padrão da amostra por sextante divididos quanto à faixa etária e tipo de fissura, a variável gênero foi excluída por não ter diferença estatisticamente significante. A fissura de lábio, alvéolo e palato bilateral obteve maior média no sextante 2 nos indivíduos de 26 a 35 anos de idade $(3,18 \mathrm{~mm})$. As maiores médias de profundidade de sondagem na fissura de lábio e alvéolo do lado direito foram de $2,71 \mathrm{~mm}$ nos indivíduos de 26 a 35 anos e de $3,43 \mathrm{~mm}$ nos de 36 a 49 anos, nos sextantes 5 e 1, respectivamente. Os valores dos sextantes 3 e 4 tiveram os maiores valores na fissura de lábio e alvéolo esquerda para a mesma faixa etária de 36 a 49 anos (3,40 e 3,16 mm, respectivamente). Os indivíduos com fissura de lábio alvéolo e palato do lado direito tiveram maior média no sextante 6 com faixa etária entre 36 e 49 anos (2,97 $\mathrm{mm}$ ). Dois sextante que engloba a área da fissura (2) obtiveram as maiores médias em cada grupo (indivíduos com fissura LAPB, de 15 a 25 anos, média de 2,58 mm; indivíduos com fissura LAPB, de 26 a 35 anos, média de $3,18 \mathrm{~mm}$ ).

Ao realizarmos as médias da profundidade de sondagem de todos os sextantes por faixa etária pudemos observar que houve aumento gradativo dessa medida com o aumento da idade, na faixa etária de 15 a 25 anos a média foi de $2,31 \mathrm{~mm}$, na faixa de 26 a 35 anos o valor da média foi de $2,44 \mathrm{~mm}$ e na faixa de 36 a 49 foi de $2,62 \mathrm{~mm}$.

Tabela 7. Comparação das médias da profundidade de sondagem $(\mathrm{mm})$ entre faixas etárias (1), tipos de fissura (2) e sextantes (3) - ANOVA (três critérios).

\begin{tabular}{ll}
\hline Critérios & $p$ \\
\hline 1 & $\mathrm{p}<0,001^{*}$ \\
2 & $\mathrm{p}<0,001^{*}$ \\
3 & $\mathrm{p}<0,001^{*}$ \\
$1 \times 2$ & $\mathrm{p}<0,001^{*}$ \\
$1 \times 3$ & $\mathrm{p}<0,001^{*}$ \\
$2 \times 3$ & $\mathrm{p}<0,001^{*}$ \\
$1 \times 2 \times 3$ & $\mathrm{p}<0,001^{*}$ \\
\hline${ }^{*}$ Estatisticamente significante &
\end{tabular}

Como não houve diferença estatisticamente significante para o gênero foi realizado o teste de ANOVA a três critérios. Comparando-se as médias de profundidade de sondagem entre faixa etária, tipo de fissura e sextante observou-se que houve diferença estatisticamente significante entre todos os critérios avaliados (tabela 7). 
Tabela 8. Teste de Tukey - Comparação das médias de profundidade de sondagem $(\mathrm{mm})$ entre faixas etárias (1 - 15 a 25 anos, 2 - 26 a 35 anos, 3 - 36 a 49 anos) e tipos de fissuras por sextante.

\begin{tabular}{|c|c|c|c|c|c|c|}
\hline \multirow{2}{*}{$\begin{array}{l}\text { Faixas etárias } \\
\text { x tipos de fissuras }\end{array}$} & \multicolumn{6}{|c|}{ Sextantes } \\
\hline & 1 & 2 & 3 & 4 & 5 & 6 \\
\hline $1 \times$ LAPD & $2,89^{\mathrm{c}, \mathrm{d}}$ & $2,65^{a, b}$ & $2,69^{b, c}$ & $2,22^{a, b}$ & $2,03^{a, b, c}$ & $2,52^{a, b}$ \\
\hline $1 \times \mathrm{LAB}$ & $2,24^{a, b}$ & $2,31^{a}$ & $2,37^{a, b}$ & $2,17^{a, b}$ & $1,90^{a, b}$ & $2,19^{a, b}$ \\
\hline $1 \times$ LAD & $2,52^{a, b, c, d}$ & $2,21^{a}$ & $2,44^{a, b}$ & $2,21^{a, b}$ & $2,04^{a, b, c}$ & $2,40^{a, b}$ \\
\hline $1 \times$ LAPB & $2,46^{a, b, c}$ & $2,58^{\mathrm{a}, \mathrm{b}}$ & $2,41^{a, b}$ & $2,16^{a, b}$ & $2,10^{a, b, c}$ & $2,35^{a, b}$ \\
\hline $1 \times$ LAPE & $2,46^{a, b, c}$ & $2,27^{a}$ & $2,50^{a, b}$ & $2,25^{a, b}$ & $1,96^{a, b, c}$ & $2,23^{a, b}$ \\
\hline $1 \times$ LAE & $2,50^{a, b, c}$ & $2,33^{a}$ & $2,60^{a, b, c}$ & $2,12^{a, b}$ & $2,10^{a, b, c}$ & $2,50^{a, b}$ \\
\hline $2 \times \mathrm{LAB}$ & $2,51^{a, b, c, d}$ & $2,01^{a}$ & $2,26^{a, b}$ & $1,98^{a}$ & $1,96^{a, b, c}$ & $2,07^{a}$ \\
\hline $2 \times$ LAPB & $2,54^{\mathrm{a}, \mathrm{b}, \mathrm{c}, \mathrm{d}}$ & $3,18^{b}$ & $2,81^{b, c}$ & $2,70^{b, c, d}$ & $2,52^{\mathrm{c}, \mathrm{d}}$ & $2,53^{a, b}$ \\
\hline $2 \times$ LAPE & $2,70^{a, b, c, d}$ & $2,57^{a, b}$ & $2,68^{b, c}$ & $2,35^{a, b, c}$ & $2,23^{a, b, c}$ & $2,39^{a, b}$ \\
\hline $2 \times \operatorname{LAE}$ & $2,85^{\mathrm{a}, \mathrm{b}, \mathrm{c}, \mathrm{d}}$ & $2,52^{a, b}$ & $2,83^{b, c}$ & $2,68^{a, b, c, d}$ & $2,25^{a, b, c}$ & $2,57^{a, b}$ \\
\hline $2 \times$ LAPD & $2,42^{a, b, c}$ & $2,37^{\mathrm{a}}$ & $2,72^{a, b, c}$ & $2,18^{\mathrm{a}, \mathrm{b}}$ & $1,87^{a, b}$ & $2,14^{\mathrm{a}}$ \\
\hline $2 \times$ LAD & $2,89^{c, d}$ & $2,81^{a, b}$ & $2,73^{a, b, c}$ & $2,68^{\mathrm{a}, \mathrm{b}, \mathrm{c}, \mathrm{d}}$ & $2,71^{\mathrm{c}, \mathrm{d}}$ & $2,83^{b}$ \\
\hline $3 \times$ LAPB & $3,13^{c, d}$ & $2,40^{a, b}$ & $3,05^{b, c}$ & $2,51^{a, b, c, d}$ & $3,55^{d}$ & $2,76^{a, b}$ \\
\hline $3 \times$ LAD & $3,43^{b, c, d, e}$ & $2,73^{a, b}$ & $3,0^{a, b, c}$ & $2,67^{a, b, c, d}$ & $2,27^{a, b, c, d}$ & $2,60^{a, b}$ \\
\hline $3 \times$ LAPD & $3,43^{\mathrm{d}, \mathrm{e}}$ & $2,87^{a, b}$ & $3,28^{b, c}$ & $3,08^{c, d}$ & $2,03^{a, b, c}$ & $2,97^{a, b}$ \\
\hline $3 \times$ LAE & $4,31^{\mathrm{e}}$ & $2,63^{a, b}$ & $3,40^{\mathrm{C}}$ & $3,16^{d}$ & $2,66^{b, c, d}$ & $2,51^{a, b}$ \\
\hline $3 \times \mathrm{LAB}$ & $2,04^{a}$ & $1,97^{a}$ & $1,96^{a}$ & $2,09^{a, b}$ & $1,75^{a}$ & $2,17^{a, b}$ \\
\hline $3 \times$ LAPE & $2,41^{a, b, c}$ & $2,38^{a}$ & $2,50^{\mathrm{a}, \mathrm{b}, \mathrm{c}}$ & $2,21^{a, b}$ & $2,09^{a, b, c}$ & $2,25^{a, b}$ \\
\hline
\end{tabular}

Grupos com a mesma letra não possuem diferença estatisticamente significante entre si

$\mathrm{Na}$ tabela 8 foi realizada comparação entre as médias de profundidade de sondagem entre faixas etárias e tipos de fissura por sextante. Os grupos com a mesma letra não possuem diferença estatisticamente significante entre si. Para um melhor entendimento, os resultados foram divididos por faixa etária.

Para faixa etária 1 (15 a 25 anos) não houve diferença estatisticamente significante entre os indivíduos com as fissuras LAPB, LAPE e LAE. Na faixa etária 2, de 26 a 35 anos de idade, pode-se observar que somente nos indivíduos com as fissuras LAPD e LAD foram diferentes das demais. Todos os tipos de fissura da faixa etária 3 foram diferentes estatisticamente entre si quanto à profundidade de sondagem. 
Tabela 9. Teste de Tukey - Comparação das médias de profundidade de sondagem ( $\mathrm{mm}$ ) entre os sextantes e tipos de fissuras dos indivíduos de 15 a 25 anos.

\begin{tabular}{lcccccc}
\hline Sextantes & \multicolumn{5}{c}{ Tipos de fissuras } \\
& LAPE & LAB & LAPD & LAPB & LAE & LAD \\
\hline 1 & $2,46^{\mathrm{c}}$ & $2,24^{\mathrm{b}}$ & $2,89^{\mathrm{c}}$ & $2,46^{\mathrm{b}, \mathrm{c}}$ & $2,50^{\mathrm{b}, \mathrm{c}}$ & $2,52^{\mathrm{c}}$ \\
2 & $2,27^{\mathrm{b}}$ & $2,31^{\mathrm{b}}$ & $2,65^{\mathrm{b}}$ & $2,58^{\mathrm{c}}$ & $2,33^{\mathrm{a}, \mathrm{b}}$ & $2,21^{\mathrm{ab}}$ \\
3 & $2,50^{\mathrm{c}}$ & $2,37^{\mathrm{b}}$ & $2,69^{\mathrm{b}, \mathrm{c}}$ & $2,41^{\mathrm{b}, \mathrm{c}}$ & $2,60^{\mathrm{c}}$ & $2,44^{\mathrm{b}, \mathrm{c}}$ \\
4 & $2,25^{\mathrm{b}}$ & $2,17^{\mathrm{b}}$ & $2,22^{\mathrm{a}}$ & $2,16^{\mathrm{a}}$ & $2,12^{\mathrm{a}}$ & $2,21^{\mathrm{a}, \mathrm{b}}$ \\
5 & $1,96^{\mathrm{a}}$ & $1,90^{\mathrm{a}}$ & $2,03^{\mathrm{a}}$ & $2,10^{\mathrm{a}}$ & $2,10^{\mathrm{a}}$ & $2,04^{\mathrm{a}}$ \\
6 & $2,23^{\mathrm{b}}$ & $2,19^{\mathrm{a}}$ & $2,52^{\mathrm{b}}$ & $2,35^{\mathrm{b}}$ & $2,50^{\mathrm{b}, \mathrm{c}}$ & $2,40^{\mathrm{b}, \mathrm{c}}$ \\
\hline
\end{tabular}

Grupos com a mesma letra não possuem diferença estatisticamente significante entre si

A comparação entre as médias de profundidade de sondagem mostrou diferença estatisticamente significante na fissura LAPE, do sextante $1 \mathrm{com} \mathrm{2,} \mathrm{4,} 5$ e 6; do sextante 2 com o 1, 3 e 5; do sextante 3 com 2, 4 e 5, do sextante 4 com 1, 3 e 5; do sextante 5 com todos os demais e do sextante 6 com o sextante 1, 3, e 5. Na fissura LAB os sextantes 5 e 6 não apresentam diferenças estatisticamente significantes entre si assim como os sextantes 1, 2, 3 e 4. Na fissura LAPD não houve diferença estatística entre os sextantes 4 - 5 e também entre os sextantes 2 - 6; as demais comparações foram estatisticamente significantes. Os sextantes 4 - 5 não foram estatisticamente diferentes na fissura LAPB e LAE e em ambos os tipos de fissura no sextante 2 tiveram diferença estatisticamente significante quando comparados com os demais sextantes. Na fissura LAD podemos observar que os sextantes 1 e 5 são diferentes dos demais (tabela 9).

Tabela 10. Teste de Tukey - Comparação das médias de profundidade de sondagem (mm) entre os sextantes e tipos de fissuras dos indivíduos de 26 a 35 anos.

\begin{tabular}{lcccccc}
\hline Sextantes & \multicolumn{5}{c}{ Tipos de Fissuras } \\
& LAPE & LAB & LAPD & LAPB & LAE & LAD \\
\hline 1 & $2,70^{\mathrm{c}}$ & $2,51^{\mathrm{b}}$ & $2,42^{\mathrm{b}, \mathrm{c}}$ & $2,54^{\mathrm{a}}$ & $2,85^{\mathrm{c}}$ & $2,89^{\mathrm{a}}$ \\
2 & $2,57^{\mathrm{b}, \mathrm{c}}$ & $20,1^{\mathrm{a}}$ & $2,37^{\mathrm{b}}$ & $3,18^{\mathrm{b}}$ & $2,52^{\mathrm{b}}$ & $2,81^{\mathrm{a}}$ \\
3 & $2,68^{\mathrm{c}}$ & $2,26^{\mathrm{a}, \mathrm{b}}$ & $2,72^{\mathrm{c}}$ & $2,81^{\mathrm{a}, \mathrm{b}}$ & $2,83^{\mathrm{c}}$ & $2,73^{\mathrm{a}}$ \\
4 & $2,35^{\mathrm{a}, \mathrm{b}}$ & $1,98^{\mathrm{a}}$ & $2,18^{\mathrm{a}, \mathrm{b}}$ & $2,70^{\mathrm{a}}$ & $2,68^{\mathrm{b}, \mathrm{c}}$ & $2,68^{\mathrm{a}}$ \\
5 & $2,23^{\mathrm{a}}$ & $1,96^{\mathrm{a}}$ & $1,87^{\mathrm{a}}$ & $2,52^{\mathrm{a}}$ & $2,25^{\mathrm{a}}$ & $2,71^{\mathrm{a}}$ \\
6 & $2,39^{\mathrm{a}, \mathrm{b}}$ & $2,07^{\mathrm{a}}$ & $2,14^{\mathrm{a}, \mathrm{b}}$ & $2,53^{\mathrm{a}}$ & $2,57^{\mathrm{b}}$ & $2,83^{\mathrm{a}}$ \\
\hline
\end{tabular}

Grupos com a mesma letra não possuem diferença estatisticamente significante entre si

$\mathrm{Na}$ tabela 10 estão descritas as comparações das médias de profundidade de sondagem entre os sextantes e tipos de fissura nos indivíduos de 26 a 35 anos. Na fissura LAPE os únicos sextantes com diferença estatisticamente significante em relação aos 
demais são 1, 2 e cinco e na fissura LAB são um e três. O sextante dois possui diferença estatisticamente significante aos demais somente nas fissuras LAPE, LAPD e LAPB. Na fissura LAE somente há diferença estatística entre os sextantes quatro e cinco com os demais. Não houve diferença estatisticamente significante entre os sextantes da fissura LAD.

Tabela 11. Teste de Tukey - Comparação das médias de profundidade de sondagem ( $\mathrm{mm}$ ) entre os sextantes e tipos de fissuras dos indivíduos de 36 a 49 anos.

\begin{tabular}{lcccccc}
\hline Sextantes & \multicolumn{5}{c}{ Tipos de fissuras } \\
& LAPE & LAB & LAPD & LAPB & LAE & LAD \\
\hline 1 & $2,44^{\mathrm{a}, \mathrm{b}}$ & $2,04^{\mathrm{a}, \mathrm{b}}$ & $2,88^{\mathrm{b}, \mathrm{c}}$ & $3,22^{\mathrm{b}}$ & $4,31^{\mathrm{c}}$ & $3,43^{\mathrm{c}}$ \\
2 & $2,42^{\mathrm{a}, \mathrm{b}}$ & $1,97^{\mathrm{a}, \mathrm{b}}$ & $2,55^{\mathrm{a}, \mathrm{b}}$ & $2,40^{\mathrm{a}, \mathrm{b}}$ & $2,63^{\mathrm{a}}$ & $2,73^{\mathrm{a}, \mathrm{b}}$ \\
3 & $2,58^{\mathrm{b}}$ & $1,96^{\mathrm{a}, \mathrm{b}}$ & $3,08^{\mathrm{c}}$ & $2,98^{\mathrm{b}}$ & $3,40^{\mathrm{b}}$ & $3,00^{\mathrm{b}, \mathrm{c}}$ \\
4 & $2,23^{\mathrm{a}, \mathrm{b}}$ & $2,09^{\mathrm{b}}$ & $2,40^{\mathrm{a}}$ & $2,52^{\mathrm{a}, \mathrm{b}}$ & $3,16^{\mathrm{b}}$ & $2,67^{\mathrm{a}, \mathrm{b}}$ \\
5 & $2,09^{\mathrm{a}}$ & $1,75^{\mathrm{a}}$ & $2,85^{\mathrm{a}, \mathrm{b}, \mathrm{c}}$ & $2,13^{\mathrm{a}}$ & $2,66^{\mathrm{a}}$ & $2,27^{\mathrm{a}}$ \\
6 & $2,18^{\mathrm{a}}$ & $2,17^{\mathrm{b}}$ & $2,97^{\mathrm{b}, \mathrm{c}}$ & $2,95^{\mathrm{a}}$ & $2,51^{\mathrm{a}}$ & $2,60^{\mathrm{a}, \mathrm{b}}$ \\
\hline
\end{tabular}

Grupos com a mesma letra não possuem diferença estatisticamente significante entre si

Nos indivíduos de 36 a 49 anos, a comparação entre as médias de profundidade de sondagem entre os sextantes e tipo de fissura, demonstrou diferença estatisticamente significante entre várias associações. Na fissura LAPE houve diferença entre o sextante 3 com todos os demais. O sextante 2 não teve diferença estatística com o 1 e 4 .

$\mathrm{Na}$ fissura de lábio e alvéolo bilateral (LAB) não houve diferença estatística entre os sextantes superiores (1, 2 e 3 ) e houve entre o sextante 5 com os demais.

Todos os sextantes da fissura LAPD foram diferentes entre si e essa diferença foi estatisticamente significante.

Os sextantes superiores na fissura LAPB foram diferentes dos inferiores, exceto entre o sextante 2 e 4 . Não houve diferença estatisticamente significante entre os sextantes 1- 3, 2 - 4, e 5 - 6.

A comparação entre as médias dos sextantes da fissura de lábio e alvéolo do lado esquerdo (LAE) e lábio e alvéolo do lado esquerdo demonstrou que a diferença entre o sextante 1 e os demais foi estatisticamente significante (tabela 11). 
Tabela 12. Correlação de Pearson - Comparação da profundidade de sondagem ( $\mathrm{mm}$ ) entre os sextantes.

\begin{tabular}{|c|c|c|c|c|c|c|c|}
\hline & & 1 & 2 & 3 & 4 & 5 & 6 \\
\hline \multirow[t]{2}{*}{1} & $r$ & 1 & 0,60 & 0,74 & 0,67 & 0,67 & 0,63 \\
\hline & $p$ & $\square$ & $p<0,001^{*}$ & $p<0,001^{*}$ & $p<0,001^{*}$ & $p<0,001^{*}$ & $\mathrm{p}<0,001^{*}$ \\
\hline \multirow[t]{2}{*}{2} & $r$ & 0,60 & 1 & 0,65 & 0,60 & 0,65 & 0,59 \\
\hline & $p$ & $p<0,001^{*}$ & & $p<0,001^{*}$ & $p<0,001^{*}$ & $p<0,001^{*}$ & $p<0,001^{*}$ \\
\hline \multirow[t]{2}{*}{3} & $r$ & 0,74 & 0,65 & 1 & 0,63 & 0,63 & 0,66 \\
\hline & $p$ & $p<0,001^{*}$ & $p<0,001^{*}$ & & $\mathrm{p}<0,001^{*}$ & $p<0,001^{*}$ & $p<0,001^{*}$ \\
\hline \multirow[t]{2}{*}{4} & $r$ & 0,67 & 0,60 & 0,63 & 1 & 0,71 & 0,68 \\
\hline & $p$ & $p<0,001^{*}$ & $p<0,001^{*}$ & $p<0,001^{*}$ & & $p<0,001^{*}$ & $p<0,001^{*}$ \\
\hline \multirow[t]{2}{*}{5} & $r$ & 0,67 & 0,65 & 0,63 & 0,71 & 1 & 0,75 \\
\hline & $p$ & $p<0,001^{*}$ & $p<0,001^{*}$ & $p<0,001^{*}$ & $p<0,001^{*}$ & & $p<0,001^{*}$ \\
\hline \multirow[t]{2}{*}{6} & $r$ & 0,63 & 0,59 & 0,66 & 0,68 & 0,75 & 1 \\
\hline & $p$ & $p<0,001^{*}$ & $p<0,001^{*}$ & $p<0,001^{*}$ & $p<0,001^{*}$ & $p<0,001^{*}$ & 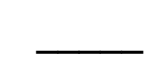 \\
\hline
\end{tabular}

* Diferença estatisticamente significante

As correlações entre os sextantes quanto à profundidade de sondagem foram positivas, fortes e significantes. Houve forte correlação entre os sextantes 1 x 3 , 4 x 5 e 5 x 6, todas as demais foram médias (tabela 12). 
Tabela 13. Médias e desvios padrão do nível de inserção clínica $(\mathrm{mm})$ por faixas etárias, gêneros, tipos de fissuras dos sextantes superiores.

\begin{tabular}{|c|c|c|c|c|c|c|c|c|}
\hline \multirow{2}{*}{$\begin{array}{l}\text { Faixas } \\
\text { Etárias }\end{array}$} & \multirow[t]{2}{*}{ Gêneros } & \multirow{2}{*}{$\begin{array}{l}\text { Tipos de } \\
\text { fissuras }\end{array}$} & \multicolumn{2}{|c|}{ S1 } & \multicolumn{2}{|c|}{ S2 } & \multicolumn{2}{|c|}{ S3 } \\
\hline & & & Média & $d p$ & Média & $d p$ & Média & $d p$ \\
\hline \multirow[t]{12}{*}{$15-25$} & $M$ & LAPE & 1,58 & 0,767 & 1,38 & 0,650 & 1,58 & 0,779 \\
\hline & $M$ & LAB & 1,41 & 0,431 & 1,41 & 0,620 & 1,54 & 0,512 \\
\hline & $M$ & LAPD & 2,09 & 1,430 & 2,02 & 1,353 & 1,81 & 0,775 \\
\hline & $\mathrm{M}$ & LAPB & 1,45 & 0,527 & 1,59 & 0,629 & 1,37 & 0,518 \\
\hline & $\mathrm{M}$ & LAE & 1,14 & 0,457 & 1,03 & 0,580 & 0,88 & 0,412 \\
\hline & $\mathrm{M}$ & LAD & 1,26 & 0,768 & 1,06 & 0,631 & 1,25 & 0,633 \\
\hline & $\mathrm{F}$ & LAPE & 1,46 & 0,770 & 1,37 & 0,690 & 1,54 & 0,787 \\
\hline & $F$ & LAB & 1,45 & 0,442 & 1,40 & 0,511 & 1,68 & 0,608 \\
\hline & $\mathrm{F}$ & LAPD & 2,15 & 1,559 & 2,01 & 1,361 & 1,75 & 0,905 \\
\hline & $F$ & LAPB & 1,36 & 0,376 & 1,39 & 0,529 & 1,32 & 0,528 \\
\hline & $\mathrm{F}$ & LAE & 0,97 & 0,486 & 1,14 & 0,481 & 0,78 & 0,448 \\
\hline & $\mathrm{F}$ & LAD & 1,30 & 0,727 & 1,04 & 0,650 & 1,19 & 0,507 \\
\hline \multirow[t]{12}{*}{$26-35$} & $M$ & LAPE & 1,67 & 0,612 & 1,57 & 0,788 & 1,70 & 0,771 \\
\hline & $M$ & LAB & 1,56 & 0,397 & 1,08 & 0,205 & 1,40 & 0,400 \\
\hline & $M$ & LAPD & 1,77 & 0,843 & 1,63 & 1,095 & 1,66 & 1,222 \\
\hline & $M$ & LAPB & 1,70 & 0,600 & 1,97 & 0,689 & 1,86 & 0,563 \\
\hline & $M$ & LAE & 1,60 & 0,628 & 1,34 & 0,527 & 1,56 & 0,796 \\
\hline & $M$ & LAD & 1,77 & 0,311 & 1,73 & 0,676 & 1,49 & 0,337 \\
\hline & $F$ & LAPE & 1,70 & 0,699 & 1,70 & 0,941 & 1,69 & 0,737 \\
\hline & $F$ & LAB & 1,50 & 0,495 & 1,08 & 0,249 & 1,42 & 0,370 \\
\hline & $F$ & LAPD & 1,85 & 1,345 & 1,56 & 1,244 & 1,83 & 1,139 \\
\hline & $F$ & LAPB & 1,88 & 0,593 & 2,39 & 0,645 & 1,96 & 0,425 \\
\hline & $F$ & LAE & 1,50 & 0,654 & 1,20 & 0,562 & 1,63 & 0,656 \\
\hline & $\mathrm{F}$ & LAD & 1,48 & 0,164 & 1,74 & 0,723 & 1,22 & 0,164 \\
\hline \multirow[t]{12}{*}{$36-49$} & $M$ & LAPE & 2,60 & 0,782 & 1,97 & 1,134 & 2,15 & 0,841 \\
\hline & $M$ & LAB & 1,98 & 0,438 & 1,90 & 0,274 & 1,98 & 0,712 \\
\hline & $M$ & LAPD & 1,60 & 0,000 & 1,50 & 0,000 & 1,60 & 0,000 \\
\hline & $M$ & LAPB & 2,28 & 0,096 & 2,25 & 0,614 & 2,90 & 1,092 \\
\hline & $M$ & LAE & 2,38 & 0,492 & 1,58 & 0,320 & 3,05 & 1,179 \\
\hline & M & LAD & 2,30 & 0,707 & 1,80 & 0,141 & 2,50 & 1,131 \\
\hline & $\mathrm{F}$ & LAPE & 2,16 & 0,913 & 1,74 & 0,914 & 1,81 & 0,811 \\
\hline & $\mathrm{F}$ & LAB & 1,88 & 0,392 & 1,83 & 0,339 & 1,87 & 0,731 \\
\hline & $\mathrm{F}$ & LAPD & 1,65 & 0,071 & 1,25 & 0,354 & 1,70 & 0,141 \\
\hline & $\mathrm{F}$ & LAPB & 2,80 & 0,849 & 2,00 & 0,283 & 2,95 & 0,919 \\
\hline & $\mathrm{F}$ & LAE & 2,50 & 0,520 & 1,50 & 0,346 & 2,67 & 1,097 \\
\hline & $\mathrm{F}$ & LAD & 1,80 & 0,000 & 1,90 & 0,000 & 1,70 & 0,000 \\
\hline
\end{tabular}


Tabela 14. Médias e desvios padrão do nível de inserção clínica $(\mathrm{mm})$ por faixas etárias, gênero, tipos de fissuras dos sextantes inferiores.

\begin{tabular}{|c|c|c|c|c|c|c|c|c|}
\hline \multirow{2}{*}{$\begin{array}{l}\text { Faixas } \\
\text { Etárias }\end{array}$} & \multirow[t]{2}{*}{ Gêneros } & \multirow{2}{*}{$\begin{array}{l}\text { Tipos de } \\
\text { fissuras }\end{array}$} & \multicolumn{2}{|c|}{ S4 } & \multicolumn{2}{|c|}{ S5 } & \multicolumn{2}{|c|}{ S6 } \\
\hline & & & Média & $d p$ & Média & $d p$ & Média & $d p$ \\
\hline \multirow[t]{12}{*}{$15-25$} & $\bar{M}$ & LAPE & 1,29 & 0,675 & 1,08 & 0,555 & 1,26 & 0,604 \\
\hline & M & LAB & 1,34 & 0,538 & 1,15 & 0,376 & 1,36 & 0,527 \\
\hline & M & LAPD & 1,52 & 0,955 & 1,38 & 0,995 & 1,84 & 1,096 \\
\hline & M & LAPB & 1,33 & 0,451 & 1,27 & 0,411 & 1,51 & 0,470 \\
\hline & M & LAE & 1,37 & 1,113 & 1,39 & 1,559 & 1,36 & 0,572 \\
\hline & M & LAD & 0,92 & 0,471 & 1,08 & 0,839 & 1,08 & 0,492 \\
\hline & $F$ & LAPE & 1,26 & 0,683 & 1,09 & 0,577 & 1,23 & 0,593 \\
\hline & $F$ & LAB & 1,41 & 0,514 & 1,19 & 0,438 & 1,29 & 0,427 \\
\hline & $F$ & LAPD & 1,51 & 1,044 & 1,42 & 1,082 & 1,79 & 1,172 \\
\hline & $F$ & LAPB & 1,29 & 0,442 & 1,18 & 0,377 & 1,42 & 0,454 \\
\hline & $F$ & LAE & 1,37 & 0,896 & 1,79 & 2,017 & 1,27 & 0,458 \\
\hline & $F$ & LAD & 0,95 & 0,470 & 1,03 & 0,896 & 1,08 & 0,506 \\
\hline \multirow[t]{12}{*}{$26-35$} & $M$ & LAPE & 1,77 & 0,779 & 1,42 & 0,804 & 1,60 & 0,544 \\
\hline & M & LAB & 1,42 & 0,820 & 1,28 & 0,559 & 1,46 & 0,422 \\
\hline & M & LAPD & 2,76 & 1,951 & 1,57 & 0,670 & 1,98 & 1,387 \\
\hline & M & LAPB & 2,02 & 0,857 & 2,21 & 0,784 & 1,95 & 0,680 \\
\hline & M & LAE & 1,46 & 0,639 & 1,12 & 0,694 & 1,28 & 0,622 \\
\hline & M & LAD & 1,48 & 0,359 & 1,85 & 0,720 & 1,38 & 0,221 \\
\hline & $F$ & LAPE & 1,74 & 0,745 & 1,41 & 0,863 & 1,63 & 0,853 \\
\hline & $F$ & LAB & 1,14 & 0,313 & 1,24 & 0,590 & 1,48 & 0,383 \\
\hline & $F$ & LAPD & 2,29 & 1,482 & 1,51 & 0,530 & 2,15 & 1,476 \\
\hline & $F$ & LAPB & 2,06 & 0,686 & 2,21 & 0,426 & 2,11 & 0,521 \\
\hline & $F$ & LAE & 1,32 & 0,685 & 1,08 & 0,618 & 1,37 & 0,565 \\
\hline & $F$ & LAD & 1,40 & 0,464 & 1,66 & 0,730 & 1,74 & 0,619 \\
\hline \multirow[t]{12}{*}{$36-49$} & $M$ & LAPE & 2,03 & 0,572 & 2,08 & 0,739 & 1,50 & 0,559 \\
\hline & M & LAB & 2,10 & 0,548 & 2,00 & 0,274 & 2,34 & 0,493 \\
\hline & M & LAPD & 1,40 & 0,000 & 1,70 & 0,000 & 1,70 & 0,000 \\
\hline & M & LAPB & 1,98 & 1,069 & 1,20 & 0,337 & 2,40 & 0,163 \\
\hline & M & LAE & 3,40 & 1,369 & 2,13 & 0,645 & 2,83 & 1,524 \\
\hline & M & LAD & 3,70 & 0,990 & 1,65 & 0,919 & 2,65 & 1,909 \\
\hline & $F$ & LAPE & 1,87 & 0,553 & 1,80 & 0,835 & 1,59 & 0,495 \\
\hline & $F$ & LAB & 1,97 & 0,489 & 1,97 & 0,258 & 2,18 & 0,471 \\
\hline & $F$ & LAPD & 1,60 & 0,283 & 1,20 & 0,707 & 1,25 & 0,636 \\
\hline & $F$ & LAPB & 2,50 & 0,566 & 1,35 & 0,495 & 2,50 & 0,141 \\
\hline & $F$ & LAE & 3,43 & 1,674 & 1,93 & 0,635 & 2,93 & 1,848 \\
\hline & $F$ & LAD & 3,00 & 0,000 & 1,00 & 0,000 & 1,30 & 0,000 \\
\hline
\end{tabular}

Nas tabelas 13 e 14 estão descritas as médias e desvio padrão do nível de inserção clínico de cada sextante, divididos quanto à faixa etária, gênero e tipo de fissura. A maior média de cada sextante foi: $2,80 \mathrm{~mm}$ (sextante 1, fissura LAPB, gênero feminino, faixa etária de 36 a 49 anos), 2,39 mm (sextante 2, fissura LAPB, gênero feminino, faixa etária de 26 a 35 anos, 2,95 mm (sextante 3, fissura LAPB, gênero feminino, faixa etária de 36 a 49 anos), $3,70 \mathrm{~mm}$ (sextante 4 , fissura $L A D$, gênero masculino e da faixa etária de 36 a 49 anos), 2,21 
$\mathrm{mm}$ (sextante 5, fissura LAPB, de ambos os gêneros, na faixa etária de 26 a 35 anos), 2,93 mm (sextante 6 fissura LAE, gênero feminino, faixa etária de 36 a 49 anos).

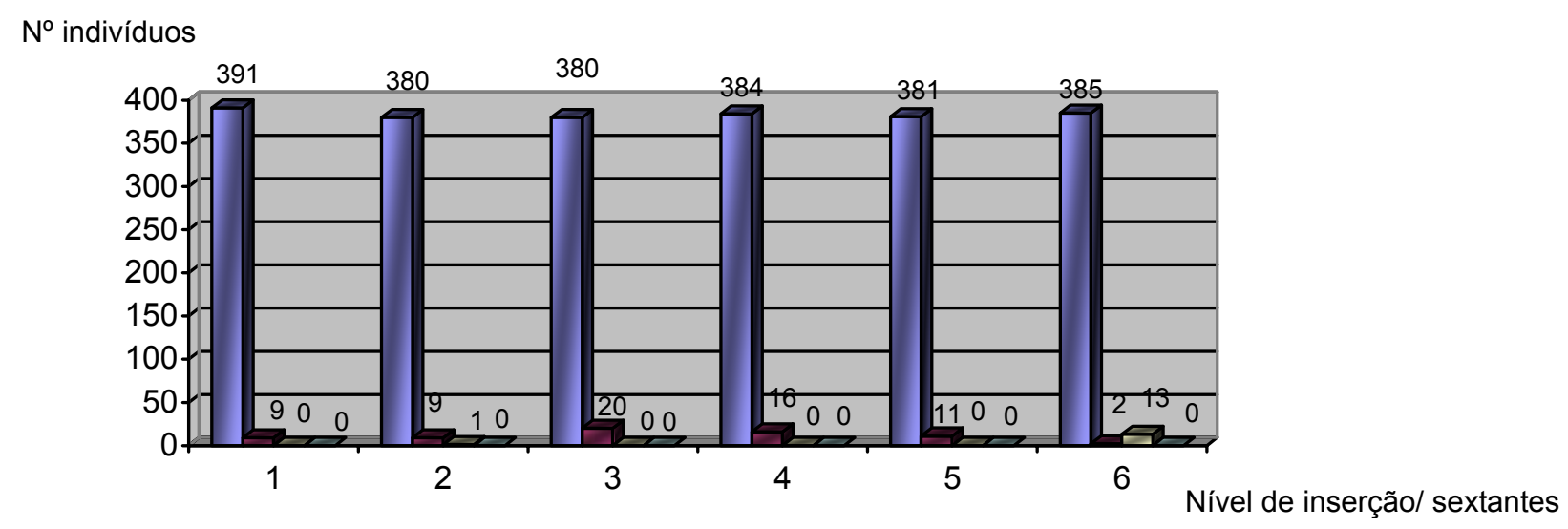

$\square<$ ou igual $3 \mathrm{~mm} \square>3$ e $<4 \mathrm{~mm} \square 4-6 \mathrm{~mm} \square>6 \mathrm{~mm}$

Figura 13. Distribuição das medidas do nível de inserção clínico por sextante.

A medida do nível de inserção clínico menor ou igual a $3 \mathrm{~mm}$ foi a mais prevalente na maioria dos sextantes. Considerando-se os valores médios, não houve nenhum sextante com nível de inserção maior que 6 mm (figura 13).

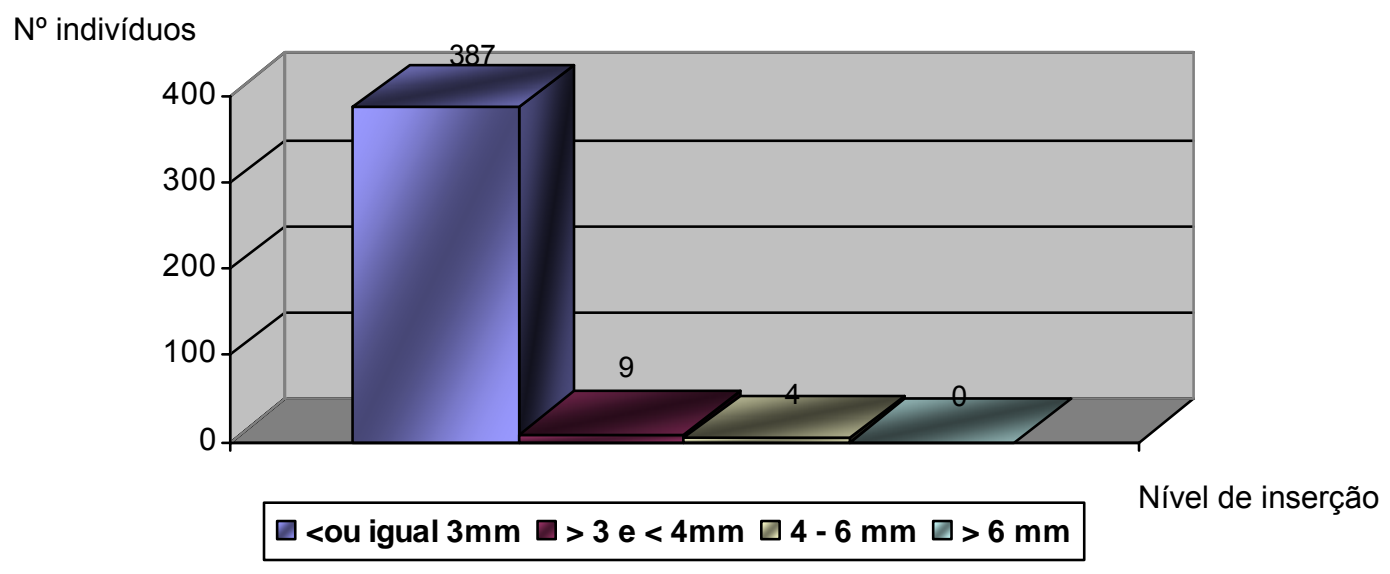

Figura 14. Distribuição das medidas do nível de inserção clínco da amostra.

Quando foram observados os dados do nível de inserção para a média geral da amostra os mesmos resultados foram observados, poucos indivíduos apresentaram medidas de 4 a $6 \mathrm{~mm}(\mathrm{n}=4)$, nenhum com médias maiores que $6 \mathrm{~mm}$. 387 indivíduos apresentaram nível de inserção clínica menor ou igual a $3 \mathrm{~mm}$ (figura 14). 
Tabela 15. Comparação do nível de inserção clínico $(\mathrm{mm})$ entre faixas etárias (1), gêneros (2), tipos de fissuras (3) e sextante (4) - ANOVA (quatro critérios).

\begin{tabular}{lc}
\hline Critérios & $p$ \\
\hline 1 & $\mathrm{p}<0,001^{*}$ \\
2 & 0,491 \\
3 & 0,326 \\
4 & $\mathrm{p}<0,001^{*}$ \\
$1 \times 2$ & 0,798 \\
$1 \times 3$ & $0,0093^{*}$ \\
$2 \times 3$ & 0,970 \\
$1 \times 4$ & $\mathrm{p}<0,001^{*}$ \\
$2 \times 4$ & 0,988 \\
$3 \times 4$ & $\mathrm{p}<0,001^{*}$ \\
$1 \times 2 \times 3$ & 0,999 \\
$1 \times 2 \times 4$ & 0,517 \\
$1 \times 3 \times 4$ & $\mathrm{p}<0,001^{*}$ \\
$2 \times 3 \times 4$ & 0,998 \\
$1 \times 2 \times 3 \times 4$ & 0,999 \\
\hline * Diferença estatisticamente significante
\end{tabular}

Ao compararmos o nível de inserção clínico entre faixa etária, gênero, tipo de fissura e sextante constatou-se que não houve diferença estatisticamente significante nas comparações entre faixa etária e gênero; gênero e tipo de fissura; gênero e sextante; faixa etária, gênero e tipo de fissura; tipo de fissura, gênero e sextante, gênero, tipo de fissura e sextante; faixa etária, gênero, tipo de fissura e sextante. Não houve diferença estatisticamente significante entre o gênero e as demais variáveis (tabela 15). 
Tabela 16. Médias e desvios padrão do nível de inserção clínico por faixas etárias e tipos de fissuras dos sextantes superiores.

\begin{tabular}{lcrrrrrr}
\hline Faixas & Tipos de & \multicolumn{2}{c}{ S1 } & \multicolumn{2}{c}{$S 2$} & \multicolumn{2}{c}{$S 3$} \\
etárias & fissuras & Média & \multicolumn{1}{c}{$d p$} & Média & \multicolumn{1}{c}{$d p$} & Média & $d p$ \\
\hline $15-25$ & LAPE & 1,51 & 0,765 & 1,38 & 0,668 & 1,56 & 0,778 \\
& LAB & 1,43 & 0,429 & 1,40 & 0,555 & 1,61 & 0,558 \\
& LAPD & 2,13 & 1,478 & 2,01 & 1,332 & 1,77 & 0,837 \\
& LAPB & 1,40 & 0,454 & 1,49 & 0,584 & 1,34 & 0,519 \\
& LAE & $\mathbf{1 , 0 5}$ & 0,470 & 1,08 & 0,526 & 0,83 & 0,425 \\
& LAD & 1,28 & 0,728 & 1,05 & 0,625 & 1,22 & 0,556 \\
\hline $26-35$ & LAPE & 1,68 & 0,645 & 1,63 & 0,853 & 1,70 & 0,746 \\
& LAB & 1,53 & 0,424 & 1,08 & 0,215 & 1,41 & 0,363 \\
& LAPD & 1,81 & 1,060 & 1,60 & 1,129 & 1,73 & 1,154 \\
& LAPB & 1,78 & 0,588 & 2,16 & 0,685 & 1,90 & 0,495 \\
& LAE & 1,55 & 0,612 & 1,26 & 0,524 & 1,60 & 0,686 \\
& LAD & 1,69 & 0,304 & 1,74 & 0,667 & 1,41 & 0,318 \\
\hline $36-49$ & LAPE & 2,36 & 0,851 & 1,85 & 0,984 & 1,97 & 0,809 \\
& LAB & 1,93 & 0,395 & 1,86 & 0,298 & 1,92 & 0,688 \\
& LAPD & 1,63 & 0,050 & 1,38 & 0,250 & 1,65 & 0,100 \\
& LAPB & 2,45 & 0,472 & $\mathbf{2 , 1 7}$ & 0,509 & $\mathbf{2 , 9 2}$ & 0,941 \\
& LAE & 2,43 & 0,464 & 1,54 & 0,305 & 2,89 & 1,067 \\
& LAD & 2,13 & 0,577 & 1,83 & 0,115 & 2,23 & 0,924 \\
\hline
\end{tabular}

Nos sextantes superiores a média do nível de inserção clínico por faixa etária e tipo de fissura variou de 1,05 a 2,92 mm. A maior média foi na faixa etária de 36 a 49 anos, fissura LAPB no sextante 3 (tabela 16). 
Tabela 17. Médias e desvios padrão do nível de inserção clínico $(\mathrm{mm})$ por faixas etárias e tipos de fissuras dos sextantes inferiores.

\begin{tabular}{|c|c|c|c|c|c|c|c|}
\hline \multirow{2}{*}{$\begin{array}{l}\text { Faixas } \\
\text { Etárias }\end{array}$} & \multirow{2}{*}{$\begin{array}{l}\text { Tipos de } \\
\text { fissuras }\end{array}$} & \multicolumn{2}{|c|}{$S 4$} & \multicolumn{2}{|c|}{ S5 } & \multicolumn{2}{|c|}{ S6 } \\
\hline & & Média & $d p$ & Média & $d p$ & Média & $d p$ \\
\hline \multirow[t]{6}{*}{$15-25$} & LAPE & 1,27 & 0,675 & 1,09 & 0,563 & 1,25 & 0,594 \\
\hline & LAB & 1,37 & 0,516 & 1,17 & 0,402 & 1,33 & 0,470 \\
\hline & LAPD & 1,52 & 0,988 & 1,40 & 1,027 & 1,81 & 1,119 \\
\hline & LAPB & 1,31 & 0,443 & 1,23 & 0,394 & 1,46 & 0,460 \\
\hline & LAE & 1,37 & 0,991 & 1,59 & 1,781 & 1,32 & 0,511 \\
\hline & LAD & 0,93 & 0,459 & 1,05 & 0,848 & 1,08 & 0,486 \\
\hline \multirow[t]{6}{*}{$26-35$} & LAPE & 1,76 & 0,754 & 1,42 & 0,820 & 1,61 & 0,694 \\
\hline & LAB & 1,28 & 0,603 & 1,26 & 0,542 & 1,47 & 0,380 \\
\hline & LAPD & 2,55 & 1,725 & 1,54 & 0,595 & 2,06 & 1,387 \\
\hline & LAPB & 2,04 & 0,765 & 2,21 & 0,632 & 2,03 & 0,603 \\
\hline & $\mathrm{LAE}$ & 1,38 & 0,635 & 1,10 & 0,620 & 1,33 & 0,562 \\
\hline & LAD & 1,46 & 0,379 & 1,79 & 0,706 & 1,49 & 0,397 \\
\hline \multirow[t]{6}{*}{$36-49$} & LAPE & 1,95 & 0,544 & 1,93 & 0,773 & 1,55 & 0,504 \\
\hline & LAB & 2,03 & 0,494 & 1,98 & 0,252 & 2,25 & 0,463 \\
\hline & LAPD & 1,50 & 0,200 & 1,45 & 0,500 & 1,48 & 0,450 \\
\hline & LAPB & 2,15 & 0,907 & 1,25 & 0,351 & 2,43 & 0,151 \\
\hline & LAE & 3,41 & 1,368 & 2,04 & 0,594 & 2,87 & 1,517 \\
\hline & LAD & 3,47 & 0,808 & 1,43 & 0,751 & 2,20 & 1,559 \\
\hline
\end{tabular}

Na tabela 16 estão descritas as médias do nível de inserção clínico por faixa etária e tipo de fissura dos sextantes inferiores. As médias variaram de 0,93 a 3,47 mm e essa variação foi muito maior do que nos superiores. A maior média foi encontrada nos indivíduos mais velhos, fissura de lábio e alvéolo direita no sextante 4 (tabela 17).

A média do nível de inserção aumentou com o avanço da idade, nos indivíduos na faixa etária de 15 a 25 anos foi de $1,35 \mathrm{~mm}$, nos com idade entre 26 e 35 anos foi $1,58 \mathrm{~mm}$ e nos indivíduos mais velhos foi de $2,10 \mathrm{~mm}$.

Tabela 18. Comparação do nível de inserção clínico $(\mathrm{mm})$ entre faixas etárias (1), tipos de fissuras (2) e sextante (3) - ANOVA (três critérios).

\begin{tabular}{lc}
\hline Critérios & $p$ \\
\hline 1 & $\mathrm{p}<0,001^{*}$ \\
2 & $0,331^{*}$ \\
3 & $\mathrm{p}<0,001^{*}$ \\
$1 \times 2$ & $0,005^{*}$ \\
$1 \times 3$ & $\mathrm{p}<0,001^{*}$ \\
$2 \times 3$ & $\mathrm{p}<0,001^{*}$ \\
$1 \times 2 \times 3$ & $\mathrm{p}<0,001^{*}$ \\
\hline *
\end{tabular}

* Diferença estatisticamente significante 
Ao compararmos o nível de inserção clínico com as variáveis faixa etária, tipo de fissura e sextante constatou-se que não houve diferença estatisticamente significante entre os tipos de fissura e também a faixa etária, tipos de fissuras e sextantes (tabela 18).

Tabela 19. Teste de Tukey - Comparação das médias do nível de inserção clínico (mm) entre faixas etárias (1- 15 a 25 anos, 2- 26 a 35 anos, 3- 36 a 49 anos) e tipos de fissuras por sextante.

\begin{tabular}{|c|c|c|c|c|c|c|}
\hline \multirow{2}{*}{$\begin{array}{l}\text { Faixas etárias } \\
\text { x fissuras }\end{array}$} & \multicolumn{6}{|c|}{ Sextantes } \\
\hline & 1 & 2 & 3 & 4 & 5 & 6 \\
\hline $1 \times$ LAE & $1,05^{a}$ & $1,08^{a, b}$ & $0,83^{a}$ & $1,37^{\mathrm{a}, \mathrm{b}}$ & $1,59^{a, b}$ & $1,33^{a, b, c}$ \\
\hline $1 \times$ LAD & $1,28^{a, b}$ & $1,05^{\mathrm{a}}$ & $1,22^{a, b}$ & $0,93^{a}$ & $1,05^{a}$ & $1,08^{a}$ \\
\hline $1 \times$ LAPB & $1,40^{a, b, c}$ & $1,49^{a, b}$ & $1,34^{a, b}$ & $1,31^{\mathrm{a}, \mathrm{b}}$ & $1,23^{a, b}$ & $1,46^{a, b, c}$ \\
\hline $1 \times$ LAB & $1,43^{a, b, c, d}$ & $1,40^{a, b}$ & $1,41^{a, b}$ & $1,37^{\mathrm{a}, \mathrm{b}}$ & $1,17^{\mathrm{a}, \mathrm{b}}$ & $1,33^{a, b, c}$ \\
\hline $1 \times$ LAPE & $1,51^{a, b, c, d}$ & $1,38^{a, b}$ & $1,56^{b, c}$ & $1,27^{\mathrm{a}, \mathrm{b}}$ & $1,09^{a}$ & $1,25^{a, b}$ \\
\hline $1 \times$ LAPD & $2,13^{d}$ & $2,01^{b}$ & $1,77^{\mathrm{b}, \mathrm{c}, \mathrm{d}}$ & $1,52^{\mathrm{a}, \mathrm{b}}$ & $1,40^{a, b}$ & $1,81^{a, b, c, d}$ \\
\hline $2 \times$ LAB & $1,53^{a, b, c, d}$ & $1,08^{a, b}$ & $1,61^{b, c, d}$ & $1,28^{a, b}$ & $1,26^{a, b}$ & $1,47^{a, b, c}$ \\
\hline $2 \times$ LAE & $1,55^{a, b, c, d}$ & $1,26^{a, b}$ & $1,60^{a, b, c, d}$ & $1,38^{a, b}$ & $1,10^{a, b}$ & $1,33^{a, b, c}$ \\
\hline $2 \times$ LAPE & $1,68^{a, b, c, d}$ & $1,63^{a, b}$ & $1,70^{\mathrm{b}, \mathrm{c}, \mathrm{d}}$ & $1,76^{a, b, c}$ & $1,42^{a, b}$ & $1,61^{a, b, c, d}$ \\
\hline $2 \times$ LAD & $1,69^{a, b, c, d}$ & $1,74^{a, b}$ & $1,41^{a, b}$ & $1,46^{a, b}$ & $1,79^{a, b}$ & $1,49^{a, b, c, d}$ \\
\hline $2 \times$ LAPB & $1,78^{\mathrm{a}, \mathrm{b}, \mathrm{c}, \mathrm{d}}$ & $2,16^{b}$ & $1,90^{\mathrm{b}, \mathrm{c}, \mathrm{d}}$ & $2,04^{b, c, d}$ & $2,21^{b}$ & $2,03^{c, d}$ \\
\hline $2 \times$ LAPD & $1,81^{a, b, c, d}$ & $1,60^{a, b}$ & $1,73^{\mathrm{b}, \mathrm{c}, \mathrm{d}}$ & $2,55^{\mathrm{c}, \mathrm{d}}$ & $1,54^{a, b}$ & $2,06^{\mathrm{c}, \mathrm{d}}$ \\
\hline $3 \times L A B$ & $1,93^{a, b, c, d}$ & $1,86^{a, b}$ & $1,92^{b, c, d}$ & $2,03^{a, b, c, d}$ & $1,98^{a, b}$ & $2,25^{b, c, d}$ \\
\hline $3 \times L A D$ & $2,13^{a, b, c, d}$ & $1,83^{a, b}$ & $2,23^{a, b, c, d}$ & $3,47^{a, b, c}$ & $1,43^{a, b}$ & $2,20^{a, b, c, d}$ \\
\hline $3 \times$ LAPB & $2,18^{b, c, d}$ & $2,17^{\mathrm{a}, \mathrm{b}}$ & $2,52^{c, d}$ & $1,85^{\mathrm{a}, \mathrm{b}, \mathrm{c}}$ & $1,18^{a, b}$ & $2,06^{a, b, c, d}$ \\
\hline $3 \times$ LAPE & $2,31^{c, d}$ & $1,78^{a, b}$ & $1,91^{b, c, d}$ & $1,91^{\mathrm{a}, \mathrm{b}, \mathrm{c}}$ & $1,89^{a, b}$ & $1,53^{a, b, c, d}$ \\
\hline $3 \times$ LAE & $2,43^{b, c, d}$ & $1,54^{\mathrm{a}, \mathrm{b}}$ & $2,89^{d}$ & $3,41^{d}$ & $2,04^{a, b}$ & $2,87^{d}$ \\
\hline $3 \times$ LAPD & $2,60^{b, c, d}$ & $1,80^{a, b}$ & $2,13^{a, b, c, d}$ & $2,13^{\mathrm{a}, \mathrm{b}, \mathrm{c}, \mathrm{d}}$ & $2,28^{a, b}$ & $1,48^{\mathrm{a}, \mathrm{b}, \mathrm{c}, \mathrm{d}}$ \\
\hline
\end{tabular}

Grupos com a mesma letra não possuem diferença estatisticamente significante entre si

A comparação das médias do nível de inserção clínico entre faixas etárias e tipo de fissura por sextantes está descrita na tabela 19. Na faixa etária 1 não houve diferença estatisticamente significante somente entre as fissuras LAB e LAPE no sextante 1. Já no sextante 2 houve diferença estatisticamente significante somente entre os indivíduos com fissura LAD e LAPD. Houve diferença estatisticamente significante entre LAE, LAPE e LAPD no sextante 3 . No sextante 4 somente os com fissura LAD foi diferente estatisticamente significante dos demais tipos de fissura. Não houve diferença estatisticamente significante entre os com fissura de LAD e LAPB, LAB e LAPD; e entre LAD e LAPE, no sextante 6.

$\mathrm{Na}$ faixa etária 2, sextante 1 não houve diferença estatisticamente significante entre nenhum tipo de fissura. Tanto para o sextante 2 quanto para o 5 somente a fissura LAPB foi diferente das demais. No sextante 3 somente as fissuras LAE e LAD foram estatisticamente diferentes. As fissuras LAPE, LAPB e LAPD não foram diferentes no sextante 4. e no sextante 6, não houve diferença entre as fissuras LAB e LAE, LAPE e LAD, LAPB e LAPD. 
Para a faixa etária 3 somente a fissura LAPE foi diferente das demais no sextante 1. Não houve diferença estatisticamente significante entre nenhuma das fissuras dos sextantes 2 e 5 . No sextante 3 as fissuras LAPB e LAE foram diferentes. Somente a fissura LAE foi diferente das demais no sextante 4 . As fissuras LAB e LAE foram diferentes no sextante 6 .

Tabela 20. Teste de Tukey - Comparação das médias do nível de inserção clínico (mm) entre os sextantes dos indivíduos de 15 a 25 anos de idade e tipos de fissuras.

\begin{tabular}{lcccccc}
\hline Sextantes & \multicolumn{5}{c}{ Tipos de fissuras } \\
& LAPE & LAB & LAPD & LAPB & LAE & LAD \\
\hline 1 & $1,51^{\mathrm{d}}$ & $1,43^{\mathrm{b}, \mathrm{c}}$ & $2,13^{\mathrm{d}}$ & $1,40^{\mathrm{a}, \mathrm{b}}$ & $1,05^{\mathrm{a}, \mathrm{b}}$ & $1,28^{\mathrm{b}}$ \\
2 & $1,38^{\mathrm{c}}$ & $1,40^{\mathrm{a}, \mathrm{b}, \mathrm{c}}$ & $2,01^{\mathrm{c}, \mathrm{d}}$ & $1,49^{\mathrm{b}}$ & $1,08^{\mathrm{a}, \mathrm{b}}$ & $1,05^{\mathrm{a}, \mathrm{b}}$ \\
3 & $1,56^{\mathrm{d}}$ & $1,61^{\mathrm{c}}$ & $1,77^{\mathrm{b}}$ & $1,34^{\mathrm{a}, \mathrm{b}}$ & $0,83^{\mathrm{a}}$ & $1,22^{\mathrm{b}}$ \\
4 & $1,27^{\mathrm{b}, \mathrm{c}}$ & $1,37^{\mathrm{a}, \mathrm{b}, \mathrm{c}}$ & $1,52^{\mathrm{a}}$ & $1,31^{\mathrm{a}, \mathrm{b}}$ & $1,37^{\mathrm{a}, \mathrm{b}}$ & $0,93^{\mathrm{a}}$ \\
5 & $1,09^{\mathrm{a}}$ & $1,17^{\mathrm{a}}$ & $1,40^{\mathrm{a}}$ & $1,23^{\mathrm{a}}$ & $1,59^{\mathrm{b}}$ & $1,05^{\mathrm{a}, \mathrm{b}}$ \\
6 & $1,25^{\mathrm{b}}$ & $1,33^{\mathrm{a}, \mathrm{b}}$ & $1,81^{\mathrm{b}, \mathrm{c}}$ & $1,46^{\mathrm{b}}$ & $1,32^{\mathrm{a}, \mathrm{b}}$ & $1,08^{\mathrm{a}, \mathrm{b}}$ \\
\hline
\end{tabular}

Grupos com a mesma letra não possuem diferença estatisticamente significante entre si

$\mathrm{Na}$ tabela 20 podemos observar a comparação entre as médias do nível de inserção clinico entre os sextantes dos indivíduos com idade entre 15 e 25 anos de idade. Nos indivíduos com fissura de LAPE houve diferença estatisticamente significante entre todos os sextantes. Somente os sextantes 2 e 4 não tiveram diferença estatística nos indivíduos portadores de fissura LAB. Os sextantes 4 e 5 , dos indivíduos com LAPD, foram os únicos sextantes em que as diferenças não foram estatisticamente significantes. Na fissura LAPB não houve diferença estatisticamente significante entre os sextantes 1, 3 e 4 e entre os sextantes 2 e 6 ; o sextante 5 foi diferente estatisticamente em relação a todos os outros sextantes.

$\mathrm{Na}$ fissura LAE os sextantes 3 e 5 foram estatisticamente diferentes em relação a todos os outros. Na fissura LAD não houve diferença estatisticamente significante entre o sextante 1 e 3 , entre 2, 5 e 6 , o 4 foi diferente a todos os outros. 
Tabela 21. Teste de Tukey - Comparação das médias do nível de inserção clínico (mm) entre os sextantes dos indivíduos de 26 a 35 anos de idade e tipos de fissuras.

\begin{tabular}{lcccccc}
\hline Sextantes & \multicolumn{5}{c}{ Tipos de fissuras } \\
& LAPE & LAB & LAPD & LAPB & LAE & LAD \\
\hline 1 & $1,68^{\mathrm{b}}$ & $1,53^{\mathrm{b}}$ & $1,81^{\mathrm{a}, \mathrm{b}}$ & $1,78^{\mathrm{c}}$ & $1,55^{\mathrm{a}, \mathrm{b}}$ & $1,69^{\mathrm{a}, \mathrm{b}}$ \\
2 & $1,63^{\mathrm{a}, \mathrm{b}}$ & $1,08^{\mathrm{a}}$ & $1,60^{\mathrm{a}}$ & $2,16^{\mathrm{a}}$ & $1,26^{\mathrm{a}, \mathrm{b}}$ & $1,74^{\mathrm{a}, \mathrm{b}}$ \\
3 & $1,70^{\mathrm{b}}$ & $1,41^{\mathrm{a}, \mathrm{b}}$ & $1,73^{\mathrm{a}, \mathrm{b}}$ & $1,90^{\mathrm{a}}$ & $1,60^{\mathrm{a}}$ & $1,41^{\mathrm{a}}$ \\
4 & $1,76^{\mathrm{b}}$ & $1,28^{\mathrm{a}, \mathrm{b}}$ & $2,55^{\mathrm{b}}$ & $2,04^{\mathrm{a}}$ & $1,38^{\mathrm{a}, \mathrm{b}, \mathrm{c}}$ & $1,46^{\mathrm{a}, \mathrm{b}}$ \\
5 & $1,42^{\mathrm{a}}$ & $1,26^{\mathrm{a}, \mathrm{b}}$ & $1,54^{\mathrm{a}}$ & $2,21^{\mathrm{a}}$ & $1,10^{\mathrm{a}}$ & $1,79^{\mathrm{a}}$ \\
6 & $1,61^{\mathrm{a}, \mathrm{b}}$ & $1,47^{\mathrm{a}, \mathrm{b}}$ & $2,06^{\mathrm{a}, \mathrm{b}}$ & $2,03^{\mathrm{a}}$ & $1,33^{\mathrm{a}, \mathrm{b}, \mathrm{c}}$ & $1,49^{\mathrm{a}, \mathrm{b}}$ \\
\hline \multicolumn{5}{l}{ Grupos com a mesma letra não possuem diferença estatisticamente significante entre si }
\end{tabular}

Grupos com a mesma letra não possuem diferença estatisticamente significante entre si

Nos indivíduos com fissura LAPE, o sextante que engloba a própria fissura não foi estatisticamente diferente somente do sextante 6 e o 5 foi diferente de todos os outros. Nos indivíduos com $L A B$ os sextantes 3, 4, 5 e 6 não tiveram diferença estatística entre si, enquanto que os sextantes 1 e 2 foram diferentes entre si e entre os demais. Os sextantes 1, 3 e 6, e o 2 e 5 não tiveram diferença estatisticamente entre si nos indivíduos com LAPD. Somente o sextante 4 foi estatisticamente diferentes de todos os outros nos indivíduos portadores da fissura LAPB. Os sextantes 1 e 2 não foram diferentes tanto nos com fissura LAE quanto LAD, assim como entre os sextantes 3 e 5, 4 e 6 (tabela 21).

Tabela 22. Teste de Tukey - Comparação das médias do nível de inserção clínico ( $\mathrm{mm}$ ) entre os sextantes dos indivíduos de 36 a 49 anos e tipos de fissuras.

\begin{tabular}{lcccccc}
\hline Sextantes & \multicolumn{5}{c}{ Tipos de fissuras } \\
& LAPE & LAB & LAPD & LAPB & LAE & LAD \\
\hline 1 & $2,36^{\mathrm{b}}$ & $1,93^{\mathrm{a}}$ & $1,63^{\mathrm{a}}$ & $2,45^{\mathrm{b}}$ & $2,43^{\mathrm{a}, \mathrm{b}}$ & $2,13^{\mathrm{a}, \mathrm{b}}$ \\
2 & $1,85^{\mathrm{a}, \mathrm{b}}$ & $1,86^{\mathrm{a}}$ & $1,38^{\mathrm{a}}$ & $2,17^{\mathrm{a}, \mathrm{b}}$ & $1,54^{\mathrm{a}}$ & $1,83^{\mathrm{a}}$ \\
3 & $1,97^{\mathrm{a}, \mathrm{b}}$ & $1,92^{\mathrm{a}}$ & $1,65^{\mathrm{a}}$ & $2,92^{\mathrm{b}}$ & $2,89^{\mathrm{b}, \mathrm{c}}$ & $2,23^{\mathrm{a}, \mathrm{b}}$ \\
4 & $1,95^{\mathrm{a}, \mathrm{b}}$ & $2,03^{\mathrm{a}}$ & $1,50^{\mathrm{a}}$ & $2,15^{\mathrm{a}, \mathrm{b}}$ & $3,14^{\mathrm{c}}$ & $3,47^{\mathrm{b}}$ \\
5 & $1,93^{\mathrm{a}, \mathrm{b}}$ & $1,98^{\mathrm{a}}$ & $1,45^{\mathrm{a}}$ & $1,25^{\mathrm{a}}$ & $2,04^{\mathrm{a}, \mathrm{b}}$ & $1,43^{\mathrm{a}}$ \\
6 & $1,55^{\mathrm{a}}$ & $2,25^{\mathrm{b}}$ & $1,48^{\mathrm{a}}$ & $2,43^{\mathrm{b}}$ & $2,87^{\mathrm{b}, \mathrm{c}}$ & $2,20^{\mathrm{a}, \mathrm{b}}$ \\
\hline
\end{tabular}

Grupos com a mesma letra não possuem diferença estatisticamente significante entre si

A comparação entre as médias do nível de inserção clínico entre os sextantes dos indivíduos com idade entre 36 e 49 anos está descrita na tabela 22. Não houve diferença estatisticamente significante entre nenhum dos sextantes dos indivíduos com fissura LAPD. $\mathrm{Na}$ fissura LAPE, houve diferença somente do sextante 1 e do 6 entre si e entre os demais. Somente o sextante 6 foi diferente dos demais na fissura LAB. Na fissura LAPB, os sextantes 2 e 4, 1, 3 e 4, não foram estatisticamente diferentes entre si, já o sextante 5 foi diferente de todos os outros. A fissura LAE teve seus sextante 1 e 5 iguais e o 3 e 6 
também, já o 2 e o 3 foram diferentes entre todos. A fissura LAD os sextante 1, 3 e 6 foram iguais, 2 e 5 também, e o 4 foi diferente dos outros.

Tabela 23. Correlação de Pearson - Comparação do nível de inserção clínico (mm) entre os sextantes.

\begin{tabular}{|c|c|c|c|c|c|c|c|}
\hline & & 1 & 2 & 3 & 4 & 5 & 6 \\
\hline \multirow[t]{2}{*}{1} & $r$ & 1 & 0,78 & 0,80 & 0,61 & 0,55 & 0,68 \\
\hline & $p$ & 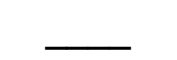 & $p<0,001^{*}$ & $p<0,001^{*}$ & $p<0,001^{*}$ & $p<0,001^{*}$ & $p<0,001^{*}$ \\
\hline \multirow[t]{2}{*}{2} & $r$ & 0,78 & 1 & 0,71 & 0,52 & 0,53 & 0,60 \\
\hline & $p$ & $p<0,001^{*}$ & $\bar{\square}$ & $p<0,001^{*}$ & $p<0,001^{*}$ & $p<0,001^{*}$ & $p<0,001^{*}$ \\
\hline \multirow[t]{2}{*}{3} & $r$ & 0,80 & 0,71 & 1 & 0,61 & 0,42 & 0,65 \\
\hline & $p$ & $p<0,001^{*}$ & $p<0,001^{*}$ & & $p<0,001^{*}$ & $p<0,001^{*}$ & $p<0,001^{*}$ \\
\hline \multirow[t]{2}{*}{4} & $r$ & 0,61 & 0,52 & 0,61 & 1 & 0,67 & 0,77 \\
\hline & $p$ & $p<0,001^{*}$ & $p<0,001^{*}$ & $p<0,001^{*}$ & & $p<0,001^{*}$ & $p<0,001^{*}$ \\
\hline \multirow[t]{2}{*}{5} & $r$ & 0,55 & 0,53 & 0,42 & 0,67 & 1 & 0,58 \\
\hline & $p$ & $p<0,001^{*}$ & $p<0,001^{*}$ & $p<0,001^{*}$ & $\mathrm{p}<0,001^{*}$ & 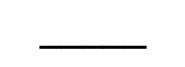 & $p<0,001^{*}$ \\
\hline \multirow[t]{2}{*}{6} & $r$ & 0,68 & 0,60 & 0,65 & 0,77 & 0,58 & 1 \\
\hline & $p$ & $p<0,001^{*}$ & $p<0,001^{*}$ & $p<0,001^{*}$ & $p<0,001^{*}$ & $p<0,001^{*}$ & 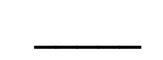 \\
\hline
\end{tabular}

* Diferença estatisticamente significante

As correlações entre os sextantes quanto ao nível de inserção clínico foram todas positivas e significantes. Houve forte correlação nas seguintes comparações: $1 \times 2,1 \times 3,2$ $\times 3,6 \times 5$; todas as outras foram médias. Não houve nenhuma correlação fraca (tabela 23). 
Tabela 24. Médias e desvios padrão do índice gengival por faixas etárias, gêneros e tipos de fissuras dos sextantes superiores.

\begin{tabular}{|c|c|c|c|c|c|c|c|c|}
\hline \multirow{2}{*}{$\begin{array}{l}\text { Faixas } \\
\text { etárias }\end{array}$} & \multirow[t]{2}{*}{ Gênero } & \multirow{2}{*}{$\begin{array}{l}\text { Tipos de } \\
\text { fissuras }\end{array}$} & \multicolumn{2}{|c|}{ S1 } & \multicolumn{2}{|c|}{ S2 } & \multicolumn{2}{|c|}{ S3 } \\
\hline & & & Média & $d p$ & Média & $d p$ & Média & $d p$ \\
\hline \multirow[t]{12}{*}{$15-25$} & $\mathrm{M}$ & LAPE & 1,61 & 0,495 & 1,77 & 0,425 & 1,74 & 0,444 \\
\hline & M & LAB & 1,53 & 0,518 & 1,53 & 0,518 & 1,61 & 0,506 \\
\hline & $M$ & LAPD & 2,00 & 0,000 & 2,00 & 0,000 & 2,00 & 0,000 \\
\hline & $M$ & LAPB & 1,65 & 0,483 & 1,68 & 0,470 & 1,75 & 0,435 \\
\hline & $M$ & LAE & 1,35 & 0,497 & 1,57 & 0,513 & 1,57 & 0,513 \\
\hline & $\mathrm{M}$ & LAD & 1,90 & 0,316 & 1,90 & 0,316 & 2,00 & 0,000 \\
\hline & $F$ & LAPE & 1,76 & 0,430 & 1,92 & 0,273 & 1,89 & 0,311 \\
\hline & $F$ & LAB & 1,42 & 0,513 & 1,57 & 0,513 & 1,64 & 0,497 \\
\hline & $F$ & LAPD & 1,93 & 0,250 & 1,93 & 0,250 & 2,00 & 0,000 \\
\hline & $F$ & LAPB & 1,63 & 0,490 & 1,66 & 0,479 & 1,76 & 0,430 \\
\hline & $F$ & LAE & 1,64 & 0,497 & 1,78 & 0,425 & 1,78 & 0,425 \\
\hline & $F$ & LAD & 1,90 & 0,301 & 1,90 & 0,301 & 2,00 & 0,000 \\
\hline \multirow[t]{12}{*}{$26-35$} & $\mathrm{M}$ & LAPE & 1,66 & 0,483 & 1,66 & 0,483 & 1,61 & 0,497 \\
\hline & M & LAB & 1,60 & 0,547 & 1,60 & 0,547 & 1,60 & 0,547 \\
\hline & $\mathrm{M}$ & LAPD & 1,80 & 0,421 & 1,90 & 0,316 & 2,00 & 0,000 \\
\hline & $\mathrm{M}$ & LAPB & 1,63 & 0,504 & 2,09 & 0,539 & 1,81 & 0,404 \\
\hline & $\mathrm{M}$ & LAE & 2,00 & 0,000 & 2,00 & 0,000 & 2,00 & 0,000 \\
\hline & $\mathrm{M}$ & LAD & 2,00 & 0,000 & 2,00 & 0,000 & 2,00 & 0,000 \\
\hline & $F$ & LAPE & 1,55 & 0,511 & 1,72 & 0,460 & 1,55 & 0,511 \\
\hline & $F$ & LAB & 1,60 & 0,547 & 1,60 & 0,547 & 1,60 & 0,547 \\
\hline & $F$ & LAPD & 1,62 & 0,517 & 1,87 & 0,353 & 2,00 & 0,000 \\
\hline & $F$ & LAPB & 1,88 & 0,781 & 2,11 & 0,781 & 1,88 & 0,333 \\
\hline & $F$ & LAE & 2,00 & 0,000 & 1,83 & 0,408 & 1,83 & 0,408 \\
\hline & $\mathrm{F}$ & LAD & 2,00 & 0,000 & 2,00 & 0,000 & 2,00 & 0,000 \\
\hline \multirow[t]{12}{*}{$36-49$} & $M$ & LAPE & 1,85 & 0,377 & 1,71 & 0,487 & 1,42 & 0,534 \\
\hline & $M$ & LAB & 1,00 & 0,000 & 1,00 & 0,000 & 1,00 & 0,000 \\
\hline & $M$ & LAPD & 1,66 & 0,577 & 2,00 & 0,000 & 2,00 & 0,000 \\
\hline & $M$ & LAPB & 1,57 & 0,534 & 1,50 & 0,577 & 1,71 & 0,487 \\
\hline & $M$ & LAE & 2,00 & 0,000 & 2,00 & 0,000 & 2,00 & 0,000 \\
\hline & $M$ & LAD & 2,00 & 0,000 & 2,00 & 0,000 & 2,00 & 0,000 \\
\hline & $\mathrm{F}$ & LAPE & 1,62 & 0,517 & 1,62 & 0,517 & 1,62 & 0,517 \\
\hline & $\mathrm{F}$ & LAB & 1,00 & 0,000 & 1,00 & 0,000 & 1,00 & 0,000 \\
\hline & $\mathrm{F}$ & LAPD & 2,00 & 0,000 & 2,00 & 0,000 & 2,00 & 0,000 \\
\hline & $F$ & LAPB & 1,75 & 0,500 & 1,50 & 0,707 & 1,75 & 0,500 \\
\hline & $F$ & LAE & 2,00 & 0,000 & 2,00 & 0,000 & 2,00 & 0,000 \\
\hline & $F$ & LAD & 2,00 & 0,000 & 2,00 & 0,000 & 2,00 & 0,000 \\
\hline
\end{tabular}

$\mathrm{Na}$ tabela 24 estão descritas as médias do índice gengival dos sextantes superiores. $2,7 \%$ dos sextantes apresentaram gengivite incipiente, $97,22 \%$ gengivite moderada e somente $1,85 \%$ gengivite severa. Somente o sextante dois apresentou gengivite severa. 
Tabela 25. Médias e desvios padrão do índice gengival por faixas etárias, gêneros e tipos de fissura dos sextantes inferiores.

\begin{tabular}{|c|c|c|c|c|c|c|c|c|}
\hline \multirow{2}{*}{$\begin{array}{l}\text { Faixas } \\
\text { etárias }\end{array}$} & \multirow[t]{2}{*}{ Gênero } & \multirow{2}{*}{$\begin{array}{l}\text { Tipos de } \\
\text { Fissuras }\end{array}$} & \multicolumn{2}{|c|}{ S4 } & \multicolumn{2}{|c|}{ S5 } & \multicolumn{2}{|c|}{56} \\
\hline & & & Média & $d p$ & Média & $d p$ & Média & $d p$ \\
\hline \multirow[t]{12}{*}{$15-25$} & $\mathrm{M}$ & LAPE & 1,70 & 0,461 & 1,80 & 0,401 & 1,67 & 0,475 \\
\hline & $\mathrm{M}$ & LAB & 1,53 & 0,518 & 1,61 & 0,506 & 1,53 & 0,518 \\
\hline & $\mathrm{M}$ & LAPD & 1,91 & 0,288 & 2,00 & 0,000 & 1,91 & 0,288 \\
\hline & $\mathrm{M}$ & LAPB & 1,72 & 0,454 & 1,82 & 0,539 & 1,62 & 0,493 \\
\hline & $\mathrm{M}$ & LAE & 1,92 & 0,267 & 1,71 & 0,468 & 2,00 & 0,000 \\
\hline & $\mathrm{M}$ & LAD & 1,90 & 0,316 & 1,90 & 0,316 & 2,00 & 0,000 \\
\hline & $F$ & LAPE & 1,71 & 0,459 & 1,84 & 0,369 & 1,78 & 0,413 \\
\hline & $F$ & LAB & 1,50 & 0,518 & 1,50 & 0,518 & 1,50 & 0,518 \\
\hline & $F$ & LAPD & 1,93 & 0,250 & 2,00 & 0,000 & 1,93 & 0,250 \\
\hline & $F$ & LAPB & 1,70 & 0,466 & 1,80 & 0,484 & 1,63 & 0,490 \\
\hline & $F$ & LAE & 1,85 & 0,363 & 1,85 & 0,363 & 2,00 & 0,000 \\
\hline & $F$ & LAD & 1,81 & 0,404 & 1,90 & 0,301 & 2,00 & 0,000 \\
\hline \multirow[t]{12}{*}{$26-35$} & $\mathrm{M}$ & LAPE & 1,76 & 0,436 & 1,66 & 0,483 & 1,76 & 0,436 \\
\hline & $\mathrm{M}$ & LAB & 1,60 & 0,547 & 1,60 & 0,547 & 1,80 & 0,447 \\
\hline & $\mathrm{M}$ & LAPD & 1,80 & 0,421 & 1,90 & 0,316 & 1,90 & 0,316 \\
\hline & M & LAPB & 1,90 & 0,301 & 1,90 & 0,301 & 1,90 & 0,301 \\
\hline & M & LAE & 2,00 & 0,000 & 2,00 & 0,000 & 2,00 & 0,000 \\
\hline & M & LAD & 2,00 & 0,000 & 2,00 & 0,000 & 2,00 & 0,000 \\
\hline & $F$ & LAPE & 1,72 & 0,460 & 1,66 & 0,485 & 1,72 & 0,460 \\
\hline & $F$ & LAB & 1,40 & 0,547 & 1,60 & 0,547 & 1,80 & 0,447 \\
\hline & $\mathrm{F}$ & LAPD & 2,00 & 0,000 & 1,87 & 0,353 & 1,87 & 0,353 \\
\hline & $\mathrm{F}$ & LAPB & 2,00 & 0,000 & 1,88 & 0,333 & 1,88 & 0,333 \\
\hline & $\mathrm{F}$ & $\mathrm{LAE}$ & 2,00 & 0,000 & 1,83 & 0,408 & 1,83 & 0,408 \\
\hline & $\mathrm{F}$ & LAD & 2,00 & 0,000 & 2,00 & 0,000 & 2,00 & 0,000 \\
\hline \multirow[t]{12}{*}{$36-49$} & $M$ & LAPE & 2,00 & 0,000 & 2,00 & 0,000 & 2,00 & 0,000 \\
\hline & M & LAB & 1,40 & 0,547 & 1,20 & 1,095 & 1,60 & 0,547 \\
\hline & $\mathrm{M}$ & LAPD & 2,00 & 0,000 & 2,00 & 0,000 & 2,00 & 0,000 \\
\hline & M & LAPB & 1,71 & 0,487 & 1,71 & 0,487 & 1,57 & 0,534 \\
\hline & $\mathrm{M}$ & LAE & 2,00 & 0,000 & 2,00 & 0,000 & 1,50 & 0,577 \\
\hline & M & LAD & 2,00 & 0,000 & 2,00 & 0,000 & 2,00 & 0,000 \\
\hline & $F$ & LAPE & 2,00 & 0,000 & 2,00 & 0,000 & 2,00 & 0,000 \\
\hline & $F$ & LAB & 1,33 & 0,516 & 1,00 & 1,095 & 1,33 & 0,516 \\
\hline & $F$ & LAPD & 2,00 & 0,000 & 1,66 & 0,577 & 2,00 & 0,000 \\
\hline & $F$ & LAPB & 1,75 & 0,500 & 1,75 & 0,500 & 1,75 & 0,500 \\
\hline & $\mathrm{F}$ & LAE & 2,00 & 0,000 & 2,00 & 0,000 & 1,66 & 0,577 \\
\hline & $\mathrm{F}$ & LAD & 2,00 & 0,000 & 2,00 & 0,000 & 2,00 & 0,000 \\
\hline
\end{tabular}

De todos os sextantes inferiores $0,93 \%$ apresentaram gengivite incipiente, 99,07\% gengivite moderada e nenhum com gengivite severa (tabela 25 ).

Nas tabelas 24 e 25 podem-se observar as médias e desvio padrão do índice gengival por faixa etária, gênero e tipo de fissura de todos os sextantes.

Na faixa etária de 15 a 25 anos de idade, a maior média foi de 2,00 tanto para os sextantes superiores quanto para os inferiores; e o menor foi de 1,50 nos sextantes inferiores e 1,35 nos superiores. 
Nos indivíduos com faixa etária intermediária, as maiores médias foram 2,11 (sextante 2) e 2,00 (sextantes inferiores). A menor média foi de 1,55 nos superiores e 1.40 nos inferiores.

A maior média para os indivíduos com idade entre 36 e 49 anos também foi 2,00 e a menor foi 1,00 em ambas as arcadas.

Tabela 26. Distribuição da freqüência $(\mathrm{N})$ dos escores do índice gengival dos dentes inferiores.

\begin{tabular}{c|cccccccccccccc}
\hline IG & \multicolumn{1}{|c}{ Dentes } \\
& 47 & 46 & 45 & 44 & 43 & 42 & 41 & 31 & 32 & 33 & 34 & 35 & 36 & 37 \\
\hline 0 & 0 & 0 & 0 & 0 & 4 & 5 & 5 & 5 & 5 & 5 & 1 & 0 & 0 & 0 \\
1 & 98 & 59 & 73 & 74 & 82 & 94 & 70 & 77 & 67 & 88 & 103 & 73 & 65 & 63 \\
2 & 232 & 194 & 283 & 309 & 311 & 293 & 313 & 287 & 317 & 295 & 285 & 293 & 211 & 269 \\
3 & 2 & 0 & 0 & 0 & 2 & 4 & 4 & 3 & 4 & 7 & 2 & 0 & 0 & 0 \\
\hline
\end{tabular}

Tabela 27. Distribuição da freqüência $(\mathrm{N})$ dos escores do índice gengival dos dentes superiores.

\begin{tabular}{c|cccccccccccccc}
\hline IG & \multicolumn{10}{c}{ Dentes } \\
& 17 & 16 & 15 & 14 & 13 & 12 & 11 & 21 & 22 & 23 & 24 & 25 & 26 & 27 \\
\hline 0 & 0 & 0 & 0 & 0 & 0 & 0 & 0 & 0 & 0 & 0 & 0 & 0 & 0 & 0 \\
1 & 102 & 88 & 113 & 199 & 103 & 75 & 85 & 77 & 46 & 92 & 94 & 100 & 58 & 60 \\
2 & 278 & 266 & 239 & 258 & 263 & 160 & 240 & 222 & 93 & 243 & 270 & 265 & 303 & 299 \\
3 & 1 & 5 & 5 & 2 & 6 & 1 & 4 & 1 & 1 & 5 & 0 & 0 & 0 & 0 \\
\hline
\end{tabular}

Houve sangramento a sondagem na maior parte da amostra, tanto para os dentes superiores quanto para os inferiores. A ausência de sangramento foi insignificante na amostra, representada por $0,31 \%$. A inflamação branda representada pelo escore 1 e a inflamação moderada representada pelo escore 2 estiveram em 23,64\% e 75,44\% da amostra. Não houve quase a presença de inflamação grave $(0,61 \%)$. Os dentes próximos a área da fissura seguiram o mesmo padrão dos demais dentes da maxila, ou seja, a maioria apresentou inflamação moderada com sangramento à sondagem (tabelas 26 e 27). 
Tabela 28. Médias e desvios padrão do índice gengival por sextante.

\begin{tabular}{ccc}
\hline Sextantes & Média & Desvio padrão \\
\hline 1 & 1,69 & 0,471 \\
2 & 1,77 & 0,447 \\
3 & 1,77 & 0,418 \\
4 & 1,78 & 0,412 \\
5 & 1,80 & 0,446 \\
6 & 1,78 & 0,410 \\
\hline
\end{tabular}

O índice gengival por sextante variou entre 1,69 e 1,80. O sextante 2 , da área da fissura não foi o que apresentou os maiores escores do índice gengival. A maioria dos valores foi próximo do escore 2 que indica inflamação moderada (tabela 28).

Tabela 29. Distribuição da freqüência (\%) dos escores do índice gengival em cada sextante.

\begin{tabular}{ccccccc}
\hline Escores & Sextante 1 & Sextante 2 & Sextante 3 & Sextante 4 & Sextante 5 & Sextante 6 \\
\hline 0 & 00,00 & 00,00 & 0,00 & 00,00 & 1,25 & 00,00 \\
1 & 31,00 & 24,75 & 22,50 & 22,00 & 18,00 & 21,75 \\
2 & 68,00 & 74,00 & 77,50 & 78,00 & 80,00 & 78,25 \\
3 & 00,50 & 01,25 & 00,00 & 00,00 & 00,75 & 00,00 \\
\hline
\end{tabular}

A distribuição da freqüência dos escores do índice gengival para cada sextante pode ser observada na tabela 29. A freqüência mais observada ocorreu no escore 2 em todos os sextantes, que representa presença de inflamação moderada. Os escores extremos foram os que menos apareceram, e a presença de inflamação leve variou de 18 a $31 \%$.

Tabela 30. Médias e desvios padrão do índice gengival por tipos de fissura nos sextantes superiores.

\begin{tabular}{lcccccc}
\hline $\begin{array}{l}\text { Tipos de } \\
\text { fissuras }\end{array}$ & Média & \multicolumn{2}{c}{ S1 } & \multicolumn{2}{c}{ S2 } & \multicolumn{2}{c}{ S3 } \\
\hline LAPE & 1,67 & 0,470 & 1,78 & 0,415 & 1,71 & 0,453 \\
LAB & $\mathbf{1 , 3 9}$ & 0,494 & 1,43 & 0,501 & $\mathbf{1 , 4 7}$ & 0,504 \\
LAPD & 1,86 & 0,344 & 1,94 & 0,235 & $\mathbf{2 , 0 0}$ & 0,000 \\
LAPB & 1,66 & 0,519 & 1,76 & 0,548 & 1,77 & 0,418 \\
LAE & 1,69 & 0,465 & 1,78 & 0,417 & 1,78 & 0,417 \\
LAD & $\mathbf{1 , 9 5}$ & 0,218 & $\mathbf{1 , 9 5}$ & 0,218 & $\mathbf{2 , 0 0}$ & 0,000 \\
\hline
\end{tabular}

A média do índice gengival variou bastante nos sextantes superiores em relação a cada tipo de fissura. A fissura de lábio e alvéolo bilateral ( $L A B)$ foi o grupo com menores índices gengivais, variando de 1,39 a 1,47 e o tipo de fissura com menores índices foi a LAD variando de 1,95 a 2,00. Ao analisarmos os resultados no sextante onde a fissura está presente podemos notar que não apresentou valores muito discrepantes quando comparamos com os outros sextantes superiores. O sextante 2 não apresentou as maiores 
médias, em relação ao tipo de fissura as maiores médias foram encontradas na LAD (tabela 30).

Tabela 31. Médias e desvios padrão do índice gengival por tipos de fissuras nos sextantes inferiores.

\begin{tabular}{lllcccc}
\hline $\begin{array}{l}\text { Tipos de } \\
\text { fissuras }\end{array}$ & Média & $d p$ & Média & $d p$ & \multicolumn{2}{c}{ Média } \\
\hline LAPE & 1,75 & 0,433 & 1,79 & 0,404 & 1,77 & 0,421 \\
LAB & 1,47 & 0,504 & 1,45 & 0,682 & 1,56 & 0,501 \\
LAPD & 1,92 & 0,269 & 1,94 & 0,235 & 1,92 & 0,274 \\
LAPB & 1,76 & 0,425 & 1,82 & 0,463 & 1,68 & 0,465 \\
LAE & 1,93 & 0,249 & 1,84 & 0,363 & 1,91 & 0,284 \\
LAD & 1,92 & 0,263 & 1,95 & 0,218 & 2,00 & 0,000 \\
\hline
\end{tabular}

Assim como nos sextantes superiores, os inferiores variaram de 1,47 a 2,00. A fissura de lábio e alvéolo bilateral (LAB) nos sextantes inferiores apresentou médias menores e o tipo LAD as menores médias (tabela 31).

Tabela 32. Médias e desvios padrão do índice gengival dos sextantes por tipos de fissuras.

\begin{tabular}{lll}
\hline Tipos de fissuras & \multicolumn{2}{c}{ Amostra } \\
& Média & $d p$ \\
\hline LAPE & 1,82 & 0,351 \\
LAB & 1,48 & 0,474 \\
LAPD & 1,96 & 0,154 \\
LAPB & 1,80 & 0,353 \\
LAE & 1,90 & 0,252 \\
LAD & 2,00 & 0,000 \\
\hline
\end{tabular}

$\mathrm{Na}$ tabela 32 foram apresentados os dados globais do índice gengival em cada tipo de fissura. A fissura com menores índices foi a de lábio e alvéolo bilateral ( $L A B)$ e a com maiores foi a de lábio alvéolo direita (LAD). As médias demonstraram que todos os tipos de fissuras apresentavam valores compatíveis com gengivite moderada (tabela 32). 
Tabela 33. Médias e desvios padrão do índice gengival por gêneros dos sextantes superiores.

\begin{tabular}{lcccccc}
\hline Gêneros & \multicolumn{2}{c}{$S 1$} & \multicolumn{2}{c}{$S 2$} & \multicolumn{2}{c}{$S 3$} \\
& Média & $d p$ & Média & $d p$ & Média & $d p$ \\
\hline Masculino & $\mathbf{1 , 6 8}$ & 0,465 & 1,76 & 0,449 & 1,75 & 0,430 \\
Feminino & 1,70 & 0,479 & 1,78 & 0,446 & 1,79 & 0,405 \\
\hline
\end{tabular}

Nos sextantes superiores as maiores médias foram encontradas nos indivíduos do gênero feminino (tabela 33), nos sextantes inferiores as maiores médias ocorreram no gênero masculino (tabela 34).

Tabela 34. Médias e desvios padrão do índice gengival por gêneros dos sextantes inferiores.

\begin{tabular}{lllllll}
\hline Gêneros & \multicolumn{2}{c}{$S 4$} & \multicolumn{2}{c}{ S5 } & \multicolumn{2}{c}{$S 6$} \\
& Média & $d p$ & Média & $d p$ & Média & $d p$ \\
\hline Masculino & 1,79 & 0,404 & $\mathbf{1 , 8 1}$ & 0,440 & 1,78 & 0,411 \\
Feminino & 1,77 & 0,420 & 1,79 & 0,452 & 1,78 & 0,409 \\
\hline
\end{tabular}

As distribuições das médias e desvios padrão do índice gengival por gênero em cada sextante estão descritas nas tabelas 33 e 34 . As médias entre os gêneros, em todos os sextantes, foram muito semelhantes. A maior média foi de 1,81 (sextante 5, gênero masculino) e a menor 1,68 (sextante 1, gênero masculino).

Tabela 35. Médias e desvios padrão do índice gengival por faixas etárias dos sextantes superiores.

\begin{tabular}{llllccc}
\hline Faixas & \multicolumn{2}{c}{$S 1$} & \multicolumn{2}{c}{$S 2$} & \multicolumn{2}{c}{$S 3$} \\
etárias & Média & $d p$ & Média & $d p$ & Média & $d p$ \\
\hline $15-25$ & 1,68 & 0,465 & 1,77 & 0,420 & 1,80 & 0,396 \\
$26-35$ & $\mathbf{1 , 7 4}$ & 0,474 & $\mathbf{1 , 8 5}$ & 0,463 & $\mathbf{1 , 7 9}$ & 0,408 \\
$36-49$ & 1,62 & 0,489 & 1,60 & 0,494 & 1,60 & 0,493 \\
\hline
\end{tabular}

Tabela 36. Médias e desvios padrão do índice gengival por faixas etárias dos sextantes inferiores.

\begin{tabular}{llllccc}
\hline Faixas & \multicolumn{2}{c}{$S 4$} & \multicolumn{2}{c}{$S 5$} & \multicolumn{2}{c}{$S 6$} \\
etárias & Média & $d p$ & Média & $d p$ & Média & $d p$ \\
\hline $15-25$ & 1,75 & 0,433 & 1,81 & 0,421 & 1,76 & 0,426 \\
$26-35$ & $\mathbf{1 , 8 4}$ & 0,364 & $\mathbf{1 , 8 0}$ & 0,395 & $\mathbf{1 , 8 5}$ & 0,356 \\
$36-49$ & 1,80 & 0,400 & 1,73 & 0,624 & 1,74 & 0,440 \\
\hline
\end{tabular}


De maneira geral, os indivíduos com idade entre 26 e 35 anos tiveram as maiores médias do índice gengival (tabelas 35 e 36). Não houve constância do aumneto do índice gengival com o aumento da idade.

Tabela 37. Teste de Friedman - Comparação entre o índice gengival e os sextantes.

\begin{tabular}{ccc}
\hline Sextantes & Média & Desvio Padrão \\
\hline 1 & 1,69 & 0,472 \\
2 & 1,77 & 0,446 \\
3 & 1,77 & 0,418 \\
4 & 1,78 & 0,414 \\
5 & 1,80 & 0,448 \\
6 & 1,78 & 0,411 \\
\hline $\mathrm{x}^{2}=25,11, \mathrm{p}=0,000$ & &
\end{tabular}

$\mathrm{Na}$ tabela 37 pode-se observar pelo Teste de Friedman que houve diferença estatisticamente significante entre o índice gengival e os sextantes. Aplicando-se o Teste de Dunn observamos que houve diferença estatisticamente significante somente entre os sextantes 1 e $5(p<0,001)$.

Nas comparações entre o índice gengival e os sextantes, o teste de Kruskal-Wallis não mostrou haver diferença estatisticamente significante entre as faixas etárias para o índice gengival nos sextantes $1(H=2,54 ; p=0,280), 4(H=4,09 ; p=0,129), 5(H=0,00$; $p=0,996)$ e $6(H=4,23 ; p=0,120)$. Houve diferença somente nos sextantes 2 e 3 (tabelas 38 e 39)

Tabela 38. Teste de Kruskal-Wallis - Comparação entre índice gengival e faixa etária para sextante 2.

\begin{tabular}{lcc}
\hline Faixas etárias & Escores & $N$ \\
\hline $15-25$ & 1 & 232 \\
$26-35$ & 2 & 115 \\
$36-49$ & 3 & 48 \\
\hline $\mathrm{H}=9,89 ; \mathrm{p}=0,007$ & &
\end{tabular}

Como houve diferença estatística foi aplicado o Teste de Dunn o qual demonstrou haver diferença estatisticamente significante entre o índice gengival e todas as faixas etárias, no sextante 2. O índice gengival e faixa etária apresentaram tendência de aumento entre a faixa 1 e 2 e diminuição entre as faixas 2 e 3. 
Tabela 39. Teste de Kruskal-Wallis - Comparação entre índice gengival e faixa etária para sextante 3 .

\begin{tabular}{lcc}
\hline Faixas Etárias & Escores & $N$ \\
\hline $15-25$ & 1 & 232 \\
$26-35$ & 2 & 115 \\
$36-49$ & 3 & 53 \\
\hline
\end{tabular}

$\mathrm{H}=10,34 ; \mathrm{p}=0,005$

O Teste de Dunn demonstrou haver diferença estatisticamente significante entre as faixas etárias 15-25 e 36-49, 26-35 e 36-49, no sextante 3.

As comparações entre os tipos de fissura quanto ao índice gengival estão descritos nas tabelas 40, 41, 42, 43, 44, 45 e 46.

Tabela 40. Teste de Kruskal-Wallis - Comparação entre o índice gengival e os tipos de fissura do sextante 1.

\begin{tabular}{lc}
\hline Tipos de fissuras & $N$ \\
\hline LAPE & 123 \\
LAB & 48 \\
LAPD & 52 \\
LAPB & 90 \\
LAE & 46 \\
LAD & 41 \\
\hline H=39,53; $=0,000$ &
\end{tabular}

$\mathrm{H}=39,53 ; \mathrm{p}=0,000$

A diferença na comparação entre índice gengival e os tipos de fissura no sextante 1 foi estatisticamente significante $(p=0,000)$. O Teste de Dunn foi utilizado para as comparações múltiplas e constatou-se diferença estatisticamente significante entre as fissuras $L A D$ e $L A B$, LAD e LAPB, LAD e LAPE, LAPD e LAB, LAE e LAB, LAPE e LAB, LAPB e LAB (tabela 40).

Tabela 41. Teste de Kruskal-Wallis - Comparação entre o índice gengival e os tipos de fissura do sextante 2 .

\begin{tabular}{lc}
\hline Tipos de fissuras & $N$ \\
\hline LAPE & 123 \\
LAB & 48 \\
LAPD & 52 \\
LAPB & 85 \\
LAE & 46 \\
LAD & 41 \\
\hline H=42,52; $=0,000$ &
\end{tabular}


$\mathrm{Na}$ tabela 41 observa-se a comparação entre o índice gengival e os tipos de fissura no sextante 2. Houve diferença estatisticamente significante entre as fissuras LAD e LAB, LAPD e LAB, LAE e LAB, LAPE e LAB, LAPB e LAB (Teste de Dunn).

Tabela 42. Teste de Kruskal-Wallis - Comparação entre o índice gengival e os tipos de fissura do sextante 3 .

\begin{tabular}{lc}
\hline Tipos de fissuras & $N$ \\
\hline LAPE & 123 \\
LAB & 48 \\
LAPD & 52 \\
LAPB & 90 \\
LAE & 46 \\
LAD & 41 \\
\hline H=53,47; $=0,000$ &
\end{tabular}

No sextante 3 houve diferença estatisticamente significante $(p=0,000$; tabela 42$)$ entre as fissuras LAD e LAB, LAPD e LAB, LAE e LAB, LAPE e LAB, LAPB e LAB (Teste de Dunn).

Tabela 43. Teste de Kruskal-Wallis - Comparação entre o índice gengival e os tipos de fissura do sextante 4 .

\begin{tabular}{lc}
\hline Tipos de fissuras & $N$ \\
\hline LAPE & 121 \\
LAB & 48 \\
LAPD & 52 \\
LAPB & 90 \\
LAE & 46 \\
LAD & 41 \\
\hline
\end{tabular}

$\mathrm{H}=44,15 ; p=0,000$

Houve diferença estatisticamente significante no sextante 4 quando comparados o índice gengival e os tipos de fissura (tabela 43). As fissuras LAPD e LAB, LAPD e LAPE, LAPD e LAPB, LAD e LAB, LAD e LAPE, LAE e LAB, LAPB e LAB, LAPE e LAB, foram diferentes entre si (Teste de Dunn). 
Tabela 44. Teste de Kruskal-Wallis - Comparação entre o índice gengival e os tipos de fissura do sextante 5 .

\begin{tabular}{lc}
\hline Tipos de fissuras & $N$ \\
\hline LAPE & 123 \\
LAB & 48 \\
LAPD & 52 \\
LAPB & 90 \\
LAE & 46 \\
LAD & 41 \\
\hline
\end{tabular}

$\mathrm{H}=31,38 ; \mathrm{p}=0,000$

As fissuras $L A D$ e $L A B$, LAPD e $L A B$, $L A E$ e $L A B$, LAPB e $L A B$, LAPE e LAB foram diferentes entre si, quanto as índice gengival,no sextante 5 (tabela 44).

Tabela 45. Teste de Kruskal-Wallis - Comparação entre o índice gengival e os tipos de fissura do sextante 6 .

\begin{tabular}{lc}
\hline Tipos de fissuras & $N$ \\
\hline LAPE & 123 \\
LAB & 48 \\
LAPD & 50 \\
LAPB & 90 \\
LAE & 46 \\
LAD & 41 \\
\hline H=40,30; $p=0,000$ &
\end{tabular}

Houve diferença estatisticamente significante na comparação entre as médias do índice gengival e os tipos de fissura no sextante $6(p=0,000$, tabela 45). Pelo Teste de Dunn, notou-se que esta diferença ocorreu entre as seguintes fissuras: $L A D$ e $L A B, L A D$ e $L A P B$, LAD e LAPE, LAPD e LAB, LAPD e LAPB, LAE e LAB, LAE e LAPB, LAPE e LAB.

Tabela 46. Teste Mann-Whitney - Comparação entre índice gengival, sextantes e gêneros.

\begin{tabular}{lccc}
\hline Sextantes & $p$ & Mascuino & Feminino \\
& & $N$ & $N$ \\
\hline 1 & 0,766 & 201 & 199 \\
2 & 0,603 & 198 & 197 \\
3 & 0,366 & 201 & 199 \\
4 & 0,589 & 200 & 198 \\
5 & 0,769 & 201 & 199 \\
6 & 0,944 & 200 & 198 \\
\hline
\end{tabular}

Não houve diferença estatisticamente significante entre o índice gengival, sextante e gênero (tabela 46). 
Tabela 47. Médias e desvios padrão do índice de placa por faixas etárias, gêneros e tipos de fissura dos sextantes superiores.

\begin{tabular}{|c|c|c|c|c|c|c|c|c|}
\hline \multirow{2}{*}{$\begin{array}{l}\text { Faixas } \\
\text { etárias }\end{array}$} & \multirow[t]{2}{*}{ Gêneros } & \multirow{2}{*}{$\begin{array}{l}\text { Tipos de } \\
\text { fissuras }\end{array}$} & \multicolumn{2}{|c|}{ S1 } & \multicolumn{2}{|c|}{ S2 } & \multicolumn{2}{|c|}{ S3 } \\
\hline & & & Média & $d p$ & Média & $d p$ & Média & $d p$ \\
\hline \multirow[t]{12}{*}{$15-25$} & $M$ & LAPE & 1,38 & 0,558 & 1,16 & 0,373 & 1,45 & 0,505 \\
\hline & $M$ & LAB & 1,30 & 0,630 & 1,38 & 0,650 & 1,53 & 0,660 \\
\hline & $M$ & LAPD & 1,66 & 0,492 & 1,25 & 0,753 & 1,33 & 0,492 \\
\hline & $M$ & LAPB & 1,51 & 0,574 & 1,44 & 0,506 & 1,48 & 0,574 \\
\hline & $M$ & LAE & 1,42 & 0,513 & 1,28 & 0,825 & 1,07 & 0,267 \\
\hline & $M$ & LAD & 1,70 & 0,823 & 1,50 & 0,707 & 1,90 & 0,875 \\
\hline & $F$ & LAPE & 1,47 & 0,646 & 1,23 & 0,430 & 1,50 & 0,506 \\
\hline & $F$ & LAB & 1,42 & 0,646 & 1,35 & 0,744 & 1,71 & 0,611 \\
\hline & $F$ & LAPD & 1,81 & 0,655 & 1,43 & 0,727 & 1,43 & 0,512 \\
\hline & $F$ & LAPB & 1,46 & 0,507 & 1,36 & 0,490 & 1,46 & 0,681 \\
\hline & $F$ & LAE & 1,28 & 0,726 & 1,14 & 0,770 & 1,21 & 0,425 \\
\hline & $F$ & LAD & 1,72 & 0,786 & 1,45 & 0,522 & 2,00 & 0,894 \\
\hline \multirow[t]{12}{*}{$26-35$} & $M$ & LAPE & 1,19 & 0,511 & 1,09 & 0,436 & 1,23 & 0,436 \\
\hline & $M$ & LAB & 1,20 & 0,836 & 1,00 & 0,707 & 1,00 & 0,707 \\
\hline & $M$ & LAPD & 1,50 & 0,707 & 1,50 & 0,707 & 1,90 & 0,737 \\
\hline & $M$ & LAPB & 1,63 & 0,674 & 1,90 & 0,539 & 1,90 & 0,539 \\
\hline & $M$ & LAE & 1,60 & 0,547 & 1,60 & 0,547 & 1,60 & 0,547 \\
\hline & $M$ & LAD & 1,66 & 0,651 & 1,83 & 0,389 & 2,25 & 0,452 \\
\hline & $\mathrm{F}$ & LAPE & 1,22 & 0,548 & 1,16 & 0,383 & 1,22 & 0,427 \\
\hline & $F$ & LAB & 1,00 & 0,707 & 1,00 & 0,707 & 1,00 & 0,707 \\
\hline & $\mathrm{F}$ & LAPD & 1,50 & 0,755 & 1,37 & 0,744 & 1,50 & 0,755 \\
\hline & $F$ & LAPB & 1,66 & 0,500 & 1,77 & 0,440 & 1,88 & 0,333 \\
\hline & $F$ & LAE & 1,50 & 0,547 & 1,50 & 0,547 & 1,66 & 0,816 \\
\hline & $\mathrm{F}$ & LAD & 2,20 & 0,447 & 2,00 & 0,000 & 2,40 & 0,547 \\
\hline \multirow[t]{12}{*}{$36-49$} & $M$ & LAPE & 1,14 & 0,377 & 1,14 & 0,377 & 1,28 & 0,487 \\
\hline & $M$ & LAB & 1,00 & 0,000 & 1,00 & 0,000 & 1,00 & 0,000 \\
\hline & $M$ & LAPD & 2,33 & 0,577 & 2,00 & 0,000 & 2,33 & 0,577 \\
\hline & $M$ & LAPB & 1,57 & 0,534 & 1,50 & 0,577 & 1,71 & 0,487 \\
\hline & $M$ & LAE & 1,25 & 0,500 & 1,25 & 0,500 & 1,25 & 0,500 \\
\hline & $M$ & LAD & 2,00 & 1,414 & 1,50 & 0,707 & 1,50 & 0,707 \\
\hline & $\mathrm{F}$ & LAPE & 1,25 & 0,462 & 1,50 & 0,534 & 1,50 & 0,534 \\
\hline & $\mathrm{F}$ & LAB & 1,00 & 0,000 & 1,00 & 0,000 & 1,00 & 0,000 \\
\hline & $F$ & LAPD & 2,00 & 1,000 & 2,00 & 1,000 & 2,33 & 0,577 \\
\hline & $F$ & LAPB & 1,75 & 0,500 & 1,50 & 0,707 & 1,75 & 0,500 \\
\hline & $F$ & LAE & 1,33 & 0,577 & 1,33 & 0,577 & 1,33 & 0,577 \\
\hline & $\mathrm{F}$ & LAD & 3,00 & 0,000 & 2,00 & 0,000 & 2,00 & 0,000 \\
\hline
\end{tabular}


Tabela 48. Médias e desvios padrão do índice de placa por faixas etárias, gêneros e tipos de fissura dos sextantes inferiores.

\begin{tabular}{|c|c|c|c|c|c|c|c|c|}
\hline \multirow{2}{*}{$\begin{array}{l}\text { Faixas } \\
\text { etárias }\end{array}$} & \multirow{2}{*}{ Gêneros } & \multirow{2}{*}{$\begin{array}{l}\text { Tipos de } \\
\text { fissuras }\end{array}$} & \multicolumn{2}{|c|}{ S4 } & \multicolumn{2}{|c|}{ S5 } & \multicolumn{2}{|c|}{56} \\
\hline & & & Média & $d p$ & Média & $d p$ & Média & $d p$ \\
\hline \multirow[t]{12}{*}{$15-25$} & $\mathrm{M}$ & LAPE & 1,41 & 0,501 & 1,41 & 0,501 & 1,54 & 0,623 \\
\hline & M & LAB & 1,46 & 0,518 & 1,38 & 0,506 & 1,30 & 0,480 \\
\hline & M & LAPD & 1,50 & 0,674 & 1,66 & 0,492 & 1,75 & 0,452 \\
\hline & M & LAPB & 1,41 & 0,501 & 1,34 & 0,720 & 1,48 & 0,574 \\
\hline & $\mathrm{M}$ & LAE & 1,50 & 0,518 & 1,50 & 0,518 & 1,57 & 0,513 \\
\hline & $\mathrm{M}$ & LAD & 1,90 & 0,875 & 1,80 & 0,918 & 2,00 & 0,666 \\
\hline & $\mathrm{F}$ & LAPE & 1,36 & 0,488 & 1,39 & 0,495 & 1,52 & 0,603 \\
\hline & $F$ & $L A B$ & 1,50 & 0,518 & 1,42 & 0,513 & 1,35 & 0,497 \\
\hline & $F$ & LAPD & 1,50 & 0,632 & 1,68 & 0,602 & 1,75 & 0,447 \\
\hline & $F$ & LAPB & 1,33 & 0,479 & 1,16 & 0,647 & 1,46 & 0,571 \\
\hline & $F$ & LAE & 1,57 & 0,513 & 1,42 & 0,513 & 1,64 & 0,497 \\
\hline & $\mathrm{F}$ & LAD & 1,81 & 0,873 & 1,90 & 0,943 & 2,09 & 0,700 \\
\hline \multirow[t]{12}{*}{$26-35$} & $\mathrm{M}$ & LAPE & 1,19 & 0,402 & 1,57 & 0,507 & 1,28 & 0,462 \\
\hline & $\mathrm{M}$ & $\mathrm{LAB}$ & 1,60 & 0,894 & 1,40 & 1,341 & 1,80 & 0,836 \\
\hline & M & LAPD & 1,60 & 0,699 & 1,60 & 0,699 & 1,50 & 0,707 \\
\hline & M & LAPB & 2,09 & 0,539 & 1,90 & 0,539 & 2,09 & 0,301 \\
\hline & $\mathrm{M}$ & LAE & 2,00 & 0,707 & 2,40 & 0,894 & 1,80 & 0,836 \\
\hline & $\mathrm{M}$ & LAD & 2,00 & 0,000 & 2,66 & 0,492 & 2,25 & 0,452 \\
\hline & $\mathrm{F}$ & LAPE & 1,22 & 0,427 & 1,50 & 0,514 & 1,44 & 0,511 \\
\hline & $\mathrm{F}$ & $\mathrm{LAB}$ & 1,60 & 0,894 & 1,40 & 1,341 & 1,60 & 0,894 \\
\hline & $\mathrm{F}$ & LAPD & 1,50 & 0,755 & 1,50 & 0,755 & 1,75 & 0,707 \\
\hline & $\mathrm{F}$ & LAPB & 2,00 & 0,000 & 1,88 & 0,333 & 1,77 & 0,440 \\
\hline & $\mathrm{F}$ & LAE & 1,83 & 0,752 & 2,00 & 0,894 & 1,83 & 0,752 \\
\hline & $\mathrm{F}$ & LAD & 2,20 & 0,447 & 2,40 & 0,547 & 2,00 & 0,000 \\
\hline \multirow[t]{12}{*}{$36-49$} & $M$ & LAPE & 2,00 & 0,632 & 1,85 & 0,690 & 1,57 & 0,534 \\
\hline & M & LAB & 1,00 & 0,000 & 1,00 & 0,000 & 1,00 & 0,000 \\
\hline & M & LAPD & 2,33 & 0,577 & 2,66 & 0,577 & 2,00 & 0,000 \\
\hline & $\mathrm{M}$ & LAPB & 1,28 & 0,487 & 1,57 & 0,534 & 1,57 & 0,534 \\
\hline & $\mathrm{M}$ & LAE & 2,00 & 0,000 & 1,25 & 0,500 & 1,25 & 0,500 \\
\hline & $\mathrm{M}$ & LAD & 2,00 & 0,000 & 1,50 & 0,707 & 2,00 & 0,000 \\
\hline & $\mathrm{F}$ & LAPE & 2,00 & 0,577 & 2,00 & 0,755 & 1,75 & 0,462 \\
\hline & $\mathrm{F}$ & LAB & 1,00 & 0,000 & 1,00 & 0,000 & 1,00 & 0,000 \\
\hline & $\mathrm{F}$ & LAPD & 2,33 & 0,577 & 2,33 & 0,577 & 2,50 & 0,707 \\
\hline & $\mathrm{F}$ & LAPB & 1,50 & 0,577 & 1,25 & 0,500 & 1,75 & 0,500 \\
\hline & $\mathrm{F}$ & LAE & 2,00 & 0,000 & 1,33 & 0,577 & 1,33 & 0,577 \\
\hline & $\mathrm{F}$ & LAD & 2,00 & 0,000 & 2,00 & 0,000 & 2,00 & 0,000 \\
\hline
\end{tabular}

As tabelas 47 e 48 demonstram os resultados médios do índice de placa por faixa etária, gêneros e tipos de fissura nos sextantes superiores e inferiores.

$\mathrm{Na}$ faixa etária de 15 a 25 anos de idade a maior média do índice de placa foi 2,09 no sextante 6 , fissura de LAD, gênero feminino e o menor valor foi 1,07 , no sextante 3 , gênero masculino e fissura de LAE.

Para os indivíduos de 26 a 35 anos, a maior média foi de 2,66 (sextante 5, gênero masculino, fissura tipo LAD) e o menor de 1,00, em vários sextantes e tipos de fissura. 
Os indivíduos mais velhos, de 36 a 49 anos de idade, tiveram a maior média do índice de placa $(3,00)$.

Tabela 49. Distribuição da freqüência $(\mathrm{N})$ dos escores do índice de placa dos dentes inferiores.

\begin{tabular}{c|cccccccccccccc}
\hline IG & \multicolumn{10}{c}{ Dentes } \\
& 47 & 46 & 45 & 44 & 43 & 42 & 41 & 31 & 32 & 33 & 34 & 35 & 36 & 37 \\
\hline 0 & 0 & 4 & 1 & 8 & 11 & 16 & 16 & 13 & 12 & 19 & 12 & 2 & 0 & 0 \\
1 & 123 & 104 & 155 & 197 & 220 & 178 & 148 & 142 & 174 & 200 & 204 & 185 & 146 & 117 \\
2 & 172 & 129 & 175 & 148 & 129 & 141 & 157 & 170 & 158 & 147 & 143 & 160 & 118 & 199 \\
3 & 37 & 16 & 25 & 30 & 36 & 61 & 71 & 57 & 49 & 29 & 32 & 19 & 199 & 16 \\
\hline
\end{tabular}

Tabela 50. Distribuição da freqüência $(\mathrm{N})$ dos escores do índice de placa dos dentes superiores.

\begin{tabular}{c|cccccccccccccc}
\hline IG & \multicolumn{1}{c}{ Dentes } \\
& 17 & 16 & 15 & 14 & 13 & 12 & 11 & 21 & 22 & 23 & 24 & 25 & 26 & 27 \\
\hline 0 & 2 & 5 & 16 & 21 & 16 & 9 & 8 & 11 & 7 & 15 & 7 & 14 & 7 & 0 \\
1 & 153 & 173 & 184 & 219 & 216 & 142 & 201 & 170 & 86 & 192 & 214 & 214 & 158 & 123 \\
2 & 185 & 145 & 145 & 114 & 118 & 75 & 110 & 107 & 44 & 119 & 128 & 112 & 168 & 204 \\
3 & 41 & 36 & 12 & 15 & 23 & 10 & 10 & 12 & 3 & 14 & 15 & 25 & 28 & 32 \\
\hline
\end{tabular}

A ausência de placa foi encontrada somente em 2,60\% da amostra, enquanto que em 48,95\% e 40,50\% apresentaram escores 2 e 3 respectivamente. A freqüência de placa representou $97,40 \%$ da totalidade de dentes examinados. A distribuição destes valores foi semelhante entre os arcos dentários. Os dentes próximos a área da fissura, pertencentes ao sextante 2, apresentaram valores semelhantes aos demais (tabelas 49 e 50).

Tabela 51. Médias e desvios padrão do índice de placa por sextante.

\begin{tabular}{lcc}
\hline Sextantes & Média & Desvio padrão \\
\hline 1 & 1,47 & 0,624 \\
2 & $\mathbf{1}, 36$ & 0,581 \\
3 & 1,52 & 0,620 \\
4 & 1,54 & 0,595 \\
5 & 1,57 & 0,689 \\
6 & $\mathbf{1 , 6 0}$ & 0,591 \\
\hline
\end{tabular}


A média do índice de placa por sextante variou de 1,36 a 1,60. 0 sextante 2 , que compreende a área da fissura, verificou-se a menor média (tabela 51).

Tabela 52. Distribuição da freqüência (\%) dos escores do índice de placa em cada sextante.

\begin{tabular}{ccccccc}
\hline Escores & Sextante 1 & Sextante 2 & Sextante 3 & Sextante 4 & Sextante 5 & Sextante 6 \\
\hline 0 & 01,25 & 03,29 & 00,50 & 00,50 & 02,50 & 00,00 \\
1 & 56,00 & 59,24 & 53,25 & 49,25 & 46,75 & 44,97 \\
2 & 37,00 & 35,44 & 40,00 & 45,48 & 41,75 & 79,50 \\
3 & 05,75 & 02,03 & 06,25 & 04,77 & 09,00 & 05,53 \\
\hline
\end{tabular}

A tabela 52 retrata a distribuição da freqüência em porcentual dos escores de índice de placa em cada sextante. O escore 0 que representa ausência de placa, teve uma pequena freqüência $(00,00$ a 3,29\%). O escore 2 foi o escore mais encontrado em cinco dos seis sextantes, e o menor percentual estava no sextante da área da fissura $(59,24 \%)$ e o maior no sextante $6(79,50 \%)$, enquanto que o escore 3 teve maior freqüência no sextante 5 $(9,00 \%)$. O sextante da área da fissura (2) não foi o que obteve maior ocorrência de placa quando comparados com os demais.

Tabela 53. Médias e desvios padrão do índice de placa por tipos de fissura nos sextantes superiores.

\begin{tabular}{lllllll}
\hline Tipos de Fissuras & \multicolumn{2}{c}{ S1 } & \multicolumn{2}{c}{$S 2$} & \multicolumn{2}{c}{$S 3$} \\
& Média & $d p$ & Média & $d p$ & Média & $d p$ \\
\hline LAPE & 1,33 & 0,567 & 1,19 & 0,418 & 1,39 & 0,489 \\
LAB & 1,22 & 0,592 & 1,20 & 0,617 & 1,35 & 0,635 \\
LAPD & 1,71 & 0,666 & 1,46 & 0,726 & 1,61 & 0,661 \\
LAPB & 1,54 & 0,543 & 1,51 & 0,525 & 1,60 & 0,595 \\
LAE & 1,39 & 0,576 & 1,30 & 0,695 & 1,28 & 0,501 \\
LAD & 1,80 & 0,748 & 1,65 & 0,529 & 2,07 & 0,720 \\
\hline
\end{tabular}

Tabela 54. Médias e desvios padrão do índice de placa por tipos de fissura nos sextantes inferiores.

\begin{tabular}{lcccccc}
\hline Tipos de Fissuras & \multicolumn{2}{c}{$S 4$} & \multicolumn{2}{c}{$S 5$} & \multicolumn{2}{c}{$S 6$} \\
& Média & $d p$ & Média & $d p$ & Média & $d p$ \\
\hline LAPE & 1,39 & 0,524 & 1,51 & 0,548 & 1,49 & 0,563 \\
LAB & 1,39 & 0,573 & 1,31 & 0,689 & 1,33 & 0,558 \\
LAPD & 1,61 & 0,690 & 1,73 & 0,660 & 1,74 & 0,564 \\
LAPB & 1,52 & 0,545 & 1,42 & 0,670 & 1,60 & 0,556 \\
LAE & 1,69 & 0,552 & 1,60 & 0,682 & 1,60 & 0,576 \\
LAD & 1,95 & 0,630 & 2,14 & 0,823 & 2,09 & 0,538 \\
\hline
\end{tabular}


As fissuras bilaterais (LAB, LAPB) não tiveram as maiores médias no sextante que engloba a área da fissura. No sextante 2 não se verificou maiores valores (tabela 53).

O tipo de fissura com maior média foi a LAD, no sextante $5(2,14)$. Considerando todos os sextantes, as médias variaram de 1,19 a 2,14 (tabelas 53 e 54).

Tabela 55. Médias e desvios padrão do índice de placa por gêneros dos sextantes superiores.

\begin{tabular}{lllllll}
\hline \multicolumn{1}{c}{ Gênero } & \multicolumn{2}{c}{$S 1$} & \multicolumn{2}{c}{$S 2$} & \multicolumn{2}{c}{$S 3$} \\
& Média & $d p$ & Média & $d p$ & Média & $d p$ \\
\hline Masculino & 1,45 & 0,607 & 1,36 & 0,587 & 1,51 & 0,617 \\
Feminino & 1,48 & 0,642 & 1,35 & 0,576 & 1,52 & 0,626 \\
\hline
\end{tabular}

Tabela 56. Médias e desvios padrão do índice de placa por gêneros dos sextantes inferiores.

\begin{tabular}{lcccccc}
\hline \multirow{1}{*}{ Gênero } & \multicolumn{2}{c}{ S4 } & \multicolumn{2}{c}{ S5 } & \multicolumn{2}{c}{ S6 } \\
& Média & $d p$ & Média & $d p$ & Média & $d p$ \\
\hline Masculino & 1,56 & 0,597 & 1,62 & 0,704 & 1,60 & 0,600 \\
Feminino & 1,52 & 0,593 & 1,52 & 0,672 & 1,60 & 0,584 \\
\hline
\end{tabular}

As tabelas 55 e 56 demonstram as médias e desvio padrão do índice de placa por gênero dos sextantes superiores e inferiores respectivamente. Não houve grande diferença das médias entre os gêneros em cada sextante.

Tabela 57. Médias e desvios padrão do índice de placa por faixas etárias dos sextantes superiores.

\begin{tabular}{llllrrr}
\hline Faixas etárias & \multicolumn{2}{c}{ S1 } & \multicolumn{2}{c}{$S 2$} & \multicolumn{2}{c}{$S 3$} \\
& Média & $d p$ & Média & $d p$ & Média & $d p$ \\
\hline $15-25$ & 1,49 & 0,617 & 1,31 & 0,582 & 1,48 & 0,602 \\
$26-35$ & 1,44 & 0,637 & 1,44 & 0,595 & 1,60 & 0,672 \\
$36-49$ & 1,43 & 0,635 & 1,37 & 0,530 & 1,49 & 0,575 \\
\hline
\end{tabular}

Tabela 58. Médias e desvios padrão do índice de placa por faixas etárias dos sextantes inferiores.

\begin{tabular}{ccccccc}
\hline Faixa etária & \multicolumn{2}{c}{$S 4$} & \multicolumn{2}{c}{$S 5$} & \multicolumn{2}{c}{$S 6$} \\
& Média & $d p$ & Média & $d p$ & Média & $d p$ \\
\hline $15-25$ & 1,46 & 0,565 & 1,44 & 0,622 & 1,57 & 0,583 \\
$26-35$ & 1,63 & 0,625 & 1,80 & 0,759 & 1,69 & 0,623 \\
$36-49$ & 1,68 & 0,616 & 1,60 & 0,688 & 1,52 & 0,542 \\
\hline
\end{tabular}


Quanto à faixa etária, pudemos observar que em quase todos os sextantes os indivíduos com idade entre 26 e 35 anos tiveram um pouco mais de placa, com exceção dos sextantes 1 e 4 (tabelas 57 e 58 ).

Tabela 59. Teste de Friedman - Comparação entre o índice de placa e os sextantes.

\begin{tabular}{lcc}
\hline Sextantes & Média & Desvio padrão \\
\hline 1 & 1,46 & 0,618 \\
2 & 1,35 & 0,577 \\
3 & 1,50 & 0,615 \\
4 & 1,53 & 0,588 \\
5 & 1,57 & 0,686 \\
6 & 1,60 & 0,593 \\
\hline $\mathrm{X}^{2}=92,23 ; p<0,000$ & &
\end{tabular}

A comparação entre as médias do índice de placa e sextantes foi feita pelo Teste de Friedman (tabela 59), houve diferença estatisticamente significante.

Tabela 60. Teste de Student-Newman-Keuls - Comparação múltipla entre índice de placa e sextantes.

\begin{tabular}{lc}
\hline Índice placa $\times$ sextante & $p$ \\
\hline $6 \times 2$ & $\mathrm{p}<0.05^{\star}$ \\
$6 \times 1$ & $\mathrm{p}<0.05^{\star}$ \\
$6 \times 3$ & $\mathrm{p}<0.05^{\star}$ \\
$6 \times 4$ & $\mathrm{p}<0.05^{\star}$ \\
$6 \times 5$ & $\mathrm{p}<0.05^{\star}$ \\
$5 \times 2$ & $\mathrm{p}<0.05^{\star}$ \\
$5 \times 1$ & $\mathrm{p}<0.05^{\star}$ \\
$5 \times 3$ & $\mathrm{p}<0.05^{\star}$ \\
$5 \times 4$ & $\mathrm{p}<0.05^{\star}$ \\
$4 \times 2$ & $\mathrm{p}<0.05^{\star}$ \\
$4 \times 1$ & $\mathrm{p}<0.05^{\star}$ \\
$4 \times 3$ & $\mathrm{p}>0,05^{\star}$ \\
$3 \times 2$ & $\mathrm{p}<0.05^{\star}$ \\
$3 \times 1$ & $\mathrm{p}<0.05^{\star}$ \\
$1 \times 2$ & $\mathrm{p}<0.05^{*}$ \\
\hline
\end{tabular}

Não houve diferença estatisticamente significante somente entre os sextantes 4 e 3 (tabela 60). 
Tabela 61. Teste de Kruskal-Wallis - Comparação entre índice gengival e faixas etárias para sextante 4 .

\begin{tabular}{lcc}
\hline Faixas etárias & Escores & $N$ \\
\hline $15-25$ & 1 & 232 \\
$26-35$ & 2 & 115 \\
$36-49$ & 3 & 51 \\
\hline
\end{tabular}

$\mathrm{H}=7,95 ; \mathrm{p}=0,018$

Houve diferença estatisticamente significante entre as faixas etárias 15-25 e 36-49 anos de idade (tabela 61).

Tabela 62. Teste de Kruskal-Wallis - Comparação entre índice de placa e faixas etárias para sextante 5 .

\begin{tabular}{rcc}
\hline Faixas etárias & Escores & $N$ \\
\hline $15-25$ & 1 & 232 \\
$26-35$ & 2 & 115 \\
$36-49$ & 3 & 53 \\
\hline
\end{tabular}

$\mathrm{H}=20,83 ; p=0,000$

A comparação entre o índice de placa e as faixas etárias em cada sextante foi obtida pelo teste estatístico de Kruskal-Wallis, que demosntrou não haver diferença estatisticamente significante entre as faixas etárias para o índice de placa nos sextantes 1 $(H=1,36 ; p=0,505), 2(H=3,54 ; p=0,169), 3(H=2,86 ; p=238)$ e $6(H=3,43 ; p=0,179)$. Houve diferença somente no sextante 4 (tabela 62), sextante 5 (tabela 62).

Houve diferença estatisticamente significante entre as faixas etárias 15-25 e 26-35 anos de idade (tabela 62).

As comparações entre o índice de placa e os tipos de fissuras para cada sextante estão representadas nas tabelas $63,64,65,66,67$ e 68. Todas as comparações foram estatisticamente significantes.

Tabela 63. Teste de Kruskal-Wallis - Comparação entre índice de placa e tipos de fissuras no sextante 1.

\begin{tabular}{lc}
\hline Tipos de fissuras & $N$ \\
\hline LAPE & 123 \\
LAB & 48 \\
LAPD & 52 \\
LAPB & 90 \\
LAE & 46 \\
LAD & 41 \\
\hline H=35,74; $p=0,000$ &
\end{tabular}

$H=35,74 ; p=0,000$ 
Houve diferença estatisticamente significante entre o índice de placa e os tipos de fissuras no sextante $1(p=0,000)$ (tabela 63).

Nas comparações individuais (Teste de Dunn) observou-se que a comparação entre as fissuras LAD e LAB, LAD e LAPE, LAPD e LAB, LAPD e LAPE, LAPB e LAB, LAPB e LAPE foram diferentes entre si e essa diferença foi estatisticamente significante.

Tabela 64. Teste de Kruskal-Wallis - Comparação entre índice de placa e tipos de fissuras no sextante 2 .

\begin{tabular}{lc}
\hline Tipos de fissuras & $N$ \\
\hline LAPE & 123 \\
LAB & 48 \\
LAPD & 52 \\
LAPB & 85 \\
LAE & 46 \\
LAD & 41 \\
\hline H= 36,30; $=0,000$ &
\end{tabular}

Houve diferença estatisticamente significante entre o índice de placa e os tipos de fissuras no sextante 2 ( $p=0,000$ ) (tabela 64).

Nas comparações individuais (Teste de Dunn) observou-se que a comparação entre as fissuras LAD e LAPE, LAD e LAB, LAPB e LAPE, LAPB e LB, foram diferentes entre si e essa diferença foi estatisticamente significante.

Tabela 65. Teste de Kruskal-Wallis - Comparação entre índice de placa e tipos de fissuras no sextante 3.

\begin{tabular}{lc}
\hline Tipos de fissuras & $N$ \\
\hline LAPE & 123 \\
LAB & 48 \\
LAPD & 52 \\
LAPB & 90 \\
LAE & 46 \\
LAD & 41 \\
\hline H= 43,24; $p=0,000$ &
\end{tabular}

Houve diferença estatisticamente significante entre o índice de placa e os tipos de fissuras no sextante $3(p=0,000)$ (tabela 65).

Nas comparações individuais (Teste de Dunn) observou-se que a comparação entre as fissuras LAD e LAE, LAD e LAB, LAD e LAPE, LAD e LAPD, LAD e LAPB, LAPB e LAE foram diferentes entre si e essa diferença foi estatisticamente significante. 
Tabela 66. Teste de Kruskal-Wallis - Comparação entre índice de placa e tipos de fissuras no sextante 4.

\begin{tabular}{lc}
\hline Tipos de fissuras & $N$ \\
\hline LAPE & 121 \\
LAB & 48 \\
LAPD & 52 \\
LAPB & 90 \\
LAE & 46 \\
LAD & 41 \\
\hline H=32,57: $=0,000$ &
\end{tabular}

Houve diferença estatisticamente significante entre o índice de placa e os tipos de fissuras no sextante $4(p=0,000)$ (tabela 66$)$.

Nas comparações individuais (Teste de Dunn) observou-se que a comparação entre as fissuras LAD e LAB, LAD e LAPE, LAD e LAPB, foram diferentes entre si e essa diferença foi estatisticamente significante.

Tabela 67. Teste de Kruskal-Wallis - Comparação entre o índice de placa e tipos de fissuras no sextante 5 .

\begin{tabular}{lc}
\hline Tipos de fissuras & $N$ \\
\hline LAPE & 123 \\
LAB & 48 \\
LAPD & 52 \\
LAPB & 90 \\
LAE & 46 \\
LAD & 41 \\
\hline H=34,89; $=0,000$ &
\end{tabular}

Houve diferença estatisticamente significante entre o índice de placa e os tipos de fissuras no sextante 5 ( $p=0,000)$ (tabela 67 ).

Nas comparações individuais (Teste de Dunn) observou-se que a comparação entre as fissuras $L A D$ e $L A B, L A D$ e $L A P B, L A D$ e $L A P E, L A D$ e $L A E$, LAPD e $L A B$ foram diferentes entre si e essa diferença foi estatisticamente significante.

Tabela 68. Teste de Kruskal-Wallis - Comparação entre índice de placa e tipos de fissura no sextante 6 .

\begin{tabular}{|c|c|}
\hline Tipos de fissuras & $\bar{N}$ \\
\hline LAPE & 123 \\
\hline LAB & 48 \\
\hline LAPD & 50 \\
\hline LAPB & 90 \\
\hline LAE & 46 \\
\hline LAD & 41 \\
\hline
\end{tabular}


Houve diferença estatisticamente significante entre o índice de placa e os tipos de fissuras no sextante $6(p=0,000)$ (tabela 68).

Nas comparações individuais (Teste de Dunn) observou-se que a comparação entre as fissuras $L A D$ e $L A B$, LAD e LAPE, LAD e LAPB, LAD e LAE, LAPD e LAB foram diferentes entre si e essa diferença foi estatisticamente significante.

Tabela 69. Teste de Kruskal-Wallis - Comparação entre índice de placa e tipos de fissuras nos sextantes.

\begin{tabular}{lc}
\hline Tipos de fissuras & $N$ \\
\hline LAPE & 123 \\
LAB & 48 \\
LAPD & 52 \\
LAPB & 90 \\
LAE & 46 \\
LAD & 41 \\
\hline H=35,10; $=0,000$ &
\end{tabular}

Houve diferença estatisticamente significante entre o índice de placa e os tipos de fissuras em todos os sextantes ( $p=0,000)$ (tabela 69 ).

Nas comparações individuais (Teste de Dunn) observou-se que a comparação entre as fissuras LAD e LAB, LAD e LAPE, LAD e LAE, LAD e LAPB, LAPD e LAB, LAPD e LAPE foram diferentes entre si e essa diferença foi estatisticamente significante.

Tabela 70. Teste Mann-Whitney - Comparação entre os gêneros, por sextante, quanto ao índice de placa.

\begin{tabular}{lccc}
\hline Sextantes & $p$ & Masculino & Feminino \\
& & $N$ & $N$ \\
\hline 1 & 0,551 & 201 & 199 \\
2 & 0,917 & 198 & 197 \\
3 & 0,965 & 201 & 199 \\
4 & 0,488 & 200 & 198 \\
5 & 0,188 & 201 & 199 \\
6 & 0,926 & 200 & 198 \\
\hline
\end{tabular}

Na comparação entre os gêneros, por sextante quanto ao índice de placa pelo Teste de Mann-Whitney. Não houve diferença estatisticamente significante entre nenhuma das comparações (tabela 70). 
Tabela 71. Correlação entre a classificação sócio-econômica e os parâmetros periodontais (Correlação de Sperman).

\begin{tabular}{lcc}
\hline Parâmetros periodontais & $r$ & $p$ \\
\hline PS & $-0,06$ & 0,179 \\
NI & 0,09 & $0,046^{*}$ \\
IP & $-0,19$ & $0,000^{*}$ \\
IG & $-0,20$ & $0,000^{*}$ \\
\hline
\end{tabular}

${ }^{*}$ Diferença estatisticamente significante

A comparação entre os parâmetros periodontais: profundidade de sondagem (PS), nível de inserção (NI), índice de placa (IP) e índice gengival (IG) com a classificação sócioeconômica foi realizada pelo teste de correlação de Spearman (tabela 71). Houve diferença estatisticamente significante entre a classe social e nível de inserção $(r=-0,06 ; p=0,046)$, índice de placa $(r=-0,19 ; p=0,00)$ e índice gengival $(r=-0,20, p=0,00)$, as correlações foram fracas. A correlação foi positiva somente com o nível de inserção. 
Tabela 72. Médias e desvios padrão da recessão gengival por faixas etárias, gêneros, tipos de fissuras dos sextantes superiores.

\begin{tabular}{|c|c|c|c|c|c|c|c|c|}
\hline \multirow{2}{*}{$\begin{array}{l}\text { Faixas } \\
\text { etárias }\end{array}$} & \multirow[t]{2}{*}{ Gêneros } & \multirow{2}{*}{$\begin{array}{l}\text { Tipos de } \\
\text { fissuras }\end{array}$} & \multicolumn{2}{|c|}{ S1 } & \multicolumn{2}{|c|}{ S2 } & \multicolumn{2}{|c|}{ S3 } \\
\hline & & & Média & $d p$ & Média & $d p$ & Média & $d p$ \\
\hline \multirow[t]{12}{*}{$15-25$} & $\mathrm{M}$ & LAPE & 0,00 & 0,000 & 0,06 & 0,249 & 0,00 & 0,00 \\
\hline & M & LAB & 0,23 & 0,438 & 0,15 & 0,375 & 0,00 & 0,00 \\
\hline & $M$ & LAPD & 0,50 & 0,904 & 0,41 & 0,668 & 0,16 & 0,57 \\
\hline & $M$ & LAPB & 0,00 & 0,000 & 0,10 & 0,309 & 0,06 & 0,25 \\
\hline & $\mathrm{M}$ & LAE & 0,14 & 0,363 & 0,21 & 0,425 & 0,07 & 0,26 \\
\hline & M & LAD & 0,20 & 0,421 & 0,10 & 0,316 & 0,00 & 0,00 \\
\hline & $\mathrm{F}$ & LAPE & 0,00 & 0,000 & 0,10 & 0,311 & 0,00 & 0,00 \\
\hline & $\mathrm{F}$ & LAB & 0,14 & 0,363 & 0,14 & 0,363 & 0,00 & 0,00 \\
\hline & $\mathrm{F}$ & LAPD & 0,75 & 1,238 & 0,37 & 0,718 & 0,18 & 0,54 \\
\hline & $\mathrm{F}$ & LAPB & 0,03 & 0,182 & 0,10 & 0,305 & 0,00 & 0,00 \\
\hline & $\mathrm{F}$ & LAE & 0,21 & 0,425 & 0,21 & 0,425 & 0,21 & 0,57 \\
\hline & $\mathrm{F}$ & LAD & 0,18 & 0,404 & 0,09 & 0,301 & 0,00 & 0,00 \\
\hline \multirow[t]{12}{*}{$26-35$} & M & LAPE & 0,33 & 0,795 & 0,23 & 0,700 & 0,28 & 0,71 \\
\hline & M & LAB & 0,20 & 0,447 & 0,40 & 0,894 & 0,20 & 0,44 \\
\hline & M & LAPD & 0,60 & 0,516 & 0,80 & 1,549 & 0,60 & 0,69 \\
\hline & M & LAPB & 0,27 & 0,467 & 0,63 & 0,924 & 0,27 & 0,46 \\
\hline & M & LAE & 0,20 & 0,447 & 0,00 & 0,000 & 0,20 & 0,44 \\
\hline & M & LAD & 0,16 & 0,389 & 0,41 & 0,514 & 0,16 & 0,38 \\
\hline & $\mathrm{F}$ & LAPE & 0,27 & 0,751 & 0,33 & 0,766 & 0,50 & 0,78 \\
\hline & $\mathrm{F}$ & LAB & 0,20 & 0,447 & 0,40 & 0,894 & 0,20 & 0,44 \\
\hline & $\mathrm{F}$ & LAPD & 1,00 & 1,309 & 0,50 & 1,069 & 0,62 & 0,74 \\
\hline & $\mathrm{F}$ & LAPB & 0,44 & 0,527 & 1,00 & 0,866 & 0,22 & 0,44 \\
\hline & $\mathrm{F}$ & LAE & 0,00 & 0,000 & 0,00 & 0,000 & 0,33 & 0,81 \\
\hline & $\mathrm{F}$ & LAD & 0,20 & 0,447 & 0,40 & 0,547 & 0,00 & 0,00 \\
\hline \multirow[t]{12}{*}{$36-49$} & $\mathrm{M}$ & LAPE & 2,14 & 1,069 & 0,42 & 0,786 & 1,00 & 0,57 \\
\hline & M & LAB & 0,80 & 1,095 & 1,20 & 1,643 & 0,40 & 0,54 \\
\hline & M & LAPD & 0,00 & 0,000 & 0,00 & 0,000 & 0,00 & 0,00 \\
\hline & M & LAPB & 0,57 & 0,975 & 1,75 & 2,061 & 0,71 & 1,25 \\
\hline & M & LAE & 0,25 & 0,500 & 0,00 & 0,000 & 1,00 & 0,00 \\
\hline & M & LAD & 0,00 & 0,000 & 0,50 & 0,707 & 0,50 & 0,70 \\
\hline & F & LAPE & 1,50 & 1,309 & 0,25 & 0,707 & 0,75 & 0,70 \\
\hline & $\mathrm{F}$ & LAB & 1,16 & 1,329 & 1,33 & 1,505 & 0,50 & 0,54 \\
\hline & $\mathrm{F}$ & LAPD & 1,00 & 1,000 & 0,33 & 0,577 & 0,33 & 0,57 \\
\hline & $\mathrm{F}$ & LAPB & 0,50 & 1,000 & 0,00 & 0,000 & 0,75 & 1,50 \\
\hline & $\mathrm{F}$ & LAE & 0,33 & 0,577 & 0,00 & 0,000 & 0,66 & 0,57 \\
\hline & $\mathrm{F}$ & LAD & 0,00 & 0,000 & 1,00 & 0,000 & 0,00 & 0,00 \\
\hline
\end{tabular}


Tabela 73. Médias e desvios padrão da recessão gengival por faixas etárias, gêneros, tipos de fissuras dos sextantes inferiores.

\begin{tabular}{|c|c|c|c|c|c|c|c|c|}
\hline \multirow{2}{*}{$\begin{array}{l}\text { Faixas } \\
\text { etárias }\end{array}$} & \multirow[t]{2}{*}{ Gêneros } & \multirow{2}{*}{$\begin{array}{l}\text { Tipos de } \\
\text { fissuras }\end{array}$} & \multicolumn{2}{|c|}{ S4 } & \multicolumn{2}{|c|}{ S5 } & \multicolumn{2}{|c|}{ S6 } \\
\hline & & & Média & $d p$ & Média & $d p$ & Média & $d p$ \\
\hline \multirow[t]{12}{*}{$15-25$} & $M$ & LAPE & 0,03 & 0,179 & 0,00 & 0,000 & 0,09 & 0,300 \\
\hline & M & LAB & 0,00 & 0,000 & 0,00 & 0,000 & 0,23 & 0,438 \\
\hline & $\mathrm{M}$ & LAPD & 0,16 & 0,389 & 0,16 & 0,577 & 0,41 & 0,668 \\
\hline & $\mathrm{M}$ & LAPB & 0,06 & 0,257 & 0,13 & 0,515 & 0,17 & 0,384 \\
\hline & $\mathrm{M}$ & LAE & 0,35 & 0,744 & 0,28 & 0,726 & 0,28 & 0,611 \\
\hline & M & LAD & 0,00 & 0,000 & 0,00 & 0,000 & 0,10 & 0,316 \\
\hline & $F$ & LAPE & 0,02 & 0,162 & 0,00 & 0,000 & 0,10 & 0,388 \\
\hline & $\mathrm{F}$ & LAB & 0,00 & 0,000 & 0,00 & 0,000 & 0,28 & 0,468 \\
\hline & $\mathrm{F}$ & LAPD & 0,25 & 0,577 & 0,31 & 0,704 & 0,37 & 0,619 \\
\hline & $\mathrm{F}$ & LAPB & 0,03 & 0,182 & 0,06 & 0,365 & 0,23 & 0,430 \\
\hline & $\mathrm{F}$ & LAE & 0,28 & 0,611 & 0,42 & 0,851 & 0,35 & 0,744 \\
\hline & $\mathrm{F}$ & LAD & 0,00 & 0,000 & 0,18 & 0,603 & 0,09 & 0,301 \\
\hline \multirow[t]{12}{*}{$26-35$} & M & LAPE & 0,76 & 0,830 & 0,52 & 0,813 & 0,38 & 0,804 \\
\hline & M & LAB & 0,40 & 0,894 & 0,20 & 0,447 & 0,60 & 0,547 \\
\hline & M & LAPD & 1,50 & 1,779 & 0,60 & 0,516 & 1,10 & 1,523 \\
\hline & M & LAPB & 1,18 & 1,401 & 1,45 & 1,507 & 0,81 & 0,750 \\
\hline & M & LAE & 0,20 & 0,447 & 0,20 & 0,447 & 0,00 & 0,000 \\
\hline & M & LAD & 0,08 & 0,288 & 0,83 & 1,029 & 0,16 & 0,389 \\
\hline & $F$ & LAPE & 0,88 & 0,832 & 0,38 & 0,607 & 0,38 & 0,849 \\
\hline & $F$ & LAB & 0,40 & 0,894 & 0,20 & 0,447 & 0,60 & 0,547 \\
\hline & $\mathrm{F}$ & LAPD & 1,50 & 1,309 & 0,62 & 0,517 & 1,12 & 1,642 \\
\hline & $\mathrm{F}$ & LAPB & 1,11 & 1,364 & 1,11 & 1,691 & 1,11 & 0,781 \\
\hline & $\mathrm{F}$ & LAE & 0,16 & 0,408 & 0,16 & 0,408 & 0,00 & 0,000 \\
\hline & $\mathrm{F}$ & LAD & 0,00 & 0,000 & 0,80 & 1,095 & 0,20 & 0,447 \\
\hline \multirow[t]{12}{*}{$36-49$} & $M$ & LAPE & 2,00 & 0,000 & 1,00 & 1,000 & 0,71 & 0,951 \\
\hline & M & LAB & 1,20 & 1,643 & 1,20 & 1,643 & 1,20 & 1,643 \\
\hline & M & LAPD & 0,00 & 0,000 & 0,00 & 0,000 & 0,00 & 0,000 \\
\hline & $\mathrm{M}$ & LAPB & 0,28 & 0,755 & 0,14 & 0,377 & 1,14 & 1,345 \\
\hline & $\mathrm{M}$ & LAE & 1,00 & 0,000 & 1,00 & 0,816 & 1,75 & 1,500 \\
\hline & $\mathrm{M}$ & LAD & 2,00 & 0,000 & 0,50 & 0,707 & 1,50 & 2,121 \\
\hline & $F$ & LAPE & 1,71 & 0,755 & 0,87 & 0,991 & 0,62 & 0,916 \\
\hline & $\mathrm{F}$ & LAB & 1,33 & 1,505 & 1,50 & 1,643 & 1,33 & 1,505 \\
\hline & $\mathrm{F}$ & LAPD & 1,00 & 1,000 & 0,33 & 0,577 & 0,00 & 0,000 \\
\hline & $\mathrm{F}$ & LAPB & 0,50 & 1,000 & 0,00 & 0,000 & 0,75 & 1,500 \\
\hline & $\mathrm{F}$ & LAE & 1,00 & 1,000 & 0,33 & 0,577 & 1,00 & 1,732 \\
\hline & $F$ & LAD & 1,00 & 0,000 & 0,00 & 0,000 & 0,00 & 0,000 \\
\hline
\end{tabular}

As médias de recessão gengival variaram de 0,0 a $2,14 \mathrm{~mm}$ nos sextantes superiores e de 0,0 a 2,00 nos sextantes inferiores. Houve aumento na média da recessão gengival com o avanço da idade (tabelas 73 e 74). 
Tabela 74. Médias e desvios padrão da recessão gengival por sextantes.

\begin{tabular}{ccc}
\hline Sextantes & Média & $\begin{array}{c}\text { Desvio } \\
\text { padrão }\end{array}$ \\
\hline 1 & 0,30 & 0,708 \\
2 & 0,28 & 0,692 \\
3 & 0,20 & 0,519 \\
4 & 0,41 & 0,843 \\
5 & 0,33 & 0,768 \\
6 & 0,39 & 0,795 \\
\hline
\end{tabular}

Os sextantes 2 e 3 foram os que tiveram menores valores médios de recessão gengival. A maior média foi do sextante 4 (tabela 74).

Tabela 75. Médias e desvios padrão da recessão gengival por tipos de fissuras nos sextantes superiores.

\begin{tabular}{llllclcl}
\hline $\begin{array}{l}\text { Tipos de } \\
\text { fissuras }\end{array}$ & Média & $d p$ & Média & $d p$ & \multicolumn{2}{c}{$S 3$} \\
\hline LAPE & 0,31 & 0,823 & 0,17 & 0,528 & 0,22 & 0,555 \\
LAB & 0,37 & 0,732 & 0,45 & 0,944 & $\mathbf{0 , 1 4}$ & 0,356 \\
LAPD & 0,67 & 1,004 & 0,46 & 0,938 & 0,32 & 0,617 \\
LAPB & 0,15 & 0,447 & 0,34 & 0,764 & 0,16 & 0,545 \\
LAE & 0,17 & 0,383 & 0,13 & 0,340 & 0,28 & 0,544 \\
LAD & 0,17 & 0,380 & 0,26 & 0,448 & 0,07 & 0,263 \\
\hline
\end{tabular}

Tabela 76. Médias e desvios padrão da recessão gengival por tipos de fissuras nos sextantes inferiores.

\begin{tabular}{lcccrrrr}
\hline $\begin{array}{l}\text { Tipos de } \\
\text { fissuras }\end{array}$ & Média & $d p$ & \multicolumn{2}{c}{ S5 } & \multicolumn{2}{c}{$S 6$} \\
\hline LAPE & 0,47 & 0,786 & 0,26 & 0,611 & 0,26 & 0,638 \\
LAB & 0,37 & 0,936 & 0,35 & 0,933 & 0,56 & 0,896 \\
LAPD & $\mathbf{0 , 6 9}$ & 1,163 & 0,36 & 0,595 & 0,62 & 1,085 \\
LAPB & 0,33 & 0,834 & 0,36 & 0,953 & 0,46 & 0,752 \\
LAE & 0,39 & 0,649 & 0,36 & 0,710 & 0,41 & 0,883 \\
LAD & 0,14 & 0,477 & 0,41 & 0,805 & 0,19 & 0,557 \\
\hline
\end{tabular}

Nas tabelas 75 e 76 estão descritos os valores médios da recessão gengival por fissura nos sextantes superiores e inferiores, respectivamente. A fissura de LAPD foi a com as maiores médias em quase todos os sextantes com exceção do sextante 5 . As médias variaram de 0,14 a $0,69 \mathrm{~mm}$. 
Tabela 77. Médias e desvios padrão da recessão gengival por gêneros nos sextantes superiores.

\begin{tabular}{lllllll}
\hline Gêneros & \multicolumn{2}{c}{$S 1$} & \multicolumn{2}{c}{ S2 } & \multicolumn{2}{c}{ S3 } \\
& Média & $d p$ & Média & $d p$ & Média & $d p$ \\
\hline Masculino & 0,28 & 0,658 & 0,30 & 0,746 & 0,21 & 0,518 \\
Feminino & 0,32 & 0,756 & 0,27 & 0,635 & 0,20 & 0,522 \\
\hline
\end{tabular}

Tabela 78. Médias e desvios padrão da recessão gengival por gêneros dos sextantes inferiores.

\begin{tabular}{lcccrrr}
\hline Gêneros & \multicolumn{2}{c}{ S4 } & \multicolumn{2}{c}{ S5 } & \multicolumn{2}{c}{ S6 } \\
& Média & $d p$ & Média & $d p$ & Média & \multicolumn{1}{c}{$d p$} \\
\hline Masculino & 0,43 & 0,876 & 0,36 & 0,789 & 0,41 & 0,816 \\
Feminino & 0,40 & 0,811 & 0,30 & 0,746 & 0,38 & 0,776 \\
\hline
\end{tabular}

A média da recessão gengival por gênero foi muito semelhante em todos os sextantes (tabelas 77 e 78).

Tabela 79. Médias e desvios padrão da recessão gengival por faixas etárias dos sextantes superiores.

\begin{tabular}{lrrrrrr}
\hline Faixas etárias & \multicolumn{2}{c}{$S 1$} & \multicolumn{2}{c}{$S 2$} & \multicolumn{2}{c}{$S 3$} \\
& Média & $d p$ & Média & $d p$ & Média & $d p$ \\
\hline $15-25$ & 0,14 & 0,484 & 0,15 & 0,393 & 0,04 & 0,267 \\
$26-35$ & 0,33 & 0,673 & 0,43 & 0,849 & 0,33 & 0,617 \\
$36-49$ & 0,92 & 1,141 & 0,60 & 1,124 & 0,64 & 0,761 \\
\hline
\end{tabular}

Nos sextantes superiores houve um aumento dos valores das médias da recessão gengival com o aumento da idade (tabela 79). O mesmo ocorreu com os sextantes inferiores (tabela 80).

Tabela 80. Médias e desvios padrão da recessão gengival por faixas etárias dos sextantes inferiores.

\begin{tabular}{lcccccc}
\hline Faixas etárias & \multicolumn{2}{c}{$S 4$} & \multicolumn{2}{c}{ S5 } & \multicolumn{2}{c}{ S6 } \\
& Média & $d p$ & Média & $d p$ & Média & $d p$ \\
\hline $15-25$ & 0,08 & 0,337 & 0,10 & 0,447 & 0,20 & 0,465 \\
$26-35$ & 0,77 & 1,092 & 0,63 & 0,958 & 0,54 & 0,919 \\
$36-49$ & 1,11 & 1,051 & 0,69 & 1,030 & 0,94 & 1,255 \\
\hline
\end{tabular}




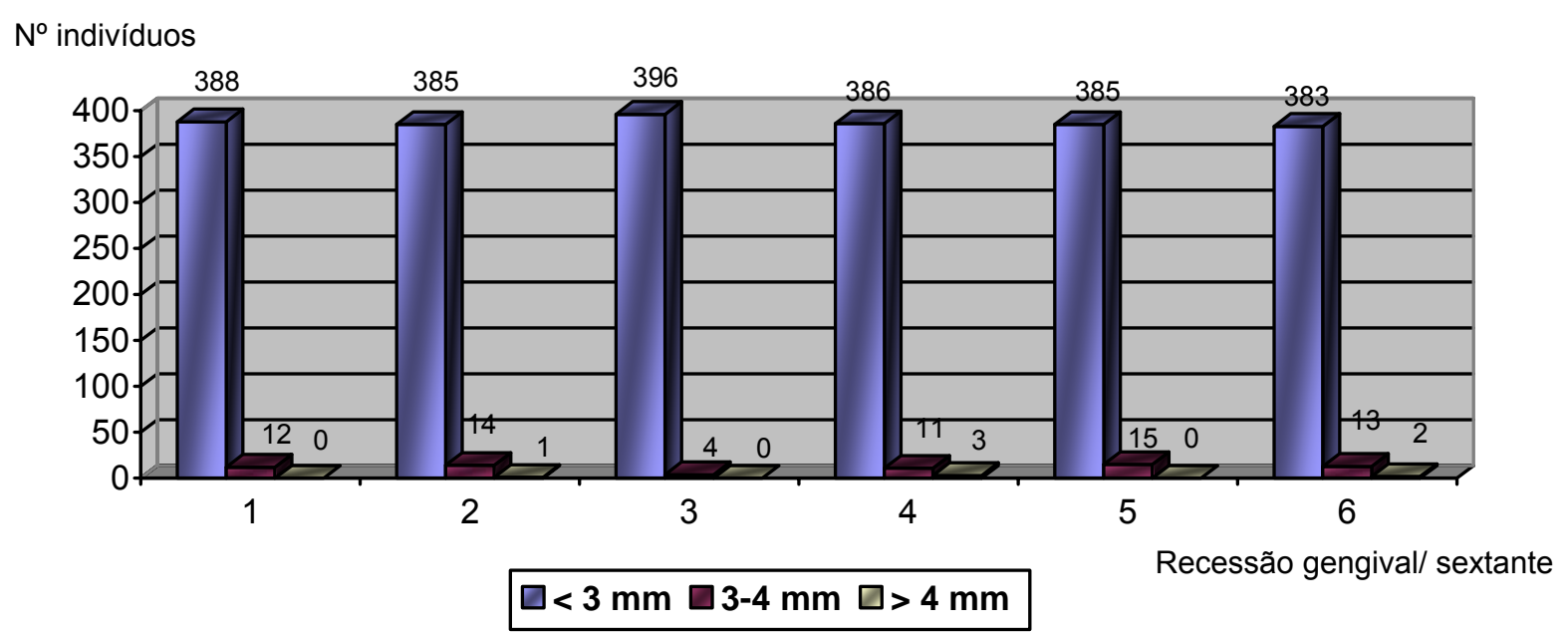

Figura 15. Distribuição da extensão da recessão gengival por sextante.

Em todos os sextantes houve predomínio das recessões menores que $3 \mathrm{~mm}$ e nos sextantes 1, 3 e 5 não houve nenhum dente com recessão maior que $4 \mathrm{~mm}$ (figura 15).

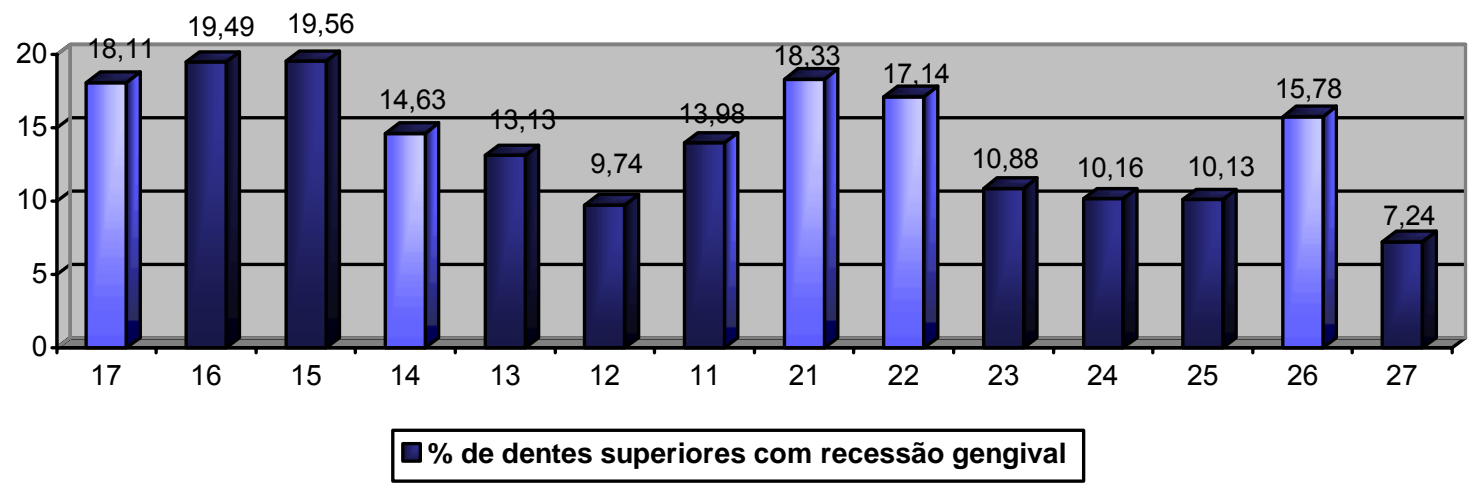

Figura 16. Distribuição da recessão gengival em cada dente superior.

Na figura 16 podemos observar a freqüência da presença da recessão gengival nos dentes superiores. Os dentes com maiores porcentagens foram o 15 e 16 . Dos dentes próximos na área da fissura o 21 e 22 foram os com maiores médias $(18,33 \%$ e 17,14\%, respectivamente). 


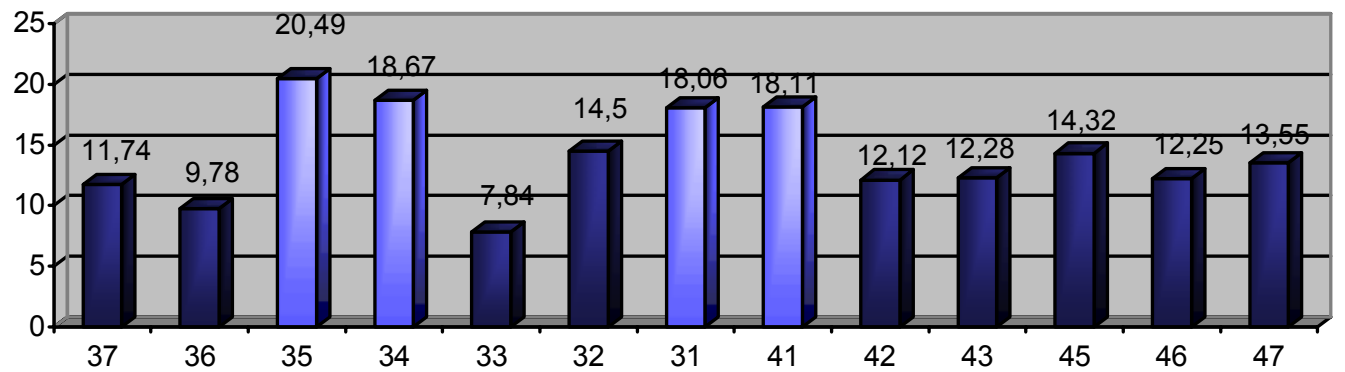

$\square \%$ de dentes inferiores com recessão gengival

Figura 17. Distribuição da recessão gengival de cada dente inferior.

Os dentes inferiores que tiveram maiores porcentagens foram $35(20,49 \%), 34(18,67$ $\%), 31(18,06 \%)$ e 41 (18,11\%) (figura 17$)$.

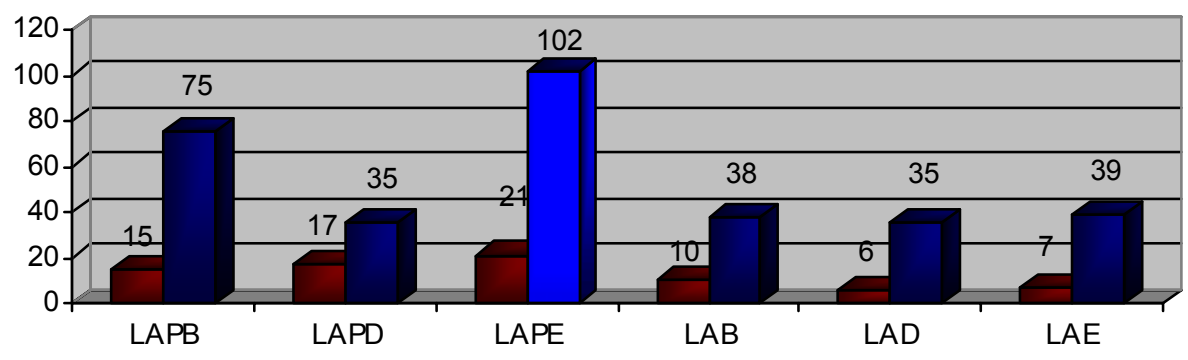

$\square$ sem recessão $\square$ com recessão

Figura 18. Distribuição da recessão gengival por tipo de fissura.

O tipo de fissura com maior número de dentes com recessão gengival foi a LAPE, e a com menos foram LAPD e LAD (figura 18). 


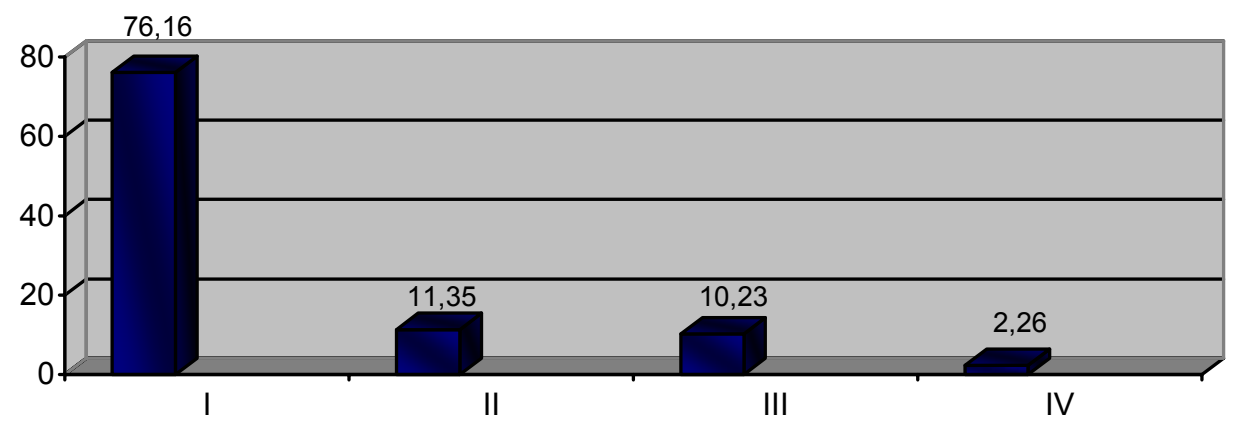

\% de dentes com recessão em cada classe de Miller

Figura 19. Distribuição da freqüência dos dentes com recessão gengival de acordo com a classificação de Miller (1985).

As recessões gengivais quando presentes foram classificadas conforme Miller. A Classe I foi a mais predominante $(76,16 \%)$, seguida pela classe II, III e IV $(11,35 \%, 10,23 \%$ e $2,26 \%$ respectivamente).

Tabela 81. Teste de Friedman - Comparação entre a recessão gengival e os sextantes.

\begin{tabular}{lcc}
\hline Sextantes & Média & Desvio padrão \\
\hline 1 & 0,30 & 0,714 \\
2 & 0,28 & 0,694 \\
3 & 0,20 & 0,520 \\
4 & 0,42 & 0,849 \\
5 & 0,34 & 0,774 \\
6 & 0,40 & 0,801 \\
\hline
\end{tabular}

$X^{2}=41,18 ; p<0,0001$

$\mathrm{Na}$ comparação entre a recessão gengival e os sextantes houve diferença estatisticamente significante ( $p<0,0001$; tabela 81$)$.

Tabela 82. Teste de Kruskal - Wallis - Comparação entre recessão gengival e faixas etárias para o sextante 1 .

\begin{tabular}{ccc}
\hline Faixas etárias & Escores & $N$ \\
\hline $15-25$ & 1 & 232 \\
$26-35$ & 2 & 115 \\
$36-49$ & 3 & 53 \\
\hline
\end{tabular}


Todas as faixas etárias foram diferentes entre si na comparação entre recessão gengival e faixas etárias para o sextante 1 e essa diferença foi estatisticamente significante $(p=0,000$; tabela 82).

Tabela 83. Teste de Kruskal - Wallis - Comparação entre recessão gengival e faixas etárias para o sextante 2.

\begin{tabular}{ccc}
\hline Faixas etárias & Escores & $N$ \\
\hline $15-25$ & 1 & 232 \\
$26-35$ & 2 & 115 \\
$36-49$ & 3 & 48 \\
\hline
\end{tabular}

$H=14,15 ; p=0,000$

Houve diferença estatisticamente significante entre as faixas etárias 15-25 e 26-35, 15 25 e 36-49 anos de idade (tabela 83).

Tabela 84. Teste de Kruskal - Wallis - Comparação entre recessão gengival e faixas etárias para o sextante 3.

\begin{tabular}{ccc}
\hline Faixas etárias & Escores & $N$ \\
\hline $15-25$ & 1 & 232 \\
$26-35$ & 2 & 115 \\
$36-49$ & 3 & 53 \\
\hline $\mathrm{H}=81,98 ; \mathrm{p}=0,000$ & &
\end{tabular}

Todas as faixas etárias foram diferentes entre si quanto às médias de recessão gengival no sextante 3 (tabela 84).

Tabela 85. Teste Kruskal - Wallis - Comparação entre recessão gengival e faixas etárias para o sextante 4 .

\begin{tabular}{ccc}
\hline FaixasEtárias & Escores & $N$ \\
\hline $15-25$ & 1 & 232 \\
$26-35$ & 2 & 115 \\
$36-49$ & 3 & 51 \\
\hline
\end{tabular}

$\mathrm{H}=97,38 ; \mathrm{p}=0,000$

No sextante 4, houve diferença estatisticamente significante das médias da recessão gengival entre todas as faixas etárias (tabela 85). 
Tabela 86. Teste Kruskal - Wallis - Comparação entre recessão gengival e faixas etárias para o sextante 5 .

\begin{tabular}{ccc}
\hline Faixas etárias & Escores & $N$ \\
\hline $15-25$ & 1 & 232 \\
$26-35$ & 2 & 115 \\
$36-49$ & 3 & 53 \\
\hline
\end{tabular}

$\mathrm{H}=68,99 ; \mathrm{p}=0,000$

Houve diferença estatisticamente significante entre as faixas etárias 15-25 e 26-35, 1525 e 36-49 anos de idade (tabela 86).

Tabela 87. Teste Kruskal - Wallis - Comparação entre recessão gengival e faixas etárias para o sextante 6 .

\begin{tabular}{ccc}
\hline Faixas etárias & Escores & $N$ \\
\hline $15-25$ & 1 & 232 \\
$26-35$ & 2 & 115 \\
$36-49$ & 3 & 51 \\
\hline
\end{tabular}

$\mathrm{H}=26,63 ; \mathrm{p}=0,000$

Houve diferença estatisticamente significante entre as faixas etárias 15-25 e 26-35, 15-25 e 36-49 anos de idade (tabela 87).

A comparação entre tipos de fissura e recessão gengival nos sextantes tiveram diferenças estatisticamente significante somente entre os sextantes 1, 4 e 6 (tabelas 89, 90 e 91). O teste de Dunn que faz comparações individuais mostrou diferença estatisticamente significante entre os tipos de fissura para a recessão gengival nos sextantes $2(H=9,70$; $p=0,084), 3(H=9,43 ; p=0,093), 5(H=4,38 ; p=0,49)$.

Tabela 88. Teste de Kruskal-Wallis - Comparação entre tipos de fissuras e recessão gengival no sextante 1 .

\begin{tabular}{lc}
\hline Tipos de fissuras & $N$ \\
\hline LAPE & 123 \\
LAB & 48 \\
LAPD & 52 \\
LAPB & 90 \\
LAE & 46 \\
LAD & 41 \\
\hline H=24,71; $=0,000$ &
\end{tabular}

$H=24,71 ; p=0,000$ 
Houve diferença estatisticamente significante entre a presença da recessão gengival e os tipos de fissuras no sextante $1(p=0,000)$ (tabela 88).

Nas comparações individuais (Teste de Dunn) observou-se que a comparação entre as fissuras LAPD e LAPB, LAPD e LAD, LAPD e LAPE, LAPD e LAE foram diferentes entre si e essa diferença foi estatisticamente significante.

Tabela 89. Teste de Kruskal-Wallis - Comparação entre tipos de fissuras e recessão gengival no sextante 4 .

\begin{tabular}{lc}
\hline Tipos de fissuras & $N$ \\
\hline LAPE & 121 \\
LAB & 48 \\
LAPD & 52 \\
LAPB & 90 \\
LAE & 46 \\
LAD & 41 \\
\hline H=15,27; $p=0,009$
\end{tabular}

Houve diferença estatisticamente significante entre a presença da recessão gengival e os tipos de fissuras no sextante $4(p=0,009)$ (tabela 89$)$.

Nas comparações individuais (Teste de Dunn) observou-se que somente a comparação entre as fissuras LAPD e LAD foi diferente entre si e essa diferença foi estatisticamente significante.

Tabela 90. Teste de Kruskal-Wallis - Comparação entre tipos de fissuras e recessão gengival no sextante 6 .

\begin{tabular}{lc}
\hline Tipos de fissuras & $N$ \\
\hline LAPE & 123 \\
LAB & 48 \\
LAPD & 50 \\
LAPB & 90 \\
LAE & 46 \\
LAD & 41 \\
\hline $\mathrm{H}=17,75 ; p=0,003$ &
\end{tabular}

Houve diferença estatisticamente significante entre a presença da recessão gengival e os tipos de fissuras no sextante $6(p=0,003)$ (tabela 90). 
Nas comparações individuais (Teste de Dunn) observou-se que somente a comparação entre as fissuras LAPD e LAD foi diferente entre si e essa diferença foi estatisticamente significante

Tabela 91. Teste de Mann-Whitney - Comparação entre recessão gengival, sextantes e gêneros.

\begin{tabular}{lccc}
\hline Sextantes & $p$ & Masculino & Feminino \\
& & $N$ & $N$ \\
\hline 1 & 0,817 & 201 & 199 \\
2 & 0,908 & 198 & 197 \\
3 & 0,649 & 201 & 199 \\
4 & 0,856 & 200 & 198 \\
5 & 0,303 & 201 & 199 \\
6 & 0,706 & 200 & 198 \\
\hline
\end{tabular}

Não houve diferença estatisticamente significante na comparação entre recessão gengival, sextantes e gênero (tabela 91). 


\section{DISCUSSÃO}




\section{DISCUSSÃO}

A fissura labiopalatina é uma anomalia congênita, que acomete indivíduos de todas as raças, resulta da falta de coalescência dos processos maxilares e frontal. Pode acometer lábio, rebordo alveolar e/ou palato, ser uni ou bilaterais.

Vários estudos foram realizados nas últimas décadas para investigar a prevalência dos diversos tipos de fissuras labiopalatinas, sua etiologia, inter-relação com gênero, raça e classe sócio-econômica.

Em um estudo realizado em Bauru por NAGEM FILHO; MORAIS; ROCHA ${ }^{101}$ (1968) foi observada, em crianças com idade escolar, a incidência de um fissurado para cada 650 crianças; dados semelhantes aos encontrados por FONSECA; REZENDE ${ }^{58}$ (1971) cuja prevalência foi de 1:673. Os autores ainda afirmaram que proporcionalmente houve uma predominância da raça amarela entre as crianças com fissura, seguida pelas raças branca e negra. Quanto ao gênero foi observada uma predominância do gênero masculino, em uma proporção de $2,3: 1$.

ARCE ${ }^{17}$ (1968) não observou influência do nível sócio-econômico sobre a ocorrência da fissura, e também não foi encontrada diferença significante na prevalência de fissuras entre pacientes brancos e de outras etnias. Neste estudo aleatório houve número semelhante de indivíduos do gênero masculino e feminino ( $n=199$ e 201, respectivamente).

No presente estudo a classificação sócio-econômica mais prevalente foi a baixa superior $(n=221$ ), aliás, a classe baixa é a mais encontrada dentre os pacientes matriculados no Hospital de Reabilitação de Anomalias Craniofaciais da Universidade de São Paulo (figura 7). A raça mais prevalente na amostra foi a branca $(n=352)$ corroborando com os estudos de DALBEN ${ }^{50}$ (2002) e FREITAS et al ${ }^{59}$ (2004) (figura 8).

O tipo de fissura descrito na literatura como o mais prevalente no Brasil, é a fissura que acomete concomitantemente lábio, alvéolo e palato, variando de $39 \%$ a $92 \%{ }^{17,43,50,59}$.

O Hospital de Reabilitação de Anomalias Craniofaciais da Universidade de São Paulo foi considerado uma referência internacional pela OMS (Organização Mundial de Saúde). Possui cerca de 60 mil pessoas do país e países vizinhos matriculados, incluindo portadores de fissura labiopalatina e síndromes diversas. Neste estudo foram examinados 400 indivíduos portadores de fissura, casos novos, ou seja, que nunca receberam tratamento nesta instituição, assim como a ausência de tratamento periodontal prévio. Nenhum estudo em periodontia descrito na literatura, com a amostra com essas características, foi relatado na literatura (tabela 92). 
Tabela 92- Descrição da amostra dos estudos de periodontia em indivíduos portadores de fissura labiopalatina.

\begin{tabular}{|c|c|c|c|c|}
\hline Autores & $\begin{array}{c}\text { Ano de } \\
\text { publicação }\end{array}$ & $\begin{array}{c}\text { Número da } \\
\text { amostra }\end{array}$ & $\begin{array}{l}\text { Tipos de } \\
\text { Fissura }\end{array}$ & $\begin{array}{c}\text { Faixa etária da } \\
\text { amostra }\end{array}$ \\
\hline Hinrich et al. ${ }^{69}$ & 1984 & 18 & Unilateral & 7,3 a 13,9 anos \\
\hline Brägger et al. ${ }^{31}$ & 1985 & 80 & LAP, $P, L$ & Não especifica \\
\hline Paul, Brant ${ }^{108}$ & 1988 & 114 & LAP, LA & 3 a 18 anos \\
\hline Ramstad $^{113}$ & 1989 & 50 & LAP, unilateral & 20 a 35 anos \\
\hline Andrade ${ }^{14}$ & 1990 & 41 & LAP, LA & 16 a 31 anos \\
\hline Botta ${ }^{29}$ & 1990 & 50 & LP & $\geq 16$ anos \\
\hline Brägger et al. ${ }^{32}$ & 1990 & 19 & LAP, L, P & 18 a 20 anos \\
\hline Brägger et al. ${ }^{33}$ & 1992 & 52 & $\mathrm{LAP}, \mathrm{L}, \mathrm{P}$ & 18 a 20 anos \\
\hline Teja; Person, Omnell ${ }^{130}$ & 1992 & 18 & $L, P$, unilateral & 31,11 anos \\
\hline Dourado ${ }^{56}$ & 1993 & 200 & Todas & 12 a 66 anos \\
\hline Campos* 40 & 1995 & 404 & Todas & $>10$ anos \\
\hline $\begin{array}{l}\text { Andlin-Sobocki, Ellason, } \\
\text { Paulin }{ }^{13}\end{array}$ & 1995 & 28 & LAP, unilateral & 8 a 13 anos \\
\hline Tan et al. ${ }^{129}$ & 1996 & Adolescentes & Não especifica & 8 a 20 anos \\
\hline Pedreira ${ }^{109}$ & 1998 & 219 & $\mathrm{~L}$ & $\geq 18$ anos \\
\hline $\begin{array}{l}\text { Schutles, Gaggle, } \\
\text { Karcher }{ }^{118}\end{array}$ & 1999 & 30 & $\begin{array}{l}\text { LAP, unilateral, } \\
\mathrm{P}\end{array}$ & 17 a 24 anos \\
\hline Gaggl et al. ${ }^{60}$ & 1999 & 80 & $\begin{array}{l}\text { LAP, uni e } \\
\text { bilateral, LP }\end{array}$ & 17 a 24 anos \\
\hline Costa et a. ${ }^{48}$ & 2003 & 57 & $\begin{array}{l}\text { LAP, unilateral, } \\
\text { Controle }\end{array}$ & 5 a 6 anos \\
\hline Dewinter et al. ${ }^{51}$ & 2003 & 75 & LAP, unilateral & 8 a 20 anos \\
\hline Quirynen ${ }^{110}$ & 2003 & 75 & LAP, unilateral & 8 a 20 anos \\
\hline Salvi, Bragger, Lang ${ }^{115}$ & 2003 & 40 & LA, LAP & Não especifica \\
\hline Lages, Badeia, Pordeus & 2004 & 75 & LAP, LA & 10 a 28 anos \\
\hline $\begin{array}{l}\text { Al-Wahadini, AlHaija, } \\
\text { Al-Omari }^{7}\end{array}$ & 2005 & 31 & LAP, controle & 10 a 28 anos \\
\hline Siqueira ${ }^{122}$ & 2006 & 50 & LAP, controle & 16 a 50 anos \\
\hline Stec et al. ${ }^{127}$ & 2007 & 100 & LAP, unilateral & 3,5 a 18 anos \\
\hline Almeida et al. ${ }^{11}$ & 2007 & 200 & LAP, LA, P & 13 a 56 anos \\
\hline
\end{tabular}

${ }^{*}$ Campos, 1995 - trabalho de análise de prontuário 
Neste trabalho, como critério de inclusão os indivíduos deveriam ter a fissura acometendo necessariamente o rebordo alveolar; foram examinados indivíduos com fissura de lábio e rebordo (135) e com fissura de lábio, rebordo e palato (265), tanto uni quanto bilateral, para avaliar se a fissura que acomete o rebordo seria um fator de risco para a doença periodontal ou apresentassem maior perda de inserção clínica como alguns autores sugeriram em seus estudos ${ }^{60,69}$. Houve maior prevalência dos indivíduos portadores de fissura de lábio, rebordo e palato e somente em algumas comparações os resultados foram significantes, o que era de se esperar já que não houve muita variação nos tipos de fissura (figuras 6, 9 e 10).

A amostra selecionada compreendeu somente os indivíduos com dentição permanente, evitando assim possíveis variáveis que poderiam ocorrer nos resultados ao incluir indivíduos com dentes decíduos ou dentição mista (figura 5). Uma variabilidade de alterações biológicas ocorre durante a infância/adolescência e têm um impacto sobre o desenvolvimento de doença gengival inflamatória.

Durante certos períodos o risco de desenvolvimento de gengivite é relativamente baixo, enquanto em outros os tecidos gengivais são mais susceptíveis e reagem á irritação bacteriana com inflamação. Os fatores que podem ser responsáveis por estas mudanças incluem diferenças na composição da placa bacteriana, nos sistemas de defesa imune e na morfologia dos tecidos gengivais e também fatores relacionados á erupção dentária e puberdade. Pode-se também considerar que ocorre um maior risco ao acúmulo de placa em áreas de esfoliação de dentes decíduos e erupção de dentes permanentes quando a situação torna a escovação mais difícil de ser realizada ${ }^{27,89,90 . ~ A p e s a r ~ d e ~ s e r ~ c e r t a ~ a ~}$ diferença entre as dentições, alguns estudos incluíram em sua amostra indivíduos com faixas etárias muito variadas examinando crianças, jovens e adultos $7,51,56,74,108,110,129$, Outro fator relevante na amostra deste estudo é que nenhum deles estava usando ou tinha usado aparelho ortodôntico, pois segundo a literatura em indivíduos fissurados os braquetes e bandas e a utilização prolongada dos acessórios ortodônticos podem ocasionar um maior acúmulo de placa e inflamação gengival ${ }^{31,60,110}$. Além disso, nenhum dos integrantes da amostra realizou tratamento periodontal anteriormente aos exames, proporcionando resultados mais confiáveis da situação dos tecidos periodontais, ou seja, da prevalência da doença periodontal nesse grupo de indivíduos.

A faixa etária mais predominante neste estudo foi a de 15 a 25 anos, provavelmente pelos fatores de exclusão. Nenhum indivíduo deveria ter realizado tratamento periodontal prévio, ter pelo menos 15 dentes na boca, fatores que limitaram o aceite de vários indivíduos de faixa etária maior (figura 5). Além disso, há uma maior procura por tratamento no Hospital de indivíduos com idade mais precoce. 
Segundo HOHLFELD; BERNIOULIN ${ }^{67}$ (1993), os resultados obtidos de indivíduos com grande número de dentes remanescentes não podem ser comparados com os dados de amostras com poucos dentes; uma amostra com maior número de dentes é fundamental para maior exatidão na determinação dos níveis da doença.

O tratamento dos indivíduos portadores dessa anomalia deve ser realizado por uma equipe multidisciplinar, composta por profissionais especializados de todas as áreas da saúde, sendo a odontologia responsável pela prevenção e tratamento das alterações bucais destes indivíduos.

A Periodontia, especialidade odontológica, responde pela manutenção da saúde bucal (periodontal) e de certa forma, sistêmica dos indivíduos, já que é sabido que alguns patógenos periodontais pode estar relacionado com doenças sistêmicas, assim como a terapêutica da doença periodontal.

$\mathrm{Na}$ literatura existem centenas de estudos que avaliaram as condições periodontais de indivíduos não portadores de fissura. Os trabalhos mais recentes, a partir da década de 80 , demonstraram que a doença periodontal não é universal, apenas alguns indivíduos são susceptíveis, e nestes indivíduos pode ser que somente alguns sítios apresentem (ou possam apresentar) doença periodontal ${ }^{20,71,84,89,90,}$.

Os parâmetros clínicos utilizados no exame periodontal incluem medidas e índices de sinais e sintomas da doença periodontal assim como fatores que predispõem a destruição periodontal. Esses parâmetros são baseados principalmente no grau de inflamação, no nível de comprometimento do tecido de suporte e em fatores que influenciem ou indiquem o nível de higiene oral.

Os exames mais comumente utilizados são profundidade de sondagem e nível de inserção clínica, sendo que o melhor método de avaliação é a medida do nível de inserção clínica, utilizado tanto em trabalhos epidemiológicos transversais como longitudinais $5,16,23$, $32,33,49,81,82,110,111,115,118,122,125$.

A análise periodontal realizada somente em alguns dentes como muitos índices ou estudos preconizam pode subestimar ou superestimar a ocorrência da doença periodontal. Geralmente os grupos de indivíduos mais jovens e nas populações periodontalmente mais

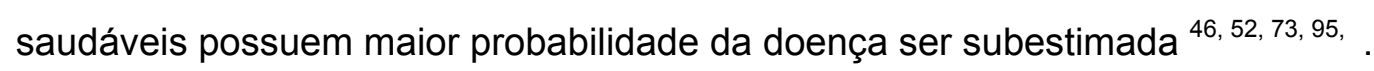

A descrição da distribuição da doença periodontal considerando-se o indivíduo como unidade prove informação sobre a existência, severidade e extensão da doença entre eles, enquanto que a descrição por sextante e faces fornece uma caracterização detalhada da doença nos mesmos ${ }^{36}$, por essas razões este estudo optou por uma análise de boca toda.

O único inconveniente do estudo mais detalhado é o fato de criar dificuldades na comparação com resultados de estudos com metodologia menos meticulosa, ou seja, estudos que utilizam apenas alguns sítios ou dente ${ }^{111}$. 
Os indivíduos portadores de fissura apresentam algumas peculiaridades na cavidade bucal, como a presença de múltiplas bridas cicatriciais, vestíbulo raso decorrentes

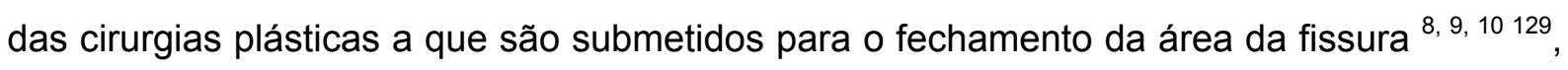
ausência de mucosa queratinizada assim como recessões gengivais e ausência de tecido ósseo em dentes próximos a área da fissura ${ }^{8,9,10,11 .}$

Muitos autores afirmam que os sítios e dentes próximos a essa área tenderiam a ser mais susceptíveis a doença periodontal e perda óssea o que levou muitos estudos a avaliar somente essa área ${ }^{14,29,31,60,115,118}$. Alguns outros encontraram que os sextantes anteriores tiveram menos doença periodontal que os sextantes posteriores e os inferiores médias maiores que os superiores ${ }^{109}$ ou ainda os sextantes ou dentes próximos a fissura não apresentaram resultados piores que os demais $31,32,33,56,110$.

Com o advento dos conceitos de medicina periodontal, e os novos conceitos da epidemiologia da doença periodontal fica difícil pensar em avaliar somente alguns sítios ou alguns dentes de um grupo populacional, o que pode subestimar ou supra-estimar a doença $3,46,52,73,95$

Este estudo foi realizado analisando os parâmetros periodontais em todos os sítios de todos os dentes, com exceção dos terceiros molaresl. No total foram examinados 9679 sítios de 400 indivíduos. DOWSETT et al. ${ }^{54}$ (2001) concluiu em seu estudo que para minimizar a possibilidade de subestimar o nível da doença periodontal, devem ser medidas pelo menos quatro faces (sítios) de todos os dentes presentes no indivíduo.

As médias gerais de todos os parâmetros periodontais utilizados neste estudo foram descritos na tabela 1. Essas médias, de maneira geral, apresentaram valores muito baixos, demonstrando de antemão que a grande maioria desses indivíduos não apresentava doença periodontal severa. GAGGL et al. ${ }^{60}$ (1999) observou médias altas de inflamação gengival, placa e nível de inserção nas fissuras de lábio, rebordo alveolar e palato. Porém a grande maioria dos estudos indicou pequenas perdas de inserção, seja na área da fissura ou regiões contralaterais ${ }^{31,32,33,69}$.

A medida da profundidade de sondagem foi utilizada neste estudo, pois ela é o parâmetro clínico mais utilizado pelos demais autores que estudaram a doença periodontal em fissurados $7,13,14,29,56,69,74,118,127,130$.

As medidas da profundidade de sondagem foram correlacionadas com as faixas etárias, gêneros, tipos de fissuras e sextantes (tabelas 2, 3 e 5).

Não foram encontradas médias maiores ou iguais a $6 \mathrm{~mm}$ em nenhum dos sextantes, ou seja, nenhum indivíduo apresentou bolsas profundas, também observamos que foram poucos os indivíduos com bolsas com profundidades médias (figuras 11 e 12, tabela 5), LAGES; BADEIA; PRODEUS ${ }^{74}$ (2004) descreveram em seu estudo que $100 \%$ da amostra não apresentou profundidade de sondagem maior que $5 \mathrm{~mm}$ resultados que 
também corroboraram com de STEC et al. ${ }^{127}$ (2007) que também não encontraram bolsas periodontais mais profundas ( $\geq 5 \mathrm{~mm}$ ). BRÄGGER et al. ${ }^{31}$ (1985) encontraram média de profundidade de sondagem entre 2,6 a 2,9 mm. ANDRADE ${ }^{14}$ (1990) avaliou somente as faces palatinas, encontraram $37,50 \%$ de bolsas de $4-5 \mathrm{~mm}$ e $29,50 \%$ de bolsas maiores ou iguais a $6 \mathrm{~mm}$.

$\mathrm{Na}$ análise estatística foram comparadas as médias da profundidade de sondagem quanto ao tipo de fissura, idade e gênero. Observou-se que as médias aumentaram com o passar da idade e foi estatisticamente significante; a comparação entre as fissuras também foi estatisticamente significante, entretanto as maiores médias não ocorreram no sextante da fissura, o que nos leva a crer que a fissura parece não ter participação direta na ocorrência da doença periodontal.

Muitos estudos demonstraram que a área da fissura não mostrou maiores médias que as demais áreas $32,33,56$. O fator idade foi a variável mais importante nessas comparações (tabelas 4, 5, 6 e 7).

Como já relatado anteriormente, a área da fissura, representada neste estudo pelo sextante 2, não exibiu maiores médias de profundidade de sondagem quando comparada com as demais tanto na avaliação por sextantes, corroborando com outros estudos que concluíram que dentes próximos a área da fissura não apresentaram diferenças estatisticamente significante quanto à profundidade de sondagem quando comparados com

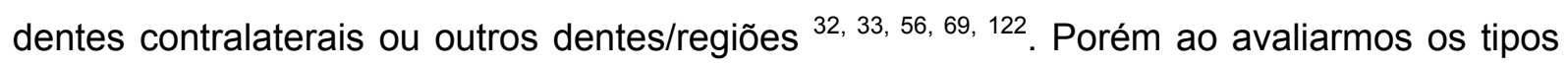
de fissura que apresentaram as maiores médias no sextante dois, ocorreu uma maior prevalência da fissura LAPB (tabelas 5, 6 e 7).

Os estudos de TEJA; PERSON; OMNELL ${ }^{130}$ (1992), BOTTA ${ }^{29}$ (1990); QUIRYNEN et al. ${ }^{110}$ (2003) apontaram que os sítios, sextantes, dentes da área da fissura apresentam profundidade de sondagem maior que os dentes contralaterais ou sextantes. SCHUTLES; GAGGL; KARCHER ${ }^{118}$ (1999) apresentaram resultados semelhantes aos desses autores e ainda afirmaram que a região anterior superior de indivíduos com fissura de lábio, rebordo alveolar e palato apresenta extensa lesão periodontal quando comparada com a população geral.

Segundo a literatura, os tipos de fissuras que acometem o rebordo alveolar apresentam maior profundidade de sondagem que as demais, quando comparados os dentes próximos a fissura e dentes contralaterais ou outros. SCHUTLES; GAGGL; KARCHER ${ }^{118}$ (1999) compararam fissura de lábio, rebordo alveolar e palato e fissura de palato e concluíram que a fissura que acomete o rebordo alveolar apresentam lesão mais extensa na região anterior superior que a fissura de palato em relação à população geral. Ao contrário, DOURADO ${ }^{56}$ (1993) demonstrou não haver diferença estatisticamente significante entre os tipos de fissuras. 
Uma pequena porcentagem de sítios com bolsas moderadas e profundas também foi encontrada em indivíduos não fissurados ${ }^{5}$, 24, 76, 86, 99, 102, 119, 125, 137.

$\mathrm{Na}$ comparação das médias de profundidade de sondagem entre as faixas etárias, e tipos de fissuras por sextantes pudemos observar que houve um aumento das médias de profundidade de sondagem com avanço da idade (tabela 8, 9, 10 e 11).

A correlação entre idade e aumento na profundidade de sondagem também foi descrita em estudos com amostras de indivíduos sem fissura labiopalatina 1, 22, 24, 35, 44, 49,55, ${ }^{111}$. Já CARLOS; BRUNELLE; WOLFE ${ }^{46}$ (1987) não encontraram uma forte correlação entre profundidade de sondagem e idade.

A comparação das médias de profundidade de sondagem entre faixas etárias, gêneros, tipos de fissura e sextantes demonstrou que somente o gênero não foi estatisticamente significante, resultado similar ao encontrado por MUMGHAMBA; MARKKANEN; HONKALA ${ }^{99}$ (1995), este mesmo resultado ocorreu quando foi comparada a média geral da amostra com as variáveis acima citadas (tabelas 4 a 12). Neste estudo esse resultado pode ter ocorrido pelo fato da amostra ter sido muito proporcional quanto ao gênero, contrariando alguns resultados encontrados na literatura.

Alguns estudos encontraram maior prevalência em mulheres ${ }^{40,49}$ enquanto que outros observaram no gênero masculino ${ }^{5,37,86}$. Em indivíduos fissurados não foi encontrado relação direta das médias de profundidade de sondagem entre idade e gênero ${ }^{14}$. CAMPOS 40 (1995) observou que a doença periodontal foi responsável por 7,01\% da perda dentária e o gênero feminino foi o mais atingido.

Neste estudo houve diferenças estatisticamente significantes quando se comparou a profundidade de sondagem e sextantes. A comparação entre sextantes, quadrantes, dentes e arcos foi realizada por outros autores que assim como neste estudo encontraram diferenças entre tipos de dentes, regiões e arcadas ${ }^{15,22,49,82,87,111,137 .}$

A maioria dos estudos realizados em indivíduos portadores de fissura labiopalatina comparou lados opostos, o lado da fissura e contralateral. Alguns não encontraram diferenças estatisticamente significantes ${ }^{32,33,56,69}$ enquanto que outros observaram que a área da fissura apresentava maiores médias de profundidade de sondagem ${ }^{130,110}$.

A diferença entre as médias de profundidade de sondagem e os tipos de fissura também foi objeto de análise neste trabalho. Houve diferença estatisticamente significante entre alguns tipos de fissuras em alguns sextantes, corroborando com outros trabalhos ${ }^{7,60}$, 108, 118, Nas tabelas 9, 10 e 11 fica claro que só na fissura LAPB o sextante 2 apresentou maiores médias de profundidade de sondagem, para as faixas etárias de 15 a 25 anos e 26 a 35 anos. Já na faixa etária de 36 a 49 anos em nenhum tipo de fissura o sextante 2 foi o que apresentou maiores médias de profundidade de sondagem (tabela 12). Neste estudo 
somente dois tipo de fissuras foram incluídas na amostra, ambas englobando o rebordo alveolar, podendo ser uni ou bilaterais assim como em outros estudos ${ }^{7,32,122}$.

Quando foram realizadas as diversas comparações da profundidade de sondagem com os tipos de fissuras, entre os gêneros, sextantes e faixas etárias os resultados foram muito dispersos, ora houve diferença estatisticamente significante entre uns determinados tipos de fissuras ora outros e também não houve predominância em um sextante; em muitas ocasiões era no sextante 2 que apresentava diferenças entre alguns tipos de fissuras em outras era outro sextante (tabelas 8, 9, 10 e 11). Como não houve concordância de resultados em detrimento a um único tipo de fissura e nem em relação ao sextante 2, tornase difícil afirmar se há um tipo de fissura que apresente maior prevalência e severidade da doença periodontal quando comparado aos demais tipos, o mesmo raciocínio se equivale para o lado da fissura e o fato de ser uni ou bilateral, e ainda a fissura parece não ser um fator de risco à doença periodontal quando é avaliada a profundidade de sondagem por sextantes.

Assim como a profundidade de sondagem, o nível de inserção clínico não exibiu médias muito elevadas na maioria dos indivíduos avaliados (tabelas 13 e 14). Poucos indivíduos apresentaram valores maiores que $4 \mathrm{~mm}$, grande parte da amostra $(96,75 \%)$ apresentou nível de inserção clínico < $3 \mathrm{~mm}$ (figuras 13 e 14), demonstrando que esses indivíduos não apresentam muito risco a doença periodontal. Em muitos estudos foi constatado que poucos dentes ou indivíduos apresentaram perda de inserção maior que 3 $\mathrm{mm}$, variando de 2 a $76 \%{ }^{16,119}$. Neste estudo, na maioria das comparações realizadas o sextante 2 que engloba a área da fissura não apresentou a maior média (figura 13).

A fissura que envolve lábio, rebordo alveolar e palato (LAP) apresentou as maiores médias de perda de inserção quando comparadas com as de lábio e rebordo alveolar (tabelas 13 e 14, figura 13). No estudo de GAGGL et al. ${ }^{60}$ (1999) as médias do nível de inserção clínico foram maiores que as encontradas neste estudo, variaram de 2,9 a $4.3 \mathrm{~mm}$ dependendo do tipo de fissura; a fissura de lábio, rebordo alveolar e palato bilateral foi a que apresentou as maiores médias, principalmente nos dentes próximos a área da fissura.

A média do nível de inserção clínico aumentou com a idade e houve diferenças estatisticamente significantes neste estudo, quanto mais velhos os indivíduos, maior a perda de inserção, resultados que podem ser observado nas tabelas $13,14,15,16$ e 17 , corroborando com os de outros autores ${ }^{1,3,5,15,16,22,37,44,46,49,55,81,82,83,86,102,103,111,117,137 .}$

ABDELLATIF; BURT ${ }^{1}$ (1987) afirmaram que a idade pode estar correlacionada à prevalência e severidade da doença periodontal, mas não seria considerado um fator de risco. Contrariando essa idéia BECK et al. ${ }^{24}$ (1984) concluíram que a idade seria um possível fator de risco para a doença periodontal. Na verdade o fato de um dente estar 
presente na cavidade oral por um período maior de tempo pode levá-lo à uma maior exposição dos fatores risco à doença periodontal com o aumento da idade ${ }^{55}$.

Nas comparações realizadas das médias do nível de inserção clínico entre os sextantes e tipos de fissura em cada faixa etária também foi observado que a idade foi um fator relevante, houve um aumento nas médias com a progressão da faixa etária (tabelas 20, 21 e 22). Estudos epidemiológicos em indivíduos não fissurados também encontraram um aumento da prevalência na perda de inserção com o avanço da idade ${ }^{5}$.

Os valores mínimos e máximos do nível de inserção clínico entre os sextantes variaram entre 0,0 e 6,7 mm, sendo que o maior valor ocorreu nos sextantes 3, 4 e 5 (figura 13). Este resultado corrobora com o de ALBANDAR; BRUNELLE; KINGMAN ${ }^{5}$ (1999) que relataram perda de inserção mais freqüente em incisivos inferiores e molares superiores, com perda menos freqüente em incisivos centrais superiores. SCHÜRCH Jr. ${ }^{119}$ (1988) observou maior perda de inserção clínica na mandíbula do que na maxila, outros observaram perdas mais freqüentes nos molares ${ }^{49,118}$ ou ainda menor nos inferiores ${ }^{67}$.

CUTRESS; POWELL; BALL ${ }^{49}$ (1982) encontraram maior perda na maxila que na mandíbula. Também foi descrito na literatura que os dentes anteriores mostraram menor perda de inserção quando comparados aos posteriores, assim como os inferiores em relação aos superiores ${ }^{39,67}$. RAGGHIANTI ${ }^{111}$ (2003) afirmou ocorrer maior perda na maxila sendo os sextantes posteriores de maior susceptibilidade a doença periodontal. O nível de inserção clínico pode variar entre diferentes tipos dentários ${ }^{22}$. Houve diferença estatisticamente significante quando se comparou o nível de inserção clínico entre os sextantes (tabela 15).

Nas tabelas 16 e 17 podemos observar que sempre as médias nas fissuras LAP foram maiores independentemente da faixa etária (houve aumento das médias com aumento da idade), com exceção para os indivíduos com idade entre 36 e 49 anos. O sextante 2 não exibiu as maiores médias. Analisando as tabelas também observamos que grande totalidade das médias foram baixas $(<3 \mathrm{~mm})$ e aumentaram com a faixa etária. No estudo de GAGGL et al. ${ }^{60}$ (1999) as fissuras de lábio, rebordo alveolar e palato apresentaram maiores perdas de inserção quando comparadas com as de palato. Alguns estudos demonstraram que a perda de inserção não é diferente na região da fissura quando comparada com as demais ${ }^{32,33}$; porém HINRICHS et al. ${ }^{69}$ (1994), GAGGL et al. ${ }^{60}$ (1999), SCHUTLES; GAGGL; KARCHER 118 (1999), SALVI; BRÄGGER; LANG 115 (2003) apresentaram resultados diferentes, demonstraram que a área da fissura apresenta maior perda de inserção.

A área da fissura, representada neste estudo pelo sextante 2, como já salientado anteriormente, não mostrou maiores médias de nível de inserção clínico assim com a 
profundidade de sondagem quando comparadas aos demais sextantes. BRAGGER et al. ${ }^{32}$ (1990) observou que a média de perda de inserção variou entre 1,7 e 1,9 mm na área da fissura, enquanto neste estudo o sextante que compreende a fissura apresentou uma média do nível de inserção clínico de 1,03 a 2,39 mm. Como o sextante 2 inclui 6 dentes, de canino esquerdo ao canino direito, com fissura unilateral e bilateral fica difícil comparar os resultados com a literatura já que a maioria dos estudos avaliou os dentes próximos a área da fissura e compararam com os dentes contralaterais ${ }^{32,33,56,69}$ ou compararam fissuras que acometem lábio, rebordo alveolar e palato com fissuras de palato ${ }^{60}$.

Nas tabelas 15 e 23 não houve diferença estatisticamente significante entre as médias do nível de inserção clínico e os sextantes, e também que os sextantes apresentam forte correlação entre si, ou seja, se comportam de maneira diferente frente ao risco de desenvolver a doença periodontal. Mais uma vez fica demonstrado que a área da fissura não apresenta maior predisposição à doença periodontal que as demais ${ }^{15,22,49,82,87,111,137}$.

A maioria dos estudos realizados em indivíduos portadores de fissura labiopalatina comparou lados opostos, em sua grande maioria o lado da fissura e contralateral. Alguns encontraram diferenças estatisticamente significantes ${ }^{115}$ e com maiores perdas de inserção nos dentes próximos a área da fissura e outros não ${ }^{51}$. SIQUEIRA ${ }^{122}$ (2006) comparou indivíduos fissurados e não fissurados, observou maiores médias do nível de inserção em indivíduos portadores de fissura, porém não cita qual área foi responsável pelas maiores médias.

A comparação das médias de nível de inserção clínica entre faixas etárias, gêneros, tipos de fissura e sextantes demonstrou que somente o gênero não foi estatisticamente significante, assim como no estudo de SCHÜRCH Jr. ${ }^{119}$ (1988) (tabela 15). Outros estudos encontraram resultados diferentes, BAELUM; FEJERSKOV; MANJI ${ }^{22}$ (1988), ALBANDAR; BRUNELLE; KINGMAN ${ }^{6}$ (1999), RAGGHIANTI ${ }^{111}$ (2003) e BURT et al. ${ }^{37}$ (2005) demonstraram que os homens apresentaram mais perda de inserção do que as mulheres, enquanto que CUTRESS, POWELL, BALL ${ }^{49}$ (1982) descreveram que o gênero feminino apresentava maior perda. Nenhum trabalho realizado com indivíduos fissurados comparou 0 nível de inserção clínico quanto ao gênero.

A influência do gênero na condição periodontal ainda é uma incerteza na epidemiologia da doença periodontal ${ }^{12}$. A perda de inserção clínica em todos os níveis de severidade é geralmente mais prevalente em homens que em mulheres $1,5,22,37$, provavelmente porque os homens têm pior higiene oral quando comparados com as mulheres ${ }^{1}$.

A diferença entre a média de nível de inserção os tipos de fissura também foi analisada neste estudo. A tabela 16 descreve as médias do nível de inserção clínico por faixas etárias e tipos de fissuras dos sextantes superiores; nela podemos observar que as 
maiores médias foram nas fissuras que envolveram lábio, rebordo alveolar e palato, em todas as faixas etárias, apesar de não haver diferença estatisticamente significante entre as médias do nível de inserção clínico e os tipos de fissura (tabela 18). Nas faixas etárias de 15 a 25 anos e 26 a 35 anos, houve maiores médias na fissura de LAPB, com diferença estatisticamente significante somente para o sextante 6 , e não no 2 como poderia se esperar, demonstrando que a fissura parece não ser de maior risco para a perda de inserção periodontal (tabelas 19, 20, 21 e 22). Poucos estudos utilizaram a medida do nível de inserção ${ }^{7,32,122}$. BRAGGER et al. ${ }^{31}$ (1985) demonstraram que os dentes adjacentes à fissura que apresentam uma área maior de inserção conjuntiva não apresentaram maiores médias quanto a progressão da doença periodontal quando comparadas as áreas controles.

Para caracterizar clinicamente a inflamação gengival foi utilizado o índice gengival de LÖE $^{79}$ (1967) a qual é caracterizado por ser quantitativo e qualitativo, também é citado na literatura como um dos índices mais utilizados em estudos epidemiológicos observacionais e experimentais. Ele é sensível o bastante para detectar pequenas diferenças na inflamação gengival ${ }^{21,22,114}$. Foram examinados todos os sítios de todos os dentes, com exceção dos terceiros molares.

As médias do índice gengival por faixas etárias, gêneros e tipos de fissuras por sextantes estão descritos nas tabelas 24 e 25 . A faixa etária foi um fator importante, pois o número de indivíduos com médias maiores aumentou com a idade tanto nos sextantes superiores quanto nos inferiores. Na maioria dos casos o sextante da área da fissura não exibiu as maiores médias quando comparado com os demais (tabela 28, 29). Em relação ao tipo de fissura, o índice gengival pareceu ser mais prevalente na de lábio, rebordo alveolar e palato do lado direito (tabelas $30,31,32$ ), mas esse resultado não tem correlação clínica. No estudo de SCHUTLES; GAGGL; KARCHER ${ }^{117}$ (1999) a freqüência do sangramento à sondagem variou nos diferentes tipos de fissura e nos sextantes. Na fissura de lábio, rebordo alveolar e palato os valores foram maiores que na de palato, e no sextante anterior foi maior que o posterior. Neste estudo a média do escore do índice gengival que mede a inflamação gengival esteve entre branda e moderada.

Ao avaliar dente a dente pudemos observar que houve maior freqüência do escore 2 $(75,44 \%)$ que caracteriza a inflamação como moderada, independente do tipo dentário. Nos superiores os dentes anteriores apresentaram menor freqüência do escore 1 quando comparados com os demais dentes (tabelas 26, 27). A gengivite moderada também foi a mais encontrada em outros trabalhos descritos na literatura, muitos deles realizados em populações carentes de tratamento odontológico preventivo, como neste estudo ${ }^{16,81,82,115}$.

A freqüência de dentes com gengivite é muito variada na literatura, podendo aumentar com a idade e variar conforme o gênero. 
A gengivite esteve presente adjacente à grande maioria dos dentes assim como em outros estudos que descreveram que a presença de gengivite pode variar em média de 35 a 95\% $22,23,26,35,49,87,102,103,111$. MARKKANEN; RAJALA; PAUNIO ${ }^{86}$ (1983) tiveram 96,6\% dos indivíduos com presença de placa; OKAMOTO et al. ${ }^{102}$ (1988) 35 a 65\% de placa; BAELUM; FERJERSKOV; MANJI ${ }^{22}$ (1988) 75 a 95\%; LEMBARITI; FRENCKEN; PILOT ${ }^{76}$ (1988) $99,6 \%$ de placa em todos os grupos etários.

Neste estudo ficou demonstrado que não houve diferença estatisticamente significante entre o índice gengival, sextante e gênero (tabela 46). Quando avaliamos as médias do índice gengival por gênero pudemos observar que as médias foram maiores nos sextantes superiores no gênero feminino, já nos sextantes inferiores, as maiores médias fora encontradas nos gênero masculino (tabelas 33, 34), portanto não houve uma predominância, corroborando com outros estudos que não observaram diferenças significantes 22, 24, 119 . Alguns estudos observaram que os homens apresentam maiores índices de sangramento a sondagem que as mulheres $24,49,87,99$. A idade parece não ter grande influência no grau de inflamação nos indivíduos deste estudo já que não houve constância do aumento da severidade com o aumento da idade (tabelas 35 e 36). A comparação entre o índice gengival e os sextantes mostrou haver diferença estatisticamente significante somente nos sextantes 2 e 3 (tabelas 38 e 39). No sextante dois houve correlação com todas as idades corroborando com SCHEUTZ; HUDMANN; POULSEN ${ }^{118}$ (1983) que afirmaram que o sangramento gengival teve freqüência quase constante independente da faixa etária. Alguns estudos obtiveram resultados diferentes, observaram um aumento do grau de inflamação com o avanço da idade $15,24,22,83,86,87,102,103,119$.

O sextante que engloba a área da fissura não apresentou forte correlação com o índice gengival, ao contrário do que se poderia esperar já que muitos indivíduos apresentam muitas bridas cicatriciais, ausência de mucosa queratinizada, má posicionamento dentário, má formação dentária etc. LAGES ${ }^{74}$ (2004) concluiu em seu estudo que a doença periodontal que acomete os indivíduos portadores de fissura não difere da população em geral, cerca de $90 \%$ dos indivíduos apresentavam somente gengivite, outros estudos

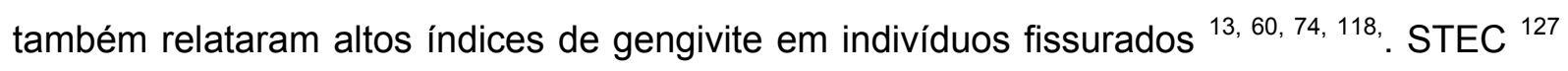
(2007) observou altos índices de placa na área próxima a fissura.

Muitos trabalhos em indivíduos não fissurados descrevem que as regiões anteriores superiores apresentam menores escores do índice gengival ${ }^{18,119}$; sendo a região posterior como mais afetada pela inflamação ${ }^{15,26,87,119,}$.

Quanto aos tipos de fissuras, como nos outros parâmetros já discutidos anteriormente, não houve diferença estatisticamente significante, a comparação entre o índice gengival e as fissuras pareceu ser ao acaso (tabelas 40, 41, 42, 43, 44 e 45). 
Os indivíduos portadores de fissuras que acometem o rebordo alveolar neste estudo apresentaram gengivite incipiente a moderada. A área da fissura parece não ter tido os maiores escores apesar da dificuldade que estes indivíduos possuem de realizar uma higiene oral eficiente devido a várias alterações locais pertinentes a fissura. Apesar destes indivíduos não terem acesso ao tratamento periodontal, foram poucas as áreas que apresentaram gengivite severa.

PAUL; BRANDT ${ }^{108}$ (1998), SCHUTLES; GAGGL; KARCHER ${ }^{118}$ (1999) e GAGGL et al. ${ }^{60}$ (1999) avaliaram indivíduos com fissura diferentes (lábio, rebordo alveolar e palato e somente com fissura de palato) e observaram que houve variação no índice gengival (sangramento a sondagem). Na região anterior ocorreu maior sangramento quando a fissura era de lábio a palato enquanto que na fissura de palato a região posterior foi a mais afetada, entretanto BRÄGGER et al. ${ }^{31}$ (1985), BRÄGGER ${ }^{32}$ (1990) e DOURADO ${ }^{56}$ (1993) não observaram diferenças estatisticamente significantes entre os tipos de fissuras.

Quanto ao fato da fissura ser unilateral ou bilateral na literatura foi encontrado diferença quando ao índice gengival,apresentando maior grau de inflamação nas fissuras bilaterais ${ }^{60}$.

O sangramento presente pode não ser um previsor seguro da doença, mas é um importante indicador de alteração periodontal ${ }^{79,132}$.. A higiene bucal pode prevenir a gengivite, sendo razoável concluir que o controle da inflamação gengival é benéfico para população em geral.

A placa bacteriana é considerada o fator etiológico primário na iniciação da doença periodontal. Fatores locais e sistêmicos podem afetar a resposta do hospedeiro e aumentar o acúmulo de placa ou mesmo modificá-la, tornando a placa patogênica.

A avaliação da presença e freqüência da placa é comumente realizada nos estudos epidemiológicos tanto de cárie dentária quanto em doença periodontal. Inúmeros índices são citados na literatura, uns avaliam dentes índices, outros boca toda. Neste estudo foi utilizado o índice de placa de SILNESS; , LÖE ${ }^{120}$ (1964) o qual avalia a presença de placa na área cervical de seis sítios por dente.

As médias dos escores do índice de placa foram agrupadas por faixas etárias, gêneros e tipos de fissuras tanto nos sextantes superiores quanto inferiores (tabelas $47 \mathrm{e}$ 48). Todos os sextantes apresentaram placa e a freqüência aumentou com o avanço da idade tanto na maxila quanto na mandíbula, 97,40\% dos dentes apresentaram placa, sendo que os escores 2 e 3 foram os mais freqüentes (48,95\% e 40,50\% respectivamente). Estudos em indivíduos portadores de fissura demonstram altos índices de placa 13,31, 32, 118 .

Neste estudo, os sextantes anteriores superiores, que englobam a área da fissura, foram os que apresentaram as menores médias enquanto que os sextante posterior inferior 
direito (6) apresentou a maior média(tabelas 51 e 52). Entre todos os sextantes, sextante 2 foi o que apresentou maior freqüência de escore $1(59,24 \%)$ e o sextante 6 do escore 3 $(79,50 \%)$ que indica presença abundante de placa. Muitos autores tiveram resultados semelhantes com amostras em fissurados ou não 21, 31, 32, 76, 83, 86, 102, 10,3, 111, 118, 129.

Quanto às fissuras, a distribuição das maiores médias foi ao acaso. A fissura LAD apresentou maiores índices porém não há uma explicação plausível a não ser que possa ter ocorrido ao acaso (tabelas 53 e 54). Nos estudos em que foram comparadas dois tipos de fissuras também não foram encontradas diferenças estatisticamente significantes quanto a presença de placa ${ }^{31,60,115}$ assim como em trabalhos onde foram comparados o lado da fissura com o contralateral ${ }^{32,33,56,69}$. Também não houve relevância para o aúmulo de placa o lado da fissura (direita ou esquerda) ou mesmo ela ocorrer somente em um lado ou ambos. PAUL; BRANDT ${ }^{108}$ (1988) observaram que a fissura bilateral apresentava maior quantidade de placa do que a fissura unilateral e SIQUEIRA ${ }^{122}$ (2006) observou maiores médias do índice de placa em indivíduos não fissurados com diferença estatisticamente significante entre os grupos.

No estudo de RAGGHIANTI ${ }^{111}$ (2003) o sextante 2 (dentes anteriores superiores) apresentou menor porcentagem de placa $(81,1 \%)$, os posteriores apresentaram maiores valores. ANERUD et al ${ }^{16}$. (1983) e SCHÜRCH Jr. et al. ${ }^{119}$ (1988) também obtiveram maiores escores do índice de placa em dentes posteriores do que em dentes anteriores

A média dos escores do índice de placa por sextante variou de 1,36 a 1,60. 0 sextante da área da fissura (2) não apresentou maiores médias (tabela 51).

A ausência de placa foi encontrada somente em $2,60 \%$ da amostra, enquanto que em 48,95\% e 40,50\% apresentaram escores 2 e 3 respectivamente. A abundância de placa representou $7,95 \%$ da totalidade de dentes examinados. A distribuição destes valores foi semelhante entre os arcos dentários (tabela 52).

A área da fissura apresenta algumas alterações teciduais decorrentes das cirurgias plásticas e algumas anomalias dentárias que poderiam dificultar demasiadamente a higiene oral, porém quando se comparou os sextantes verificou-se que os dentes próximos a área da fissura, pertencentes ao sextante 2, apresentaram valores menores (tabelas 53 e 54 . Houve diferença estatisticamente significante entre o sextante 2 e os demais (tabelas 59 e $60)$.

Não houve grande diferença das médias entre os gêneros em cada sextante, tanto nos superiores quanto inferiores (tabelas 55 e 56).

Houve uma tendência de aumento das médias dos escores do índice de placa com o aumento da idade (tabelas 57 e 58) 15, 22, 24, 83, 86, 87, 102, 103, 119 
Nas comparações entre o índice de placa e tipos de fissuras em cada sextante não houve diferença estatisticamente significante entre nenhuma das comparações (tabelas 59 , 63 a 69)

O gênero não foi um fator importante na presença de placa bacteriana, na comparação entre as média, não houve diferença estatisticamente significante nos sextantes (tabela $55,56,57,58,70$ ).

Quanto ao fator idade, neste estudo houve aumento das médias do índice de placa com o aumento da faixa etária. Na faixa etária de 26 a 35 anos, os indivíduos apresentaram um pouco mais de placa em quase todos os sextantes. Nas comparações do índice de placa e as faixas etárias houve diferença estatisticamente significante somente nos sextantes 4 e 5 (tabelas 52, 53, 61 e 62). Este resultado vem confirmar que a área da fissura não apresenta valores significativos quando comparados a outras áreas.

Apesar da placa bacteriana ser o fator mais importante para a Doença Periodontal, as populações de países em desenvolvimento, mesmo apresentando maior presença de placa e gengivite, não necessariamente obtiveram maior prevalência e severidade da Doença Periodontal ${ }^{15,16,114}$. No entanto, mesmo a Doença Periodontal não sendo uma conseqüência inevitável da inflamação gengival, ainda não existem meios para distinguir a gengivite que irá e a que não irá progredir para periodontite.

Sendo assim, a inflamação gengival causada pelo acúmulo da placa bacteriana é uma condição bucal comum que pode predispor indivíduos a Doença Periodontal destrutiva. Embora a gengivite seja uma condição reversível e que nem sempre progrida para periodontite, representa a fase precoce do processo inflamatório que leva a destruição dos tecidos periodontais ${ }^{7}$.

Os estudos epidemiológicos tem demostrado diferenças na epidemiologia da doença periodontal de acordo com a população estudada. Geralmente países subdesenvolvidos apresentam maiores índices da doença quando comparados com países desenvolvidos.

Muitos autores 16, 21, 22, 49, 54, 83, 76 relataram que as populações de países em desenvolvimento tem usualmente acesso limitado aos cuidados odontológicos, altos níveis de placa e cálculo e maior manifestação de gengivite, comparadas as populações de sociedades economicamente desenvolvidas

Neste estudo foi realizado a correlação entre os parâmetros clínicos e a classificação sócio-econômica. Houve fraca correlação entre o nível de inserção, índice de placa e índice gengival. A grande maioria dos pacientes que procuram atendimento no Hospital de Reabilitação de Anomalias Craniofaciais e que foram examinados neste estudo pertenciam a classe baixa (figura 7). A homogeniedade da amostra poderia ser uma das razões de praticamente não haver correlação entre essas variáveis (tabela 71). ANDRADE ${ }^{14}$ (1990) 
observou que não houve relação direta da profundidade de sondagem, índice de placa, índice gengival e recessão gengival com o nível sócio-econômico.

A recessão gengival é caracterizada pela migração apical da margem gengival, de sua posição normal na superfície radicular para níveis além da junção amelocementária, podendo ser localizada ou generalizada e associada com uma ou mais faces dentárias, podendo gerar vários problemas de importância funcional e clínica e na sua etiologia podem ser encontrados fatores considerados predisponentes e precipitantes ${ }^{42,53,63,75,92,93,97,98,107 .}$

A prevalência da recessão é elevada tanto na população com alto e baixo padrão de higiene bucal, com freqüência de 12 a 19\% em crianças, 15,5 a 54,5\% em adultos jovens e de $57,7 \%$ a $100 \%$ em indivíduos mais idosos. Este fato provavelmente ocorre devido a maior exposição dos elementos dentários por um longo período aos fatores etiológicos da recessão gengival. Neste estudo $100 \%$ dos indivíduos apresentaram recessão gengival menor que $3 \mathrm{~mm}$ e houve um aumento das médias com o avanço da idade (tabelas 72, 73, $79,80,82,83,84,85,86,87)$ corroborando com outros estudos como o de GORMAN ${ }^{62}$ (1967), ALBANDAR; KINGMAN ${ }^{5}$ (1999), MARINI ${ }^{85}$ (2004) e ALMEIDA et al. ${ }^{11}$ (2007) entre outros ${ }^{34,36,68,72,91,106,111,116,136,137}$. As recessões rasas foram uma constante neste em outros estudos $^{26,126,132}$.

A severidade da recessão gengival, comumente aferida pela extenão da exposição radicular, pode ser avaliada através da classificação sugerida por Miller ${ }^{96}$ em 1995. As recessões classe I foram as mais freqüentes neste e em outros estudos ${ }^{11,85}$ (figura 19).

Os elementos dentários com maior prevalência de recessão gengival foram os primeiros prés superiores e inferiores direitos, caninos inferiores e molares superiores, e os dentes com menor prevalência foram os caninos inferiores esquerdo (figuras 16 e 17). ALMEIDA et al. ${ }^{11}$ (2007) estudou a prevalência da recessão gengival em indivíduos portadores de fissuras e observou que os primeiros molares superiores, caninos e prés foram os mais acometidos e os com menores freqüências foram os incisivos laterais superiores. SIQUEIRA ${ }^{122}$ em 2006 observou que indivíduos portadores de fissura apresentavam maiores médias quando comparadas com as recessões presentes em indivíduos não fissurados. Estudos em pacientes não fissurados, GORMAN ${ }^{62}$ (1967), WOOFTER ${ }^{136}$ (1969), AINAMO et al. ${ }^{4}$ (1986), YONEYAMA et al. ${ }^{137}$ (1988) e MARINI ${ }^{85}$ (2004) observaram uma maior prevalência nos dentes unirradiculares e ALBANDAR; KINGMAN $^{6}$ (1999) demonstraram que os primeiros molares superiores eram os dentes mais acometidos. TROTT, LOVE ${ }^{132}$ (1966) observaram uma maior prevalência de recessão nos incisivos centrais inferiores em indivíduos com idade entre 14 e 19 anos. Já SERINO et al. 116 (1994) encontrou maior prevalência nos prés e molares enquanto que MURTOMAA et al. 100 (1987) e BAELUM ${ }^{18}$ (1987) nos primeiros molares superiores e primeiros prés molares inferiores. 
Os dentes ao lado da fissura, que geralmente são os caninos e incisivos centrais superiores, supostamente deveriam apresentar o maior universo de recessão em função da redução do suporte ósseo, principalmente nas faces adjacentes à fissura, e também pela pequena quantidade de mucosa ceratinizada. Apesar de não serem os dentes com maior incidência, apresentam altas porcentagens de recessão gengival quando são comparados com os dados disponíveis na a literatura os quais descrevem que os unirradiculares e primeiros molares superiores são os elementos dentários que possuem maior prevalência de recessão. Geralmente a área anterior superior apresenta bridas cicatriciais e vestíbulo raso decorrentes das cirurgias plásticas no lábio dificultando a higiene por parte dos pacientes ${ }^{8,9}$, ${ }^{10}$. Neste estudo os caninos superiores esquerdo e direito, apresentaram 13,13 e $10,88 \%$ de prevalência e os incisivos centrais esquerdo e direito, 13,98 e 18,33\% respectivamente (figuras 16 e 17); bem superiores aos resultados obtidos por MARINI ${ }^{85}$ (2004) em indivíduos não fissurados,, em que a prevalência foi muito menor, 2,6 e 2,8\% para os caninos e 2,2 e $2,1 \%$ para os incisivos, para mesma faixa etária. Nos indivíduos portadores de fissura a prevalência de recessão nos dentes próximos a área de fissura foi dez vezes maior e por isso esses dentes devem receber atenção especial quando são submetidos a tratamento odontológico; esses resultados corroboram com os de ALMEIDA et al. ${ }^{11}$ (2007).

O sextante 2 teve as menores médias quando comparado com os demais, e quando a recessão estava presente sua extensão era praticamente igual as demais (tabelas 72. 73, 74, 81 e figura 15 e 16). Esses resultados vem de encontro a outros estudos que demonstraram que a região de canino a canino superior não apresentam maior prevalência em indivíduos não fissurados. Foram poucos os estudos em fissurados mas os resultados foram similares aos deste estudo ${ }^{11}$.

As médias de recessão gengival em relação aos tipos de fissuras não variaram muito, na verdade parece que não há correlação entre esses fatores (figura 18, tabelas 75 , $76,88,89,90)$. ALMEIDA et al. ${ }^{11}$ (2007) não comparou os tipos de fissura em seu estudo apesar de ter incluído vários tipos. Alguns outros estudos compararam lado da fissura com contralateral e constaram que não havia diferença estatisticamente significante ${ }^{130}$.

Alguns estudos epidemiológicos em periodontia que avaliaram a prevalência da recessão quanto ao gênero. SUSIN et al. ${ }^{125}$ (2004) não encontrou diferenças estatisticamente significantese entre os gêneros em indivíduos com menos de 30 anos. MURTOMAA et al. ${ }^{100}$ (1987) tiveram maior prevalência em mulheres; no estudo de VEHKALAHTI ${ }^{133}$ (1989) as mulheres também tiveram maior prevalência que os homens porém sem significância estatistica. Neste estudo não houve diferença estatisticamente significante na comparação entre recessão gengival e gênero (tabela 91).

A avaliação dessa amostra foi muito importante para conhecer um pouco a situação periodontal de indivíduos portadores de fissura. Analisando todos os dados e observando 
os pacientes, ficou claro que a prevalência e severidade da doença periodontal segue os mesmos moldes da população em geral, indivíduos com perdas severas na área da fissura apresentavam perdas também em outras áreas, mas muitos indivíduos apresentaram apenas gengivite.

BENINGTON et al. ${ }^{25}$ em 1979 já discutia a importância dos aspectos preventivos nestes indivíduos. 
CONCLUSÕES 


\section{CONCLUSÕES}

De acordo com os resultados obtidos neste estudo pudemos concluir que:

1. A doença periodontal em indivíduos portadores de fissura que acometem o rebordo alveolar não é mais prevalente e severa, e a grande maioria dos indivíduos apresentou bolsas rasas e pequena perda de inserção.

2. O gênero não foi um fator de risco para a doença periodontal nestes indivíduos.

3. A idade parece ser um fator importante na prevalência e severidade da doença periodontal nessa população, para todos os parâmetros estudados.

4. Os tipos de fissuras estudados, assim como o fato de serem uni ou bilaterais, não foram relevantes nos resultados deste estudo.

5. O sextante que engloba a área da fissura (2) não apresentou maior prevalência e severidade para a doença periodontal para nenhum dos parametros avaliados, portanto a fissura parece não ser um fator de risco para o desenvolvimento da doença periodontal.

6. Houve fraca correlação entre a classificação sócio-econômica e o nível deinserção, índice gengival e índice de placa.

7. Nesta amostra, não houve diferença estatisticamente significante entre a recessão gengival, sextantes e tipos de fissuras.

8. As médias das recessões gengivais foram menores que $3 \mathrm{~mm}$, e a grande maioria foi classe I de Miller.

9. Os dentes mais afetados pela recessão gengival foram os prés e molares.

10. Os dentes próximos a área da fissura, caninos e incisivos, apresentaram freqüência de recessão 10 vezes maior que a população em geral. 
REFERÊNCIAS BIBLIOGRÁFICAS 


\section{REFERÊNCIAS BIBLIOGRÁFICAS}

1.ABDELLATIF, H.M.; BURT, B.A. An epidemiological investigation into the relative importance of age and oral hygiene status as determinants of periodontitis. $J$ Dent Res, Chicago, v.66, n.1, p.13-18, Jan 1987.

2.AINAMO, J. Significance of epidemiologic research in the understanding of periodontal disease. Scand J Dent Res, Copenhagen, v.100, n.1, p.39-46, Feb 1992.

3.AINAMO, J.; AINAMO, A. Partial indices indicators of the severity and prevalence of Periodontal Disease. Int Dent J, London, v.35, n.4, p.322-6, Dec 1985.

4.AINAMO, J. et al. Gingival recession in schoolchildren at 7, 12 and 17 years of age in Espoo, Finland. Community Dent Oral Epidemiol, London, v.14, n.5, p.283-6, Oct. 1986.

5.ALBANDAR, J.M.; BRUNELLE, J.A.; KINGMAN, A. Destructive periodontal disease in adults 30 years of age and older in the United States, 1988-1994. J Periodont, Chicago, v.70, n.1, p.13-29, Jan. 1999.

6.ALBANDAR, J.M.; KINGMAN, A. Gingival recession, gingival bleeding and dental calculus in adults 30 years of age and older in the United States, 1988-1994 National Institute of Dental Craniofacial Research, National Institutes of Health. $J$ Periodontol, Chicago, v.70, n.1, p.30-43, Jan. 1999.

7.AL - WAHADNI, A.; ALHAIJA, E.B.; AL-OMARI, M.A. Oral disease status of a sample of Jordanian people ages 10 to 28 with cleft lip and palate. Cleft Palate $\mathrm{J}$, Pittsburg, v.42, n.3, p.304-8, May 2005.

8.ALMEIDA, A.L.P.F. et al. Comparative evaluation of two different vestibuloplasty surgical procedure in cleft patients: a pilot study. Cleft Palate J, Pittsburg, v.42, n.4, p.439-441, July $2005 a$.

9.ALMEIDA, A.L.P.F. et al. Periodontal health reestablishment in cleft lip and palate patients through vestibuloplasty associated with free gingival graft. PERIO: periodontal practice today, Surrey, v.2, n.1, p.23-29, Spring 2005b.

10.ALMEIDA, A.L.P.F. et al. Surgical treatment of mucogingival alterations in cleft lip and palate patients: a clinical report. PERIO: periodontal practice today, Surrey, v.3, n.1, p. 31-35, Summer 2006.

11.ALMEIDA, A.L.P.F. et al. Cross-sectional evaluation of the presence of gingival recession in individuals with cleft lip and palate. J Periodontol, Chicago, v.78, n.1, p. 29-36, Jan 2007.

12.AMERICAN ACADEMY OF PERIODONTOLOGY. COMMITTEE ON RESEARCH, SCIENCE AND THERAPY. Epidemiology of Periodontal disease. J Periodontol, Chicago, v.67, n.9, p.935-945, sept 1996. 
13.ANDLIN-SOBOKI, A.; ELIASSON, L.A.; PAULIN, G. Periodontal evaluation on teeth in bone grafted regions in patients with unilateral cleft, lip and cleft palate. Am J Orthod Dentofacial Orthop, St. Louis, v.107, n. 2, p.144-152, Feb 1995.

14.ANDRADE, K.D. Avaliação periodontal dos dentes relacionados às incisões libertadoras da palatoplastia de Von Langenbeck. 1990. Monografia (Residência Odontológica - Periodontia) - Hospital de Pesquisa e Reabilitação de Lesão Lábio- palatais, Universidade de São Paulo, Bauru, 1990.

15.ANERUD, A. et al. The natural history of periodontal disease in man. Changes in gingival health and oral hygiene before 40 years of age. J Periodont Res, Copenhagen, v.14, n.6, p.526-540, Nov 1979.

16.ANERUD K.E. et al. Periodontal disease in three young adult populations. $J$ Periodont Res, Copenhagen, v. 18, n.6, p.655 -688, Nov 1983.

17.ARCE, B. et al. Frequências e riscos de recorrência de fissuras labiopalatinas. Rev Paul Med, São Paulo, v.72, p.239-246, 1968.

18.BAELUM, V. Pattern of periodontal breakdown in adult Tanzanians. Scand J Dent Rev, Copenhagen, v.95, n.3, p.221-228, June 1987.

19.BAELUM, V. et al. Profiles of destructive periodontal disease in different populations. J Periodont Res, Copenhagen, v.31, n.1, p.17-26, Jan. 1996.

20.BAELUM, V., FEJERSKOV, O. Tooth loss as related to dental caries and periodontal breakdown in adult Tanzanians. Community Dent Oral Epidemiol, Copenhagen, v.14,n.6, p.353-357,Dec. 1986.

21.BAELUM, V., FEJERSKOV, O.; KARRING, T. Oral higyene, gingivitis and periodontal breakdown in adult Tanzanians. J Periodont Res, Copenhagen, v.21, n.3, p.221-232, May 1986.

22.BAELUM, V.; FEJERSKOV, O.; MANJI, F. Periodontal disease in adult Kenyans. J Clin Periodontol, Copenhagen, v.15, n.7, p.445-452, Aug. 1988.

23. BAELUM, V. et al. Periodontal conditions among adults in Southern Thailand. $J$ Periodontol Res, Copenhagen, v.38, n.2, p.156-163, Apr 2003.

24.BECK, J.D. et al. Risk factors for various levels of periodontal disease and treatment needs in lowa. Community Dent Oral Epidem, Copenhagen, v.12, n.1, p.17-22, Feb. 1984. 
25.BENINGTON, I.C. et al. Restorative treatment of the cleft palate patient. 3. Preventive and periodontal aspects. Br Dent J London, v.146, n.79, p.79-86, Feb 1979.

26.BHAT, M. Periodontal health of 14 a 17 years - old US schoolchildren. $J$ of Public Health Dentistry, v.51, n.1, Winter 1991.

27.BIMSTEIN, E.; MATSSON, L. Growth and development considerations in the diagnosis of gingivitis and periodontitis in children. Ped Dent, Illinois, v.21, n.3, p.186-191, MayJune 1999. Review.

28.BLACK, A.D. Roentgenographic studies of tissues involved in chronic mouth infections. Dent Summ, v.38, p.924-32, 1918.

29.BOTTA, M.S. Avaliação periodontal de pacientes fissurados portadores de placas acrílicas de contenção pós-ortodôntica. 1990. Monografia (Residência Odontológica - Periodontia) - Hospital de Pesquisa e Reabilitação de Lesão Lábio- palatais, Universidade de São Paulo, Bauru, 1990.

30.BOWERS, G.M. A study of the width of attached gingival. J Periodontol, Chicago, v.34, p.201-209, May 1963.

31.BRÄGGER, U. et al. Periodontal conditions in adolescents with cleft lip, alveolus and palate following treatment in a co-coordinated team approach. J Clin Periodontol, Copenhagen, v.12, n.6, p.494-502, July $1985 .$.

32.BRÄGGER, U. et al. The significance of alveolar bone in periodontal disease: a long term observation in patients with cleft lip, alveolus and palate. J Clin Periodont, Copenhagen, v.17, n.6, p.379-384, July 1990

33.BRÄGGER, U.;et al. Periodontal conditions in adult patients with cleft lip, alveolus, and palate. Cleft Palate Craniof J, Pittsburg, v.29, n.2, p.179-185, Mar. 1992.

34.BROWN L J, BROUNELLE J A, KIGMAN A. Periodontal status in the United States, 1988-91: prevalence, extent and demographic variation. J Dent Res, Chicago, v.75, p.672-83, Feb.1996, Number Special.

35.BROWN, L.J; OLIVER, R.C.; LÖE, H. Periodontal diseases in the U.S. in 1981: prevalence, severity, extent, and role in tooth stability. J Periodont, Chicago, v.60, n.7, p.363-70, July 1989.

36.BROWN LJ, OLIVER RC, LÖE H. Evaluation periodontal status of United States employed adults. J Am Dent Assoc, Chicago, v.121, n.2, p.226-32, Aug.1990.

37.BURT, B.A.; ISMAIL, A.I.; EKLUND, S.A. Periodontal disease, tooth loss, and oral hygiene among older Americans. Community Dent Oral Epidem, Copenhagen, v.13, n.2, p.93-6, Apr. 1985.

38.BURT B. et al. Position paper: epidemiology of periodontal disease. $J$ Periodont, Chicago, v.76, n.8, p.1406-1419, Aug 2005. Review.

39.CAMPOS, Jr; A. et al. Análise da influência de variáveis explanatórias conjunturais e individuais na situação de saúde periodontal medida pelo CPITN. Periodontia, São Paulo, v.1, n.1, p.28-36, abr-set. 1992. 
40.CAMPOS, P.R. Causas de perdas dentais pacientes portadores de fissuras congênitas lábio-palatais - Influência dos fatores sexo e nível sócio-econômico. 1995, 72p. Monografia (Residência Odontológica - Periodontia) - Hospital de Pesquisa e Reabilitação de Lesão Lábio- palatais, Universidade de São Paulo, Bauru, 1995.

41.CAPELOZZA FILHO, L. et al. Conceitos vigentes na epidemiologia das fissuras lábio-palatinas. Rev Bras Cir, v.77, n.4, p.223-230, jul-ago. 1987.

42.CAPELOZZA FILHO, L. et al. Conceitos vigentes na etiologia das fissuras lábiopalatinas. Rev Bras Cir, v.78, n.4, p.233-240, jul-ago. 1988

43.COLLARES, M.V.M. et al. Fissuras lábio-palatinas: incidência e prevalência da patologia no Hospital de Clínicas de Porto Alegre. Um estudo de 10 anos. Rev Amregs, Porto Alegre , v.39, n.3, p.183-188, 1995.

44.COLLINS, J. et al. Prevalence of clinical attachment loss in adolescents in Santo Domingo, Domenican Republic. J Periodontol, Chicago, v.76, n.9, p.1450-1454, Sept 2005.

45.CORTELA, D.C.B. Etiologia e classificação das fissuras lábio-palatais. 1992, 67 p. Monografia (Residência Odontológica da PROFIS) - Hospital de Pesquisa e Reabilitação de Lesões Lábio-palatais - Universidade de São Paulo, Bauru, 1992.

46.CARLOS, J.P.; BRUNELLE, J.A.; WOLFE, M.D. Attachment loss vs. Pocket depth as indicators of periodontal disease: A methodologic note. J Periodont Res, Copenhagen, v.22, n.6, p.524-5, Nov. 1987.

47.CARRANZA, F.A. Periodontia Clínica. $9^{\circ}$ edição, Guanabara Koogan, Rio de Janeiro, 2004.

48.COSTA, B. et al. Clinical and microbiological evaluation of the periodontal status of children with unilateral complete cleft lip and palate. Cleft Palate Craniof J, Pittsburg, v.40, n.3, p.585-589, Nov. 2003.

49.CUTRESS, T.W.; POWELL, R.N.; BALL, M.E. Differing profiles of periodontal disease in two similar South Pacific island populations. Community Dent Oral Epidemiol, Copenhagen, v.10, n.4, p.193-203, Aug. 1982.

50.DALBEN, S.S. Prevalência dos tipos de fissuras lábio-palatais entre pacientes não operados - Levantamento realizado no ano 2000. 2002, 63p. Monografia (Aperfeiçoamento Ortodontia Preventiva) - Hospital de Reabilitação de Anomalias Craniofaciais - Universidade de São Paulo, Bauru, 2002.

51.DEWINTER, G. et al. Dental anormalities, bone graft quality, and periodontal conditions in patients with unilateral cleft lip and palate at different phases of orthodontic treatment. Cleft Palate Craniof J, Pittsburg, v.40, n.4, p.343-350, July 2003.

52.DIAMANTI-KIPOTI, A.; PAPAPANOU, P.N.; MOORAITAKI-TSAMI, A. Comparative estimation of periodontal conditions by means of different index systems. J Clin Periodont, Copehagen, v.20, n. p.656 , 1993. 
53.DORFMAN, H.S.; KENNEDY, J.E.; BIRD, W.C. Longitudinal evaluation of free gingival grafts. J Clin Periodontol, Copenhagen, v.7, p.316-324,1980.

54.DOWSETT, S.A. et al. Periodontal disease status of the indigenas population of Guatemala, Central America. J Clin Periodontol, Copenhagen, v.28, n.7, p.663-671, July 2001.

55.DOUGLASS, C. et al.. The potential increase in the periodontal diseases of the aged population. J Periodontol, Chicago, v.72, n.12, p.721-30, Dec. 1983.

56.DOURADO, I.M.C. Análise das necessidades de tratamento periodontal de pacientes portadores de fissuras lábio-palatais do HPRLL - USP/ Bauru, utilizando o índice CPITN. 1993, 24p. Monografia (Residência Odontológica da PROFIS) - Hospital de Pesquisa e Reabilitação de Lesões Lábio-palatais - Universidade de São Paulo, Bauru, 1993.

57.FOGH - ANDERSEN, P. Inheritance of harelips and cleft palate. NyT Nordisk Forlag. Copenhagen: Arnold Brisk, 1942.

58.FONSECA, E.P.; REZENDE, J.R.V Incidência das malformações congênitas associadas às fissuras lábio alvéolo palatinas. Rev Fac Odont São Paulo, São Paulo, v.9, n.1, p.45-58, 1971.

59.FREITAS, J.A. et al. Current data on the characterization of oral clefts in Brazil. Pesqui Odontol Bras, São Paulo, v.18, n.2, p.128-33, Apr-Jun, 2005.

60.GAGGL, A. et al. Periodontal disease in patients with cleft palate and patients with unilateral and bilateral clefts lip, palate and alveolus. J Periodontol, Chicago, v.70, n.2, p.171-8, Feb. 1999.

61.GARTRELL J.R., MATHEUS, D.P. Gingival recession: the condition, process and treatment. Dent Clin North Am, Philadelphia, v.20, n.1, p.199-213, Jan 1976.

62.GORMAN, W.J. Prevalence and etiology of gingival recession. J Periodontol, Chicago, v.38, n.4, p.50316-56322, July-Aug. 1967.

63.GOTTSIGEN R. Frenum position and vestibule depth in relation to gingival health. Oral Surg Oral Med Oral Path, St. Louis, v.7, p.1069-1078,1954.

64.GRACIANO, M.I.G. Critérios de avaliação para classificação sócio-economica. Bauru, HPRLLP, 1976. (Trabalho apresentado à Faculdade de Serviço Social de Bauru e Associação dos Assistentes sociais de Bauru e Região).

65.GRIFFITHS, G.S. et al. Detection of high-risk groups and individuals for periodontal diseases: Clinical assessment of the periodontium. J Clin Periodont, Copenhagen, v.15, n.7, p.403-10, Aug. 1988.

66.HALL, W.B.; LUNDERGAN, W.P. Free gingival grafts. Current indications and techniques. Dent Clin North Am, Philadelphia, v.37, n.2, p.227-242, April 1993.

67.HOHLFELD, M.; BERNIMOULIN, J.P. Application of the community periodontal index of treatment needs (CPITN) in a group of 45-54-year-old German factory workers. J Clin Periodont, Copenhagen, v.20, n.8, p.551-6, Sept. 1993 
68.HOLMGREN, C.J.; CORBET, E.F.; LIM, L.P. Periodontal conditions among the middle-aged and the elderly in Hong Kong. Community Dent Oral Epidemiol, Copenhagen, v.22, n.5-II, p.396-402, Oct. $1994 .$.

69.HINRICHS, J. E. et al. Periodontal evaluation of canines erupted through grafted alveolar cleft defects. J Oral Maxillofac Surg, Philadelphia, v.42, n.11, p.717721, Nov. 1984.

70.JENSEN, K. Dental care practices and socio-economic status in Demark. Community Dent Oral Epidemiol, Copenhagen, v.2, n.6, p.273-281,1974.

71.JOHNSON, N.W. Detection of a high risk groups and individuals for periodontal disease. Int dent J, London, v.15,n.5, p.276-82, May, 1988.

72.KASSAB, M.M.; COHEN, R.E. The etiology and prevalence of gingival recession. J Am Dent Assoc, Chicago, v.134, n.2, p.220-25, Feb. 2003. Review.

73.KINGMAN, A. et al. Systematic errors in estimating the prevalence and severity of periodontal disease. J Periodontol, Chicago, v.59, p.707-713, Nov 1988.

74.LAGES, E.M.B.; BADEIA, M.; PORDEUS, I.A. Oral health of individuals with cleft lip, cleft palate, or both. Cleft Palate J, Pittsburg, v.41, n.1, p.59-63, Jan. 2004.

75.LANG, N.P.; LÖE, H. The relationship between the width of keratinized gingival and gingival health. J Periodontol, Chicago, v.43, n.10, p.623-7,Oct. 1972.

76.LEMBARITI, B.S.; FRENCKEN, J.E.; PILOT, T. Prevalence and severity of periodontal conditions among adults in urban and rural Morogoro, Tanzania. Community Dent Oral Epidemiol, Copenhagen, v.16, n.4, p.240-3, Aug. 1988.

77.LINDHE, J.; HAFFAJEE, A.D.; SOCRANSKY, S.S. Progression of periodontal disease in adult subjects in the absence of periodontal therapy. $J$ Clin Periodontol, Copenhagen, v.10, p.433-442, 1983.

78.LINDSAY, W.K. Von Langenbeck palatorrahaphy. In: GRABB, W.C. et al.. Cleft lip and palate. $3^{\text {a }}$ Ed. Boston, Little Brown 1971, p.393-403.

79.LÖE, $\mathrm{H}$. The gingival index, the plaque index and the retention index systems. $J$ Periodontol, Chicago, v.38 (6, suppl.), n.6, p.610-616, Nov/Dec 1967.

80.LÖE, H.; THEILADE, E.; JENSEN, B.S. Experimental gingivitis in man. $J$ Periodontol, Chicago, v.36, n.3, p.177-189, May 1965.

81.LÖE, $\mathrm{H}$. et al. The natural history of periodontal disease in man. Study design and baseline data. J Periodon. Res, Copenhagen, v.13, n.6, p.550-562, Nov. 1978a.

82. LÖE, $H$. et al. The natural history of periodontal disease in man: The rate of periodontal destruction before 40 years of age. J Periodont, Chicago, v.49, n.12, p.607-20, Dec. 1978b.

83.LÖE, H. et al. Natural history of periodontal disease in man. Rapid, moderate and no attachment in Sri Lankan laborers 14 to 46 years of age. J Clin Periodontol, Copenhagen, v.13, n.5, p.413-440, May 1986. 
84.LOURENÇO, E.J.V. Monitoração da progressão da doença periodontal, por meio de avaliação longitudinal de alterações no nível de inserção, utilizando sonda computadorizada de força constante. 1996. Tese de Doutorado - Faculdade de Odontologia de Bauru, Universidade de São Paulo, 1996.

85.MARINI, M.G et al. Gingival recession: prevalence, extension and severity in adults. J Appl Oral Sci, Bauru, v.12, n.3, p. 250-255, jul./set. 2004.

86.MARKKANEN, H.; RAJALA, M.; PAUNIO, K. Periodontal treatment need of the Finnish population aged 30 years and over. Community Dent Oral Epidemiol, Copenhagen, v.11, n.1, p.25-32, Feb. 1983.

87.MARSHALL-DAY, C.D.; STEPHENS, R.G.; QUIGLEY, L.F.J. Periodontal disease: prevalence and incidence. J Periodontol, Chicago, v.26, p.185-203, 1955.

88.MATCHEI, E.E. et al. A stepwise approach to determine periodontal attachment loss in longitudinal studies. J Periodont Res, Copenhagen, v.28, n.6, pt2, p.536-539, Nov. 1993.

89.MATCHEI, E.E. et al. The rate of periodontal attachment loss in subjects with estabilished periodontitis. J Periodontol, Chicago, v.64, n.8, p.713-718, Aug. 1999.

90.MATSSON, L. Factors influencing the susceptibility to gingivitis during childhood - a review. Int J Ped Dent, v.3, n.3, p.119-127, Sept. 1993.

91.MATTHESEN $M$ et al. Dental health of children and adults in Guinea-Bissau, West Africa, in 1986. Community Dent Health, London, v.7, n.2, p.123-33, June 1990.

92.MAYNARD, J.G.; OSCHENBEIN, C. Mucogingival problems, prevalence and therapy in children. J Periodontol, Chicago, v.46, n.9, p.543-551, March 1975.

93.McGUIRE, M.K. Periodontal plastic surgery. Dental Clin North Am, Philadelphia, v.42, n.3, p.451-64, 1998.

94.MILLER, N.A; et al. Analysis of the community periodontal index of treatment needsstudy in adults in France IV - The significance of gingival recession. Community Dent Health, London, v.8, n.1, p.45-51, Mar 1991.

95.MILLER, N.A. et al.. An analysis of the community periodontal index of treatment needs. Studies on adults in France III - Partial examinations versus full-mouth examinations. Community Dent Health, London, v.7, p.249-253, Sept, 1990.

96.MILLER, P.D. A classification of marginal tissue recession. Int J Periodontol Rest Dent, v.5, n.2, p.9-37, 1995. 
97.MIRKO, P.; MIROSLAV, S.; LUBOR, M. Significance of the labial frenum attachment in periodontal disease in man. Part I: Classification and epidemiology of labial frenum attachment. J Periodontol, Chicago, v.45, n. 12, p. 891-894, Dec 1974.

98.MIYASATO, M., CRIGGER, M.; EGELBERG, J. Gingival condition in areas of minimal and appreciable width of keratinized gingival. J Clin Periodontol, Copenhagen, v. 4, p.200-209, 1977.

99.MUMGHAMBA, E.G.S.; MARKKANEN, H.A.; HONKALA, E. Risk factors for periodontal diseases in Ilala, Tanzania. J Clin Periodont, Copenhagen, v.22, n.5, p.347-354, May 1995.

100.MURTOMAA, H. et al. Periodontal status in university students. J Clin Periodont, Copenhagen, v.14, n.8, p.462-465, Sept. 1987.

101 NAGEM FILHO, H.; MORAIS, N.; ROCHA, R.G.F. Contribuição para o estudo e prevalência das más-formações congênitas lábio palatais na população escolar de Bauru. Rev Fac Odontol, Bauru, V.6, n.2, p.111-128, 1968..

102.OKAMOTO, $\mathrm{H}$. et al. Methods of evaluating periodontal disease data in epidemiological research. J Clin Periodont, Copenhagen, v.15, n.7, p.430-439, Aug. 1988.

103.OLSSON, B. Periodontal disease and oral hygiene in Arussi province, Ethiopia. Community Dental Oral Epidemiol, Copenhagen, v.6, n.3, p.139-145, May 1978.

104. O'LEARY, T.S. et al. The incidence of recession in young males: a further study. J Periodontol, Chicago, v.42, n.5, p.264-267,May 1971.

105. PAGE, R.C.; SCHROEDER, H.E. Pathogenesis of inflammatory periodontal disease. A summary of current work. Lab Invest, New York, v.33, p.235, 1976.

106.PALOHEIMO, L. et al.. Prevalence of and factors related to gingival recession in finnish 15- to 20-years old subjects. Community Dent Health, London, v.4, p.425-436,1987.

107.PARFITT, G.J. MJÖR, J.A. A clinical evaluation of local gingival recession in children. J Dent Child, Fulton, v.31, p.257-236, 1964.

108.PAUL, T.; BRANDT, R.S. Oral and dental health status of children with cleft lip and/or palate. Cleft Palate Craniofac J, Pittsburg, v.35, n.4, p.329-32, July 1988.

109.PEDREIRA, R.H.S. Necessidade de tratamento periodontal cirúrgico em portadores de fissura congênita lábio-palatal. 1998. 33p. Monografia (Residência Odontológica da PROFIS) - Hospital de Pesquisa e Reabilitação de Lesões Lábio-palatais, Universidade de São Paulo, Bauru, 1998.

110.QUIRYNEN, M. et al.. A split-mouth study on periodontal and microbial parameters in children with complete unilateral cleft lip and palate. J Clin Periodontol, Copenhagen, v.30, n.1, p.49-56, Jan 2003. 
111.RAGGHIANTI, M.S. Avaliação epidemiológica do perfil comportamental e de fatores de risco associados à doença periodontal em pacientes da Faculdade de Odontologia de Bauru. 2003. 206f. Dissertação (Mestrado em Periodontia) Faculdade de Odontologia de Bauru, Universidade de São Paulo, Bauru, 2003.

112.RAMFJORD, S.P. Indices for the prevalence and incidence of periodontal disease. $J$ Periodontol, Chicago, v.30, n.1, p.51-59, Jan 1959.

113. RAMSTAD, T. Periodontal condition in adult patients with unilateral complete cleft lip and palate. Cleft Palate Craniof J, Pittsburg, v. 26, n.1, p.14-20, Jan 1989.

114.RONDEROS, M.; MICHALOWICZ, B.S. Epidemiologia das doenças periodontais e fatores de risco. In: ROSE,L.R. et al. Periodontia: medicina, cirurgia e implantes.1ed. São Paulo: Livraria Editora Santos, 2007, cap. 3, p. 32-68.

115.SALVI, G.E.; BRÄGGER, U.; LANG,N.P. Periodontal attachment loss over 14 years in cleft lip, alveolus and palate (CLAP, CL, CP) subjects not enrolled in a supportative periodontal therapy program. J Clin Periodontol, Copenhagen, v.30, p.840-845,Sept 2003.

116.SERINO, G. et al.. The prevalence and distribution of gingival recession in subjects with a high standard of oral hygiene. J Clin Periodontol, Copenhagen, v.21, n.1, p.57-67. Jan. 1994.

117.SCHEUTZ, F.; HEIDMANN, J.; POULSEN, S. Dental health of Vietnamese boat people on Pulau Bidong, Malaysia. Community Dent Oral Epidemiol, Copenhagen, v.11, n.4, p.255-8, Aug. 1983.

118. SCHULTES, G.; GAGGL, A.; KARCHER, H. Comparison of periodontal disease in patients with clefts of palate and patients with unilateral clefts of lip, palate and alveolus. Cleft Palate Craniof J, Pittsburg, v.34, n.4, p.322-7, July 1999.

119. SCHÜRCH, Jr. E. et al.. Periodontal conditions in a randomly selected population in Switzerland. Community Dent Oral Epidemiol, Copenhagen, v.16, n.3, p.181-6, June 1988.

120.SILNESS, J., LÖE, H. Periodontal disease in pregnancy. II Correlation between oral hygiene and periodontal condition. Acta Odont Scand, Stokholm, v.22, n.1, p.12135, Feb 1964.

121.SILVA FILHO, O.G. et al. Classificação das fissuras lábio-palatais: breve histórico, considerações clínicas e sugestão de modificação. RBC, Curitiba, v.82, n.2, p.5965, 1992.

122.SIQUEIRA, E.N. Análise comparativa das condições periodontais entre indivíduos portadores de fissura labiopalatina e não portadores. 2006. 36f. Monografia (Especialização Periodontia) - Hospital de Reabilitação de Anomalias Craniofaciais, Universidade de São Paulo, Bauru, 2006.

123.SONOHARA, M.K. Atuação e importância da terapia periodontal na reabilitação dos pacientes portadores de fissuras lábio-palatais. 1992. 38f. Monografia (Residência Odontológica da PROFIS) - Hospital de Pesquisa e Reabilitação de Lesões Lábiopalatais, Universidade de São Paulo, Bauru, 1992. 
124.SOUZA, J.M.P.; BUCHALA, C.M.; LAURENTI, R. Estudo da morbidade e da mortalidade perinatal em maternidade. Parte III - anomalias congênitas em nascidos vivos. Rev Saúde Públ São Paulo, São Paulo, v.21, n.1, p.5-12, 1987.

125.SUSIN, C.; ALBANDAR, J.M. Aggressive periodontitis in an Urban Population in Southern Brazil. J Periodontol, Chicago, v.76, n.3, p.468-475, March 2005.

126.SUSIN, C. et al.. Gingival recession: epidemiology and risk indicators in a representative urban Brazilian population. J Periodontol, Chicago, v. 75, n.10, p.1377-86, Oct 2004.

127.STEC, M.; SZCZEPARISKA, J.; PYPEC, J. et al.. Periodontal status and oral hygiene in two populations of cleft patients. Cleft Palate Craniof J, Pittsburg, v.44, n.1, p.73-78, Jan, 2007.

128.STONER, J; MAZDYASNA, S. Gingival recession in the lower incisor region of 15-years-old subjects. J Periodontol, Chicago, n.51, p.74-76, Feb. 1980.

129.TAN, A.E.S. et al.. Secundary alveolar bone grafting: 5 year periodontal and radiographic evaluation in 100 consecutive cases. Cleft Palate Craniof J, Pittsburg, v.33, n.6, p.513-518, Nov. 1996.

130.TEJA, Z.; PERSSON, R.; OMNELL, M.L. Periodontal status of teeth adjacent to nongrafted unilateral alveolar clefts. Cleft Palate Craniof J, Pittsburg, v.29, n.4, p.357-362, July 1992.

131.TENENBAUM, H. A clinical study comparing the width of attached gingiva and the prevalence of gingival recessions. J Clin Periodontol, Copenhagen, v.9, n.1, p.86-92, 1982.

132.TROTT, J.R.; LOVE, B. An analysis of localized gingival recession in 766 Winning high school students. Dent Pract Dent Res, Bristol, v.16, n.6, p.20913, Feb. 1966.

133.VEHKALAHTI, M. Occurrence of gingival recession in adults. J Periodontol, Chicago, v.60, n.11, p.599-603, Nov. 1989.

134.WENNESTRÖM, J.; LINDHE, J. Plaque-induced gingival inflammation in the absence of attached gingiva in dogs. J Clin Periodontol, Copenhagen, v.10, p.266-276,1982.

135.WONG, F.W.; KING, N.M. The oral health of children with clefts - A review. Cleft Palate Craniof J, Pittsburg, v.35, n.3, p.248-54, May 1998.

136. WOOFTER, C. The prevalence and etiology of gingival recession. Periodontal Abstr, Los Angeles, v.17, n.2, p.45-50, 1969.

137.YONEYAMA, T. et al.. Probing depth, attachment loss and gingival recession. Findings from a clinical examination in Ushiku, Japan. J Clin Periodont, Copenhagen, v.15, n.9, p.581-591, Oct. 1988 
ABSTRACT 


\section{ABSTRACT \\ EPIDEMIOLOGICAL EVALUATION OF THE PERIOODNTAL STATUS OF PATIENTS WITH CLEFT LIP AND PALATE ATTENDING THE HOSPITAL FOD REHABILITATION OF CRANIOFACIAL ANOMALIES}

In Dentistry, few studies are conducted on individuals with cleft lip and palate in the field of Periodontics, either addressing the prevalence, incidence, extent and severity of periodontal lesions or the treatment of these disorders in adults. This study analyzed the prevalence and severity of periodontal disease on 400 individuals with unilateral or bilateral complete cleft lip and palate, aged 15 to 50 years, attending the Hospital for Rehabilitation of Craniofacial Anomalies, University of São Paulo, without any previous periodontal treatment. Clinical examination comprised measurements of probing depth, clinical attachment level, gingival index, plaque index and gingival recession. A total of $86.75 \%$ of patients presented probing depth $\leq 3 \mathrm{~mm}$. No sextant exhibited probing depth $\geq 6 \mathrm{~mm}$. There was statistically significant difference in probing depth according to age, types of cleft and sextant ( $p<0.001) ; 95.87 \%$ of teeth presented mean attachment level smaller than or equal to $3 \mathrm{~mm}$. The sextant with cleft did not present higher means of probing depth, clinical attachment level, plaque index and ingival index. There was no statistically significant difference between gender and the other variables. There was gingival bleeding in most of the sample, both in maxillary and mandibular teeth. The frequency and severity of gingival recessions were increased with age, affecting mainly the premolars and molars. The frequency of recession in incisors and canines was ten times higher compared to the general population. The type of cleft was not an important factor influencing the prevalence of periodontal disease. Gender did not influence any of the clinical parameters in this sample. Age seems to be an important factor influencing the prevalence and severity of periodontal disease, for all aspects investigated. Periodontal disease in individuals with clefts, in the present study, occurred in a similar manner as observed in other populations. The presence of a cleft does not seem to increase the prevalence of the disease

Key Words: periodontal disease, epidemiology, cleft lip/palate 